\title{
Show me the money
}

Citation for published version (APA):

de Groot, R. (2019). Show me the money: essays on the impact of cash transfers on child nutrition and the role of intra-household dynamics. [Doctoral Thesis, Maastricht University]. Boekenplan Maastricht. https://doi.org/10.26481/dis.20190621rg

Document status and date:

Published: 01/01/2019

DOI:

10.26481/dis.20190621rg

Document Version:

Publisher's PDF, also known as Version of record

\section{Please check the document version of this publication:}

- A submitted manuscript is the version of the article upon submission and before peer-review. There can be important differences between the submitted version and the official published version of record.

People interested in the research are advised to contact the author for the final version of the publication, or visit the DOI to the publisher's website.

- The final author version and the galley proof are versions of the publication after peer review.

- The final published version features the final layout of the paper including the volume, issue and page numbers.

Link to publication

\footnotetext{
General rights rights.

- You may freely distribute the URL identifying the publication in the public portal. please follow below link for the End User Agreement:

www.umlib.nl/taverne-license

Take down policy

If you believe that this document breaches copyright please contact us at:

repository@maastrichtuniversity.nl

providing details and we will investigate your claim.
}

Copyright and moral rights for the publications made accessible in the public portal are retained by the authors and/or other copyright owners and it is a condition of accessing publications that users recognise and abide by the legal requirements associated with these

- Users may download and print one copy of any publication from the public portal for the purpose of private study or research.

- You may not further distribute the material or use it for any profit-making activity or commercial gain

If the publication is distributed under the terms of Article $25 \mathrm{fa}$ of the Dutch Copyright Act, indicated by the "Taverne" license above, 


\section{Show Me the Money: \\ Essays on the Impact of Cash Transfers on Child Nutrition and the Role of Intra- Household Dynamics}

Richard de Groot 
(C) 2019, Richard de Groot

ISBN: 9789086664818

Published by Boekenplan, Maastricht www.boekenplan.nl

All rights reserved. No part of this publication may be reproduced, stored in a retrieval system, or transmitted in any form or by any means, electronic, mechanical, photocopying, recording or otherwise, without the written permission from the author. 


\title{
Show Me the Money: \\ Essays on the Impact of Cash Transfers \\ on Child Nutrition and the Role of Intra- Household Dynamics
}

\author{
DISSERTATION
}

\begin{abstract}
to obtain the degree of Doctor at Maastricht University,
on the authority of the Rector Magnificus Prof. Dr. Rianne M. Letschert

in accordance with the decision of the Board of Deans,

to be defended in public on Friday, 21 June 2019, at 10:00 hours
\end{abstract}

by

Richard de Groot 


\section{Supervisors}

Prof. Dr. Michael Cichon

Prof. Dr. Franziska Gassmann

\section{Co-supervisor}

Dr. Nyasha Tirivayi

\section{Assessment Committee}

Prof. Dr. Pierre Mohnen (Chair)

Dr. Stephan Dietrich

Prof. Dr. Menno Pradhan, University of Amsterdam

Prof. Dr. Tessa Roseboom, University of Amsterdam 


\section{Acknowledgements}

First of all, I would like to thank my supervisors for their guidance and support over the last years. While doing GPAC means that you are not at the same location as your supervisors, I always felt that I could reach out anytime and I always got a quick response. Michael, thank you for pushing me to think harder about the implications of my results. Franziska, I knew I wanted you to be one of my supervisors and I sincerely appreciate all the support you have given since the day I started GPAC. Nyasha, your insights and knowledge of papers that were relevant for my thesis was extraordinary and invaluable.

Most of the research for this dissertation was conducted while I was employed at the UNICEF Office of Research - Innocenti. I am very grateful for the opportunity and flexibility from the office to combine my work with doing a $\mathrm{PhD}$. A special thanks to Ashu and Tia, my main supervisors, who encouraged and supported me every step of the way. I have learned so much from you and you continue to be an inspiration for me. Thank you also for creating one of the best work environments possible: productive, fun and stimulating. A big thanks to the amazing colleagues of the Social and Economic Policy team for discussions, support and friendships. I cherish great memories of my time in Florence.

I would also like to thank my co-authors who have contributed to various parts of the research underlying this dissertation: Amber, Ashu, Jennifer, Peter, Tayllor and Tia. Your contributions and insights were invaluable and improved the papers in this dissertation immensely. I also appreciate all others who have taken the time and effort to review and comment on early drafts of the papers in this dissertation. I sincerely acknowledge the constructive comments from the assessment committee, which helped to refine this dissertation in its final stages.

The data used in this dissertation come from an impact evaluation of the Ghana LEAP 1000 programme. Many people were involved in this evaluation and I am grateful to all of them. For UNICEF Office of Research - Innocenti: Tia Palermo (Principal Investigator) and Elsa Valli. For the Institute of Statistical, Social and Economic Research (ISSER), University of Ghana: Isaac Osei-Akoto (Principal Investigator), Clement Adamba, Joseph K. Darko, Robert Darko Osei, Francis Dompae and Nana Yaw. For the Carolina Population Center, University of North Carolina at Chapel Hill: Sudhanshu Handa, Clare Barrington (Principal Investigators), Sara Abdoulayi, Gustavo Angeles, Averi Chakrabarti and Frank Otchere. For the Navrongo Health Research Centre: Akalpa J. Akaligaung (Principal Investigator) and Raymond Aborigo. I would also like to acknowledge the field teams of ISSER, who conducted the data collection for this evaluation to the highest standards and were always available to answer my million questions about the data. But most of all, I highly appreciate the people of Ghana who took 
the time to respond to our survey questions. I sincerely hope that this dissertation does justice to your answers and that they can help improve the lives of many. The impact evaluation would not have been possible without the vital support and guidance from the UNICEF Ghana country office: Sara Abdoulayi, Daisy Demirag, Christiana Gbedemah, Sarah Hague, Jonathan Nasonaa Zakaria, Luigi Peter Ragno, Tayllor Spadafora, Jennifer Yablonski and Maxwell Yiryele Kuunyem. I am also thankful for the support of the Government of Ghana for the implementation of this evaluation, in particular William Niyuni, Mawutor Ablo and Richard Adjetey from the Ministry of Gender, Children and Social Protection. Funding for the evaluation was generously provided by the Canadian International Development Agency and the United States Agency for International Development.

I am thankful for the GPAC team for their solid organization of the workshops and their continued support throughout the PhD journey: Mindel, Charlotte, Cristina, Janyl, Shivani and Sten. I may not have joined all the days of the workshop weeks, but I always felt welcome and valued. I highly appreciate the discussions with my fellow GPAC colleagues during the seminars and lunches. I really liked to have a great excuse to visit Maastricht for several times over the last years. It remains a lovely city with beautiful people.

I am grateful to my parents, Lies and Ingrid, for their consistent support for my education ever since I was young. Finally, I am indebted to my wife Naomi, for all her love, support and encouragement over the last years and for blessing us with our beautiful daughter, Nore. Words cannot express what they both mean to me. And having a daughter of my own during the research for this dissertation really puts things in perspective when writing about young child health and nutrition. 


\section{Acronyms}

ADL activities of daily living

AE adult equivalent

AIR American Institutes for Research

ARI acute respiratory infection

BCC behaviour change communication

CCT conditional cash transfer

CGP Child Grant Programme

CHPS Community-based Health Planning and Services

CI

confidence interval

CT cash transfer

DD difference-in-difference

DHS Demographic and Health Survey

DSW Department of Social Welfare

FAO Food and Agricultural Organization of the United Nations

FDR false discovery rate

FE fixed effects

FWER familywise error rate

GHC Ghana cedi

GHS Ghana Health Service

GLSS Ghana Living Standards Survey

GPS global positioning system

GSS Ghana Statistical Service

HAZ height-for-age z-score

HFIAS Household Food Insecurity and Access Scale

HSCT Harmonized Social Cash Transfer

HSNP Hunger Safety Net Programme

IFPRI International Food Policy Research Institute

IPV intimate partner violence

IPWRA inverse probability weighted regression adjustment

ISSER Institute of Statistical, Social and Economic Research

ITT intent-to-treat

IYCF infant and young child feeding

LA Latin America

LATE local average treatment effect

LEAP Livelihood Empowerment Against Poverty

LM lagrange multiplier

LMS LEAP Management Secretariat

MDG Millennium Development Goal

MoGCSP Ministry of Gender, Children and Social Protection 


$\begin{array}{ll}\text { NHIS } & \text { National Health Insurance Scheme } \\ \text { ODI } & \text { Overseas Development Institute } \\ \text { OLS } & \text { ordinary least squares } \\ \text { OPM } & \text { Oxford Policy Management } \\ \text { OVC } & \text { orphans and vulnerable children } \\ \text { PMT } & \text { proxy means test } \\ \text { pp } & \text { percentage point } \\ \text { PSNP } & \text { Productive Safety Net Programme } \\ \text { PSS } & \text { Perceived Stress Scale } \\ \text { RCT } & \text { randomized control trial } \\ \text { RD } & \text { regression discontinuity } \\ \text { RE } & \text { random effects } \\ \text { RIDIE } & \text { Registry for International Development Impact Evaluations } \\ \text { SCTP } & \text { Social Cash Transfer Programme } \\ \text { SCTPP } & \text { Social Cash Transfer Pilot Programme } \\ \text { SD } & \text { standard deviation } \\ \text { SDG } & \text { Sustainable Development Goal } \\ \text { SSA } & \text { sub-Saharan Africa } \\ \text { UCT } & \text { unconditional cash transfer } \\ \text { UNC-CH } & \text { University of North Carolina at Chapel Hill } \\ \text { UNDESA } & \text { United Nations Department of Economic and Social Affairs } \\ \text { USD } & \text { US dollar } \\ \text { VHP } & \text { Village Health Post } \\ \text { WAZ } & \text { weight-for-age z-score } \\ \text { WHO } & \text { World Health Organization } \\ \text { WHZ } & \text { weight-for-height z-score }\end{array}$




\section{Table of contents}

Acknowledgements .................................................................................................ii

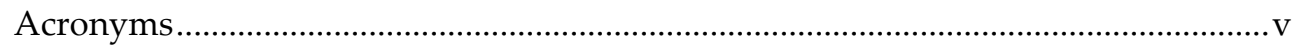

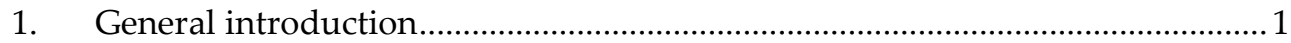

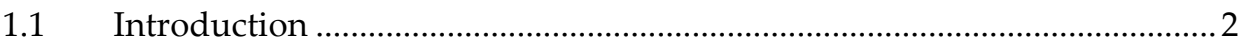

1.2 Relevance and contribution of the thesis ...................................................

1.3 Conceptual framework for child nutrition: is there a role for cash

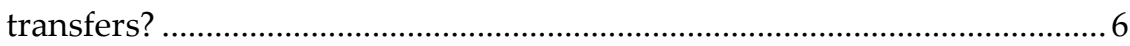

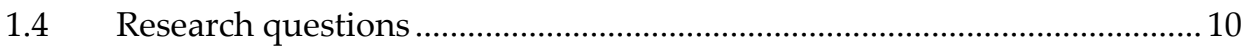

1.5 Country context and research methods .................................................... 11

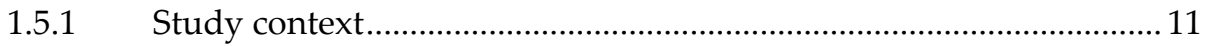

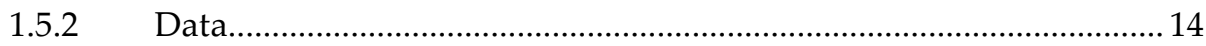

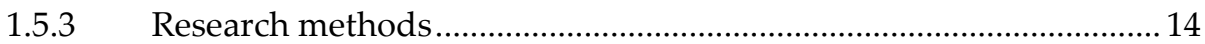

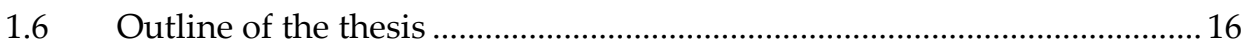

2. Cash transfers and child nutrition: pathways and impacts................................19

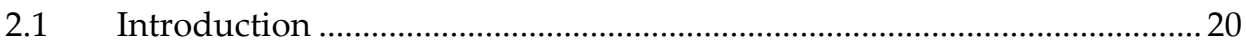

2.2 Cash transfers and child nutrition: what we know about the types of impacts and pathways................................................................................. 21

2.2.1 Cash transfers and underlying determinants of child nutrition ......22

2.2.2 Cash transfers and immediate determinants of child nutrition.......27

2.2.3 Cash transfers and child nutrition outcomes......................................29

2.2.4 Heterogeneity of impacts of CT programmes on child nutrition ....36

2.2.5 Unintended consequences...................................................................... 38

2.3 Conclusion: What do we know and what do we need to know about cash transfers and child nutrition? ........................................................................ 39

3. Determinants of child malnutrition and the potential effects of consumption growth, improved maternal care and price shocks................................................ 43

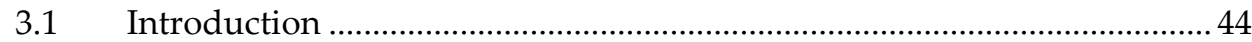

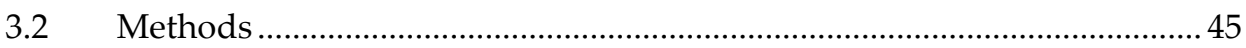

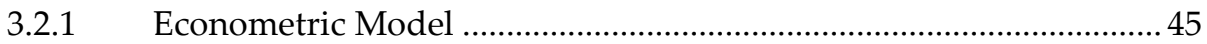

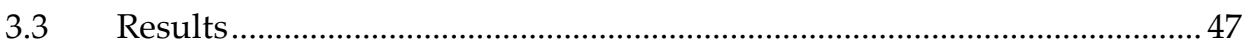

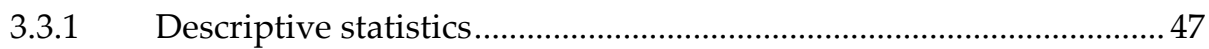

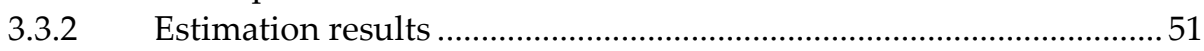

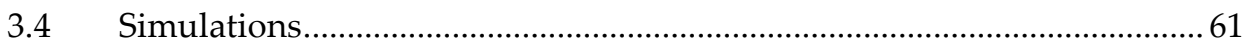

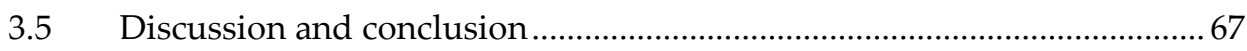

3.6 Appendix to Chapter 3 ............................................................................ 71

4. Intra-household dynamics in Northern Ghana: is there a gender bias in the

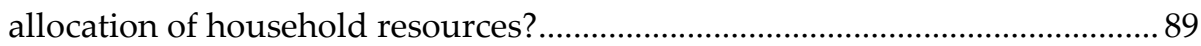

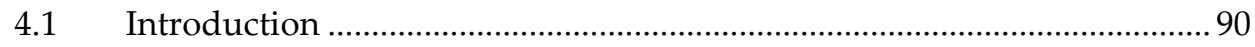

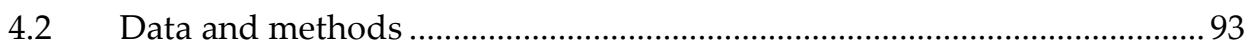




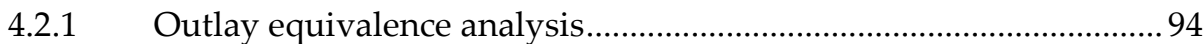

4.2.2 Testing for common preferences .......................................................... 96

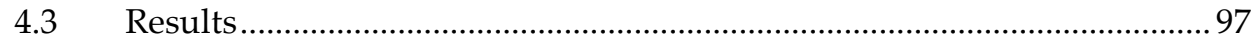

4.3.1 Outlay equivalence ratios .................................................................... 97

4.3.2 The effect of parental education on educational achievement and

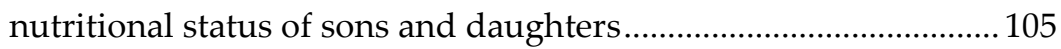

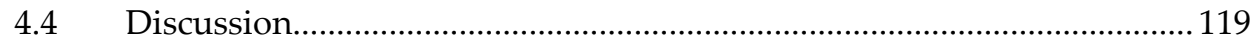

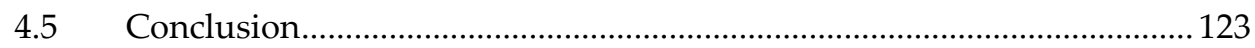

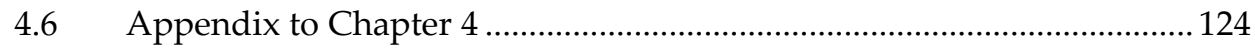

5. The impact of Ghana LEAP 1000 on young child nutritional status and its

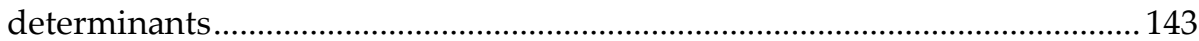

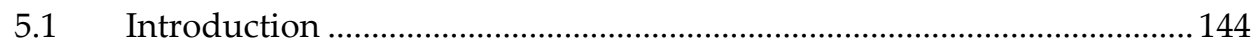

5.2 The Ghana LEAP 1000 programme and evaluation design ..................... 146

5.3 Data, baseline balance and attrition........................................................ 147

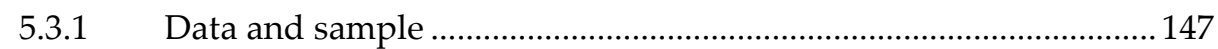

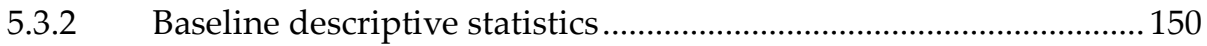

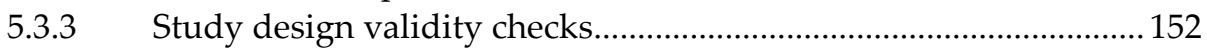

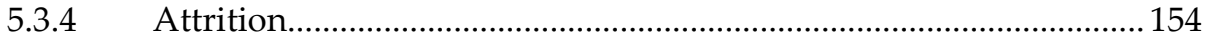

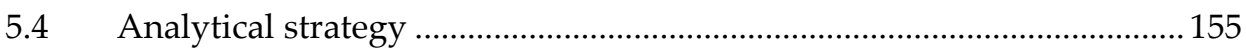

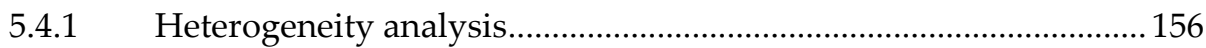

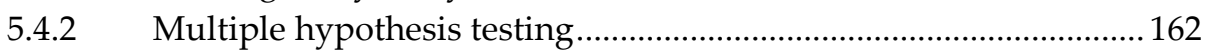

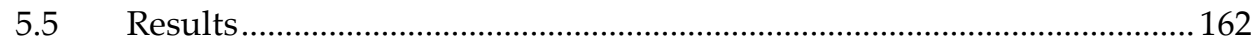

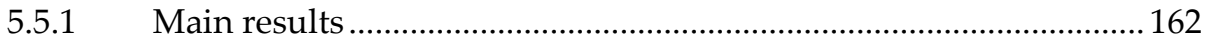

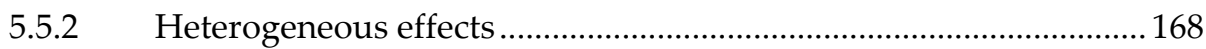

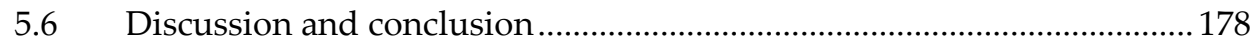

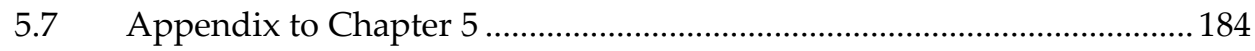

5.7.1 Appendix A: Additional tables......................................................... 184

5.7.2 Appendix B: Detailed information on indicators used in this study 195

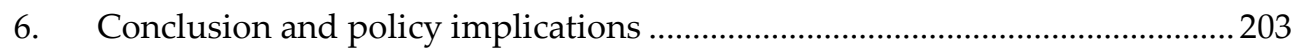

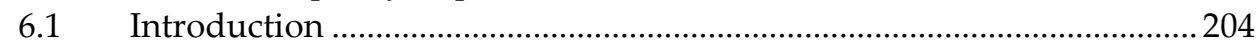

6.2 Main findings and answers to the research questions ............................. 204

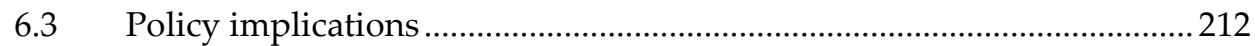

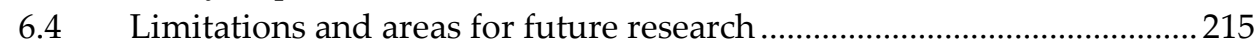

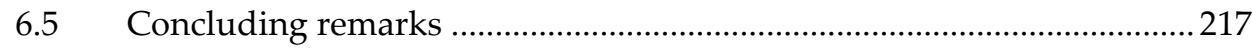

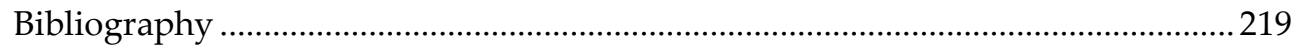

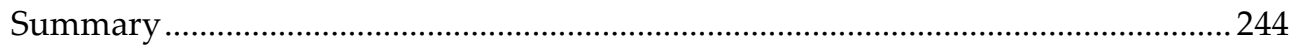

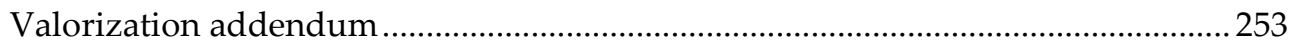

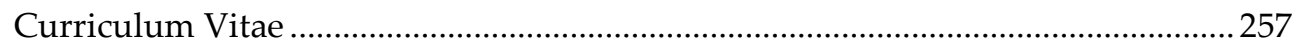




\section{General introduction}




\subsection{Introduction}

Childhood malnutrition remains a significant barrier to health and development worldwide. The most recent estimates show that globally 155 million children under the age of five years suffer from stunting (too short for one's age), a chronic condition resulting primarily from prolonged malnutrition and exposure to infectious diseases during early childhood. In sub-Saharan Africa (SSA), an estimated 34.4 percent of children under five are stunted, and progress in stunting reduction has been slower than in Asia and Latin America. In addition, while the prevalence of stunting has decreased in SSA, the number of affected children has increased from 27.4 million to 28.4 million children due to high birth rates (UNICEF/WHO/World Bank Group, 2017). Finally, previous estimates have shown that children living in the poorest households and those living in rural areas are more likely to be stunted than their richer or urban counterparts (UNICEF, 2013).

Chronic malnutrition has severe consequences for later life outcomes. Evidence shows that up to 70 percent of stunting takes place before a child's second birthday, a period commonly referred to as the first 1,000 days (Leroy et al., 2014). Stunting in this 'critical window' has been linked to impaired cognitive development, reduced school achievement, lower economic productivity in adulthood and poorer maternal reproductive outcomes, among others (Dewey and Begum, 2011). The economic costs of stunting have been estimated to be equivalent to 13.5 percent of GDP in all developing countries (Mary, 2018) and between 9-10 percent of GDP per capita in SSA (Galasso et al., 2017). Therefore, investments to improve nutritional status early in a child's life have the potential to yield large returns (Hoddinott et al., 2013).

Chronic malnutrition is a multidimensional issue with several underlying risk factors. A widely recognized framework of the determinants of malnutrition (for more detail see Section 1.3) lists food intake and health as the two immediate determinants of malnutrition. In turn, the immediate determinants are caused by three underlying determinants: food security, care for mothers and children, and the household health environment. Social protection is increasingly recognized as an important strategy to accelerate progress in improving maternal and child nutrition because it can addresses structural factors such as poverty and social vulnerability (Ruel et al., 2013). ${ }^{1}$ In particular cash transfer (CT) programmes,

\footnotetext{
${ }^{1}$ A widely used definition of social protection is from Devereux and Sabates-Wheeler (2004): "Social protection describes all public and private initiatives that provide income or consumption transfers to the poor, protect the vulnerable against livelihood risks, and enhance the social status and rights of the marginalised; with the overall objective of reducing the economic and social vulnerability of poor, vulnerable and marginalised groups." (p. 9)
} 
which deliver cash directly to households, have gained popularity with governments and other stakeholders in recent years (World Bank, 2018b).

Both the number and the coverage of CTs have increased considerably in the last two decades. Conservative estimates suggest that about 546 million people currently benefit from CTs in the developing world (World Bank, 2018b). ${ }^{2}$ The latest numbers show that in SSA, at least 42 out of 46 countries were implementing unconditional cash transfers (UCTs), 19 countries had conditional cash transfers (CCTs) and 17 countries had some form of social pension. This indicates that the social protection landscape in SSA is primarily one of UCTs. Despite their increase, however, the coverage of social protection programmes in SSA remains low. Only 29 percent of households in the poorest quintile are covered by a social protection or labour market programme. This could be due to programmes still being in their infancy stages and not yet reaching a national roll out, or due to programmes only targeting a very specific group of vulnerable populations. Besides South Asia (28 percent), SSA has the lowest coverage rates globally, indicating a great potential for expansion of social protection to address poverty and vulnerability (World Bank, 2018b).

\subsection{Relevance and contribution of the thesis}

From a policy perspective, it is imperative to research the underlying factors of child malnutrition. Evidence has shown that more than 45 percent of all deaths in children under five are linked to malnutrition (Black et al., 2008). However, the importance of addressing childhood malnutrition was not specifically recognized in Millennium Development Goal (MDG) 4 which aimed to reduce the rate of under-five mortality by two thirds. Although the global rate of under-five mortality decreased from 91 deaths per 1000 live births in 1990 to 43 in 2015, the MDG was globally not achieved. The successors of the MDGs, the Sustainable Development Goals (SDGs) more prominently feature the need to address child malnutrition. For example, SDG target 2.2 states:

“By 2030, end all forms of malnutrition, including achieving, by 2025 , the internationally agreed targets on stunting and wasting in children under 5 years of age, and address the nutritional needs of adolescent girls, pregnant and lactating women and older persons." (UN General Assembly, 2015: 15)

2 This includes beneficiaries of UCT, CCT and social pensions, based on administrative data from the countries. Some very large programmes (Brazil, China, India, Indonesia and Mexico) account for a high share of the 546 million beneficiaries.

${ }^{3}$ There are also two suggested indicators to measure progress towards this goal: indicator 2.2.1: Prevalence of stunting (height for age $<-2$ standard deviation from the median of the 
In addition to the importance of addressing child malnutrition, the considerable rise of CT programmes in the last two decades, and their potential to be scaled up to cover a larger share of the poor, opens up questions on how these programmes may have an impact on child health and nutrition. In particular UCTs, which do not condition the receipt of the cash on certain behaviour but leave households free to spend the money as they see fit, are becoming the standard approach in most of SSA. For policy makers in this region, it is important to understand if and how such programmes can contribute to reducing the burden of malnutrition in their country.

From an academic perspective, the direct relation between CTs and child nutrition has been widely studied. In fact, several systematic reviews have been published in recent years (for example Fernald et al. (2012), Leroy et al. (2009), Manley and Slavchevska (2019), Owusu-Addo and Cross (2014), Owusu-Addo et al. (2018), Pega et al. (2017)). However, the results of these studies are mixed, and several authors point to the need to better understand the pathways through which CT programmes might work to improve nutritional status. This is further demonstrated by the findings from a meta-analysis, shown in Figure 1.1. A couple of interesting issues emerge from this graph and the recent systematic reviews. First, the impacts cover quite a substantial range, from negative to positive. Most of the findings reported are not significant though: out of the 144 estimates, only 26 (18 percent) are significantly different from zero. Second, using meta-analytical techniques Manley et al. (2013), estimate that the average impact across programmes on the height-for-age z-score (HAZ) is 0.04 and not significantly different from zero. Third, most of the countries studied are in Latin America or South Asia. Fourth, most of the evidence is from CCTs, which usually have specific conditions on children's health or education. Recent work summarized in Manley and Slavchevska (2019), and Owusu-Addo et al. (2018) includes more evidence from SSA and UCTs, which is further discussed in Chapter 2 of this thesis.

World Health Organization (WHO) Child Growth Standards) among children under 5 years of age. Indicator 2.2.2: Prevalence of malnutrition (weight for height $>+2$ or $<-2$ standard deviation from the median of the WHO Child Growth Standards) among children under 5, disaggregated by type (wasting and overweight) (United Nations Economic and Social Council, 2015) 


\section{Figure 1.1, Mean impact on height-for-age z-score of CT programmes across}

the world

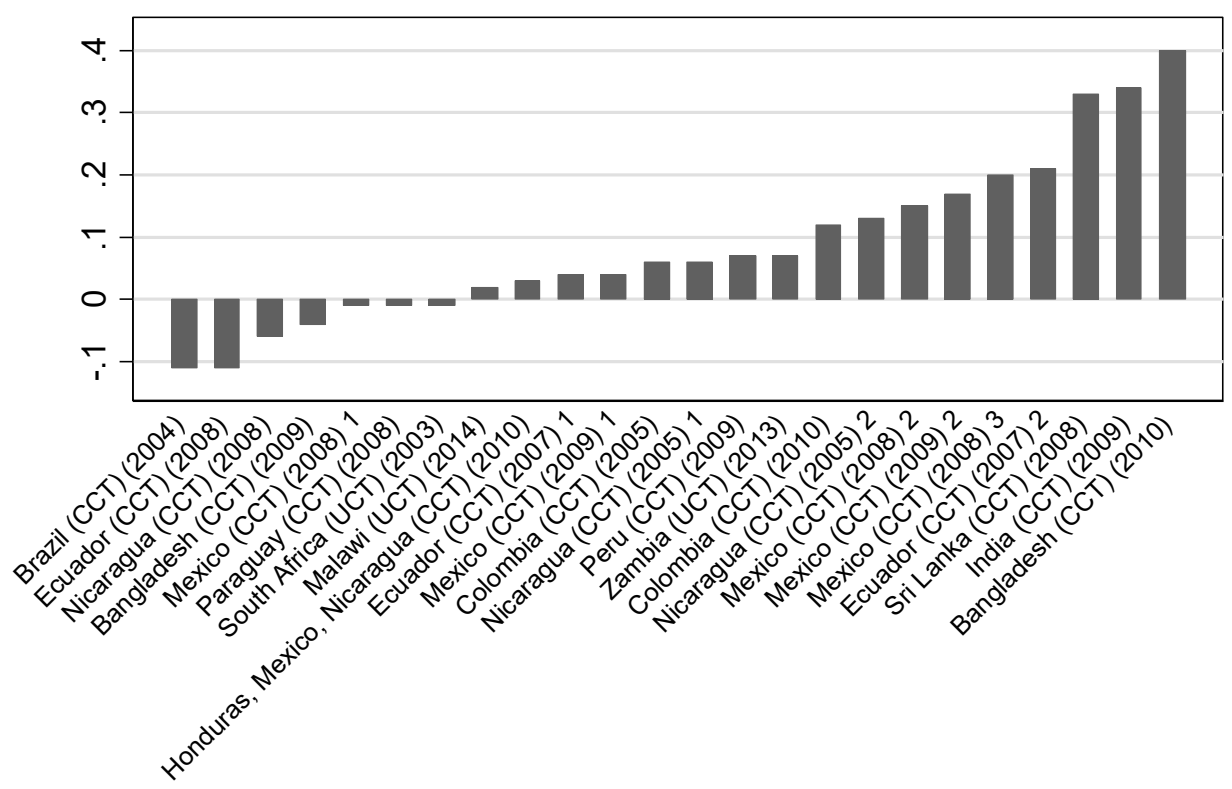

Sources: Author's compilation based on Manley et al. (2013), Zambia (AIR 2013) and Malawi (UNC-CH 2015).

Based on the conclusions from these recent studies, it follows that there is an academic need to better understand the extent through which CT programmes may affect child nutrition. In addition, based on the currently available evidence, there are knowledge gaps on the impacts of UCTs and on CT programmes taking place in SSA. More specifically, the main knowledge gap is the lack of understanding through which pathways a CT can affect malnutrition. Since malnutrition is caused by several immediate and underlying determinants, it is important to examine which determinants can be affected by a CT and through which mechanisms. As most of the currently available research covers CTs in LA, which are predominantly CCTs, there is a lack of knowledge on how UCTs, which pose no restrictions on the use of the transfer, may help address the underlying and immediate causes of malnutrition. In addition, it is unclear how CTs will affect the drivers of malnutrition in SSA, given the different institutional and cultural context compared to other regions of the world.

The contribution of this thesis is to address these knowledge gaps. It exploits an impact evaluation of a government-run cash transfer programme in Northern Ghana to study to what extent an unconditional cash transfer programme can contribute to improving child nutritional status. Given that previous research has failed to understand which pathways are important drivers 
for child malnutrition and how they are affected by a $\mathrm{CT}$, this thesis uses the UNICEF conceptual framework of child nutrition (more details in Section 1.3) to study the underlying and immediate determinant of malnutrition. One novel aspect of this study is to introduce the concept of intra-household dynamics in resource allocation and decision-making as a potential determinant of child nutrition. This concept states that there may be inequalities in the allocation of resources such as food and health care within the household, which could affect the effectiveness of a CT that aims to improve the wellbeing of children. In other words, some household members may be prioritized over others, based on some sort of sharing rules, customs or bargaining power within the household. This has thus far been ignored in the literature on CTs and nutrition, despite research showing that intra-household dynamics can be important for the health and development of children. The impact analysis presented in this thesis takes a broad perspective and examines the CT impact on all underlying and immediate determinants of malnutrition to assess which pathways are affected (or not). This study therefore provides important evidence for policy makers wishing to use CTs as a tool to help address the burden of malnutrition in their country.

\subsection{Conceptual framework for child nutrition: is there a role for cash transfers?}

Several approaches have been used to hypothesize and model the linkages between CTs and child nutrition. One possible approach would be to use the CT as starting point and conceptualize the different impacts it may have on the individual-, household- and community-levels, with one of the potential impacts being child nutritional status. Another approach is to start from the determinants of child nutrition and theorize the effects of a CT on those determinants. For this thesis, the second approach is more useful as it allows the identification of how CTs can affect the root causes of child nutrition and therefore the pathways of impact.

The starting point for our conceptual framework is UNICEF's extended model of care, first developed by Engle et al. (1997) and still widely utilized in nutrition research (Smith and Haddad, 2015). This thesis adapts the extended framework for the model of care developed by Smith and Haddad (2002), depicted in Figure 1.2. For the purpose of this research, child nutritional status is operationalized by standard measures such as height-for-age (HAZ), weight-forage (WAZ) and weight-for-height (WHZ) (WHO Multicentre Growth Reference Study Group and Onis, 2006). This framework serves as a guide to determine the appropriate impact pathways and range of determinants and outcomes to be included in this study.

The conceptual framework identifies household food security, care and a healthy environment as the underlying determinants that influence the immediate 
determinants of children's nutritional intake and health status (Figure 1.2). The combination and interaction of these two immediate determinants define the final outcome, a child's nutritional status. Household food security in this model is defined by the availability of household resources to consume sufficient food for all members in the household, either by food production, cash income or food received as gift (Smith and Haddad, 2002). ${ }^{4}$ Care in this context refers to caregiver behaviours that affect all aspects of child development including psychosocial care, feeding practices, breastfeeding, food preparation, hygiene, health seeking behaviour and health care (Engle et al., 1997). ${ }^{5}$ Care for mothers and children is determined by caregiver control over resources and autonomy, caregiver mental and physical status (i.e., level of stress, caregiver nutritional status) and knowledge (including literacy and educational attainment), preferences and beliefs of the caregiver. The third underlying determinant is the health environment, which depends on the child's access to safe water and sanitation facilities, health care and shelter (Smith and Haddad, 2002). The final underlying determinant is the intrahousehold decision-making and allocation of resources, which is located under the three main resources. Intra-household decision-making determines what part of the income or resources held by the household are distributed among the three main resource components, as well as which household member gets what share of the total available resources. This determinant is a novel addition to the framework based on emerging evidence that intra-household dynamics play an important role in the determination of child health and nutrition (Richards et al., 2013) as well as the premise that intra-household dynamics matter for the effectiveness of a transfer to the household (Haddad et al., 1997).

\footnotetext{
${ }^{4}$ In a broader context, the UN framework of food security embodies four dimensions: (1) physical availability of food, (2) economic and physical access to food, (3) food utilization, and (4) stability of the other three dimensions over time (FAO, 2008).

${ }^{5}$ In line with Engle et al. (1997) terminology, the term 'caregiver' is used rather than 'mother.' In most instances, it will be the mother of the child who is the primary caregiver, however fathers and other females in the households also provide care. Thus, it is necessary to broaden the focus of caregiving beyond the mother to include all resources for care.
} 
Figure 1.2. Conceptual framework of the determinants that affect child nutritional status

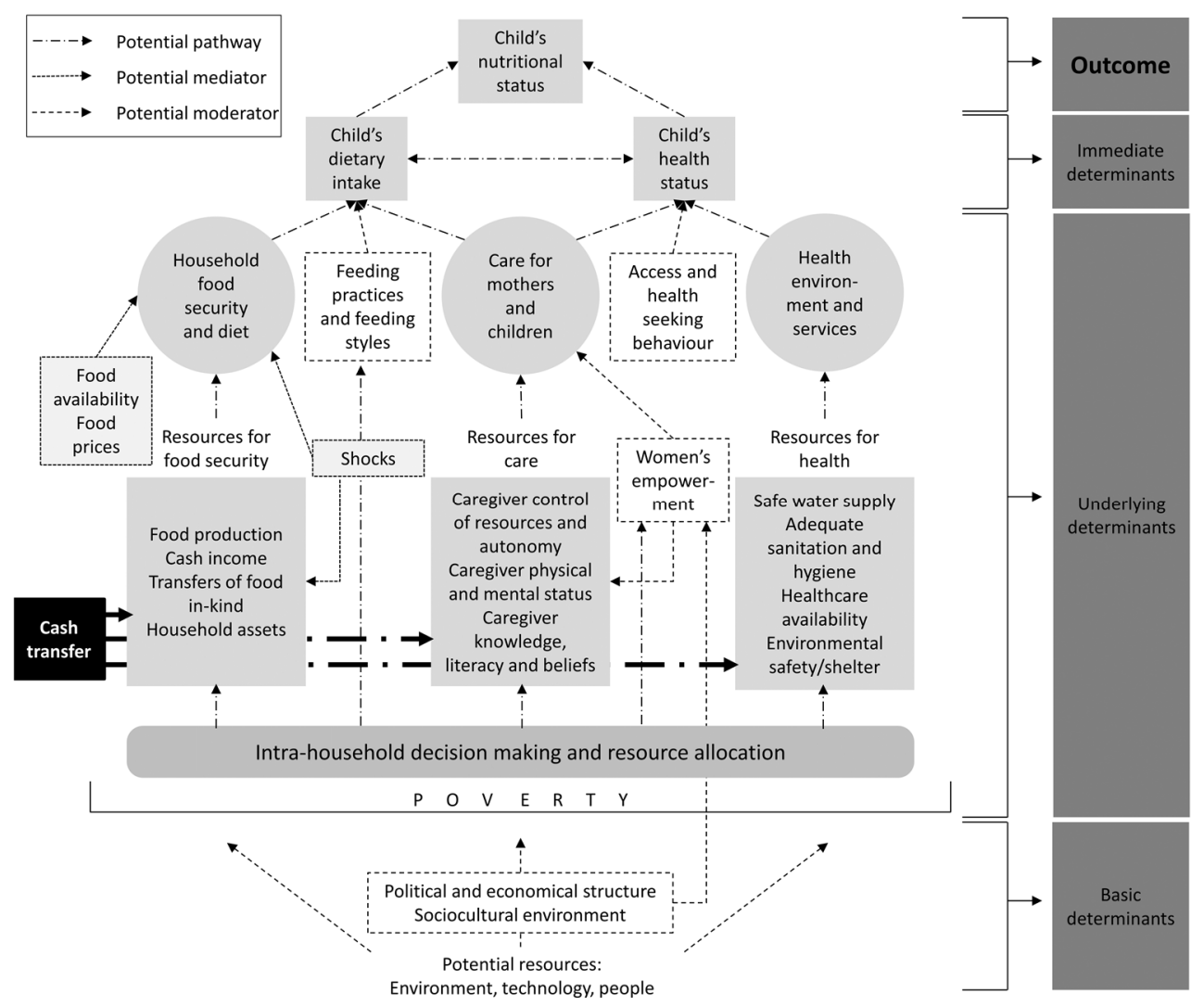

Source: Author's adaptation from Smith and Haddad (2002)

The framework also considers several moderators and mediators of the relationship between CTs and child nutrition. For example, the child's dietary intake is mediated by the caregiver's feeding practices and feeding styles. The health status of a child is mediated by the health-seeking behaviour of the caregiver. Household food security is moderated by the availability and price level of food and by external shocks. Women's empowerment (most commonly operationalized as women's decision-making or control over resources), influenced by underlying societal values, mediates the relationship between CTs and care for mothers and children.

In this framework, there are three main pathways through which CTs may affect the underlying determinants of child nutrition, by making additional financial resources available for 1) food security, 2) health, and 3) care. The distribution of these resources is influenced by intra-household decision-making 
and resource allocation. Chapter 2 of this thesis reviews the evidence of the impact of CTs on these underlying determinants in more detail.

A CT directly increases household disposable income and consequently the resources available for household food security. This is supported by a strong evidence base that CTs improve household food security and diet diversity (Hidrobo et al., 2018, Tiwari et al., 2016). If intra-household decision-making leads to using the cash to purchase higher quantity or quality food, or invest in food production or productive assets, household food security and household diet diversity are improved. However, food availability, food prices and economic shocks could moderate this pathway. Second, improved household food security and diet diversity could affect the child's nutritional intake if food resources are shared in a child-sensitive way in the household. If, for example, due to power imbalances in the intra-household allocation of resources, all additional food resources purchased using the CT go towards adult men in the household, no impact on children's nutritional intake can be expected. However, an effect can be expected if a child's food intake is improved, in combination with appropriate feeding practices (what the child is fed) and styles (how the child is fed), and good health status, allowing the efficient absorption of micronutrients in the food.

A CT can have a direct effect on the household-level resources for health. Increased resources allow the household to make improvements to sanitation facilities in the home or make housing improvements, such as installing a concrete floor, which decreases exposure to parasites (Cattaneo et al., 2009). In addition, resources could be employed to pay for out-of-pocket expenses during curative or preventive health visits, transportation to health facilities, medical supplies and preventive medicines such as deworming tablets. ${ }^{6}$ Effective use of increased resources for health therefore may results in an improved health environment for the child. However, evidence to date suggests positive impacts of CTs on health care utilisation, while other potential health pathways described above have not been studied extensively (Bastagli et al., 2018).

In terms of the care pathway, CTs may decrease poverty-related stress, which in turn may improve caregiver's physical and mental state, and thus increase positive parenting of children. Recent evidence suggest that CTs can indeed relieve stress among beneficiary households, and improve subjective wellbeing (Kilburn et al., 2018, Natali et al., 2018). Stress is also hypothesized to be linked to perpetration of intimate partner violence (IPV), which in turn affects child health outcomes (Yount et al., 2011). Thus, overall reductions in the level of household stress may also impact caregiving behaviours and directly influence

${ }^{6}$ It could also have a more indirect effect on health care availability if the increased resources result in increased demand for health care or higher quality care at the local level. 
child health. Further, CTs may relieve incentives for pregnant women to engage in dangerous or rigorous work, which has implications for birth outcomes.

CTs may also directly affect intra-household dynamics in resource allocation and decision-making. If the transfer is distributed to the main caregiver, by controlling more resources, the caregiver is better able to advocate for her preferences. Economic models of household bargaining theorize that control of resources affects bargaining through individuals' threat points and outside options, or non-cooperative equilibriums. In these models, control of resources makes outside options and threat points more credible, and thus affects an individual's ability to exert her preferences (Bolin et al., 2001). In fact, the current evidence suggest that CTs indeed have a positive effect on women's decisionmaking in the household (Bastagli et al., 2018).

Finally, there are potential positive interaction effects among the different pathways. For example, a combination of additional resources available for food, health and care, mediated by feeding practices, feeding styles and health seeking behaviour of the caregiver, may positively impact the child's health status and the child's nutritional intake to determine the nutritional status of the child.

The description in this subsection has focused on the potential pathways through which a CT can affect child nutrition. It is important to acknowledge that a CT will not be able to address all the pathways at the same time. The literature review in Chapter 2 of this thesis elaborates on the current evidence supporting or rejecting these potential pathways and identifies knowledge gaps. Chapter 2 also highlights that there are important design features of CTs that matter for their potential impact on any of the pathways described above. Features such as the amount of the transfer, the targeting criteria and the duration of the programme are all elements that need to be considered when examining the impact of a CT on child nutrition.

\subsection{Research questions}

Taking the above gaps in knowledge and theoretical framework into consideration, this thesis seeks to answer the following main research question:

To what extent can an unconditional cash transfer programme improve child nutritional status?

The following sub-questions are posed:

a. What are the pathways of impact on child nutritional status for a cash transfer programme?

b. What factors mediate or moderate CT programme impacts on child malnutrition? 
c. How does intra-household allocation of resources play a role in the determination of children's outcomes?

d. To what extent do intra-household dynamics affect the impact of a cash transfer on nutritional status?

\subsection{Country context and research methods}

\subsubsection{Study context}

This thesis aims to answer the research questions by focusing on one particular CT programme in Ghana. Ghana is currently a lower-middle income country with a gross domestic product (GDP) per capita of US\$1,783, following a period of strong economic growth in the past two decades (World Bank, 2018c). Despite this impressive economic growth, Ghana has not attained all MDGs. While the goals with regards to poverty reduction, universal primary education and gender parity in primary school were achieved, Ghana fell behind in the goals that address under-five mortality and maternal mortality (UNDP and NDPC, 2015). In addition, Cooke et al. (2016) show that economic growth was not inclusive, and inequality increased from 1992 to 2013. They furthermore show that Ghana registers high inequality between urban and rural areas and between regions, with the North being much poorer and unequal than the southern parts of the country.

In this economic and social context, chronic malnutrition of children under five remains a significant public health issue, despite important progress over the last years. The three main nutritional indicators all show improvements over the decade between 2003 and 2014. Stunting (too short for age) decreased from 35 percent to 19 percent, wasting (too thin for height) decreased from 8 percent to 5 percent and underweight (too thin for age) dropped from 18 percent to 11 percent. However, these numbers mask important inequality in the country, as levels of stunting are higher for children in rural areas, from poorly educated mothers, and those living in poor households. The Northern region shows the highest prevalence of stunting with a rate of 33 percent (GSS, GHS \& ICF International, 2015).

Against this backdrop, the Government of Ghana has embarked on an ambitious road to develop social protection programmes in the country. During the 2000s, several programmes were developed and implemented, including a contributory national health insurance scheme (NHIS) (2003) with the objective to reach universal coverage, a national school feeding programme (2005), capitation grants to expand free primary education (2005), and the flagship Livelihood Empowerment Against Poverty (LEAP) cash transfer programme (2008). In 2015, Ghana launched its first National Social Protection Policy, bringing these programmes together under one strategic vision.

This thesis primarily focuses on the LEAP programme, which started as a small pilot with 1,654 extreme poor households in 21 districts in 2008. 
Implemented by the LEAP Management Secretariat (LMS) and the Department of Social Welfare (DSW) under the Ministry of Gender, Children and Social Protection (MoGCSP), the programme was quickly scaled up over the next years and reached 140,000 households in 2015 and 213,000 households across all districts in the country by 2017. LEAP's main objective is to "increase long-term human capital development among Ghana's extreme poor and vulnerable by increasing consumption and promoting access to services and opportunities" (Ragno et al., 2016, p. 151). In addition, there are four specific objectives:

1. To improve basic household consumption and nutrition among children under the age of two, the elderly (aged sixty-five and over without productive capacity) and people with severe disability and thus unable to work;

2. To increase access to health care services among children below five years of age, the elderly (aged sixty-five and above without productive capacity), and people with severe disability;

3. To increase basic school enrolment, attendance, and retention of beneficiary children between five and fifteen years of age;

4. To facilitate access to complementary services such as welfare, livelihood, and improvement in productive capacity (Ragno et al., 2016, p. 151).

LEAP officially targets the 'extreme poor' of Ghana, but also applies a categorical targeting approach and selects households with elders over 65 years old, people with a severe disability unable to work and households caring for orphans and vulnerable children (OVC). In 2015, a new demographic group was introduced through the LEAP 1000 programme, pregnant women and households with children under the age of one year, described in more detail below. While LEAP in its early stages used a community-based targeting approach, the poverty criterion is currently assessed through a proxy means test (PMT). Households that meet the demographic eligibility are subjected to a short questionnaire, eliciting information on the demographic composition of the household, characteristics of the head and ownership of agricultural and productive assets. LEAP beneficiaries, including children and dependents under 18 years, as all other indigents are entitled to free health insurance under the NHIS, providing access to out-patient and in-patient services, dental services, and maternal health services. Households qualifying for the LEAP programme receive GHC 32, 38, 44 or 53 (approximately USD 8.00 - 13.25) per month for one, two, three or four or more eligible members in the household, respectively. ${ }^{7}$ The transfer is not conditional on household

7 The average transfer per adult equivalent per month received by the households in this study is GHC 10.06 , which is $6.4 \%$ of the national poverty line (GHC 157.17 per adult equivalent per month). 
behaviours, although households with OVC are expected to keep their children in school, register births, vaccinate their children and ensure that their children are not trafficked and do not engage in child labour. In practice, there is no monitoring system in place that verifies compliance with these 'co-responsibilities'.

As stated above, a new category was added in 2015, pregnant women and households with children under the age of one year under a pilot project called LEAP 1000 in 10 districts in the Northern and Upper East Region. This particular group was included because the targeting approach of mainstream LEAP resulted in very few eligible families with young children. In other words, LEAP captures a unique segment of the extreme poor in Ghana but excludes a large portion of other vulnerable households which also need support, particularly households with young children. Since evidence has shown that early childhood is a key development window, with long-term implications for health and well-being, LEAP 1000 aims to target children and their families during this critical time, with the main objective to reduce stunting and improve welfare of children in Ghana. The 10 districts in the Northern and Upper East Region were selected for this pilot due to the high burden of malnutrition, poverty and vulnerability in these areas.

\section{Table 1.1, Selected development indicators, Ghana and sub-Saharan Africa}

\begin{tabular}{lccc}
\hline Indicator & Ghana & SSA & $\begin{array}{c}\text { Reference } \\
\text { year }\end{array}$ \\
\hline Poverty rate (\$1.90 per day) & 12.1 & 43.8 & 2012 \\
GDP per capita (current US\$) & $1,783.1$ & $1,655.4$ & 2015 \\
Life expectancy (years) & 62.4 & 59.9 & 2015 \\
Fertility rate (births per woman) & 4.0 & 4.9 & 2015 \\
Mortality rate, under-5 (per 1,000 live births) & 54.7 & 81.4 & 2015 \\
Prevalence of underweight $(\%$ of children $<5)$ & 11.0 & 19.5 & 2014 \\
\hline
\end{tabular}

Source: World Development Indicators (World Bank, 2018c)

Ghana and the LEAP programme present a unique opportunity to answer the research questions of this thesis. While Ghana has recently transitioned to middle-income status, the country's context, particularly in the North, is in many ways similar to other countries in the SSA region. This is indicated by the comparison of key development indicators in Table 1.1. The table shows that Ghana is in general ahead of other countries in the SSA region, yet for some indicators not by far. In addition, note that Ghana's indicator values mask important inequality within the country, with the rural areas and the northern parts of the country being poorer and therefore closer to the SSA averages (Cooke et al., 2016). In addition, LEAP is a government-run, national scale CT programme with similar design features as other countries in the region (e.g. Kenya, Malawi, Zambia) and since it has been implemented since 2008, is considered one of the more 'mature' programmes in SSA (Beegle et al., 2018). Therefore, lessons learnt 
from Ghana and the LEAP programme are likely relevant to other countries in the region with similar growth and development trajectories and embarking on implementing CT programmes with similar objectives.

\subsubsection{Data}

Another unique benefit of LEAP is that the expansion to the new category of pregnant women and infants (LEAP 1000) was accompanied by a rigorous impact evaluation. Approximately 2,500 households with pregnant women or children under one year old were followed over two years, from 2015 to 2017. Half of the sample was eligible for the LEAP 1000 programme and the other half was not. As discussed above, selection into the programme was based on the PMT score and the impact evaluation used this eligibility rule to construct a treatment and comparison group through a regression discontinuity design (RD). The main idea of this approach is that households in the close vicinity of the eligibility threshold are 'as good as randomly' assigned to the treatment and comparison group. A major benefit of this evaluation is that the sample includes many young children, which make it ideal to study the determinants of malnutrition and how a CT can affect malnutrition in this population. The survey includes several sections devoted to child health, food intake, nutritional status and caregiver behaviours and characteristics that make the data from this impact evaluation uniquely suited to study the research questions posed in this thesis.

\subsubsection{Research methods}

The main part of this thesis consists of a literature review and three empirical chapters. Below is a short summary of the research methods employed, while more detailed descriptions are presented in each individual chapter. The literature review in Chapter 2 uses several techniques to collect as many studies as possible that examine the impact of CTs on any of the pathways from the conceptual framework (Figure 1.2). This includes a search of academic databases, snowballing from existing reviews and meta-analyses and contacting experts in the field. To avoid any potential publication bias, grey literature is considered along peerreviewed journal articles. The results from the selected studies are then summarized by each level according to Figure 1.2 (e.g. outcome level, immediate determinants and underlying determinants).

Chapter 3 uses the baseline data from the LEAP 1000 impact evaluation to study the determinants of malnutrition in the sample. The chapter uses a health production function to model the relationship between the immediate determinants of malnutrition (food intake and health) and child, parent, household and community characteristics using regression analysis (Behrman and Deolalikar, 1988). Next, it uses the same health production function to examine the relationship between nutritional status (height-for-age) and child, parent, household and community characteristics. Note that the results from this analysis 
are associations, rather than causal relationships, but they provide important exante information on what characteristics are associated with improved food intake, health and nutritional status. The chapter then proceeds to simulate several policy interventions, including a cash transfer, improvements in maternal care, and a price shock to examine what changes might be expected as a result of these interventions. In particular, simulated values are substituted in the regression models to account for the effect of the interventions.

Chapter 4 also uses the baseline data from the LEAP 1000 impact evaluation. The objective of Chapter 4 is to examine the intra-household dynamics in the baseline sample and whether these dynamics affect the wellbeing of children in the household. First, outlay equivalence analysis is used to assess how households change their consumption pattern when an additional child enters the household (Deaton, 1989). More specifically, this analysis uses regression methods to examine how the consumption of exclusive adult goods (items that are only consumed by adults in the household such as tobacco, alcohol, clothing for adults, etc.) responds to an addition of a child to the household. When the household budget is fixed, adults must give up spending on adult goods to cater for the needs of a child. Then, testing whether this response is different when the additional child is a boy or a girl can reveal gender preference of the household. Next, the chapter aims to analyse whether fathers and mothers have different preferences with regards to investing in their daughters or sons. This analysis uses the educational achievement of the parents as a source of bargaining power and tests how parental education has an effect on outcomes (education and nutrition) and inputs (educational expenditures and infant and young child feeding practices) for sons versus daughters (Quisumbing and Maluccio, 2000). This analysis is conducted using OLS, fixed effects and random effects.

Chapter 5 presents an impact evaluation of the Ghana LEAP 1000 programme. The evaluation contains two waves of data, collected in 2015 and 2017. As described above, the evaluation constructs a quasi-experimental treatment and comparison group by using the discontinuity of the PMT threshold as a cut-off for eligibility. Chapter 5 first establishes that this quasi-experimental strategy was valid by conducting balance tests on all the main indicators and a manipulation test to verify that the PMT scores were not compromised. The main impact analysis uses a difference-in-difference (DD) approach and compares the change in the treatment group to the change in the comparison group, while controlling for several individual and household characteristics as well as community fixed effects. The chapter then proceeds to conduct heterogeneity analysis by examining the role of i) duration in the programme, ii) distance to and quality of nearby health centres, iii) negative and positive shocks to households' livelihoods, and (iv) the intra-household dynamics. This heterogeneity analysis is conducted through a triple-difference approach which estimates how the treatment effect varies with respect to the moderators described above (Bedoya et al., 2017). 


\subsection{Outline of the thesis}

This thesis is divided in four main chapters. All chapters are based on stand-alone papers and while care has been taken to avoid repetition, there is some overlap in the description of the study context, LEAP programme and data sources. Chapter 2 starts by providing a detailed overview of what we know and don't know regarding the impact of CTs on child nutrition. Chapters 3 and 4 both use the baseline data of the impact evaluation to establish some ex-ante predictions. Chapter 3 examines the determinants of malnutrition and chapter 4 analyses intrahousehold dynamics in resource allocation and decision-making. Chapter 5 then presents results from the impact evaluation of Ghana LEAP 1000 on child nutrition and its determinants. Below is a short description of each chapter.

\section{Chapter 2: Cash transfers and child nutrition: pathways and impacts}

This chapter examines the extent to which cash transfer programmes can improve child nutrition. It uses the conceptual framework (Figure 1.2) which captures and explains the pathways and determinants of child nutrition. This framework is then used to organize and discuss relevant evidence from the impact evaluation literature, focusing on impact pathways and new and emerging findings from subSaharan Africa to identify critical elements that determine child nutrition outcomes as well as knowledge gaps requiring further research, such as children's dietary diversity, intra-household decision-making, caregiver behaviours and stress.

\section{Chapter 3: Determinants of child malnutrition and the potential effects of consumption growth, improved maternal care and price shocks}

This chapter uses the baseline data of the LEAP 1000 impact evaluation to explain the underlying causes of childhood malnutrition. Guided by the conceptual framework (Figure 1.2), it models inputs in the production of health and nutrition, as a function of child, household and community characteristics. The findings suggest that maternal agency and health contribute to improved health status. Household resources - in the form of consumption - are positively associated with food intake and nutritional outcomes. Simulations show that income growth, improving maternal care and avoiding sudden price shocks have a positive - but rather limited effect - on the reduction of malnutrition. Effects are greater in children under two. The chapter concludes that policies that address underlying determinants simultaneously, and target the youngest population of children, could have the largest effect on reducing malnutrition in this population. 
Chapter 4: Intra-household dynamics in Northern Ghana: is there a gender bias in the allocation of household resources?

The prevailing intra-household dynamics likely affect the impact of an unconditional cash transfer programme. This chapter examines the intrahousehold dynamics in the LEAP1000 sample before they receive any transfers. It employs two sets of analysis. First, outlay equivalence analysis is used to examine any gender bias in the household expenditure data. Secondly, parental education is used as a source of bargaining power to investigate its effects on the educational attainment and nutritional status of boys versus girls in the household. If gender bias is present, or if parents have different preferences in investing in their daughters versus their sons, then this is evidence of non-unitary household behaviour and can likely affect the impact of the cash transfer programme. The outlay equivalence analysis is unable to detect any gender differences in the allocation of household resources. However, the second analysis reveals suggestive evidence that fathers are more inclined to invest in their daughters compared to their sons.

\section{Chapter 5: The impact of Ghana LEAP 1000 on young child nutrition and its determinants}

This chapter takes advantage of two waves of data from the impact evaluation to estimate the impact of the CT on child nutritional status. The chapter quantitatively assesses the different pathways (food security, care and health environment) through which the cash transfer has (or has not) affected nutritional status. Moderating effects of the period benefitting from the programme, access to health facilities and experience of shocks are also examined. Finally, this chapter studies how intra-household dynamics affect the impact of the LEAP 1000 programme on child nutrition. The results show no main treatment effect on nutritional status, nor on the two immediate determinants of food intake and health. However, there is a positive effect on one of the three underlying determinants, food security. The heterogeneity analysis shows no differential impacts by age group. Quality of nearby health facilities increases the programme's impact on food security. There are also lower impacts on weight in case of crop-related shocks and higher health impacts when communities benefit from additional development programmes. Finally, there is some suggestive evidence that better-educated mothers invest fewer resources in the health of their daughters compared to their sons. The chapter concludes that cash alone is unlikely to yield impacts on young child nutrition and integrated programmes that aim to address multiple underlying determinants at the same time need to be further examined. 


\section{Chapter 6: Conclusions and policy implications}

This final chapter summarizes the main results by answering the research questions, draws conclusions and discusses the implications and way forward. The findings of this research are important for the future design of social protection measures that could help to achieve SDG 2 to end hunger, achieve food security and improved nutrition and promote sustainable agriculture. The main conclusion is that UCTs, in the context of the Ghana LEAP 1000 programme, can improve food security at the household level but have a negligible effect on the nutritional status of infants. As a result, UCTs with the objective to improve child health and nutrition are more like household benefits rather than child benefits. Therefore, additional policy measures, for example by linking social protection programmes to complementary programmes, are needed to ensure that the potential of UCTs are maximized to improve child wellbeing. 


\section{Cash transfers and child nutrition: pathways and impacts}

This chapter is an extended and updated version of:

de Groot, R., Palermo, T., Handa, S., Ragno, L. P., \& Peterman, A. (2017). Cash transfers and child nutrition: pathways and impacts. Development Policy Review, 35(5), 621-643. 


\subsection{Introduction}

As discussed in the introductory chapter of this thesis, child malnutrition remains a significant global health problem. At the same time, governments across the developing world are piloting and implementing CTs. This development started in Latin America (LA) in the 1990s and countries in SSA have begun to initiate CTs in the last decade or so. An important distinction of the government CTs in SSA is that programming is typically unconditional, whereas the majority of programmes in LA are conditional (i.e. tied to certain behaviours such as school enrolment, health check-ups, and attendance at health information sessions). ${ }^{8}$ One major argument for the absence of conditions in the SSA region is the poorly developed supply-side in terms of education and health, which would not be able to cope with increased demand resulting from monitoring and implementing sanctions in a CCT. In addition, the capacity for implementing CTs is considered much weaker in SSA than in LA (Schubert and Slater, 2006, Slater, 2011).

Further distinctions in programme design between these regions are driven by differences in context in terms of economic and social vulnerability. Due to the HIV/AIDS epidemic in SSA, programmes are typically targeted to households who are ultra-poor, labour-constrained and/or caring for orphans and vulnerable children. In addition, due to persistent and deep poverty, combined with recurrent food crises, programmes primarily aim to ensure immediate survival and food security as well as chronic and intergenerational transmission of poverty, while having a secondary (indirect) aim of improving health, nutrition and education, particularly of children (Davis et al., 2012). These programme design distinctions have implications for impacts and impact pathways, scalability, cost, and political acceptance.

The aim of this chapter is to examine to what extent and through which pathways CTs can improve child nutrition, primarily evidenced by anthropometric measures. The chapter is not a systematic review of the evidence. Rather, it is a comprehensive synthesis of evidence building on recent systematic reviews, combined with new evidence from impact evaluation studies in SSA. Relevant studies were identified through searches in electronic databases, primarily Google scholar, as well as institutional websites from International Food Policy Research Institute (IFPRI), the World Bank, UNICEF, Food and Agricultural Organization of the United Nations (FAO), Overseas Development Institute (ODI), the Registry for International Development Impact Evaluations (RIDIE) and the Transfer Project. In addition, experts in the field were consulted to identify any remaining literature. Studies were included if they used rigorous and appropriate methods

\footnotetext{
${ }^{8}$ For example, the World Bank found that out of the 48 countries in SSA included in the study, 41 had experience only with an UCT, and 18 countries had experience with a CCT (Honorati et al., 2015).
} 
(experimental or quasi-experimental, including use of the counterfactual through a comparison group) to establish causal inference about the impact of CTs on relevant outcomes.

Recent (pre-2016) systematic reviews extensively cover the LA programmes (Fernald et al., 2012, Lagarde et al., 2009, Leroy et al., 2009, Manley et al., 2013, Owusu-Addo and Cross, 2014, van den Bold et al., 2013). We summarize findings from these reviews, however the main contribution of this chapter to the existing literature is its focus on new and emerging evidence in SSA (UNICEFESARO/Transfer Project, 2015), as well as evidence on pathways of impact. To fulfil this objective, the chapter uses the conceptual framework of Figure 1.2 that outlines the pathways and determinants of child nutrition. It then identifies and discusses evidence from the impact evaluation literature to present current knowledge and gaps in knowledge surrounding the impact of CTs on child nutrition, how and why CTs (may) have an impact on child nutrition, and the key factors determining both impacts and potential unintended consequences. The following three questions guide the content of this chapter: (1) What are the range of impacts that have been found of CTs on child nutrition, focusing on the SSA region? (2) What are the hypothesized impact pathways, and how strong is evidence supporting these? (3) What factors explain the heterogeneity of impacts across studies?

The chapter proceeds as follows: Section 2.2 uses the framework of Figure 1.2 to discuss the range of impacts CTs have on child nutrition, focusing on the underlying determinants, immediate determinants and outcomes and identifies key factors that can explain heterogeneous impacts of CTs; Section 2.3 concludes by synthesizing the current knowledge on the linkages between CT and child nutrition and identifies knowledge gaps.

\subsection{Cash transfers and child nutrition: what we know about the types of impacts and pathways}

Building on the potential pathways identified in Figure 1.2, this section discusses evidence from quantitative peer-reviewed studies and impact evaluation reports on CTs in developing countries. The main criterion for inclusion was the use of rigorous and appropriate methods to establish causal interference. ${ }^{9}$ The section examines what we know in relation to the impact of CTs on the underlying

\footnotetext{
${ }^{9}$ As with any study, our results may be limited by publication bias in case findings on nutritional outcomes or intermediate outcomes are not reported in published articles or reports. We minimized this bias by cross-checking the CT programme inventory in the State of Social Safety Nets 2015, as well as contacting experts in the field, to ensure no rigorous evaluation of government-run CTs which measured outcomes relevant for our purpose was excluded.
} 
determinants of nutritional status (2.2.1); the evidence for the effect of CTs on immediate determinants (2.2.2) and direct effects on nutritional status (2.2.3). It also attempts to identify key factors that can explain the heterogeneity of impacts across CTs (2.2.4) as well as some perverse incentives and unintended consequences (2.2.5). Key characteristics of the programmes, including eligibility criteria, transfer size, coverage and other design elements are not discussed here, but available in other review studies (e.g. see supplementary file 2 from OwusuAddo et al. (2018) for an overview of CT programmes in SSA, Lagarde et al. (2009), Gaarder et al. (2010) and Glassman et al. (2013) for CT programmes in LA and Asia).

\subsubsection{Cash transfers and underlying determinants of child nutrition}

Cash transfers and food security

It is well documented that CTs directly affect overall household consumption and specifically household food consumption (Hidrobo et al., 2018, Tiwari et al., 2016). In ten countries in SSA (Ethiopia, Kenya, Lesotho, Malawi, Mozambique, Nigeria, South Africa, Uganda, Zambia and Zimbabwe), food security improved because of receiving CTs as most of the transfer income was spent on food. Most beneficiary households also improved their diet diversity (Berhane et al., 2015, Bhalla et al., 2018, Brugh et al., 2018, Carneiro et al., 2017, Case, 2004, d'Agostino et al., 2017, Handa et al., 2013b, Haushofer and Shapiro, 2016, 2018, Miller and Tsoka, 2008, OPM, 2013, 2014, 2015, Soares and Teixeira, 2010). Evidence from LA also shows that CTs increased household consumption, in particular food consumption, and households improved their diet diversity. In Brazil, households purchased healthier and non-staple items such as fruits and vegetables and in Colombia, consumption of protein-rich food increased (Attanasio et al., 2005b, Olinto et al., 2003). Similar results were found for Ecuador, Mexico and Nicaragua (Fernald et al., 2008, Leroy et al., 2008, Macours et al., 2012, Maluccio and Flores, 2005, Paxson and Schady, 2010). Also in Asia, several programmes improved food security measures, for instance in Bangladesh (Ferré and Sharif, 2014), Bihar, India (OPM, 2017) and Nepal (Harris-Fry et al., 2018) .

\section{Cash transfers and health care}

As shown in Figure 1.2, the health care pathway includes both health seeking behaviour and characteristics of the health environment. Many CT evaluations analyse impacts on preventive care and health visits. In Kenya, households spent more on health care after two years of exposure to the Hunger and Safety Net Programme (OPM, 2013) and in Malawi, beneficiaries of the Mchinji Social CT were more likely to receive care when sick compared to non-beneficiaries (Adato and Bassett, 2009). In Ghana and Tanzania, CTs increased the likelihood of children being enrolled in health insurance schemes (Evans et al., 2014, Handa et al., 2013a). Studies in Colombia, Honduras, Jamaica, Mexico, Nicaragua and the Philippines 
found positive impacts on preventive health visits and the probability that children were weighed (Attanasio et al., 2005b, Chaudhury et al., 2013, Levy and Ohls, 2007, Macours et al., 2012, Maluccio, 2005, Maluccio and Flores, 2005, Morris et al., 2004a).

A review of the impact of CTs on maternal and child health found significant effects on prenatal monitoring in five (Guatemala, Honduras, India, Mexico and Uruguay) of the seven countries studied (Glassman et al., 2013). Results for postnatal care, however, were insignificant in both countries reviewed (Honduras and El Salvador). Results from Mexico regarding frequency and quality of prenatal care are mixed (Barber and Gertler, 2008, Barber and Gertler, 2009). Other studies found a significant increase in clinic and growth monitoring visits due to Progresa, probably explained by the fact that these were programme conditionalities (Adato and Bassett, 2009). In Ecuador, no effect of the Bono de Desarrollo Humano was found on the use of growth control visits, however a positive effect was found on parasite treatment (Paxson and Schady, 2010).

In terms of hygiene, beneficiary households of the Malawian Mchinji CT were more likely to take a bath, use soap and brush teeth on a daily basis (Miller and Tsoka, 2008). In addition, households receiving the old-age pension in South Africa were more likely to have a flush toilet and less likely to report an off-site water source (Case, 2004). Finally, households benefitting from the Palestinian CT reported fewer difficulties in paying for safe drinking water (Pereznieto et al., 2014).

\section{Cash transfers and care practices, behaviour and mental health}

The relation between CTs and care practices has not been studied extensively. However, there are studies linking care practices and other mediators, such as women's empowerment and stress, on nutritional outcomes for children. For example, the link between infant and young child feeding practices and nutritional status has been widely studied with the use of indexes, comprised of indicators of age-appropriate practices in terms of breastfeeding, refraining from bottle feeding, diet diversity and meal frequency (Arimond and Ruel, 2002). These indexes have been associated with improved nutritional status in several countries across all regions of the globe (Amugsi et al., 2014, Arimond and Ruel, 2002, Kumar et al., 2006, Lohia and Udipi, 2014, Ma et al., 2012, Ruel and Menon, 2002, Saha et al., 2008, Sawadogo et al., 2006). However, in select cases, no significant effect was found between feeding practices and nutritional status, for example in Bolivia (Ruel and Menon, 2002), Senegal (Ntab et al., 2005) and Madagascar (Moursi et al., 2008).

Diet diversity is usually one component of infant and young child feeding indices; however, its effect on nutritional status has also been studied independently. In an 11-country study, a significant effect of diet diversity on nutritional status was found for 10 countries: Cambodia, Colombia, Ethiopia, Haiti, 
Malawi, Mali, Nepal, Peru, Rwanda and Zimbabwe (Arimond and Ruel, 2004). Only in Benin was no significant effect found.

Responsive feeding is a care practice that has been examined less in the literature. This concept is not yet well defined, but usually includes elements such as ensuring that the feeding context is pleasant for the child, positively interacting with the child during the feeding episode and adapting the feeding method to the child's developmental status (Black and Aboud, 2011, Engle, 2002). Responsive feeding behaviour has been linked to higher food intake for children in Bangladesh (Aboud and Akhter, 2011) and improved cognitive development of children in India (Vazir et al., 2013). Furthermore, two studies in Ghana have reported a positive association between higher responsive feeding practices and nutritional status of children (Nti and Lartey, 2008, Ruel et al., 1999). However, the study in India found no effect of responsive feeding behaviour on child nutritional outcomes. Furthermore, a review of this topic concluded that few studies find a positive relationship between responsive feeding and reduced undernutrition, with the exception of indicators for positive caregiver communication during feeding (Bentley et al., 2011). Ultimately, because of lack of standardization in measurement, results are difficult to compare across studies and settings.

In terms of psychosocial care, maternal warmth, love and affection, sensitivity to children's needs and attachment between caregiver and child have been linked to improved children's nutritional status (WHO, 2004).

A pressing question is whether CTs can affect caregiver behaviour if no supplementary educational campaigns or trainings are offered. Unfortunately, very few studies look at the impact of CTs on the specific caregiver behaviours discussed here. One exception is Zambia, where the Child Grant Programme had a significant impact on infant and young child feeding practices, as measured by the minimum age-appropriate meal frequency for children 6-23 months old (Handa et al., 2013b).

Mental health of the caregiver, in particular stress, is an important factor in the conceptual framework. Poverty-related stress is associated with shortsightedness and a focus on present consumption, potentially implicating more long-term goals such as child health and development (Haushofer and Fehr, 2014). Since CTs often target resource-constrained households, research in several SSA countries has found that transfers make recipients happier and increase measures of hopefulness about the future (Davis and Handa, 2014). This evidence is further corroborated by more detailed analysis from Malawi and Zambia (Kilburn et al., 2018, Natali et al., 2018). Furthermore, in Kenya, findings from the GiveDirectly UCT evaluation showed that the psychological well-being of beneficiary households improved (happiness, life satisfaction, stress and depression). In addition, larger transfers and transfers given to women lowered cortisol levels for both men and women significantly, although levels of cortisol did not differ overall between the pooled treatment and control groups (Haushofer and Shapiro, 2016). 
In Ethiopia, no effect on mental health was found as a result of the Social Cash Transfer in Tigray (Berhane et al., 2015). ${ }^{10}$

\section{Mediators of care practices: Women's empowerment and intimate partner violence} Previous research has suggested a positive relationship between women's empowerment and improved nutritional status (van den Bold et al., 2013). However, evidence on the impact of CTs on women's empowerment is mixed: qualitative evidence is generally positive, while quantitative evidence generates a more heterogeneous picture (van den Bold et al., 2013). This may be partially linked to the difficulty in measuring the concept of empowerment through quantitative survey indicators. For example, qualitative evidence from Mexico showed positive impacts on several dimensions of women's empowerment, such as women's control over resources, public speaking, education, mobility, decisionmaking power, and self-esteem (Adato et al., 2000, Latapi and de la Rocha, 2004). However, quantitative evidence on CCTs is mixed, with small impacts or only among selective groups (Attanasio and Lechene, 2002, de Brauw et al., 2014, Handa et al., 2009), no impacts (Hidrobo et al., 2012), or negative impacts (Gitter and Barham, 2008). Recent quantitative research on UCTs in Ecuador, Kenya, Uganda and Yemen also point toward mixed results (Hidrobo and Fernald, 2013, OPM, 2013, Peterman et al., 2015, Schady and Rosero, 2008).

Intimate partner violence (IPV) can also affect child nutritional outcomes in various ways. Globally, one in three women aged 15 and over experiences physical or sexual IPV in her lifetime (Devries et al., 2013). Women's exposure to IPV during pregnancy is associated with decreased birth weight (Aizer, 2011, Shah and Shah, 2010) and pre-term delivery (Shah and Shah, 2010). In children, exposure to maternal experience of IPV has been linked to several health and nutritional outcomes, including severe acute malnutrition (Rico et al., 2011, Salazar et al., 2012), under two mortality (Åsling-Monemi et al., 2003) and decreased growth and stunting (Salazar et al., 2012, Sobkoviak et al., 2012). Yount et al. (2011) posit that children's exposure to violence in the home may affect early childhood growth and nutrition through biological and behavioural pathways, and their review of the literature demonstrates that the strongest evidence concerns the effects of prenatal IPV on low-birth weight, which is a strong predictor for subsequent growth.

Only a handful of studies look at the impact of CTs on IPV. In Mexico, physical IPV decreased in the short run (2-6 years) as a result of Oportunidades, however effects disappeared after more than five years (Bobonis et al., 2015, Bobonis et al., 2013). Peru's CCT, Juntos, also decreased physical and emotional IPV in the short run (Perova, 2010). A study in Ecuador found that Bono de Desarollo

\footnotetext{
${ }^{10}$ Mental health was measured using the WHO Self-Reported Questionnaire (SRQ-20), which has been validated in Ethiopia.
} 
Humano, a national UCT, decreased psychological violence for women with higher than primary school education, but for women with lower education, the effect depended on the relative level of education in comparison to that of her partner, and there was an increase in emotional IPV in households where the woman's education was equal to or higher than her partner's (Hidrobo and Fernald, 2013). In contrast, another study in Ecuador of a cash, voucher and food pilot project concluded that the transfers reduced controlling behaviours and physical and/or sexual IPV, regardless of the type of transfer (Hidrobo et al., 2016).

\section{Cash transfers and intra-household decision-making}

As shown in the conceptual framework, it is likely that the impact of a CT on child nutrition is affected by the intra-household dynamics of the recipient household. Economic models describing household behaviour as a unit were pioneered by Becker (1981), addressing issues such as fertility, marriage and labour supply. Although useful, these models usually treat the household as a single unit with common preferences and the household is maximizing one single utility function. Several authors have gone beyond the idea that the household is a unitary decision-maker and included the possibility that individuals within a household have different preferences, for example a husband and wife. For example, Attanasio and Lechene (2014) reject the unitary model in favour of the collective model of the household using the Mexican CCT as an exogenous source of increased control over resources by the woman in the household.

In another example, Thomas (1990) investigates the effect of unearned income (e.g. a CT like pension or social security payments) in the hands of a mother versus the father. He finds that women direct more of their unearned income to household nutrition, and the effects of maternal unearned income on child anthropometrics are four to eight times higher than the effects of paternal unearned income. Furthermore, mothers seem to have stronger preferences to invest in their daughters compared to their sons, and the reverse is true for fathers. Similar findings emerged from South Africa, where pensions paid to females significantly increased the nutritional status of girls, but not boys, while no effects were found for pensions received by males (Duflo, 2003). Further evidence from South Africa showed that women eligible for the pension are much more likely to be primary decision-makers in the household compared to non-eligible women (Ambler, 2016). Also in Mexico, resources under the control of women were more likely to be spent on investments in children (Rubalcava et al., 2009). In Bolivia, there were strong differences in the impact of a CT programme depending on the culture of the recipient, and indigenous populations were more likely to follow a common preference model, while in non-indigenous households, decision-making more closely followed a collective and bargaining model (Yanez-Pagans, 2008). A study in Burkina Faso, which randomized the recipient of the cash transfer, found that giving cash to mothers did not lead to better child health outcomes, but 
putting money in the hands of fathers improved child health, in particular during years of poor rainfall (Akresh et al., 2016). In Brazil, nonlabour income to women through a CT was found to increase household food expenditures, but this increase was not necessarily due to the women being the recipient (Braido et al., 2012).

As a result of these mixed findings, a meta-analysis on the topic concludes that targeting CT programmes to women 'appears to improve child nutrition and health; however, it is not yet clear that such interventions consistently lead to any other systematic pattern of economic choices, let alone whether they ultimately lead to benefits for the household as a whole more than if the transfer were targeted to men' (Yoong et al., 2012, p. 1).

\subsubsection{Cash transfers and immediate determinants of child nutrition}

\section{Cash transfers and child dietary intake}

Only a few studies have specifically addressed the impact of a CT on children's nutritional intake, as opposed to household-level diet diversity. An evaluation of four social protection programmes in Bangladesh showed a significant increase in household food expenditure, but not on the caloric intake of children under five years old (Ahmed et al., 2009). Another study in Bangladesh found no significant impact of the Primary Education Stipend on the food expenditures and per capita caloric intake of children (Baulch, 2011), although this programme is not explicitly aimed at improving young child nutrition. In Nicaragua, the number of days children consumed more nutritious food increased as a result of the conditional Atención a Crisis programme (Macours et al., 2012), and in the Philippines, the Pantawid CCT led to an increase in high-protein food intake, such as eggs and fish (Chaudhury et al., 2013). The MAM'Out trial in Burkina Faso led to an increased intake of high-nutritional-value foods, such as eggs, flesh foods and iron-rich foods (Tonguet-Papucci et al., 2017). Finally, in an evaluation of a Ugandan food versus cash transfer scheme, the cash component increased children's intake of starches, meat, eggs and dairy products, while the food transfer had no significant impact on dietary intake (Gilligan and Roy, 2015).

\section{Cash transfers and child health status}

The most recent review on this topic concluded that seven out of nine studies in SSA reported a significant positive impact of CT on child health outcomes (OwusuAddo et al., 2018). In our review, several studies have reported the direct impacts of CTs on children's health status. In Zambia and Colombia, reductions in the prevalence of diarrhoea were found (Attanasio et al., 2005a, Handa et al., 2013b). However, in Colombia, the results did not hold for children older than 48 months. Evidence from Burkina Faso, Lesotho, Malawi, Mexico, Tanzania and South Africa also demonstrate positive impacts on the health status of children, with children in CT households less likely to be ill than comparison children (Akresh et al., 2016, Case, 2004, Evans et al., 2014, Gertler, 2004, Miller and Tsoka, 2008, OPM, 2014). 
For example, the Tanzanian programme reduced the number of sick days for children under five by 0.76 days per month, but only after 2.5 years in the programme (Evans et al., 2017). However studies in Mexico and Kenya found no significant impact on the number of sick days, or proportion ill or injured as a result of the programme (Fernald et al., 2008, OPM, 2013), and, in Nicaragua, the decrease in number of sick days did not hold after two years (Macours et al., 2012). Evaluations of the Palestinian CT found a significant lower prevalence of acute respiratory infection (ARI) in beneficiary households compared to a control group (Pereznieto et al., 2014) and fewer reported illnesses, but a higher rate of chronic illnesses (Hackstein et al., 2013). The Ghana LEAP programme had negative effects and slightly increased morbidity rates among children under five years old (Handa et al., 2013a).

With respect to vaccination rates, results are mixed. In Brazil, the Bolsa Família CCT increased the proportion of children who received vaccinations on time (de Brauw et al., 2012), but an earlier evaluation using only the first wave of data found no effect on child immunizations (Soares et al., 2010). The Apni Beti Apna Dhan programme in India resulted in an increased number of vaccinations in the short run (four years), but not in the long run (12 years) (Sinha and Yoong, 2009). Studies from Honduras and Colombia (both CCTs) showed positive effects on timing of vaccinations (Attanasio et al., 2005b, Morris et al., 2004a). The Nicaraguan Red de Protección Social, Jamaican PATH and Philippine Pantawid programmes (all CCTs) showed no significant impacts on vaccination uptake among beneficiaries (Chaudhury et al., 2013, Levy and Ohls, 2007, Maluccio and Flores, 2005). In addition, a social experiment in Zimbabwe, aimed at assessing differential impacts between a CCT and UCT, found no significant improvement on vaccination coverage among either treatment arm (Robertson et al., 2013).

Examining stress as a pathway for poor health is important, as low socioeconomic status is linked with increased rates of morbidity and mortality (Adler et al., 1993, Elo et al., 2006). Poverty is a chronic stressor, and it has been hypothesized that individuals of lower socioeconomic status face more stressful events in their lives and also have fewer social and material resources with which to deal with stress (Baum et al., 1999, Pearlin et al., 2005). The chronic stress of poverty in early childhood can induce significant biological changes with lasting impacts on health (Danese and McEwen, 2012), and thus, CTs which alleviate poverty have the potential for broad, long-term impacts on health. One study assessed the impact of Mexico's Oportunidades on children's cortisol levels, a stressrelated biomarker, showing that beneficiary children had lower salivary cortisol levels compared to the children in control groups and the effect was larger for children of mothers with high depressive symptoms (Fernald and Gunnar, 2009). 


\subsubsection{Cash transfers and child nutrition outcomes}

This section explicitly focuses on evidence related to the direct impact of CTs on child nutritional status, measured as HAZ, WAZ or, in some cases, WHZ. There have been six recent (pre-2016) reviews on the impacts of CTs on child nutritional status, which we summarize in Table 2.1. Two key findings emerge: 1) the focus has been primarily on CCTs in LA, with very little representation from SSA, apart from studies from South Africa, and 2) none of the reviews find conclusive evidence of a positive impact on child nutritional status, and in fact several authors point out that the pathways of impact are not clearly understood. The one metaanalysis evaluating 15 programmes in 10 countries demonstrated a minor but statistically insignificant impact on child anthropometry (Manley et al., 2013), echoing the lack of conclusive results across all reviews.

Two recent articles specifically focus on the SSA region: Manley and Slavchevska (2019) and Owusu-Addo et al. (2018). Both reviews reach similar conclusions as above. Manley and Slavchevska (2019) acknowledge that CTs have shown improvements in household food security but have not always improved child health and nutrition measures. They call for more attention during two critical windows: early childhood and adolescence during which CTs show more promise to address crucial barriers to nutritional improvements. Owusu-Addo et al. (2018) find that the effect of CTs on anthropometric measurement in SSA are generally mixed.

Building on the evidence in Table 2.1, we consider additional literature focusing more heavily on recent evidence emerging from SSA. In the studies we considered, a positive impact on child nutritional outcomes was found across several countries in SSA (Burkina Faso, Nigeria, South Africa and Zambia), Latin America (Brazil, Colombia, Ecuador, Mexico and Peru) and Asia (Pakistan, Philippines and Sri Lanka).

The old-age pension in South Africa was associated with increased HAZ in girls under two years (Duflo, 2003) and children in general (Case, 2004). In addition, longer exposure to the Child Support Grant during the first 36 months of life (66 percent versus 1 percent), increased children's HAZ with 0.25 standard deviations (SD) (Aguero et al., 2007). After two years of operation, the Zambian Child Grant Programme was associated with an increase of 0.196 WHZ among children aged three to five years (Handa et al., 2013b), but effects disappeared after four years (American Institutes for Research, 2015). The Child Development Grant in Nigeria led to a moderate increase in HAZ and reduction in the proportion of stunted children, but only for children who were born during the programme. There was also a concurrent decrease in WHZ, indicating that children were taller, but thinner (Carneiro et al., 2017). A pilot project in Burkina Faso, the Nahouri Cash Transfer Pilot Project, yielded a positive effect on stunting after two years (but not after three years) during a period of poor rainfall and in particular if the transfer 
was paid to the father (Akresh et al., 2016). Results from SSA's largest social protection programme, the Productive Safety Net Programme (PSNP) in Ethiopia have also shown mixed results. One study found a positive effect on WHZ, especially in households that are able to increase female employment through the PSNP (Debela et al., 2015). Another study, focusing on older children 5 - 15 years old, showed a positive effect on stunting (Porter and Goyal, 2016). However, two other studies have found no effect on child nutritional outcomes (Berhane et al., 2017, Gebrehiwot and Castilla, 2018).

In Sri Lanka, the effect of Samurdhi on children under five years exposed to the programme since birth ranged from 0.4-0.5 SD in terms of HAZ with larger effects for children under three years (Himaz, 2008). In Pakistan, a NGO-run programme improved rates of stunting and HAZ after six months and one year (Fenn et al., 2017). Also in Bangladesh, a pilot programme found positive effects on wasting among children 10-22 months at the start of the pilot (Ferré and Sharif, 2014). Pantawid in the Philippines decreased the rate of severe stunting among children $6-36$ months old by 10 percentage points, although no effect was found on other anthropometric indicators (Chaudhury et al., 2013, Kandpal et al., 2016).

Mexico's Progresa has been evaluated extensively and most studies find positive, significant effects on child height in the range of 1.0-1.5 centimetres, depending on the duration of exposure to the programme and child age (Behrman and Hoddinott, 2005, Fernald et al., 2009, Gertler, 2004, Leroy et al., 2008, Rivera et al., 2004). After one year, the Colombian Familias en Acción was associated with increased growth of about $0.5 \mathrm{~cm}$ among 12 month-old boys, but not for children older than 24 months (Attanasio et al., 2005a, Attanasio et al., 2005b). A study on Ecuador's Bono Solidario found that the transfer had a small but statistically significant effect on children's height and weight (León and Younger, 2007). The Peruvian CCT, Juntos, resulted in an increase of 0.19 SD in HAZ and a reduction in stunting of 9 percentage points, if children were exposed during the first four years of life (Sanchez et al., 2018). The results from Brazil are mixed. One analysis of an early CT, Bolsa Alimentação, found a negative impact on child weight and height after six months of exposure (Morris et al., 2004b), however this result was countered by a study in 2005 , finding a small but positive effect on weight gain (Hoddinott, 2010) and more recent analysis, also finding a positive effect on WAZ and HAZ (Assis et al., 2014). Results for the more recent Bolsa Familia have also been mixed, finding both negative and positive impacts across indicators (de Brauw et al., 2012, Paes-Sousa et al., 2011, Soares et al., 2010).

Several studies have found no significant impact of CTs on child nutritional status, for example in Burkina Faso's MAM'Out trial (Houngbe et al., 2017), Kenya's Hunger Safety Net Programme (OPM, 2013), Ethiopia (Tigray SCT) (Berhane et al., 2015), Tanzania (Evans et al., 2014), Uganda (OPM, 2015), Bangladesh (Ahmed et al., 2009), Ecuador (Paxson and Schady, 2010) and Nicaragua (Maluccio, 2005). Others have found mixed results: in Malawi there was 
no significant impact of the Mchinji CT Programme on WAZ, however the evaluation found a significant reduction in the prevalence of underweight after one year (Miller and Tsoka, 2008). The Food Subsidy Programme in Mozambique resulted in a 30 percent reduction in wasting, but no effect was found on other nutritional indicators (Soares and Teixeira, 2010). In Bangladesh, the effect of the Primary Education Stipend on nutritional status was only significant in areas that had not benefitted from a food transfer project prior to the CT (Baulch, 2011). India's Apni Beti Apna Dhan, targeted at new-born girls, resulted in increased WAZ after four years, but not in the long run after more than ten years (Sinha and Yoong, 2009). Effects faded in Nicaragua as well, with a significant impact on HAZ after one year, but not after three years (Macours et al., 2012). Another study on Nicaragua found that while nutritional status increased on average, households that needed to comply with educational conditionalities for older children saw no change in the nutritional status of their younger children (Gitter et al., 2013)

In addition to CT programmes as social safety nets under normal conditions, there is growing evidence of the use of cash as intervention during emergencies. In Niger, a conditional emergency CT was found to increase weight by $1.27 \mathrm{~kg}$ and $1.82 \mathrm{SD}$ in WHZ in combination with a large reduction in the probability of having acute malnutrition (Bliss et al., 2018). 


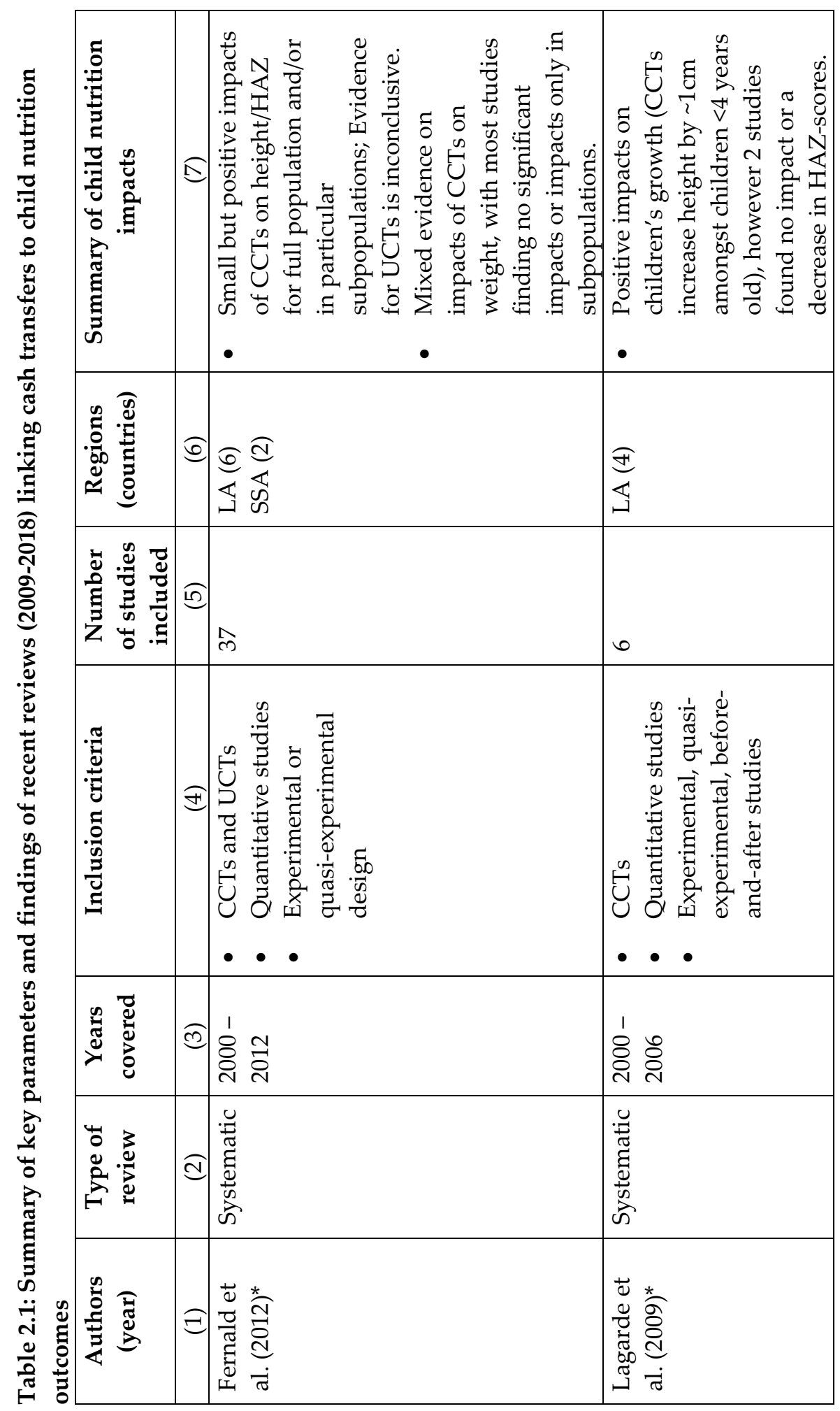




\begin{tabular}{|c|c|c|}
\hline 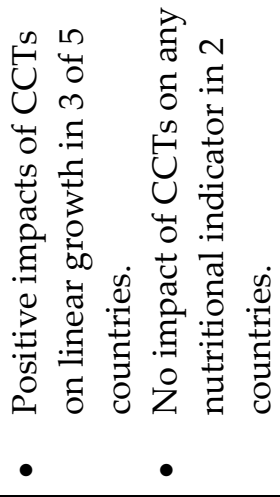 & 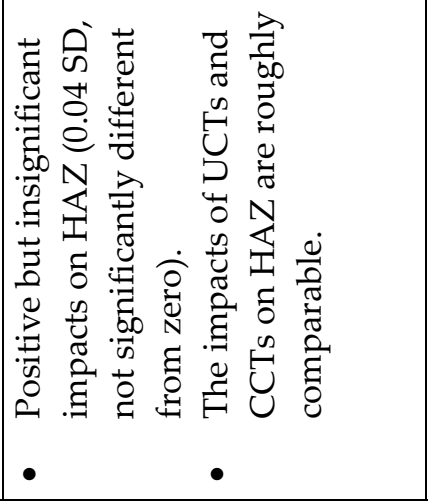 & 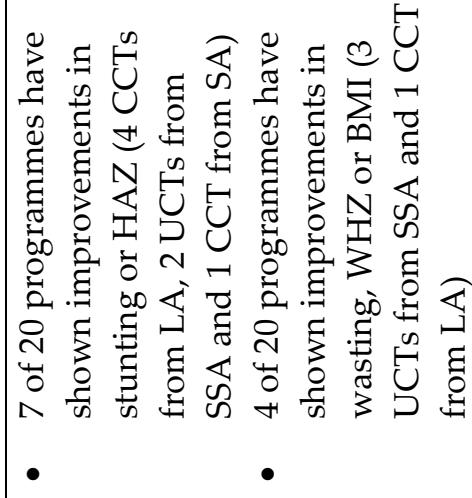 \\
\hline & 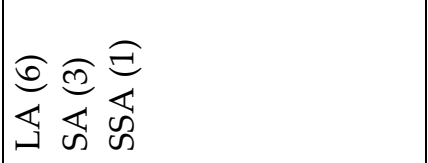 & 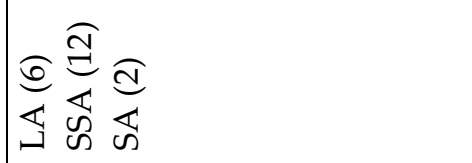 \\
\hline$\triangle$ & $\stackrel{\Delta}{\sim}$ & 오 \\
\hline 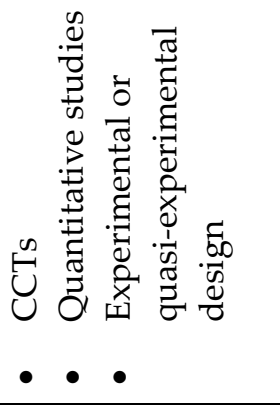 & 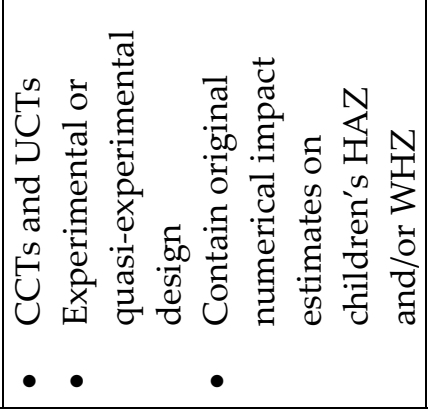 & 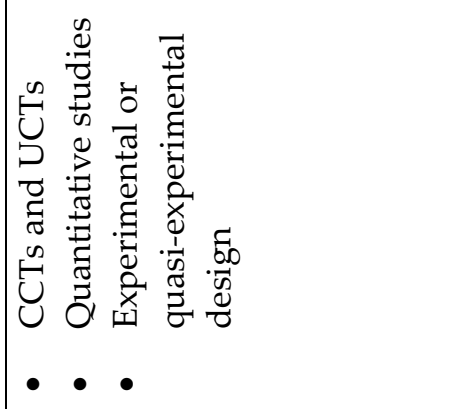 \\
\hline 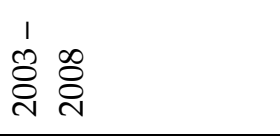 & 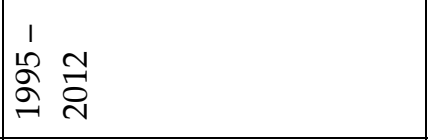 & 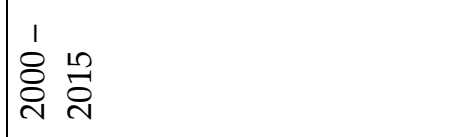 \\
\hline 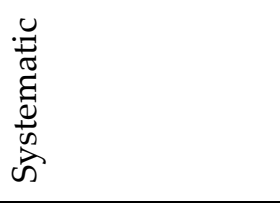 & 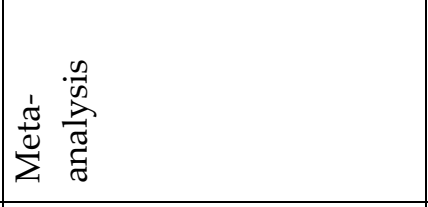 & 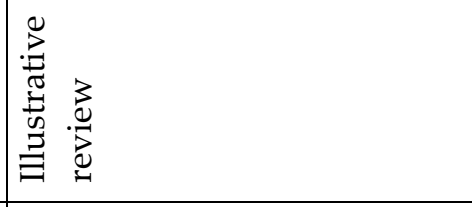 \\
\hline 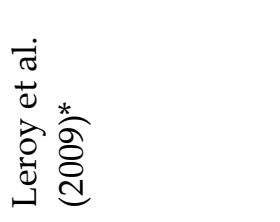 & 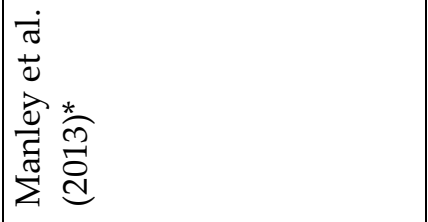 & 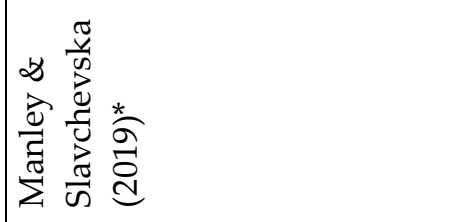 \\
\hline
\end{tabular}




\begin{tabular}{|c|c|}
\hline 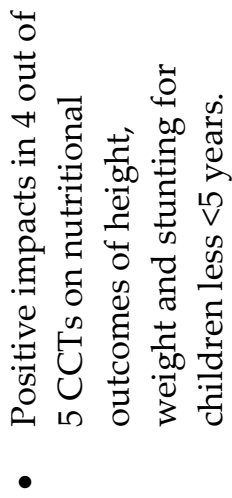 & 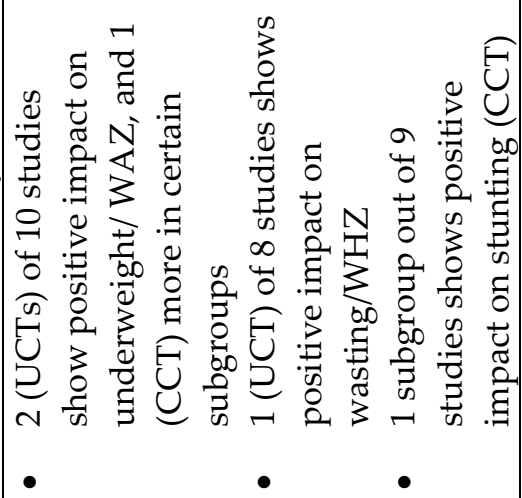 \\
\hline 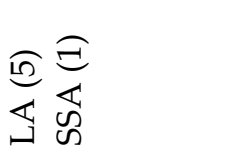 & 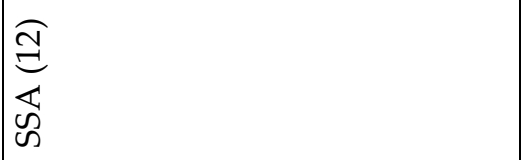 \\
\hline$\underset{r}{\sigma}$ & 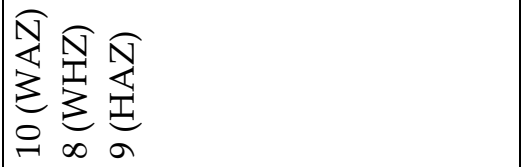 \\
\hline 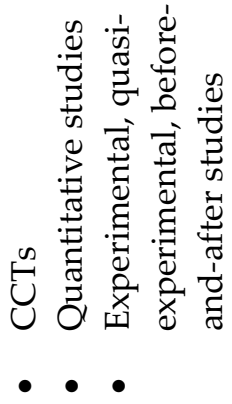 & 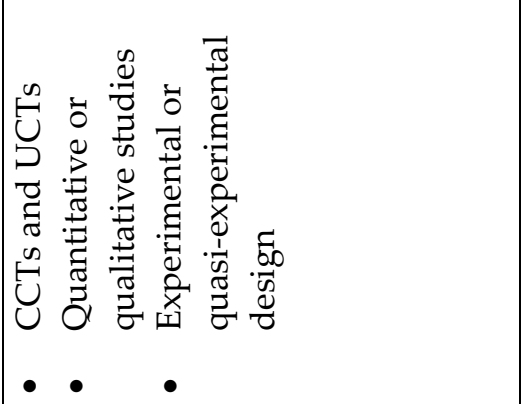 \\
\hline 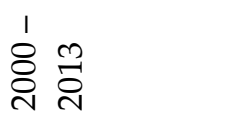 & $\frac{\tilde{\sigma}}{\not}$ \\
\hline 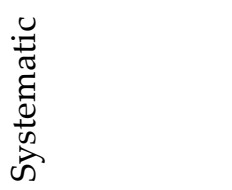 & 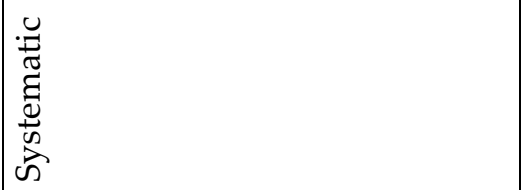 \\
\hline 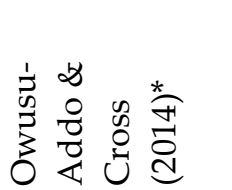 & 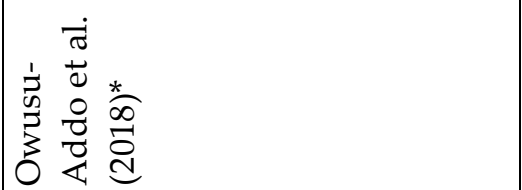 \\
\hline
\end{tabular}




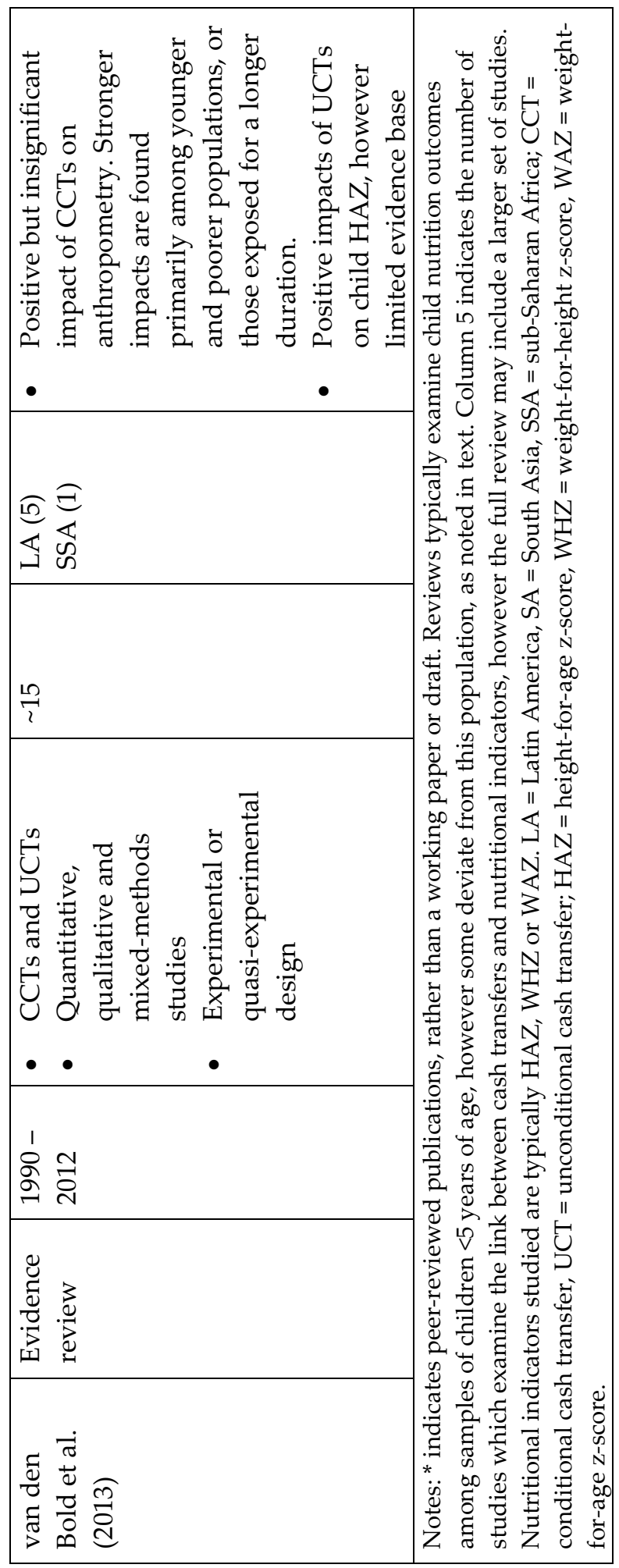




\subsubsection{Heterogeneity of impacts of CT programmes on child nutrition}

Within the studies discussed above, several factors have been identified that may help explain some of the heterogeneous impacts of CTs on child nutrition.

\section{Size of the transfer}

Several studies have argued that the size of the transfer matters. For CCTs, it is likely that the larger the transfer amount, the greater the probability that beneficiaries comply with the conditions (Lagarde et al., 2009). One study in Mexico found that a doubling of CTs, as measured by the cumulative amount of transfers received since becoming beneficiaries of the programme, significantly increased children's linear growth (Fernald et al., 2008). A study in Pakistan, comparing different cash modalities, found that the probability of being wasted was lower in a treatment arm which provided double the cash amount as the standard cash treatment. The size of the grant did not matter for the impact on stunting and HAZ, which was similarly large for both cash treatments (Fenn et al., 2017). An experiment in Rwanda, benchmarking an integrated nutrition programme with an equivalent amount of cash, and a large amount of cash (more than US\$ 500) found that the large transfer modestly improved HAZ and WAZ by about 0.1 SD (McIntosh and Zeitlin, 2018). In addition, based on a review of five CCTs in LA, Leroy et al. (2009) conclude that in countries where the size of the transfer is larger (15-25 percent of total monthly household expenditures), the effect size on children's nutritional status is greater. Manley et al. (2013) are more cautious and conclude that a larger transfer size reduces the variation of the effects, but it is not necessarily clear from their review that larger transfer sizes automatically increase effect sizes. Evidence from the Transfer Project across SSA suggests that transfers that are at least 20 percent of baseline household expenditures are more likely to have widespread impacts (Davis and Handa, 2015).

\section{Age of children}

Several studies have found larger effects for younger children. This is consistent with the literature which shows that most of the impairments in growth occur in the first two years of life (the first 1,000 days) and that interventions aimed at this age group are most effective (Leroy et al., 2009). For example, Juntos in Peru had a positive impact on HAZ and stunting for children exposed between $0-4$ years old, but not for children who were $5-8$ years old when the programme began (Sanchez et al., 2018). The targeting of young children has also been proposed under the Lancet Series on Maternal and Child Undernutrition, which estimated that by focusing interventions, including CTs, on pregnant women and young infants, malnutrition and disease burden could be reduced by 25 percent in the short term (Bhutta et al., 2008). 


\section{Targeting of transfer}

Transfers usually have higher impacts among poor and at-risk populations. Lagarde et al. (2009) argue that it is likely that the success of CTs has relied on effective mechanisms to target and monitor beneficiaries, as well as to transfer the money in a timely fashion. This sentiment is echoed by other authors, who point out that CTs provide inputs that directly address determinants of child nutrition and are targeted at populations who suffer the highest burden of nutrition deficiencies (Bassett, 2008, Leroy et al., 2009). In addition, Manley et al. (2013) find that people in areas with high morbidity rates and poor access to health services, are more likely to benefit from a transfer. This does not mean that targeting is necessarily more effective, as it is widely known that targeting, especially using PMT methods, also leads to inclusion and exclusion errors (Brown et al., 2018, Coady et al., 2004). It simply says that the poor benefit more from a transfer than the non-poor.

\section{Supply side}

The access and quality of services (for example food markets and health care facilities) are important factors that potentially influence the success of a CT. If the main reason for poor uptake of health services is linked to financial barriers, CTs may be effective in overcoming this barrier. However, if the main reason of poor uptake is related to access and quality of the health services, CTs may not have the desired effect. For example, this is the case for Mexico's Progresa which had little impact on vaccination rates because they were already high at baseline (Lagarde et al., 2009). It is often assumed that supply side conditions are sufficient or will catch up with demand once a programme starts, especially when the supply side is involved in complying with conditions, but this is not always the case (Gaarder et al., 2010). Evidence from Zambia indicates that CTs have the ability to improve outcomes related to maternal care (skilled attendance at birth and contraceptive use), affecting new-born and child health, but only in communities which have access to health services (Handa et al., 2015a, Handa et al., 2015c). These findings underscore that demand-side interventions such as CTs often require supply-side investments as well, particularly around provision of health services. A combination of demand and supply side interventions may therefore be the best recipe for success (Manley et al., 2013).

\section{Duration of programme participation}

There is some emerging evidence that the duration of CTs increases the effects on nutritional status (Manley et al., 2013). In particular, evidence from Mexico and South Africa suggests that children who were exposed to the CT longer, have better nutrition outcomes (Aguero et al., 2007, Fernald et al., 2009). A CCT in Indonesia (Program Keluarga Harapan) also found improvements in stunting 
between 9 - 11 percentage points but only after six years of operation (Cahyadi et al., 2018).

\subsubsection{Unintended consequences}

In general, few studies have looked at potentially negative consequences of CTs (Leroy et al., 2009). For CCTs, negative consequences can include an increase in women's time burden due to the need to comply with the conditions of the programme. This effect was found in the case of Progresa, although women did not necessarily perceive this to be problematic (Parker and Skoufias, 2008).

Additionally, it has been argued that Mexico's Progresa has reinforced traditional gender norms in the sense that women should be the primary caretaker of the children in the household and are mainly responsible for their health and development (Molyneux, 2006). Another unintended consequence is the potential change in intra-household dynamics. The majority of CTs put cash in the hands of women, and while the few existing studies that have examined the impacts of CTs on IPV have generally shown a protective effect, there is the potential for an increased risk of IPV, either as a backlash to women's empowerment or to extract resources from the women.

There are a several additional examples of perverse incentives resulting from the conditions of CCTs. As mentioned before, a study on Brazil's Bolsa Alimentação found that children in beneficiary households gained less weight than comparison children and this result was attributed to the fear of mothers that they would be excluded from the programme once their children started to grow well (Morris et al., 2004b). In Honduras, the Programa de Asignación Familiar may have led to increases in fertility in the short-term (Stecklov et al., 2007), although others argue that overall fertility rates decreased and the size of the transfer was perceived as too small as an incentive for increased fertility (IFPRI, 2003). More importantly, evidence from five countries in LA and SSA has demonstrated no perverse impacts of CTs on fertility in five countries (Handa et al., 2015a, Stecklov and Winters, 2011, Stecklov et al., 2007, Todd et al., 2012), and instead has shown a reduction in first pregnancy rates in Kenya (Handa et al., 2015b) and longer birth spacing in South Africa (Rosenberg et al., 2015).

Other potential unintended effects of CTs include a reduction in adult labour supply or remittances which might reduce household income, leading to fewer resources for food and health care of young children. However, most evidence shows that adults do not reduce the number of hours worked when becoming beneficiary of a CT (Banerjee et al., 2017, Handa et al., 2018a). Only in Nicaragua, a reduction in the hours worked for adult men was found, but no reduction for women (Fiszbein and Schady, 2009). In SSA on the other hand, there is strong evidence that CTs propel a substitution away from casual labour to ownfarm or own-business work (Davis and Handa, 2014). Most of the CCT studies reviewed by Fiszbein and Schady (2009) show no crowding-out effect of private 
transfers, while evidence from SSA show that CTs in fact have a 'crowding-in' effect as households are able to re-engage in social networks and other informal organizations (FAO, 2015). In terms of other negative spillover effects, most of the evidence from CCTs suggests no negative impact on local prices and wages (Fiszbein and Schady, 2009) while in SSA, evidence suggests very strong local economy effects of UCTs and no inflationary consequences (FAO, 2015). One notable exception occurred in Mexico where a CT programme increased local prices in communities that were poorly connected to the broader economy, lacking competition for suppliers of normal goods (Cunha et al., 2019). In addition, in the Philippines the Pantawid programme resulted in higher prices of perishable protein-rich foods (eggs and fish). And while the programme significantly improved nutritional status among beneficiary children, the stunting rate among non-eligible children increased by 11 percentage points (Filmer et al., 2018).

\subsection{Conclusion: What do we know and what do we need to know about cash transfers and child nutrition?}

This chapter has examined the extent to which CTs can affect child nutrition by using the extended model of care conceptual framework of child nutrition and discussing evidence supporting or rejecting its main elements. Table 2.2 summarizes our findings and presents the current state of knowledge and knowledge gaps. The checks in the table indicate the current state of the evidence as positive, mixed or none, and asterisks provide an indication of the number of studies on the particular issues to identify areas that have been understudied. First, there is strong evidence that CTs have a positive effect on the resources for food security. Households use the transfer to buy larger quantities of and higher quality (i.e., more nutritious and diverse) food, and in many cases, household food security indicators improve.

Second, in terms of resources for health, the evidence in general points to positive impacts. CTs (especially CCTs) increase preventive health care visits and antenatal care-seeking in most cases. There are also positive effects on better hygiene and on the probability of using improved sanitation or water sources.

Third, the concept of resources for care in relation to CTs is generally understudied. The broader literature suggests that there is a clear relation between nutritional outcomes, caregiver feeding behaviours and practices, as well as psychosocial care. There is however very little evidence of the impact of CTs on these caregiver behaviours. On the other hand, there is strong evidence that CTs improve the mental health of beneficiaries, including reducing levels of stress. Furthermore, studies suggest that CTs may decrease IPV, which has implications for improved health among mothers and children.

Fourth, in relation to intra-household dynamics, women's empowerment has been studied extensively in relation to CTs, but while qualitative evidence 
points to a positive effect, the quantitative evidence presents a more mixed picture. This is in part due to the lack of consensus on how to measure women's empowerment with quantitative indicators. Moreover, there is non-conclusive evidence on whether transfers to women lead to more investments in the health and nutrition of children than transfers to men.

Fifth, we identified evidence of impacts of CTs on the two immediate determinants of child nutritional status, dietary intake and health status. The few studies that directly look specifically at children's dietary intake found no increase in caloric intake of young children, while three studies found an increase in the number of days children consumed more nutritious food. In terms of children's health status, the evidence is mixed, and the pathways are unclear. Some studies have found a significant reduction in common children's illnesses, such as diarrhoea and ARI, while in other cases, no significant or negative effects were found. Similar mixed findings appear for vaccination coverage. The only study that investigated children's levels of a stress-related biomarker found a significant reduction due to the $\mathrm{CT}$.

Sixth, the evidence of direct impact of CTs on children's nutritional status is mixed (see Table 2.2). Overall, the evidence points to a lack of knowledge on the impact pathways, a gap recognized by authors reviewing the link between CTs and child nutritional status. Furthermore, additional research is needed from SSA, as much of the results come from LA, although more recent work is coming out of the SSA region.

In summary, while an increasing number of studies have highlighted the positive role of CTs in increasing resources for food, health and care, the evidence to date on the immediate determinants of child nutrition is mixed with respect to whether CTs can positively impact growth-related outcomes among children. Key gaps should be addressed in future research, including examination of CT impacts on proximate outcomes such as children's dietary diversity, as well as intrahousehold decision-making, caregiver behaviours, IPV, and caregiver stress/mental health, all of which have implications for child health and well-being. This thesis aims to address some of the knowledge gaps identified in Table 2.2, particularly on the pathways of impact on nutrition and health, impacts on child's individual dietary intake, care practices and how intra-household dynamics affect the impact of a CT. 
Table 2.2. Summary of impacts of cash transfers on child nutritional status, and on immediate determinants and underlying determinants of child nutritional status

\begin{tabular}{|c|c|c|c|c|}
\hline & Positive & Mixed & None & Knowledge gap \\
\hline \multicolumn{5}{|l|}{ Impact on outcome } \\
\hline $\begin{array}{l}\text { Child nutritional } \\
\text { status }\end{array}$ & & $\underset{\checkmark}{\checkmark}$ & & $\begin{array}{l}\text { Pathways of impact or non- } \\
\text { impact are unclear, only few } \\
\text { studies from SSA }\end{array}$ \\
\hline \multicolumn{5}{|c|}{ Impact on immediate determinants } \\
\hline $\begin{array}{l}\text { Child dietary } \\
\text { intake }\end{array}$ & & & $\begin{array}{l}\checkmark \\
* *\end{array}$ & $\begin{array}{l}\text { Only few studies looked } \\
\text { specifically at children's } \\
\text { dietary intake, as most studies } \\
\text { assess the household-level } \\
\text { changes }\end{array}$ \\
\hline Health status & & $\begin{array}{c}\checkmark \\
* * *\end{array}$ & & $\begin{array}{l}\text { Pathways of impact or non- } \\
\text { impact are unclear with } \\
\text { limited evidence from SSA }\end{array}$ \\
\hline \multicolumn{5}{|c|}{ Impact on underlying determinants } \\
\hline \multicolumn{5}{|l|}{ 1) Food security } \\
\hline $\begin{array}{l}\text { Household } \\
\text { consumption }\end{array}$ & $\begin{array}{l}\checkmark \\
* *\end{array}$ & & & $\begin{array}{l}\text { Most of the evidence at } \\
\text { household-level, rather than } \\
\text { individual level }\end{array}$ \\
\hline $\begin{array}{l}\text { Household diet } \\
\text { diversity }\end{array}$ & $\begin{array}{l}\checkmark \\
* *\end{array}$ & & & $\begin{array}{l}\text { Most of the evidence at } \\
\text { household-level, rather than } \\
\text { individual level }\end{array}$ \\
\hline $\begin{array}{l}\text { Household food } \\
\text { security }\end{array}$ & $\begin{array}{l}\checkmark \\
* *\end{array}$ & & & $\begin{array}{l}\text { Most of the evidence at } \\
\text { household-level, rather than } \\
\text { individual level }\end{array}$ \\
\hline \multicolumn{5}{|l|}{ 2) Health care } \\
\hline $\begin{array}{l}\text { Preventive care } \\
\text { visits }\end{array}$ & $\begin{array}{l}\checkmark a \\
* *\end{array}$ & & & $\begin{array}{l}\text { Evidence is concentrated in } \\
\text { programmes with health } \\
\text { conditions from LA }\end{array}$ \\
\hline $\begin{array}{l}\text { Water, sanitation } \\
\text { and hygiene }\end{array}$ & & & $\begin{array}{l}\checkmark \\
*\end{array}$ & $\begin{array}{l}\text { Positive evidence, but only } \\
\text { limited number of studies } \\
\text { available }\end{array}$ \\
\hline $\begin{array}{l}\text { Caregiver } \\
\text { physical health }\end{array}$ & $\begin{array}{ll}\sqrt{ } a \\
* * \\
\end{array}$ & & & $\begin{array}{l}\text { Evidence concentrated on } \\
\text { antenatal care and from LA }\end{array}$ \\
\hline
\end{tabular}




\begin{tabular}{|c|c|c|c|c|}
\hline 3) Care practices & & & & \\
\hline $\begin{array}{l}\text { Feeding } \\
\text { practices }\end{array}$ & & & $\begin{array}{l}\checkmark \\
*\end{array}$ & $\begin{array}{l}\text { Not enough evidence and no } \\
\text { consensus on measurement of } \\
\text { indicators }\end{array}$ \\
\hline $\begin{array}{l}\text { Psychosocial } \\
\text { care }\end{array}$ & & & $\begin{array}{l}\checkmark \\
*\end{array}$ & $\begin{array}{l}\text { Not enough evidence to draw } \\
\text { conclusions }\end{array}$ \\
\hline $\begin{array}{l}\text { Intimate partner } \\
\text { violence }\end{array}$ & & & $\begin{array}{l}\checkmark \\
* \\
*\end{array}$ & $\begin{array}{l}\text { Lack of impact studies, only } 4 \\
\text { so far. }\end{array}$ \\
\hline $\begin{array}{l}\text { Caregiver stress/ } \\
\text { mental health }\end{array}$ & & & $\begin{array}{l}\checkmark \\
*\end{array}$ & $\begin{array}{l}\text { Subjective scales used, but lack } \\
\text { of evidence with stress-related } \\
\text { biomarkers }\end{array}$ \\
\hline \multicolumn{5}{|c|}{ 4) Intra-household dynamics } \\
\hline $\begin{array}{l}\text { Caregiver } \\
\text { empowerment }\end{array}$ & $\begin{array}{l}\sqrt{b} \\
* * *\end{array}$ & $\begin{array}{l}\sqrt{c} \\
* * *\end{array}$ & & $\begin{array}{l}\text { Qualitative evidence points to } \\
\text { positive impacts, while } \\
\text { quantitative evidence shows a } \\
\text { mixed picture. No consensus } \\
\text { on measurement of } \\
\text { empowerment and limited } \\
\text { evidence from SSA }\end{array}$ \\
\hline $\begin{array}{l}\text { Women's } \\
\text { preference for } \\
\text { child } \\
\text { investments }\end{array}$ & & $\begin{array}{l}\checkmark \\
* *\end{array}$ & & $\begin{array}{l}\text { Results for UCTs limited to } \\
\text { pension programmes }\end{array}$ \\
\hline \multicolumn{5}{|c|}{$\begin{array}{l}\text { Notes: The asterisks in the table indicate the number of studies on the particular issues: }{ }^{* * * *}> \\
20 \text { studies, }{ }^{* * *} 11-20 \text { studies, }{ }^{* *} 6-10 \text { studies and }{ }^{*} 1-5 \text { studies. } \\
\text { a Positive impacts largely driven by CCTs with conditions on health visits } \\
\text { b Based on qualitative evidence } \\
{ }^{c} \text { Based on quantitative evidence }\end{array}$} \\
\hline
\end{tabular}




\section{Determinants of child malnutrition and the potential effects of consumption growth, improved maternal care and price shocks}

This chapter is based on:

de Groot, R., Handa, S., Ragno, L. P., and Spadafora, T. (2017). Child Malnutrition, Consumption Growth, Maternal Care and Price Shocks: New Evidence from Northern Ghana, Innocenti Working Papers no. 2017-01, Florence: UNICEF Office of Research - Innocenti 


\subsection{Introduction}

As discussed in the introductory chapter, malnutrition remains a major public health problem. To implement effective policies to address malnutrition, it is imperative to understand the immediate and underlying determinants of malnutrition. A widely recognized framework, depicted in Figure 1.2, identifies food intake and health status as the two immediate determinants of nutritional status (Black et al., 2008, Smith and Haddad, 2015). These immediate determinants are caused by the underlying determinants of household food security, care for mothers and children and a healthy household environment. Poverty is driving the underlying determinants, while basic determinants at the national level include the socio-political context and availability of resources (physical, financial, human, social and natural). ${ }^{11}$

Previous research has concentrated on understanding the immediate determinants of malnutrition: food intake and health status. A systematic review of interventions concluded that feeding interventions, such as promotion of complementary feeding through nutritional education and zinc supplementation, had the highest potential to reduce stunting globally. With 99 percent coverage, such programmes would reduce the global prevalence of stunting for children up to 36 months by 15 percent and 17 percent respectively (Bhutta et al., 2008). In combination with several other interventions, including micronutrient interventions and disease control interventions, there is the potential to decrease stunting by one-third (Bhutta et al., 2008). A more recent update of these estimations, using a scale-up of ten interventions to 90 percent coverage, estimated a 20 percent reduction in stunting (Bhutta et al., 2013). While this shows large potential, the majority of stunting would not be eliminated by focusing solely on these immediate determinants. Hence there is a need to further examine how focused interventions on the underlying determinants of malnutrition can reduce child malnutrition. A review on nutrition-sensitive interventions focusing on agriculture, social protection, early childhood development and education concluded that the evidence base is limited, and such interventions require more specific nutrition goals and actions to better fulfil their potential (Ruel et al., 2013).

This chapter uses a unique dataset from Northern Ghana to study the factors associated with childhood malnutrition, focusing on its underlying determinants. It also simulates several interventions to improve the underlying determinants, to examine their potential role in reducing malnutrition. We make several contributions to the existing literature on child nutrition and public policy. First, many studies focus on one element of the underlying determinants of child

${ }^{11}$ In this chapter, we ignore the intra-household dynamics. This determinant is the main subject of Chapter 4 . 
nutrition in the framework of Figure 1.2, such as diet diversity (Arimond and Ruel, 2004), maternal education (Chen and Li, 2009, Glewwe, 1999, Handa, 1999), income growth (Haddad et al., 2003) or water and sanitation (Checkley et al., 2004, van der Hoek et al., 2002). By estimating the framework as one complete model - albeit in two stages - we quantify the underlying mechanisms determining inputs, and the likely pathways contributing to nutritional status. Second, our data is unique as it captures a particularly vulnerable population, namely rural poor households with pregnant women or young infants. Other studies usually depend on national level household data, which limits the possibility of studying a group in detail. Third, we estimate the potential and effect size of various interventions and provide suggestions for effective public action.

The chapter proceeds as follows: Section 3.2 describes the data and methods; Section 3.3 presents findings on the associations between the underlying determinants and the immediate determinants and child nutrition; Section 3.4 simulates several policy interventions to enhance child nutrition; Section 3.5 discusses the implications of the findings and concludes.

\subsection{Methods}

Data for this study are derived from the baseline survey of the Livelihood Empowerment Against Poverty (LEAP) 1000 impact evaluation. LEAP 1000 is a cash transfer programme targeted at extremely poor households with pregnant women and mothers with children under 12 months in the Northern and Upper East Regions of Ghana. The programme is an extension of Ghana's flagship poverty alleviation programme LEAP and is implemented by the LEAP Management Secretariat (LMS) and the Department of Social Welfare (DSW) under the Ministry of Gender, Children and Social Protection (MoGCSP). Baseline data for the impact evaluation was collected between July and September 2015 from 1,262 prospective beneficiary households and 1,235 comparison households in five districts in the Northern and Upper East Regions of Ghana. Ethical approval for the study was granted by the Ethics Committee for the Humanities of the University of Ghana (ECH 093/14-15). This chapter uses baseline data only, and none of the beneficiary households had yet received a transfer. ${ }^{12}$

\subsubsection{Econometric Model}

It is typical to operationalize the framework of Figure 1.2 in a health production function. The idea is that the human body is a biological system that 'produces' health using a set of inputs such as food intake and (lack of) illness. The demand for inputs in the production function are usually modelled in a separate

${ }^{12}$ For more details on the study design and baseline analysis, see the baseline report (UNICEF Office of Research - Innocenti et al., 2016). 
specification, since they may be endogenous (Behrman and Deolalikar, 1988). One way to circumvent this problem, is to find strong instruments for the inputs. Typically, the prices of foodstuff, the availability of health care or the quality of health care are used. Should adequately rich longitudinal data be available, the complete history of inputs can be used (Puentes et al., 2016). However, most datasets are not sufficiently rich to estimate the full production function, and ours is, unfortunately, no exception. ${ }^{13}$ The next best estimation in this case, is the reduced form child health function, based on the underlying model of the utilitymaximizing family (Becker, 1981, Behrman and Deolalikar, 1988). We estimate two types of reduced form equations: the input demand function, and the conditional nutrition demand function.

In these models, the outcome (demand for health inputs or nutrition, $h_{i}$ ) is a function of child characteristics $\left(x_{i}\right)$, parental characteristics $\left(x_{p}\right)$, household indicators $\left(x_{h}\right)$ and community features $\left(x_{c}\right)$ :

$$
h_{i}=h\left(x_{i}, x_{p}, x_{h}, x_{c}, \mu\right)
$$

Child characteristics include age, sex, birth outcomes, and number of siblings. Household characteristics include maternal characteristics, household size and head of family characteristics. Community features consist of the distance to the nearest health centre, water and sanitation facilities, and the prices of common food and non-food items. Finally, $\mu$ is an error term for unobserved child, household and community heterogeneity, affecting the child's nutritional status and is assumed to be uncorrelated with the $x$ variables in this model. We cluster standard errors at the community level.

An important component of the household characteristics is household welfare. In this chapter, we use household consumption as a proxy for the household's economic wellbeing. Consumption includes all contemporaneous household spending such as food, clothing, sanitary items, and other goods and services and is the standard measure of household welfare (Deaton, 1997). A potential issue with household consumption is that it may be endogenous in the above specification, as it could affect other variables within the model. An alternative approach would be to use household assets to derive an index of a household's wealth. This is not considered here for several reasons. First, assets generally represent a more long-term indicator of a household's wealth with fewer fluctuations. Since one of the objectives of this chapter is to model and then

\footnotetext{
${ }^{13}$ Previous drafts of this chapter attempted to identify and use instruments to estimate the full production function, but several sets of instruments (prices, distance to health facilities, non-self community means of inputs) were found too weak in predicting the inputs in the demand equation.
} 
simulate the effect of increased household welfare on child health and nutrition, the measure of consumption is more appropriate as it can directly capture an increase in the household's current resources. Second, an index derived from a list of household assets has no clear interpretation. It is therefore difficult to use an asset index as input for simulations that are conducted later in this chapter. This chapter therefore uses household consumption as the main indicator for the household's welfare but is careful in the interpretation of the results. The findings are interpreted as associations rather than causal effects.

We restrict the sample to children aged 6 - 59 months for several reasons. First, children under 6 months are recommended to be breastfed exclusively; this limits the number of feeding variables we can include in our models. Second, measurement errors in terms of height are generally larger for children under 6 months, due to the difficulty of accurately measuring infants. Third, stunting typically starts to become a problem when infants are transitioning from breastfeeding to complementary feeding, at 6 months of age (Shrimpton et al., 2001). We further restrict our sample to children for whom we have full information on all indicators, and children who live in communities in which five or more children were sampled, resulting in a final analysis sample of 2,460 children. ${ }^{14}$

\subsection{Results}

\subsubsection{Descriptive statistics}

Below is a short description of the explanatory variables used as underlying determinants of child nutrition, as shown in Table 3.1 Educational achievement of mothers is low, with more than 80 percent never receiving any formal schooling. Nutrition and health knowledge was constructed based on the mother's responses to six questions on child nutrition and health with an average number of correct responses higher than four. ${ }^{15}$ Maternal health could be an important determinant of child health, given the potential of the genetic endowment passed on to offspring. We use a measure of self-reported subjective health, with five response options (poor, fair, good, very good and excellent), which has been found to be a good predictor of future mortality and morbidity (DeSalvo et al., 2006). We dichotomize this indicator into self-reported good, very good or excellent health which was reported by just over three-quarters (76 percent) of mothers. Agency -

\footnotetext{
14 This is due to the calculation of community means for certain variables, further details below.

${ }^{15}$ Questions were related to the importance of exclusive breastfeeding, immediate breastfeeding after birth, duration of breastfeeding, foods rich in iron, foods rich in vitamin $\mathrm{A}$ and knowledge about home treatment of diarrhea.
} 
measuring decision-making power of the mother in the household - is an aggregate score based on six statements and cut into terciles; low (36 percent of mothers), middle (40 percent) and high (24 percent). ${ }^{16}$

Table 3.1 Explanatory variables used in study $(\mathrm{N}=2,460)$

\begin{tabular}{|c|c|c|c|c|}
\hline Variable & Mean & SD & Min & Max \\
\hline \multicolumn{5}{|l|}{ Child characteristics } \\
\hline Age in months & 26.60 & 16.81 & 6 & 59 \\
\hline Female & 0.50 & 0.50 & 0 & 1 \\
\hline Twin & 0.04 & 0.19 & 0 & 1 \\
\hline Birth order & 3.23 & 1.80 & 1 & 11 \\
\hline \multicolumn{5}{|l|}{ Birth interval } \\
\hline First birth & 0.18 & 0.39 & 0 & 1 \\
\hline$<24$ months & 0.10 & 0.30 & 0 & 1 \\
\hline $24-35$ months & 0.21 & 0.41 & 0 & 1 \\
\hline $36-47$ months & 0.22 & 0.41 & 0 & 1 \\
\hline 48 months or more & 0.29 & 0.45 & 0 & 1 \\
\hline Number of male siblings & 1.22 & 1.15 & 0 & 7 \\
\hline Number of female siblings & 1.12 & 1.05 & 0 & 6 \\
\hline \multicolumn{5}{|l|}{ Parental characteristics } \\
\hline Age of mother & 29.73 & 6.30 & 15 & 49 \\
\hline \multicolumn{5}{|l|}{ Education of mother } \\
\hline No schooling & 0.81 & 0.39 & 0 & 1 \\
\hline Some primary & 0.08 & 0.27 & 0 & 1 \\
\hline Primary completed or higher & 0.11 & 0.31 & 0 & 1 \\
\hline $\begin{array}{l}\text { Nutrition \& health knowledge }(0-6 \text {, with } \\
\text { higher values meaning more knowledgeable })\end{array}$ & 4.35 & 1.24 & 0 & 6 \\
\hline $\begin{array}{l}\text { Self-reported health good/very good/excellent } \\
\text { Agency score }\end{array}$ & 0.76 & 0.43 & 0 & 1 \\
\hline Low & 0.36 & 0.48 & 0 & 1 \\
\hline Medium & 0.40 & 0.49 & 0 & 1 \\
\hline High & 0.24 & 0.43 & 0 & 1 \\
\hline
\end{tabular}

\footnotetext{
${ }^{16}$ Agency is measured on 5-point Likert scale, with the following six statements: Your life is determined by your own actions; You have the power to make important decisions that change the course of your own life; You have the power to make important decisions that change the wellbeing of your children; You have the power to make important decisions that change the wellbeing of your household; You are capable of protecting your own interests within your household; You are capable of protecting your own interests outside of your household (e.g. in the community, in groups in which you participate). Internal consistency among the statements is high, with Cronbach's alpha of 0.77 .
} 


\begin{tabular}{lcccc}
\hline Variable & Mean & SD & Min & Max \\
\hline Father present in household & 0.87 & 0.33 & 0 & 1 \\
Household characteristics & & & & \\
$\quad$ Household size & 6.86 & 2.64 & 2 & 27 \\
Share of women 12-49 in household & 0.23 & 0.09 & 0.07 & 0.67 \\
Age of head of household & 39.10 & 12.28 & 18 & 102 \\
Female headed household & 0.08 & 0.28 & 0 & 1 \\
Head of household no formal schooling & 0.80 & 0.40 & 0 & 1 \\
Log of monthly household consumption per & 4.35 & 0.63 & 1.14 & 6.54 \\
adult equivalent & & & & \\
Community characteristics & & & & \\
Non-self mean of improved source of water & 0.58 & 0.33 & 0 & 1 \\
Non-self mean of improved source of sanitation & 0.10 & 0.17 & 0 & 1 \\
Non-self mean of floor type (1 if mud floor) & 0.25 & 0.24 & 0 & 1 \\
Non-self mean of sleeping under bed net & 0.67 & 0.19 & 0 & 1 \\
yesterday & 0.75 & 0.26 & 0 & 1 \\
Non-self mean of vaccination coverage & & & \\
Non-self mean of appropriate hand washing & 0.07 & 0.11 & 0 & 1 \\
facilities & 8.74 & 1.16 & 0.61 & 10.61 \\
Log of distance to nearest health centre & 0.77 & 0.29 & 0.45 & 1.33 \\
Price of Guinea corn/sorghum (Ghana Cedi) & 0.85 & 0.34 & 0.43 & 1.59 \\
Price of maize (Ghana Cedi) & 0.79 & 0.40 & 0.33 & 2.17 \\
Price of millet (Ghana Cedi) & 1.47 & 0.67 & 0.89 & 2.80 \\
Price of rice (local) (Ghana Cedi) & 10.37 & 4.30 & 2.00 & 20.00 \\
Price of dried fish (Ghana Cedi) & 4.38 & 2.27 & 2.22 & 10.83 \\
Price of okro (Ghana Cedi) & 3.94 & 0.33 & 2.99 & 4.75 \\
\hline Price of petrol (Ghana Cedi) & & & &
\end{tabular}

Households are large with mean household size of nearly seven members. Less than 10 percent of households are headed by a woman, and 80 percent of household heads never went to school. The mean monthly consumption expenditure per adult equivalent is approximately 92 Ghana cedi (GHC), which translates roughly into US $\$ 0.74$ per adult equivalent per day. ${ }^{17}$ We include the natural $\log$ of this measure in our analysis to account for the large right-hand tail in the distribution.

Community characteristics consider whether the household has access to improved sanitation facilities, improved sources of drinking water and appropriate hand washing facilities. The dwelling floor type, presence of bed nets, and

${ }^{17}$ Exchange rate at 15 September 2015: GHC $1=$ US $\$ 0.2448337399$. 
vaccination coverage are also considered. ${ }^{18}$ For each of these indicators, we calculate the non-self community mean ${ }^{19}$, as it is likely that these indicators are correlated with other household characteristics (Christiaensen and Alderman, 2004, Kabubo-Mariara et al., 2009). About 60 percent of children live in communities with access to an improved source of water, while only 10 percent have access to improved sanitation facilities. Appropriate hand washing facilities is even lower at 7 percent. One-quarter of the houses in these communities has a mud floor. Two-thirds sleep under a bed net and vaccination coverage is 75 percent. We include the natural log of the distance to the nearest health centre for each household, as a measure of access to health services. The average distance to the nearest health centre is about $10 \mathrm{~km}$ (not shown). The prices of seven common consumption items at the nearest market are matched to the household data.

\section{Food intake and health status}

Health status is based on the incidence of three common childhood diseases in the two weeks prior to the survey: diarrhoea, fever and symptoms of acute respiratory infections (ARI). We combine the latter two into a single indicator of nondiarrhoeal illness. To ease interpretation of results, all indicators are coded so that a higher score indicates a more positive outcome (i.e. lack of illness). About 58 percent of the children had not suffered from diarrhoea, indicating that 42 percent did experience the disease in the two weeks before the survey. In addition, 30 percent experienced fever or symptoms of ARI (Table 3.2).

Food intake of a single child is notoriously difficult to measure in largescale field surveys. We proxy the quality of food intake by looking at the different food groups proposed by WHO (World Health Organization, 2010): consumption of iron-rich foods; consumption of grains, roots and tubers; consumption of dairy products; consumption of vitamin A-rich fruits and vegetables; and consumption of other fruits and vegetables. The quality of a child's diet has been linked to nutritional status in many settings (Arimond and Ruel, 2004). To assess the quantity of food intake, we use meal frequency (whether the child had 3 meals or more). Meal frequency is a strong predictor of energy intake in infants and young children and thus an important input in the production of health (Working Group on Infant and Young Child Feeding Indicators, 2006). About two-thirds of children consumed iron-rich food (e.g. (organ) meat, fish or iron-fortified foods); 80 percent consumed grains, roots or tubers; 21 percent consumed dairy products; and 70 percent consumed vitamin A-rich plant foods (such as yellow flesh fruits and

\footnotetext{
${ }^{18}$ Definitions of improved water and sanitation facilities are based on standard classifications according to WHO and UNICEF (2016).

19 The non-self community mean is the mean value of the indicator, averaged over all observations in the community, excluding the value of the indicator for the household itself
} 
vegetables or dark green leafy vegetables). However, less than half of the children received the recommended three or more meals per day.

Nutritional status: Height-for-age

We are interested to document the effects of the underlying and immediate determinants on long-term measures of child malnutrition. The appropriate nutritional measure is therefore height-for-age z-scores (HAZ), which has been commonly used as an indicator of overall long-term health and human capital (Victora et al., 2008). In our sample, the mean HAZ score is -1.28 (SD 1.68), more than 30 percent of children are stunted (HAZ $<-2$ SD) and 13 percent are severely stunted (Table 3.2).

Table 3.2 Inputs and nutritional outcomes $(\mathrm{N}=2,460)$

\begin{tabular}{lcccc}
\hline Variable & Mean & SD & Min & Max \\
\hline Inputs: Health status & & & & \\
$\quad$ No diarrhoea in last two weeks & 0.58 & 0.49 & 0 & 1 \\
$\quad$ No other illness in last two weeks & 0.70 & 0.46 & 0 & 1 \\
$\quad$ Inputs: Food intake & & & & \\
$\quad$ Consumed iron-rich food yesterday & 0.68 & 0.47 & 0 & 1 \\
$\quad$ Consumed grains, roots and tubers yesterday & 0.80 & 0.40 & 0 & 1 \\
$\quad$ Consumed dairy products yesterday & 0.21 & 0.41 & 0 & 1 \\
$\quad$ Consumed vitamin A-rich fruits and & 0.70 & 0.46 & 0 & 1 \\
$\quad$ vegetables yesterday & & & & \\
$\quad$ Consumed other fruits and vegetables & 0.11 & 0.31 & 0 & 1 \\
$\quad$ yesterday & & & & \\
$\quad$ Consumed three or more meals yesterday & 0.45 & 0.50 & 0 & 1 \\
\hline$\quad$ Nutritional outcomes & & & & \\
$\quad$ HAZ score & -1.28 & 1.68 & -5.92 & 5.91 \\
$\quad$ Stunted (HAZ <- 2) & 0.31 & 0.46 & 0 & 1 \\
$\quad$ Severely stunted (HAZ<-3) & 0.13 & 0.34 & 0 & 1 \\
\hline
\end{tabular}

\subsubsection{Estimation results}

This section presents results of estimating equation 3.1, first on the immediate determinants of child malnutrition - food intake and health status - and then on the nutritional outcome, HAZ. We also test for the joint significance of parental, household and community characteristics respectively in each estimation separately.

\section{Food intake and health status}

The results for the eight input demand functions are presented in Table 3.3. The models are estimated with a probit model, and marginal effects are presented. We 
present estimates for the full sample of children aged 6-59 months, but also for the subsamples of children aged 6- 23 and 24-59 months, as it is likely that these different age groups have different nutritional and health needs. The results for these sub-groups are reported in Tables S3.2 and S3.3 in the appendix to this chapter. We focus the presentation and discussion of the results on parental, household and community characteristics.

Parental characteristics have a limited correlation with the demand for inputs. For example, maternal education is only significant in one case: higher maternal education is (weakly) associated with better health status. The mother's age is positively related to the lack of diarrhoea, the lack of other illnesses, and the consumption of iron-rich and vitamin A-rich foods, although the size of the associations are small. The mother's agency has some interesting and puzzling results. While higher agency is strongly associated with better health outcomes, it has a negative association with the demand for dairy products and appropriate meal frequency. Maternal self-reported health status is positively related to both child health indicators but has no association with the food inputs. Nutritional knowledge has mostly no effect on any of the inputs, except for a small and weakly significant association with the intake of dairy products. Parental characteristics are jointly significant (at the 10 percent level) in five of the eight input demand equations: both health indicators, the intake of dairy products, and vitamin A rich fruit and vegetables, and appropriate meal frequency.

Household consumption has positive associations with four of the food inputs. However, it has strongly negative effects on the health status, which seems counter-intuitive, i.e. higher welfare is associated with poorer health outcomes. The magnitude of the associations is relatively small though. For example, a 10 percent increase in household consumption is associated with a $0.0068(0.68$ percentage points) and 0.0075 ( 0.75 percentage points) increase in the probability of diarrhoea and non-diarrhoeal disease, respectively. Nonetheless, to validate these results, we perform checks with two alternative datasets, the Ghana Living Standards Survey (GLSS) 2012/2013, and the DHS 2014. We also observe a negative association between household consumption (GLSS) or wealth (DHS) and incidence of illness for children under five in these datasets, at least for the lowest two quintiles, which is where most of our households are located (Table S3.1 and Figure S3.1 in the appendix).

One potential explanation is survival bias if child mortality in the poorest households is higher than in the richer households, and only healthier and stronger children survive in the poorest households. In the Ghana DHS, all forms of child mortality are indeed higher in the lowest quintile, compared to the other quintiles (Ghana Statistical Service (GSS) et al., 2015). In our data too, we observe a negative (though statistically insignificant) relation between child mortality and household consumption (Figure S3.2 in the appendix). 
Another potential explanation is the employment status of the mother of the child. If a mother works, she may have less time to care for her child, resulting in increased risk of illness despite higher household income (Sinmegn Mihrete et al., 2014). To test this, we construct an indicator equal to one if the mother of the child performed any casual or formal work outside the home. The results (not shown but available upon request) indicate that the mothers' employment status is, indeed, negatively associated with both health indicators. However, the coefficient on consumption decreases only by a few decimal points in both equations, remaining strongly significant.

A third potential explanation is that poorer households simply underreport episodes of illness because they are unable to recognize illness, or because they forget. For example, a study in India showed that recall bias for morbidity was higher among poorer households, especially when recall periods were longer (Das et al., 2012). Another study to validate the accuracy of child morbidity data in the DHS concluded that mothers with low education and from poor household tend to report childhood illnesses less often than richer mothers (Manesh et al., 2008).

The community health characteristics have little explanatory power in the health input equations. Surprisingly, improved sanitation, improved source of water or appropriate hand washing facilities have no effect on the incidence of diarrhoea. Improved sanitation has an estimated negative association with nondiarrhoeal diseases. This is in contrast to research that finds significant associations between access to water and sanitation technologies and child morbidity (Günther and Fink, 2010). On the other hand, an improved source of drinking water is not necessarily free of microbial contamination (Bain et al., 2012). The distance to the nearest health centre generally yields opposite signs for the two health inputs: for diarrhoea, there is a small but statistically significant positive association i.e. the further away the health centre, the more likely a lack of diarrhoea, while for nondiarrhoeal diseases, it is the other way around. The distance to health centre is positively associated with the consumption of iron-rich food, and negatively associated with the intake of other fruits and vegetables. This could be due to the remoteness of communities far from health centres, with mostly 'inferior' foods available. There are only a few significant associations between local prices on health and nutritional inputs. Except for one input (dairy products), the community characteristics, including prices, are jointly significant in the input demand equations.

In the analysis by age group, most of the main results hold, with a few exceptions. For younger children, the negative association of maternal agency with intake of grains remains, but the negative association with meal frequency is no longer significant. The opposite is true for the older cohort (24-59 months). In addition, for the younger children, the negative correlation between household consumption and diarrhoea is no longer significant, but it is for older children. 


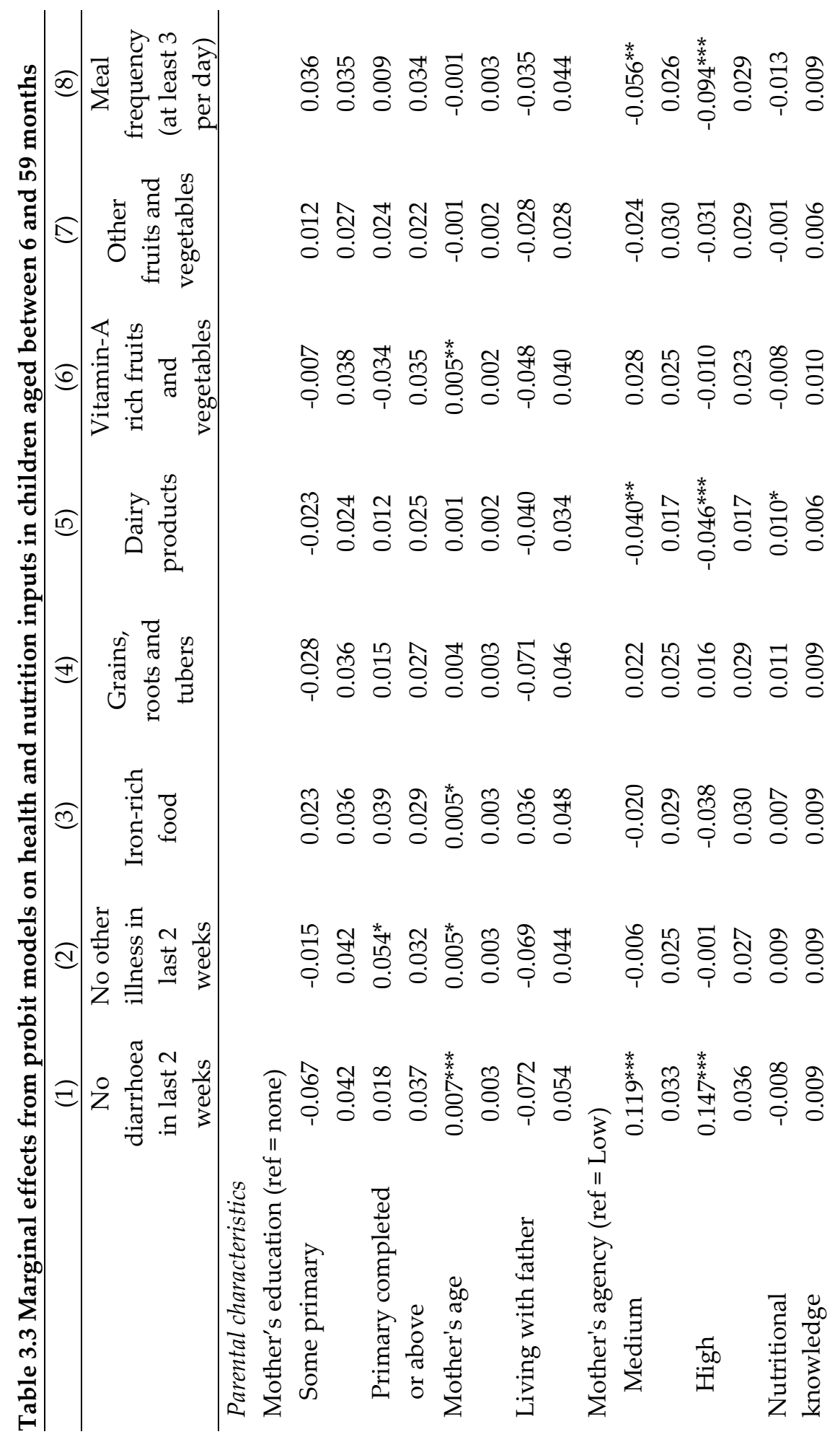




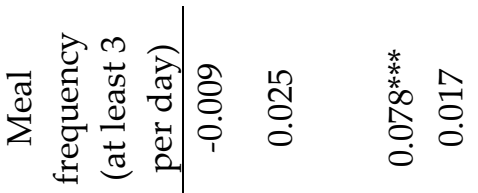

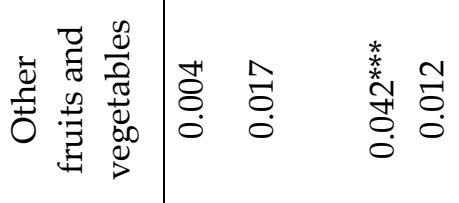

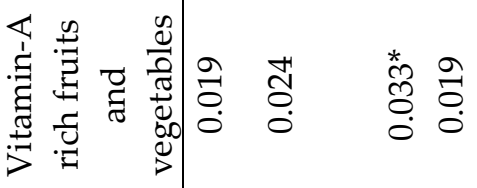

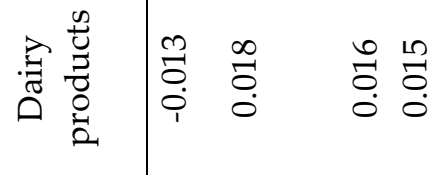

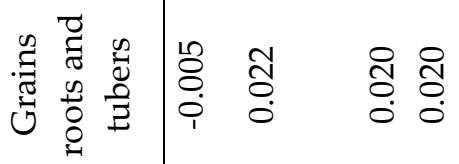

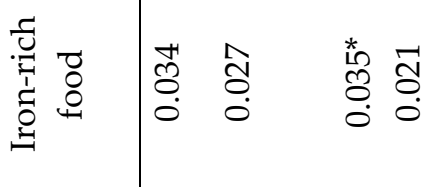

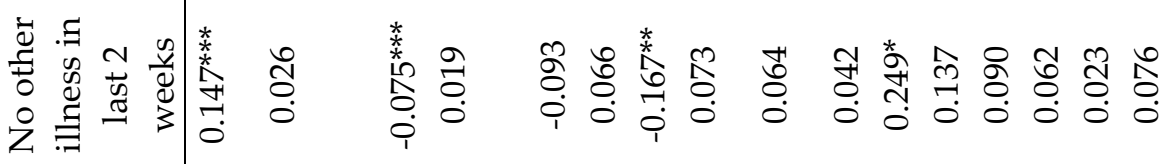

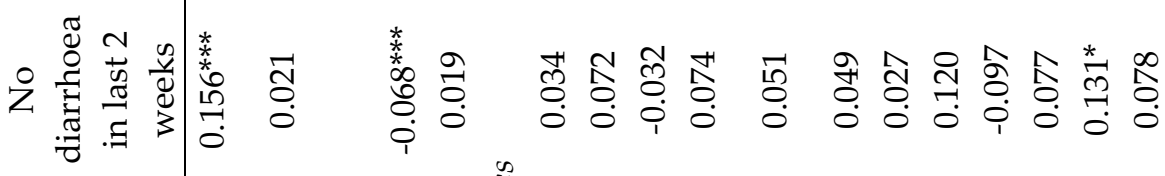

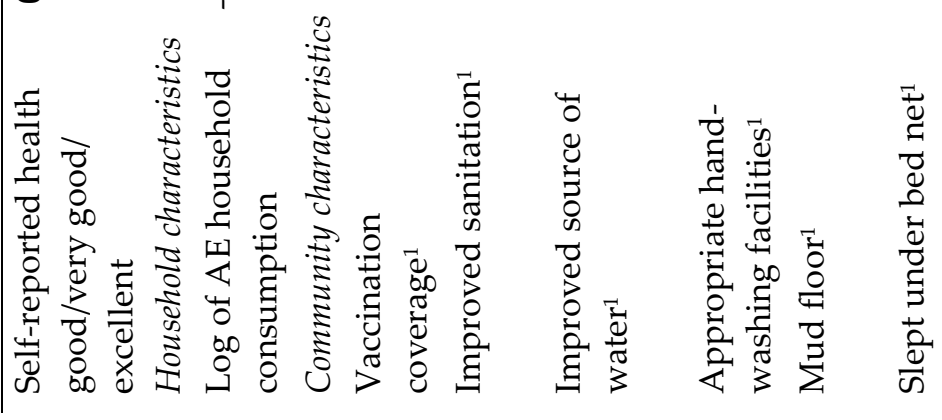




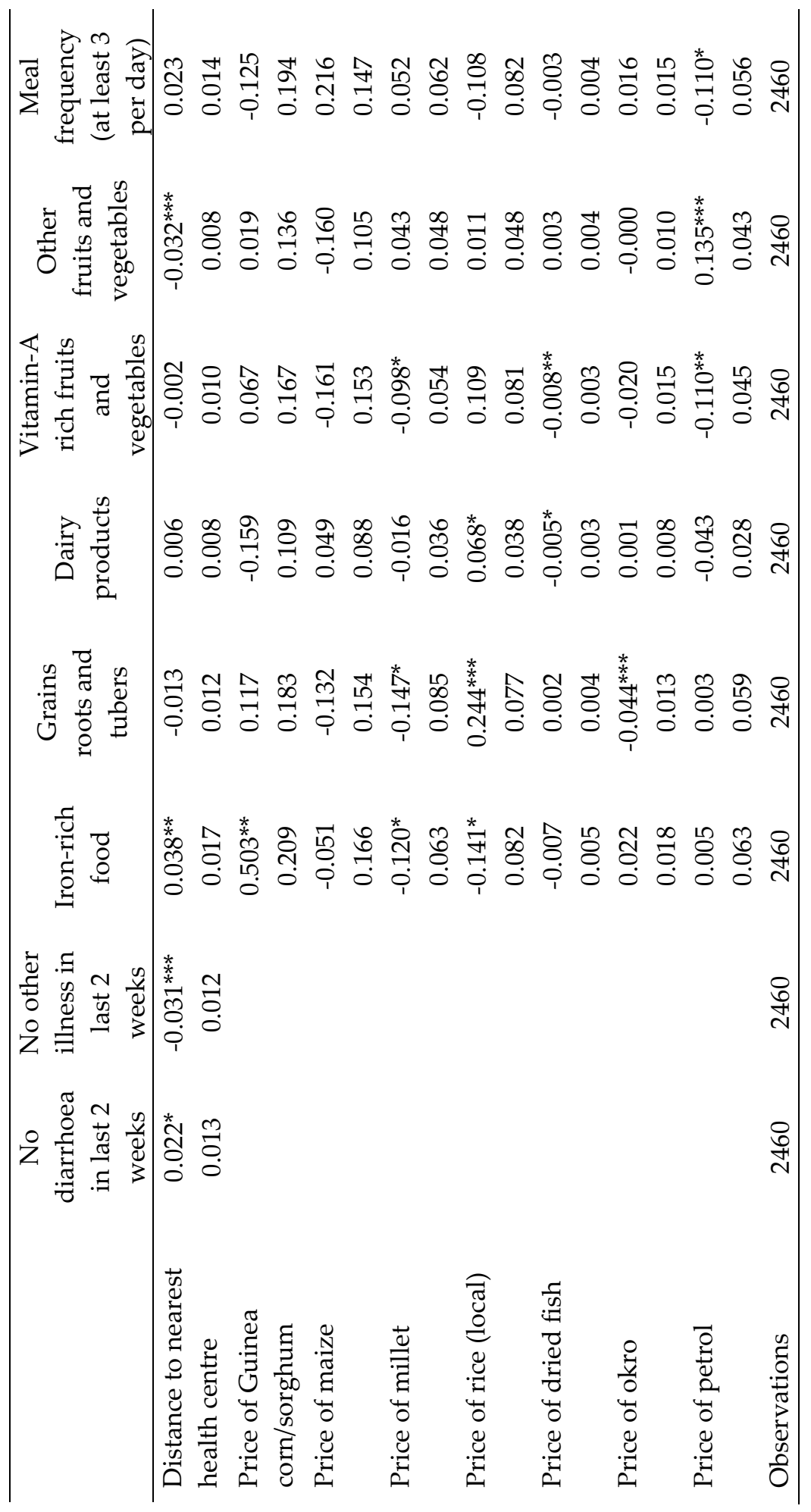




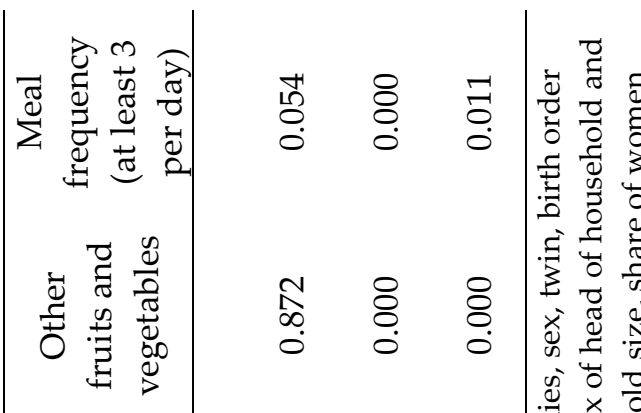

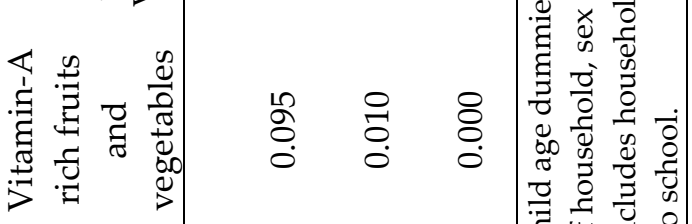

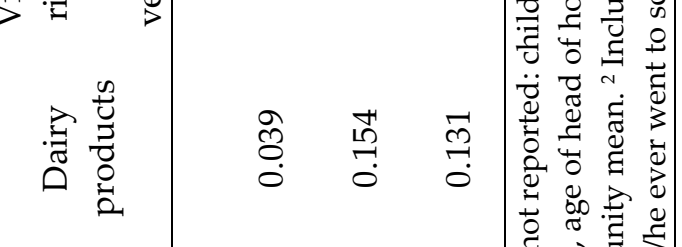

$$
\begin{aligned}
& \text { (1) }
\end{aligned}
$$

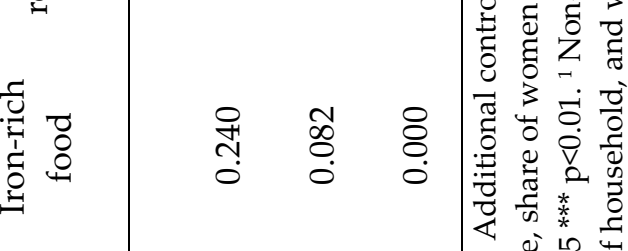

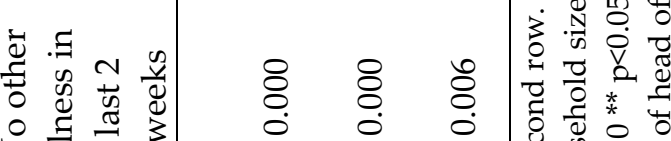

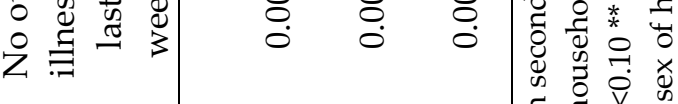

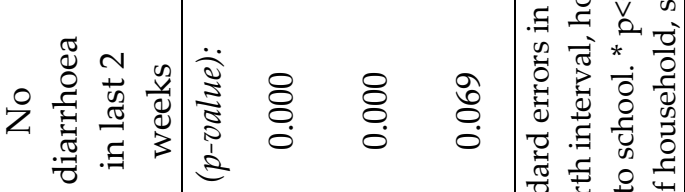

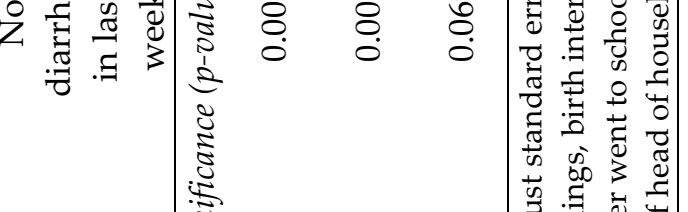

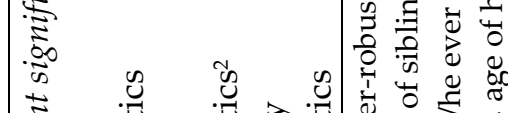

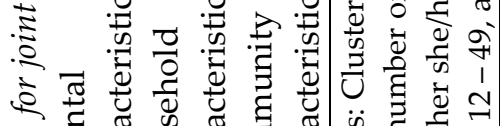

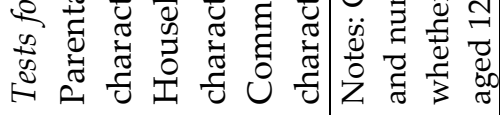




\section{Nutritional status}

The regression results of the conditional demand for height-for-age (HAZ) are presented in Table 3.4. The model is again estimated for the full sample, for the younger cohort (6-23 months) and the older cohort (24-59 months) separately, but results are only reported for the full sample in the main body of the text, whereas results by age group are reported in the appendix, Table S3.4.

Like the input demand functions, maternal characteristics have very little influence on HAZ in our data, except for a weak but significant and positive association of the mother's age. Household consumption is positively correlated with height-for-age, indicating that higher welfare is associated with better growth and development. ${ }^{20}$ However, although the association is significant, the magnitude of the effect is small: the coefficients show that a 10 percent increase in household consumption is associated with a 0.015 SD increase in HAZ. In terms of community characteristics, only the vaccination coverage and sleeping under bed nets seem to matter for HAZ. With one exception, none of the prices are significant in the model, and distance to the health centre has no significant association with HAZ. Household characteristics and community characteristics are jointly significant in the model.

For the younger cohort, there is a negative association of maternal education with HAZ, and the presence of the father in the household also has a negative association. On the other hand, the association of household consumption increases to 0.19 and remains strongly significant. For the older cohort, most of the estimates lose their significance and only the community characteristics remain jointly significant. This may be an indication that most of the changes in nutritional status appear in the first two years of life, consistent with the theory of the first 1,000 days.

\footnotetext{
${ }^{20}$ As discussed in section 3.2.1, household consumption may be endogenous in this specification. We test for endogeneity of household consumption using assets and household characteristics as identifying instruments (first-stage robust F-test: 11.4) and find no evidence of endogeneity based on the Durbin-Wu-Hausman test ( $\mathrm{p}$-values $>0.10$, results available upon request). In any case, we are careful in our interpretation and interpret all results as associations rather than causal effects.
} 
Table 3.4 OLS regression of child, parental, household and community characteristics on height-for age (children 6-59 months)

(1)

\begin{tabular}{|c|c|}
\hline & Height-for-age \\
\hline \multicolumn{2}{|l|}{ Parental characteristics } \\
\hline \multicolumn{2}{|l|}{ Mother's education (ref = none) } \\
\hline \multirow[t]{2}{*}{ Some primary } & -0.167 \\
\hline & 0.137 \\
\hline \multirow[t]{2}{*}{ Primary completed or above } & -0.076 \\
\hline & 0.109 \\
\hline \multirow[t]{2}{*}{ Mother's age } & $0.015^{*}$ \\
\hline & 0.008 \\
\hline \multirow[t]{2}{*}{ Living with father } & -0.233 \\
\hline & 0.178 \\
\hline \multicolumn{2}{|l|}{ Mother's agency (ref = Low) } \\
\hline \multirow[t]{2}{*}{ Medium } & 0.132 \\
\hline & 0.089 \\
\hline \multirow[t]{2}{*}{ High } & 0.022 \\
\hline & 0.103 \\
\hline \multirow[t]{2}{*}{ Nutritional knowledge } & 0.035 \\
\hline & 0.028 \\
\hline Self-reported health good/very & -0.088 \\
\hline good/excellent & 0.094 \\
\hline \multicolumn{2}{|l|}{ Household characteristics } \\
\hline \multirow[t]{2}{*}{ Log of AE household consumption } & $0.148^{* *}$ \\
\hline & 0.062 \\
\hline \multicolumn{2}{|l|}{ Community characteristics } \\
\hline \multirow[t]{2}{*}{ Vaccination coverage $^{1}$} & $0.392^{*}$ \\
\hline & 0.199 \\
\hline \multirow[t]{2}{*}{ Improved sanitation $^{1}$} & 0.169 \\
\hline & 0.277 \\
\hline \multirow[t]{2}{*}{ Improved source of water ${ }^{1}$} & -0.083 \\
\hline & 0.162 \\
\hline \multirow[t]{2}{*}{ Appropriate handwashing facilities ${ }^{1}$} & -0.604 \\
\hline & 0.379 \\
\hline \multirow[t]{2}{*}{ Mud floor ${ }^{1}$} & 0.204 \\
\hline & 0.246 \\
\hline \multirow[t]{2}{*}{ Slept under bed net ${ }^{1}$} & $0.593^{* *}$ \\
\hline & 0.286 \\
\hline
\end{tabular}


(1)

Height-for-age

Distance to nearest health centre $\quad 0.027$

0.057

Price of Guinea corn/sorghum $\quad-0.573$

0.591

Price of maize

0.269

0.494

Price of millet

0.063

0.229

Price of rice (local)

$0.420^{*}$

Price of dried fish

0.253

$-0.017$

0.014

Price of okro

$-0.062$

0.050

Price of petrol

0.008

0.231

Observations

2460

R-squared

0.139

Tests for joint significance ( $p$-value):

Parental characteristics

Household characteristics ${ }^{2}$

Community characteristics 0.008

Notes: Cluster-robust standard errors in second row. Additional control variables not reported: child age dummies, sex, twin, birth order and number of siblings, birth interval, household size, head characteristics. ${ }^{*} \mathrm{p}<0.10$ * $\mathrm{p}<0.05^{* * *} \mathrm{p}<0.01 .{ }^{1}$ Non-self community mean. ${ }^{2}$ Includes household size, share of women aged $12-49$, age of head, sex of head and whether head ever went to school. 


\subsection{Simulations}

In this section, we simulate three possible scenarios and their importance in reducing malnutrition. Due to the large amount of evidence on programmes addressing the immediate determinants of malnutrition (e.g. see Bhutta et al., 2008, Bhutta et al., 2013) and the lack of evidence on interventions improving the underlying determinants (Ruel et al., 2013), our simulations focus specifically on the underlying determinants of malnutrition, namely food security (proxied by household consumption), care for mothers, and community level prices. The choice of the three possible scenarios is based on the importance of these factors in the determination of immediate determinants and nutritional outcomes and on Ghanaspecific interventions or events.

For example, household consumption was found to be significantly associated with seven of the inputs and HAZ and is thus an important factor to consider. Care for mothers, operationalized by agency and self-reported health status, was highly significant in the health input equations, in two of the food inputs, but less so in the HAZ model. Several community prices were significant in the input demand models. In addition, price hikes are not uncommon in Ghana, with food inflation in the vicinity of 10 percent and non-food inflation over 20 percent, on annual basis (Ghana Statistical Service (GSS), 2016). ${ }^{21}$

We simulate three possible scenarios. One cash transfer intervention, equivalent to Ghana's national cash transfer scheme, the LEAP programme. This scenario is of primary interest for this thesis as it provides an ex-ante prediction of the effect of LEAP on child nutritional outcomes. It is important to note that the value of the cash grant is simply added to the current total household consumption, without any strict assumptions on how the additional income is spent or who in the household benefits from it. We also consider other simulations to compare the potential of additional interventions. The second scenario simulates improvements in the care environment for mothers by increasing her agency and improving her health. The last scenario simulates a sudden increase in prices, for example, because of droughts or failed harvests. Table 3.5 provides a summary of the parameters for each simulation.

The predictions are estimated using the full models from Tables 3.3 (for inputs) and 3.4 (for HAZ). For HAZ, we estimate the predicted changes for the average z-score, as well as the rate of stunting. The observed indicator values are simply substituted by the simulated value in the regression equations, while all

\footnotetext{
${ }^{21}$ We choose to focus on price increases rather than decreases. Price decreases can be realized when certain food or non-food items are subsidized. However, due to the consistent evidence that government subsidies are generally regressive (Wodon and Zaman, 2010) and governments throughout Africa, including Ghana, are removing rather than instating subsidies, we do not consider the potential of price decreases.
} 
other variables in the models are held constant. This ceteris paribus assumption is very strong as it is likely that other variables within the model are also affected through our simulations. For example, changes in prices could affect household consumption as well as the outcomes of interest (Attanasio et al., 2013). Also, increasing household consumption by a cash transfer could change household's preferences and the additional income could be spent in a different way than current income (Pace et al., 2018). The simulations in this chapter therefore represent a very simplified version of reality. Nonetheless, these simulations still serve the objective of this chapter by showing how changes in the household (consumption or maternal care) or community (local prices) are associated with our outcomes of interest (child health and nutrition), keeping in mind the above caveats.

Table 3.5 Parameters of simulations

\begin{tabular}{|l|l|l|}
\hline \multicolumn{2}{|l|}{ Simulation } & Parameters \\
\hline (1) & $\begin{array}{l}\text { Increase in income } \\
\text { by LEAP cash } \\
\text { transfer }\end{array}$ & $\begin{array}{l}\text { Increase household expenditures by monthly LEAP } \\
\text { transfer amounts: 38 for two beneficiaries, 44 for } \\
\text { three beneficiaries and 53 for four beneficiaries }\end{array}$ \\
\hline$(2)$ & $\begin{array}{l}\text { Improved care } \\
\text { environment }\end{array}$ & $\begin{array}{l}\text { Set agency at "medium" for mothers with low } \\
\text { agency and set self-reported health at "good" for all } \\
\text { mothers }\end{array}$ \\
\hline$(3)$ & Price increases & Increase all prices by 10\% \\
\hline
\end{tabular}

Notes: ${ }^{1}$ The baseline data includes the exact transfer amount for households enrolled into the LEAP programme. For comparison households, we impute the (hypothetical) transfer amount by counting the number of eligible beneficiaries in the household (number of pregnant women and infants, people with a disability, elderly, and orphans) and assigning the transfer amount accordingly.

While we have chosen our simulation scenarios using indicators that are more often than not statistically significant in the models, we acknowledge that the indicators used for the simulations are not significant in all the models. This could be because the indicator is truly zero (i.e. has no effect on the outcome) or because the estimated coefficient is imprecise, meaning that the standard error is simply large, but the coefficient is not necessarily equal to zero. ${ }^{22}$ We assume that the second explanation is more likely in our case. Even if the first explanation is true,

${ }^{22}$ Typically, standard errors increase if the residual variance in the model is large (Angrist and Pischke, 2009). Note that the R-squared in our models is relatively low (and hence the residual variance large), yet this is common in nutritional analysis. In addition, standard errors increase with low variability in the underlying variables, which is the case with the community characteristics, as the non-self means are based on dummy indicators. 
the estimated coefficients will be close to zero and will have a negligible effect in the simulations.

Results are reported in Table 3.6. Increased consumption through a CT equivalent to the LEAP programme is simulated to lead to poorer health, due to its negative association in the input demand regression. The predicted change, however, is very small, around two percent. If increases in household consumption go hand in hand with improved knowledge about child health or maternal agency, this effect may be reversed. On the other hand, increased household consumption is estimated to improve the quality and quantity of child food intake, although the increases are only marginal - in the range of one percent - for most of the inputs. Improvements in consumption have a modest, yet positive effect on nutritional status of 1.6 percent. Similar findings are reported by Alderman and Garcia (1994) for Pakistan, who find a simulated reduction of 3 percent on stunting as a result of a 10 percent increase in household consumption. In Ethiopia, a simulated increase in income of 2.5 percent for 15 years would reduce stunting by 4 percent (Christiaensen and Alderman, 2004).

Improved care is simulated to increase the probability of no diarrhoea by 14 percent and the likelihood of no other illness by 5.2 percent. Moreover, we observe positive simulated changes in the consumption of iron-rich food, grains, roots and tubers. In contrast, the simulated effect of improved care on the intake of fruits and vegetables that are not rich in vitamin A, is negative. It could be that this is a substitution effect, as vitamin A-rich foods are important for growing children. There is also a negative simulated change in the probability of eating three meals per day. The simulated effect of improved care on nutritional outcomes is positive, but also modest. The effect on HAZ-scores is similar in size as the increase in consumption, though the simulated decrease in the rate of stunting is somewhat larger at 2.3 percent.

The simulation of a price shock estimates that intake of non-vitamin A rich foods increases when prices increase, while the effect of a price shock is negative, or close to zero, for the other food inputs. It could be that this food group largely consist of foods that households consider 'inferior' and to which they resort when prices of preferred, and perhaps higher quality, food items rise. A price shock worsens nutritional status. For example, while our price shock simulation shows almost no effect on the mean z-score for height-for-age, it has a 5.5 percent simulated effect on the probability of being stunted. In other words, a price shock has almost no effect on the average HAZ-score of our population, but it does push some children over the threshold of being stunted. This indicates that children who are just at the border of being stunted, might suffer the most from such an event. Note that the simulated price shock is a one-time event where prices suddenly reach higher levels without going down afterwards. If there are continuous price shocks, raising the permanent level of prices even further, the effects on nutritional status could be even worse. 
Finally, note that our simulations are based on linear models and hence the simultaneous effects of two interventions would be about equal to the sum of their individual effects. For example, a combination of improved maternal care and the LEAP cash transfer would have a larger effect on nutritional status than any one of these interventions alone. There could even be complementary effects, (for example if a cash transfer also improves maternal care above and beyond another intervention that improves maternal care) but these could not be modelled in our linear specifications. Such complementary effects are particularly important in the simulation of the price shock as price changes likely affect household consumption (Attanasio et al., 2013). Higher prices reduce the household's disposable income if their budget is fixed and, given the association between consumption and nutritional status, can therefore translate into an even stronger negative effect on child nutrition.

Again, we perform the same simulations for each of the two age groups separately and report the results in the appendix (Tables S3.5 and S3.6). For the youngest cohort, the negative effects of consumption on health become negligible, while the positive effects of consumption on the food inputs and nutritional outcomes are similar as in the full sample. Improved care has a larger simulated effect on health status with an increased probability of nearly 19 percent on the lack of diarrhoea and six percent increased probability of not having another illness. It also has a slightly larger effect on the nutritional status than in the full sample, with an estimated 3.5 percent reduction in stunting. For the older cohort, as expected, the simulations show less potential, with lower effects of the simulated interventions on inputs and outcomes. However, price shocks seem to be more important in this age group, as a 10 percent price increase is simulated to yield a nearly 11 percent increase in the rate of stunting. 


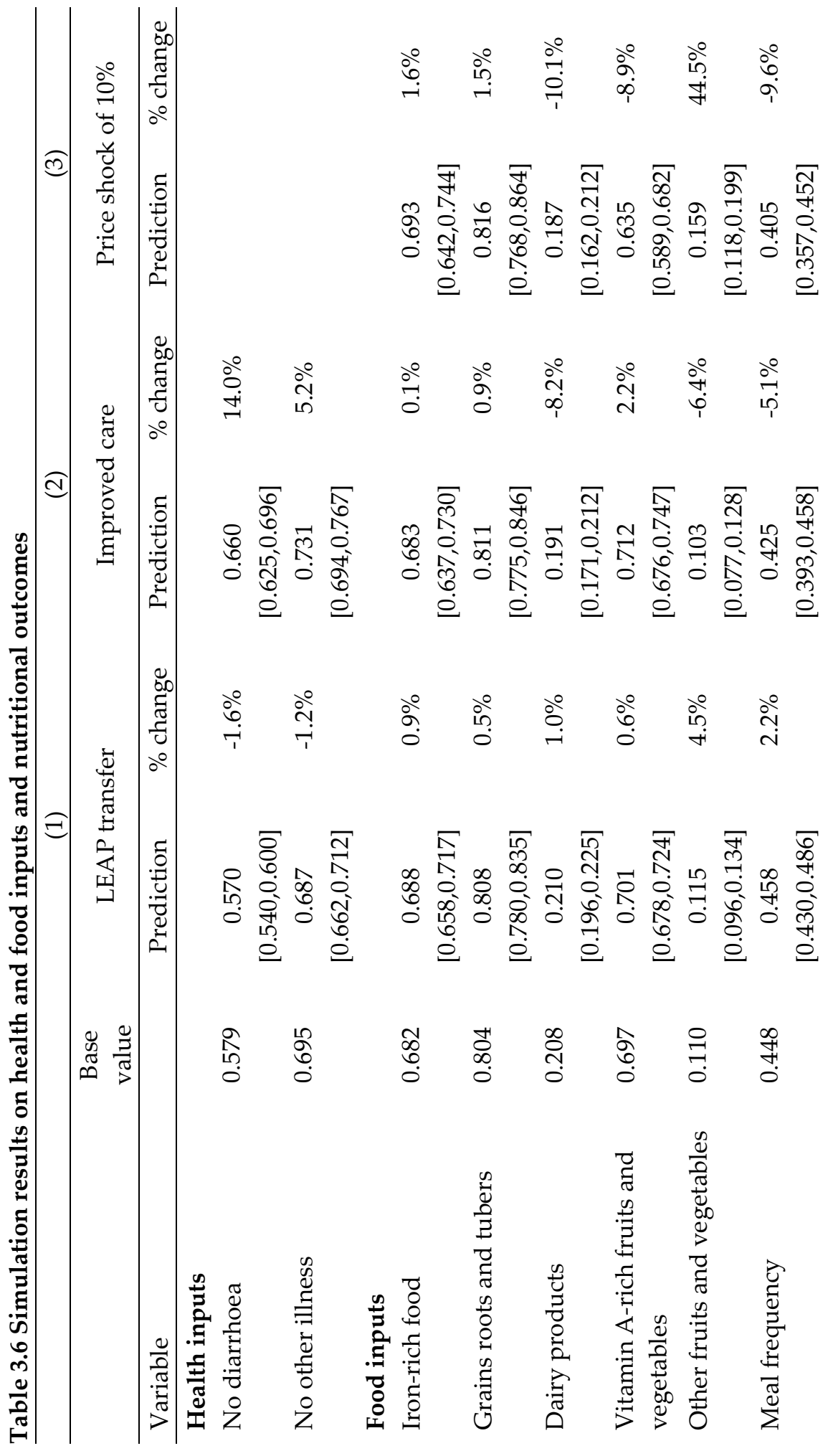




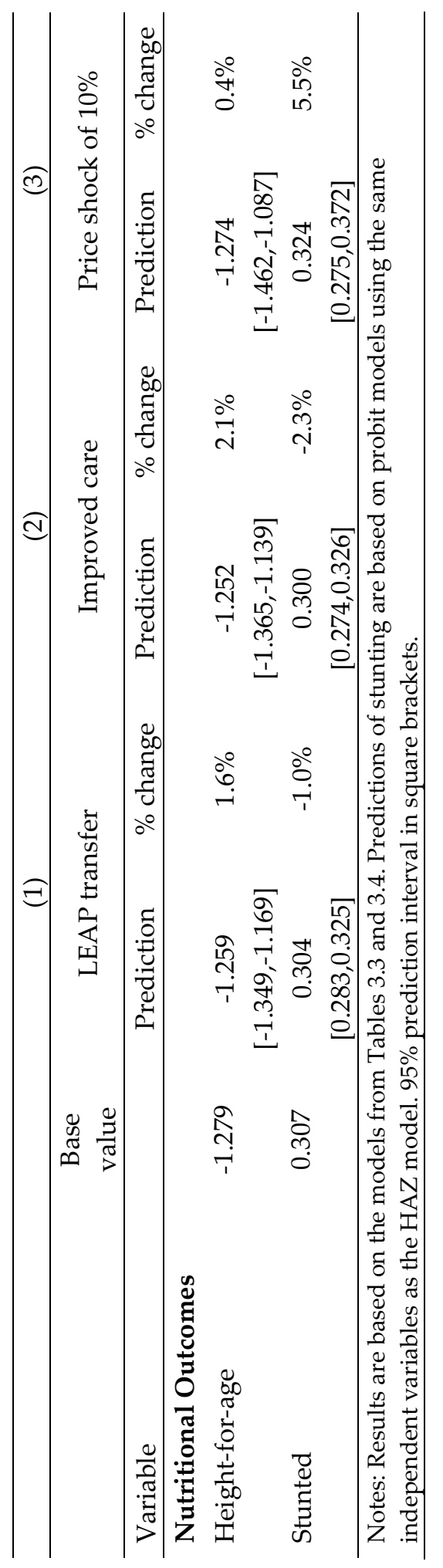




\subsection{Discussion and conclusion}

Previous research has investigated the potential of policies primarily addressing the immediate determinants of malnutrition, health status and food intake (Bhutta et al., 2008, Bhutta et al., 2013) and has suggested that such interventions yield a maximum reduction of stunting in the range of 20-35 percent. To further examine what may contribute to the reduction of stunting, we estimated a health production function and modelled interventions aimed at underlying determinants to assess their relative importance. Since the production of child nutrition is highly complex, any model that is able to shed light on the underlying mechanisms is useful to inform policy to improve child nutritional status (Alderman and Garcia, 1994). We estimate this model on a particularly unique population - children in poor households with pregnant women or women with infants.

Our results show that parental characteristics were only weakly correlated with the immediate determinants of malnutrition, food intake and health status. We found almost no association of maternal education and maternal knowledge with food intake and health status. The mother's level of agency is related to improved health, but also associated with reduced demand for dairy products and appropriate meal frequency. Mothers with higher agency may have more time commitments during the day, such as running a household business. ${ }^{23}$ Hence, higher maternal agency will likely only lead to nutritional improvements through the health pathway; not through the food intake pathway. Maternal poor health has a negative association with their children's health as well, potentially showing a genetic link or physical difficulties in taking care of children. The significantly positive - though small - correlation of the mother's age with four of the inputs, provides evidence that delaying child birth could have important benefits for children's health and nutrition.

Household consumption has a negative association with health status, but generally a positive association with food intake. The negative correlation with health is also observed in other datasets, and may be explained by survival bias, the mother's occupation, or the inability of ultra-poor households to identify and recall illnesses among their children. In addition, Figure S3.1 in the appendix shows that while the association between consumption and health may be negative for the lowest consumption quintile, there is an overall positive association between consumption and health as soon as consumption reaches a certain threshold. Since our sample primarily includes extremely poor households, it is

${ }^{23}$ Further inspection of the data shows that agency is indeed significantly higher among mothers who are also responsible for a household enterprise, which may compromise the time they have to care for their children. 
likely that these households have not yet reached this threshold. ${ }^{24}$ However, the intake of each food group also increases with household consumption and for three of the food groups and in terms of meal frequency, this relation is significant. This suggests that when household consumption grows, the quality and quantity of food intake can improve too, which is consistent with findings from many cash transfer programmes (Hidrobo et al., 2018, Tiwari et al., 2016).

The community health characteristics have little explanatory power for both health status and food intake. The distance to the nearest health centre is often used as an indicator for the cost of accessing health care and, as such, may influence decisions related to seeking care. However, the relationship between distance and our input and outcome indicators is weak. The prices of common staples are considered important community factors that may influence food intake. The results for these indicators are not coherent; sometimes positive and sometimes negative. However, it is important to differentiate between net food producers and net food consumers: the producers benefit from higher prices, to the detriment of consumers. Most households in our sample are subsistence farmers. However, we have no information on the size of their harvests, and therefore cannot determine which of the two groups they belong to, and more importantly, whether this makes a difference in terms of input demand.

We find little evidence that parental characteristics are important in the demand for nutrition. While previous research has found significant effects of maternal education on height or HAZ (Aslam and Kingdon, 2012, Chen and Li, 2009, Christiaensen and Alderman, 2004, Handa, 1999, Smith and Haddad, 2000), we find no association between the highest educated female in the household and the immediate determinants, nor a direct association with children's nutritional status. Rather, we find that the association with the mother's agency is a better indicator of her ability to improve nutritional outcomes for her children, especially through improving the health status of the child. Prior research has shown that improving health and nutritional knowledge may be more important than increasing educational achievement (Glewwe, 1999). Previous work in Ghana showed that care practices were significantly related to HAZ, although quality of care was measured in a different way across studies, and not using a similar framework to that of our study (Ruel et al., 1999, Amugsi et al., 2014, Nti and Lartey, 2008). Household consumption is positively correlated with height, showing that increased resources can help to improve child nutritional status. It is important to note that the estimated coefficients on household consumption are relatively small. For example, in a 12-country study, the estimated coefficient of log per capita consumption on weight-for-age (WAZ) ranged from 0.14 to 1.20 , with a

24 The GLSS figure suggests that this threshold is around the logged consumption value of 6 , which less than $1 \%$ of the households in our sample achieve. 
mean of 0.54 and a median of 0.47 (Haddad et al., 2003). While our study uses a different nutritional indicator, they are closely related and our estimate of 0.148 (Table 3.4) is at the lower bound of this range. ${ }^{25}$

A limitation of the analysis in this chapter is the cross-sectional nature of the data. We were not able to address the endogeneity of the inputs in the health production function and we therefore estimated reduced form demand functions. Others have used longitudinal data to instrument the endogenous inputs with prior inputs, and lagged weight and height (De Cao, 2011, Handa and Peterman, 2015, Puentes et al., 2016). This chapter is further limited by the regional scope and poverty status of the sample, potentially affecting the external validity of the results. However, the living standards in our sample are not exclusive to the study population and similar conditions are likely to be faced by rural people in the lowest economic quintile across sub-Saharan Africa. Finally, while the uniqueness of the sample is an asset because it allows the study of a particularly vulnerable population, the homogeneity in the sample may be the reason that certain relations not show up. For example, the insignificant relation between sanitation and health, and between maternal education and nutritional status, may be due to the lack of variability in the indicators. The simulations conducted in this chapter represent a very simplified version of reality in which only one component changes while everything else remains the same. This may not hold true in reality and careful expost analysis of interventions are needed to examine actual effects and pathways.

Globally, researchers have called for a more integrated approach to address malnutrition, in the form of nutrition-sensitive programming (Ruel et al., 2013). Due to the complex nature of child growth, no single programme working in isolation will be able to sustain considerable impacts on malnutrition. This is supported by our findings, which indicate that public policy - which can increase consumption, improve care for mothers, and keep down inflation - is likely to have a positive, yet modest, effect on nutritional inputs and outcomes. Hence complementary interventions, which work in tandem to address multiple underlying determinants simultaneously, may have larger potential. In addition, policies aimed at younger children are found to be more effective. This is in line with global evidence that targeting interventions during the first 1,000 days of life yields the largest benefit (Bhutta et al., 2008). Finally, while our simulations provide important insights into the potential effect of an intervention, further research is needed to estimate the actual impacts of policy on malnutrition, using rigorous evaluation designs. Such research should also focus on the effect of policy on the underlying mechanisms that determine malnutrition, to understand how

\footnotetext{
${ }^{25}$ Note that our consumption measure is per adult equivalent and not per capita. If we were to use per capita consumption, our estimates would be slightly lower than presented here.
} 
public policy can contribute to these various determinants. This will be the focus of Chapter 5 in this dissertation. 


\subsection{Appendix to Chapter 3}

Table S 3.1, Prevalence of acute respiratory infections (ARI), fever and diarrhoea among children in the poorest and second quintile

\begin{tabular}{lcc}
\hline & Poorest quintile & Second quintile \\
\hline ARI & 2.6 & 5.0 \\
Fever & 15.5 & 16.6 \\
Diarrhoea & 14.1 & 14.4 \\
\hline
\end{tabular}

Note: Children under 5, N=1,198 for poorest quintile, $\mathrm{N}=1,137$ for second quintile

Source: Ghana Demographic and Health Survey, 2014 


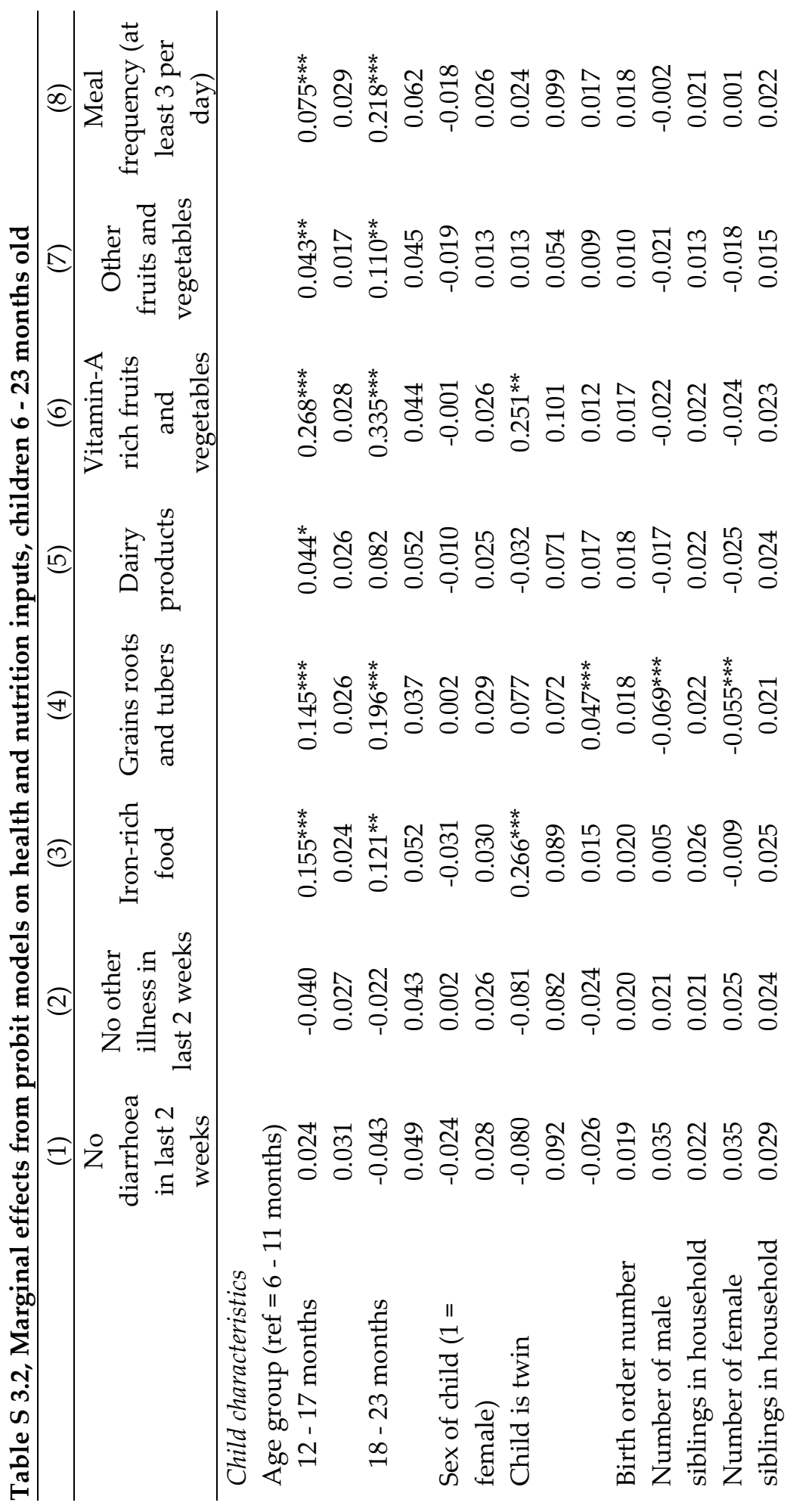




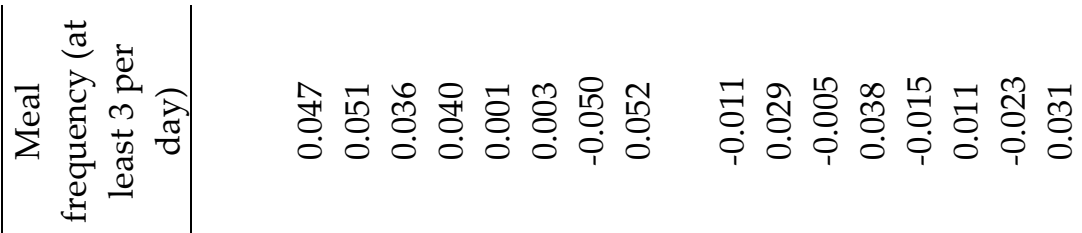

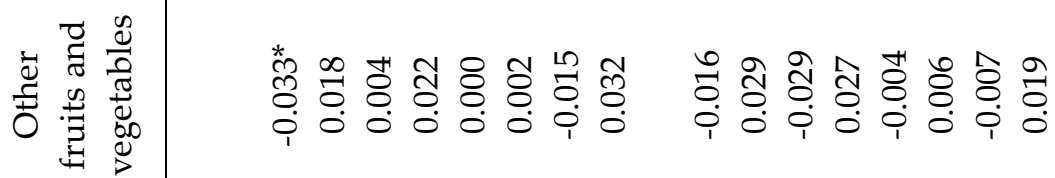

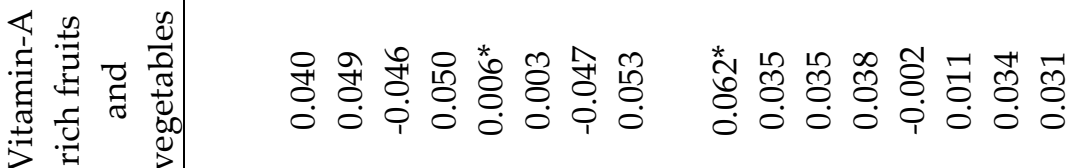

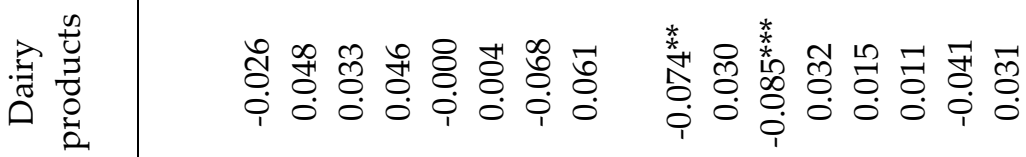

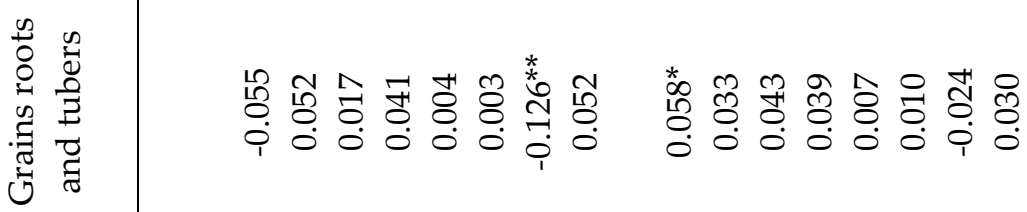

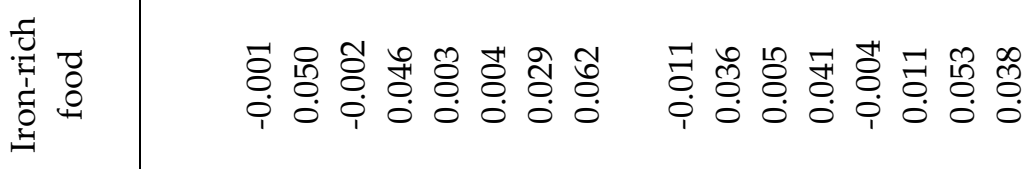

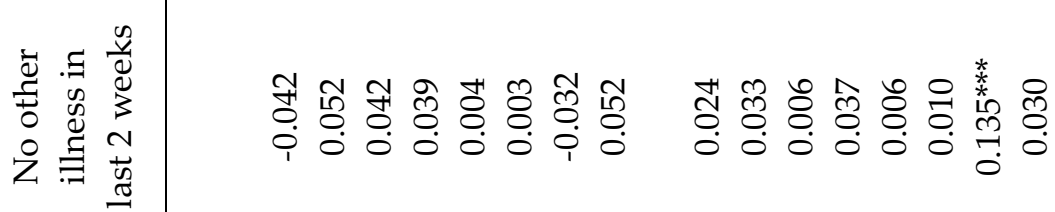

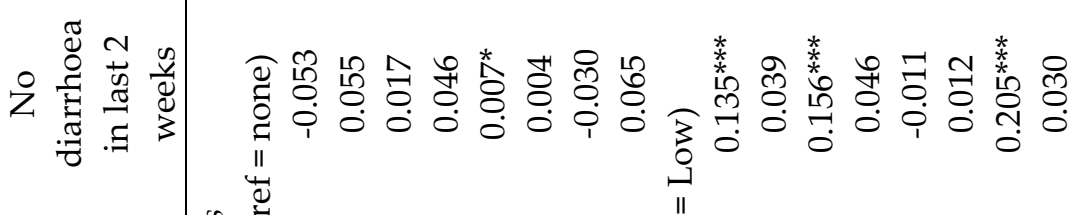

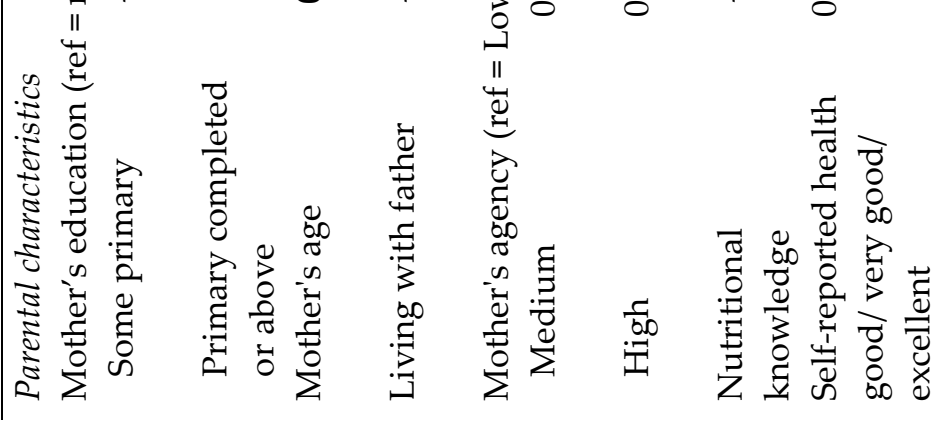




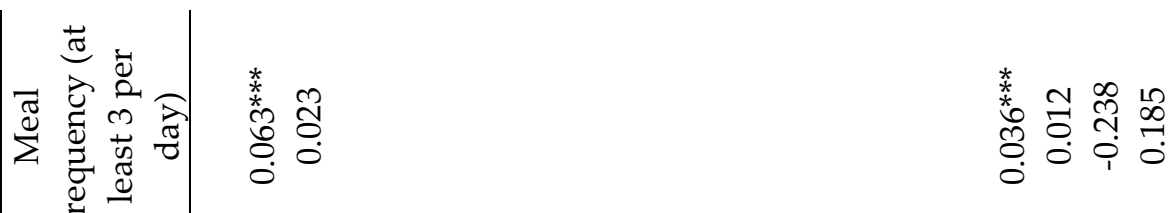

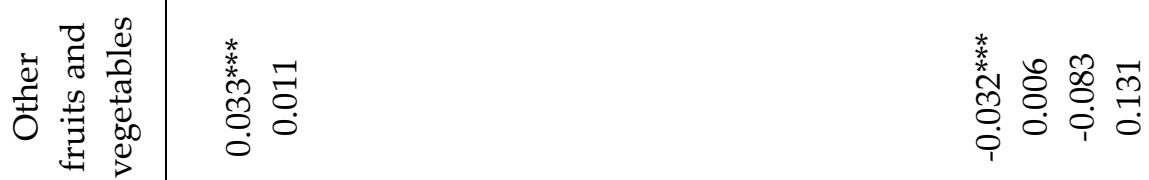

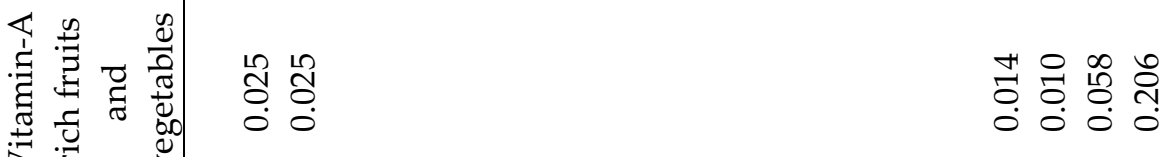

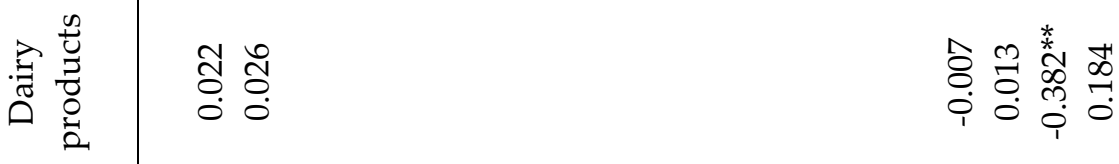

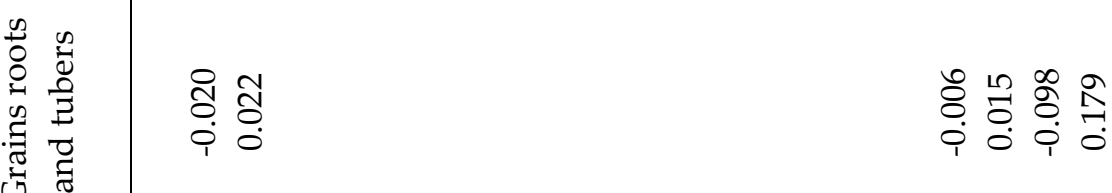

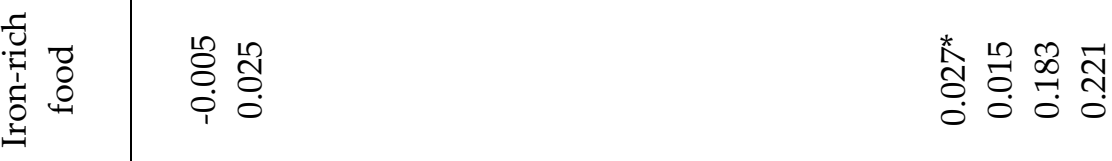

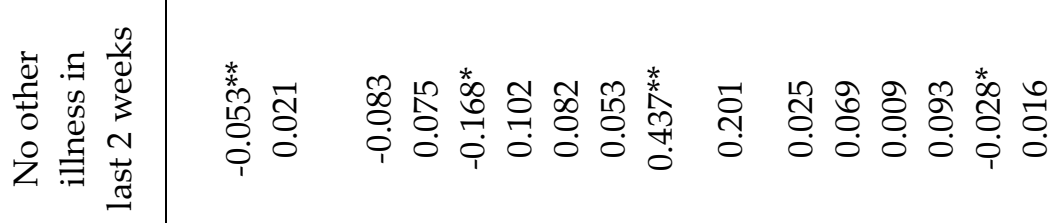

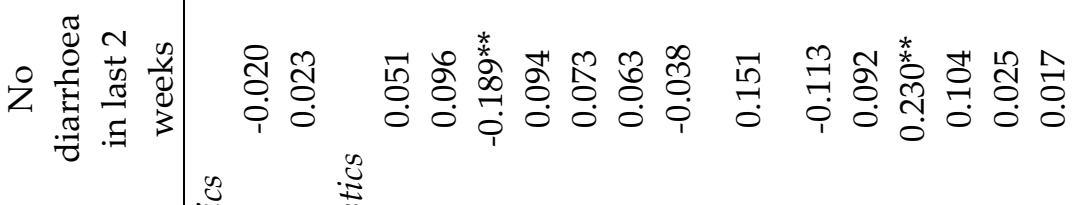

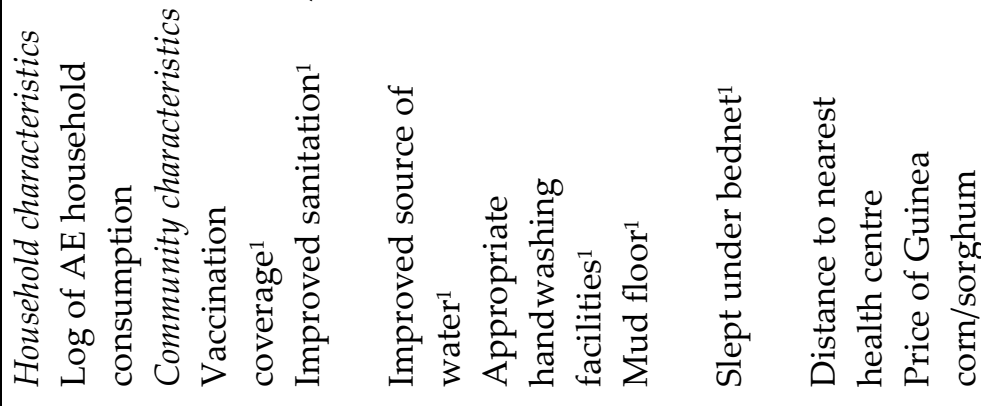




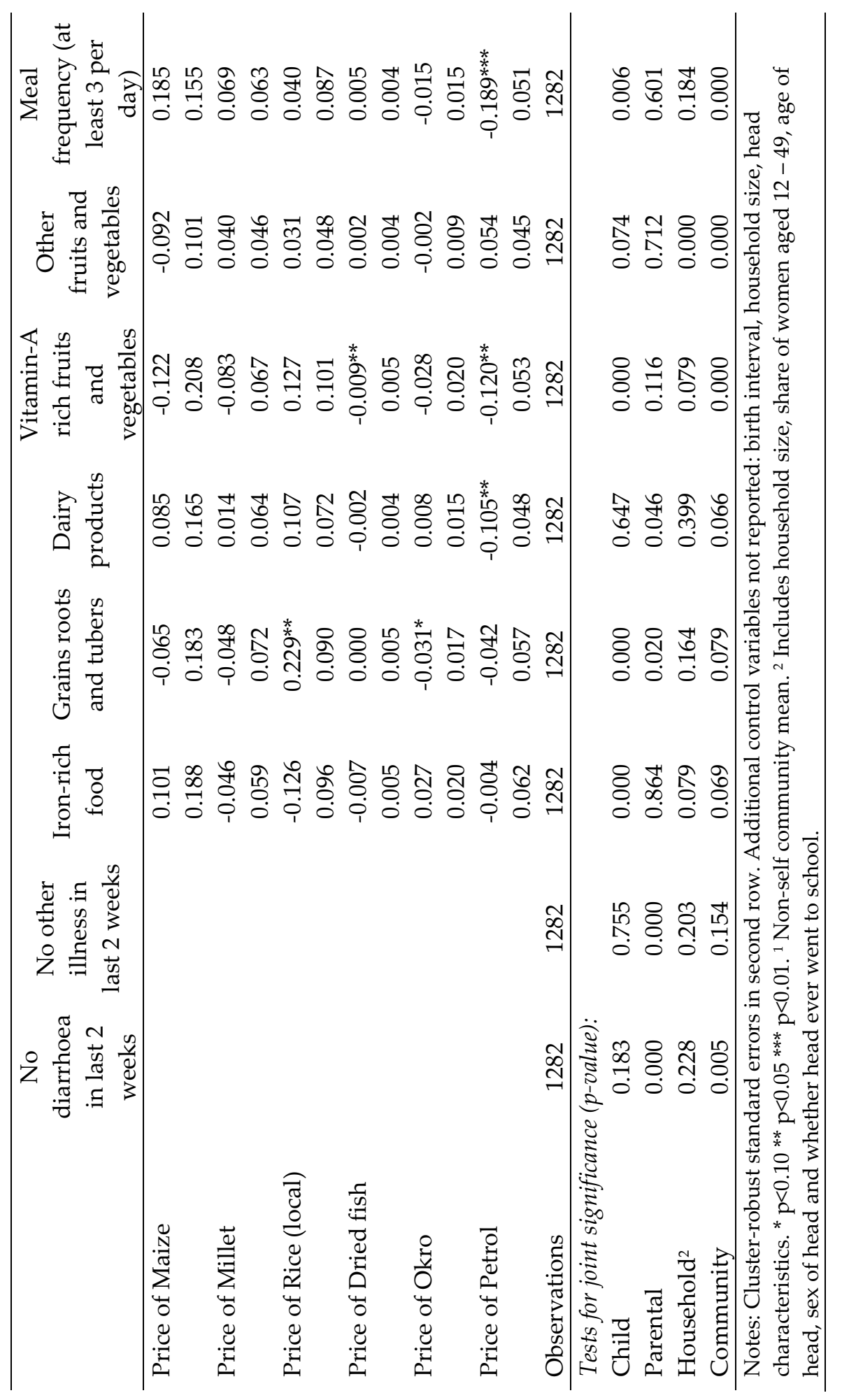




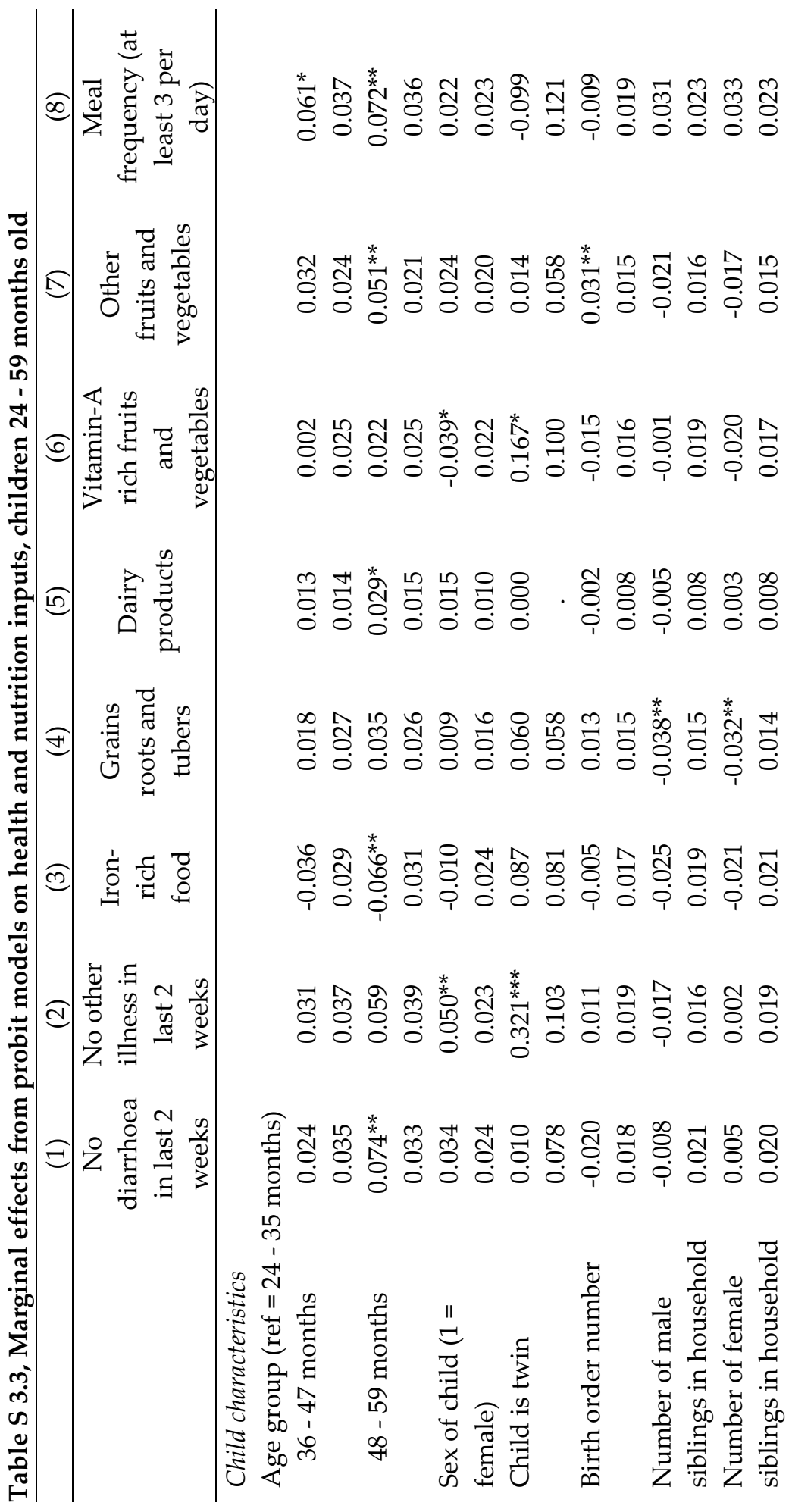




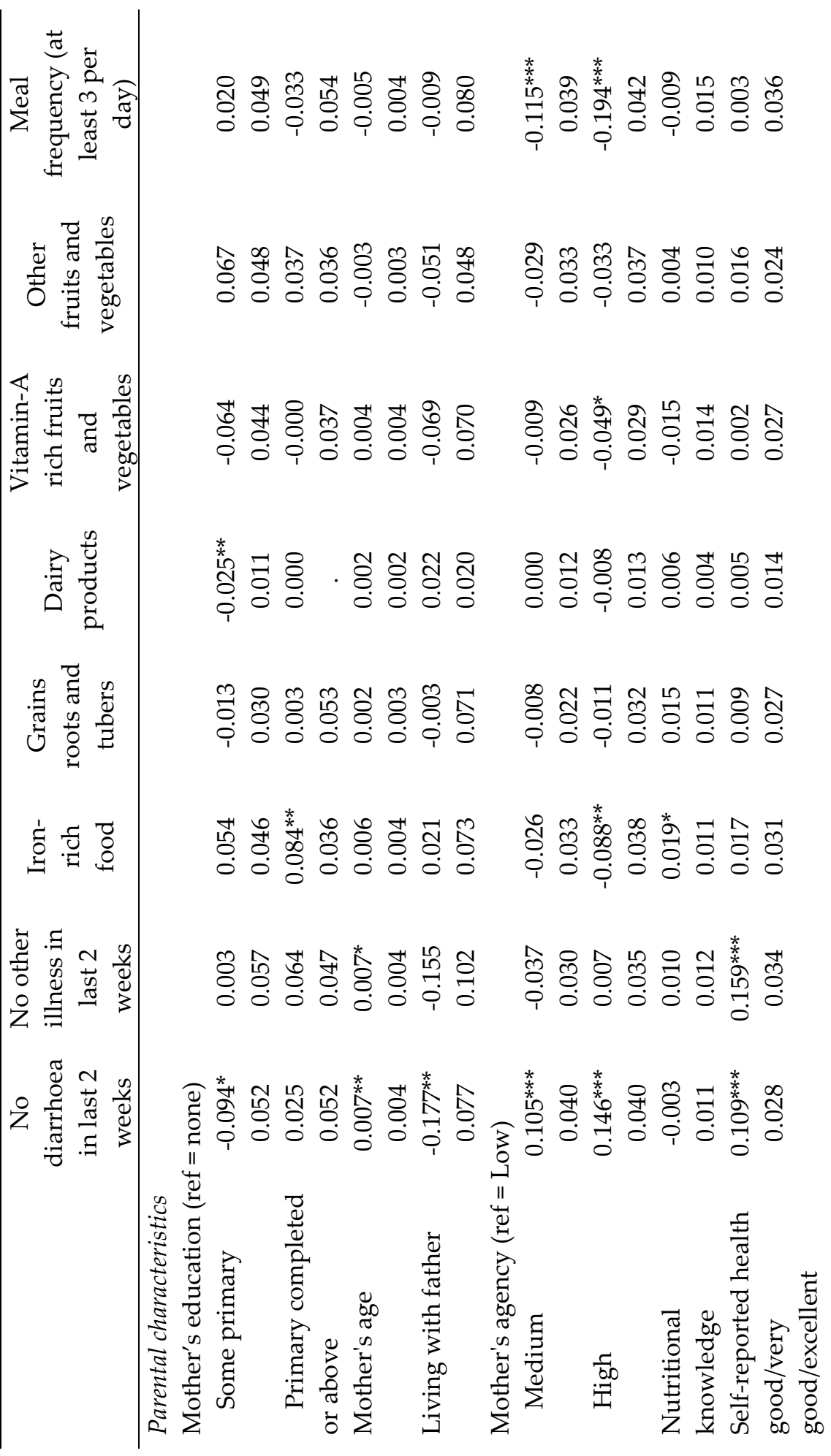




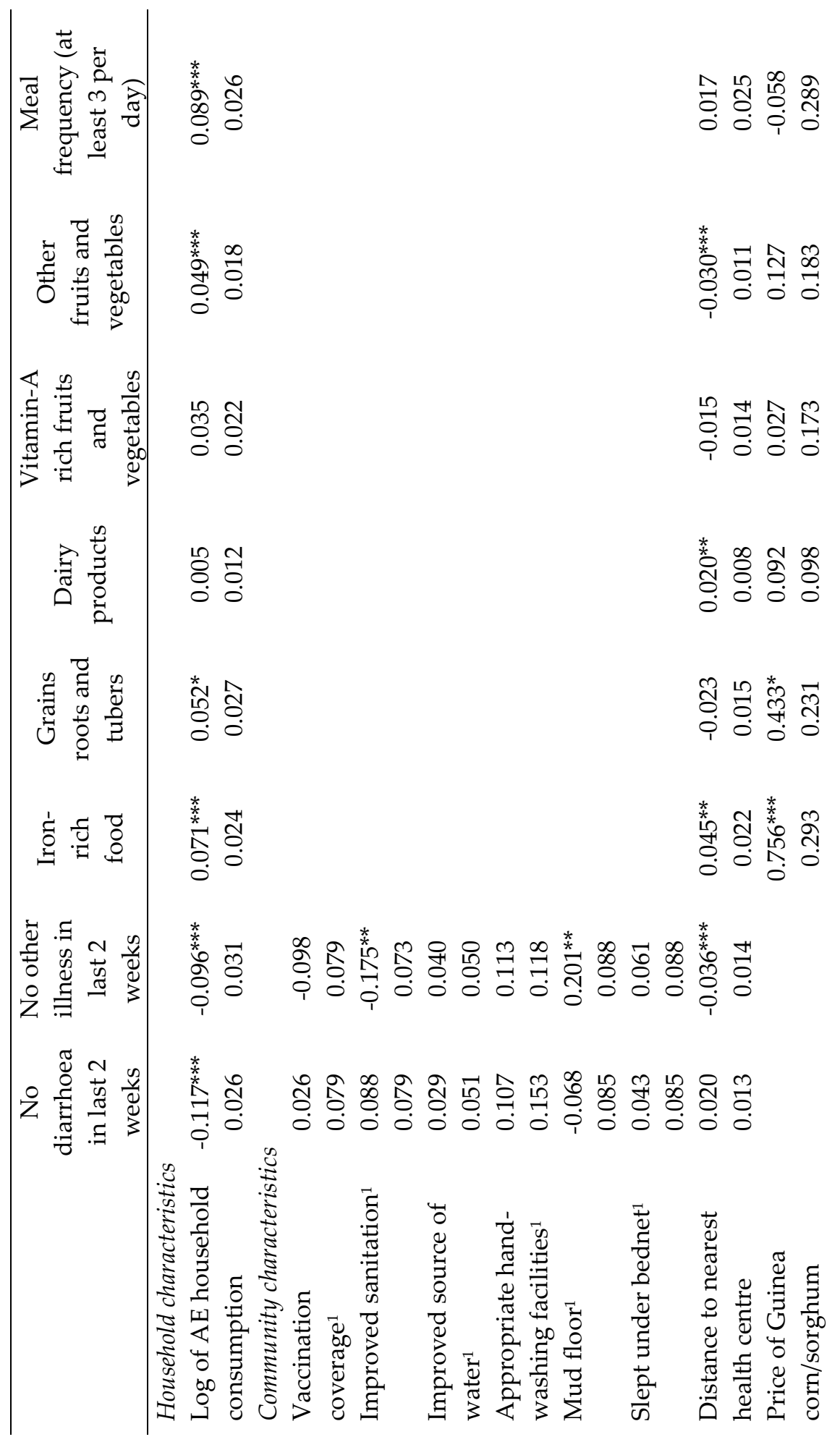




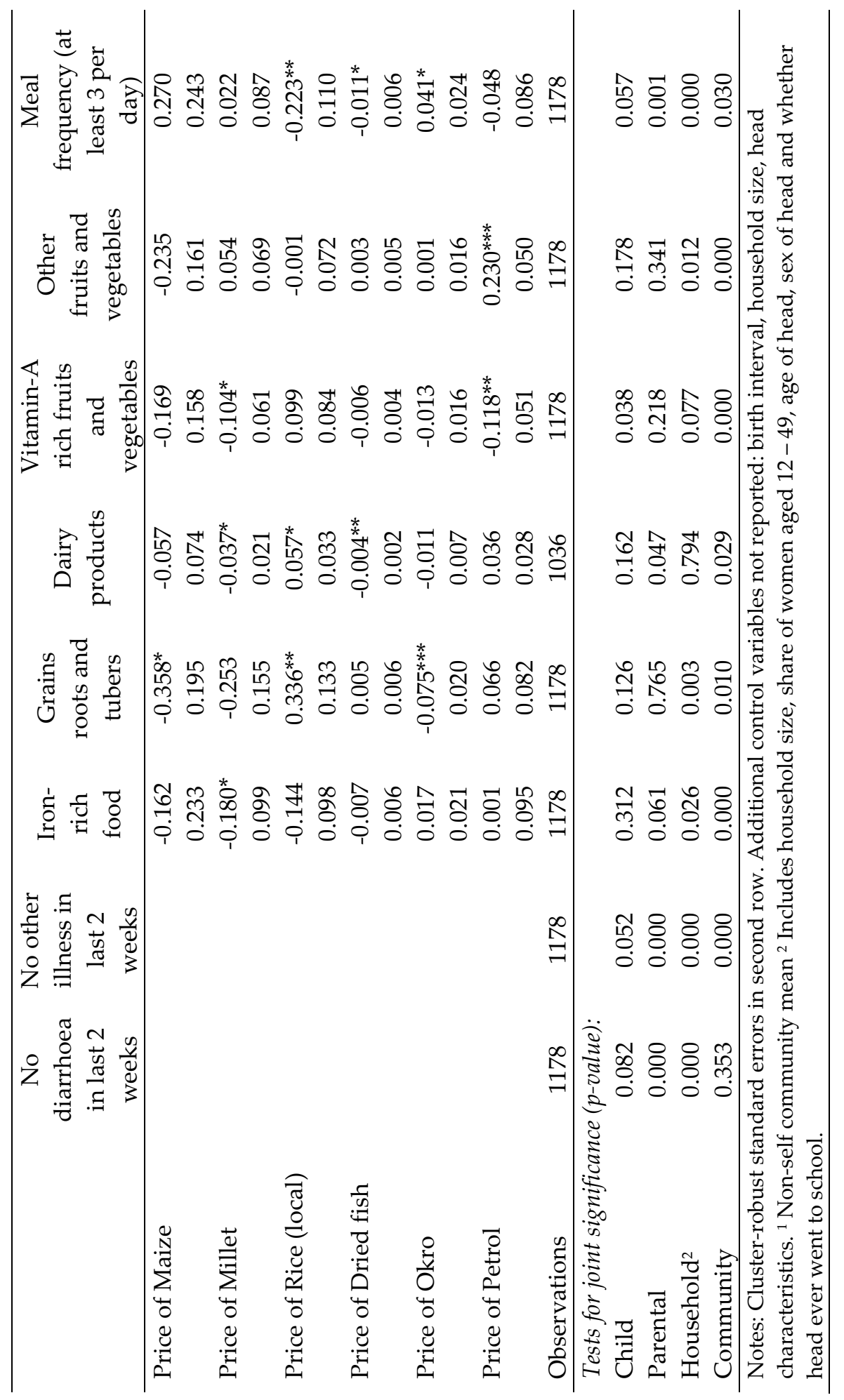


Table S 3.4, OLS regression of child, parental, household and community characteristics on height-for age (children 6 - 23 months and $24-59$ months)

Child characteristics

Age group (ref $=6-11$ months)

12 - 17 months $-0.906^{* * *}$

18 - 23 months

$-1.637^{* * *}$

0.187

Age group (ref $=24-35$ months)

36 - 47 months 0.081

48 - 59 months 0.096 0.033

Sex of child ( $1=$ female $)$

$0.210^{*}$

0.135

Child is twin

0.107

0.093

$-0.959^{* * *}$

0.073

Birth order number

0.332

$-0.295$

$-0.028$

0.244

0.073

$-0.095^{* *}$

Number of male siblings in household

0.058

0.043

0.083

$0.121^{*}$

Number of female siblings in household

0.064

0.062

0.086

$0.106^{*}$

Parental characteristics

Mother's education $(\mathrm{ref}=\mathrm{none})$

Some primary

$\begin{array}{cc}-0.445^{* *} & 0.150 \\ 0.211 & 0.133 \\ -0.126 & -0.029 \\ 0.187 & 0.153 \\ 0.017 & 0.011 \\ 0.013 & 0.011 \\ -0.361^{*} & 0.053 \\ 0.215 & 0.295\end{array}$

Mother's agency $($ ref $=$ Low $)$

Medium

0.125

0.110

0.131

0.117

High

0.010 0.006

0.162

0.132 


\begin{tabular}{|c|c|c|}
\hline & $(1)$ & $(2)$ \\
\hline & $6-23$ months & $24-59$ months \\
\hline \multirow[t]{2}{*}{ Nutritional knowledge } & 0.069 & -0.009 \\
\hline & 0.043 & 0.030 \\
\hline \multirow[t]{2}{*}{ Self-reported health good/very good/excellent } & -0.130 & -0.074 \\
\hline & 0.127 & 0.105 \\
\hline \multicolumn{3}{|l|}{ Household characteristics } \\
\hline \multirow[t]{2}{*}{ Log of AE household consumption } & $0.187^{* *}$ & 0.095 \\
\hline & 0.092 & 0.083 \\
\hline \multicolumn{3}{|l|}{ Community characteristics } \\
\hline \multirow[t]{2}{*}{ Vaccination coverage $^{1}$} & $0.565^{* *}$ & 0.230 \\
\hline & 0.262 & 0.281 \\
\hline \multirow[t]{2}{*}{ Improved sanitation $^{1}$} & 0.394 & -0.002 \\
\hline & 0.485 & 0.299 \\
\hline \multirow[t]{2}{*}{ Improved source of water ${ }^{1}$} & -0.362 & 0.166 \\
\hline & 0.246 & 0.202 \\
\hline \multirow[t]{2}{*}{ Appropriate handwashing facilities ${ }^{1}$} & -0.612 & -0.386 \\
\hline & 0.512 & 0.479 \\
\hline \multirow[t]{2}{*}{ Mud floor ${ }^{1}$} & 0.479 & -0.135 \\
\hline & 0.313 & 0.305 \\
\hline \multirow[t]{2}{*}{ Slept under bednet ${ }^{1}$} & 0.218 & $1.081^{* * *}$ \\
\hline & 0.415 & 0.343 \\
\hline \multirow[t]{2}{*}{ Distance to nearest health centre } & -0.019 & 0.068 \\
\hline & 0.085 & 0.061 \\
\hline \multirow[t]{2}{*}{ Price of Guinea corn/sorghum } & $-1.832^{* *}$ & 1.023 \\
\hline & 0.825 & 0.809 \\
\hline \multirow[t]{2}{*}{ Price of Maize } & 0.761 & -0.608 \\
\hline & 0.650 & 0.609 \\
\hline \multirow[t]{2}{*}{ Price of Millet } & 0.171 & 0.028 \\
\hline & 0.293 & 0.296 \\
\hline \multirow[t]{2}{*}{ Price of Rice (local) } & $0.777^{* *}$ & 0.126 \\
\hline & 0.357 & 0.317 \\
\hline \multirow[t]{2}{*}{ Price of Dried fish } & -0.030 & -0.003 \\
\hline & 0.022 & 0.016 \\
\hline \multirow[t]{2}{*}{ Price of Okro } & -0.007 & $-0.143^{* *}$ \\
\hline & 0.071 & 0.058 \\
\hline \multirow[t]{2}{*}{ Price of Petrol } & 0.103 & -0.045 \\
\hline & 0.299 & 0.271 \\
\hline Observations & 1,282 & 1,178 \\
\hline R-squared & 0.150 & 0.056 \\
\hline
\end{tabular}


Tests for joint significance ( $p$-value):

Child characteristics

0.000

0.222

Parental characteristics

0.056

0.654

Household characteristics ${ }^{2}$

0.087

0.127

Community characteristics

0.000

0.027

Notes: Cluster-robust standard errors in second row. Additional control variables not reported: birth interval, household size, head characteristics. ${ }^{*} \mathrm{p}<0.10^{* *} \mathrm{p}<0.05^{* * *} \mathrm{p}<0.01$. ${ }^{1}$ Non-self community mean. ${ }^{2}$ Includes household size, share of women aged $12-49$, age of head, sex of head and whether head ever went to school. 


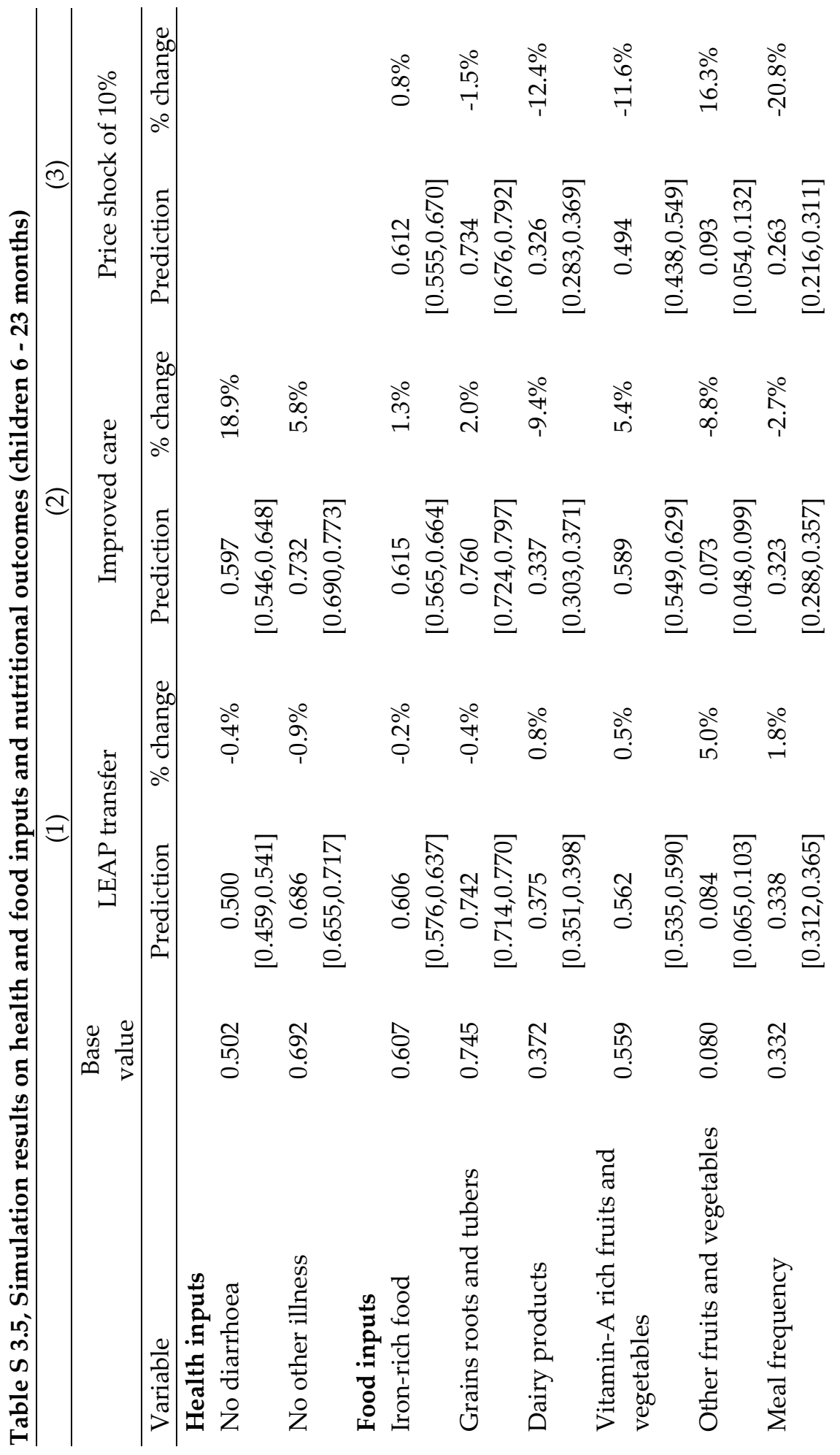




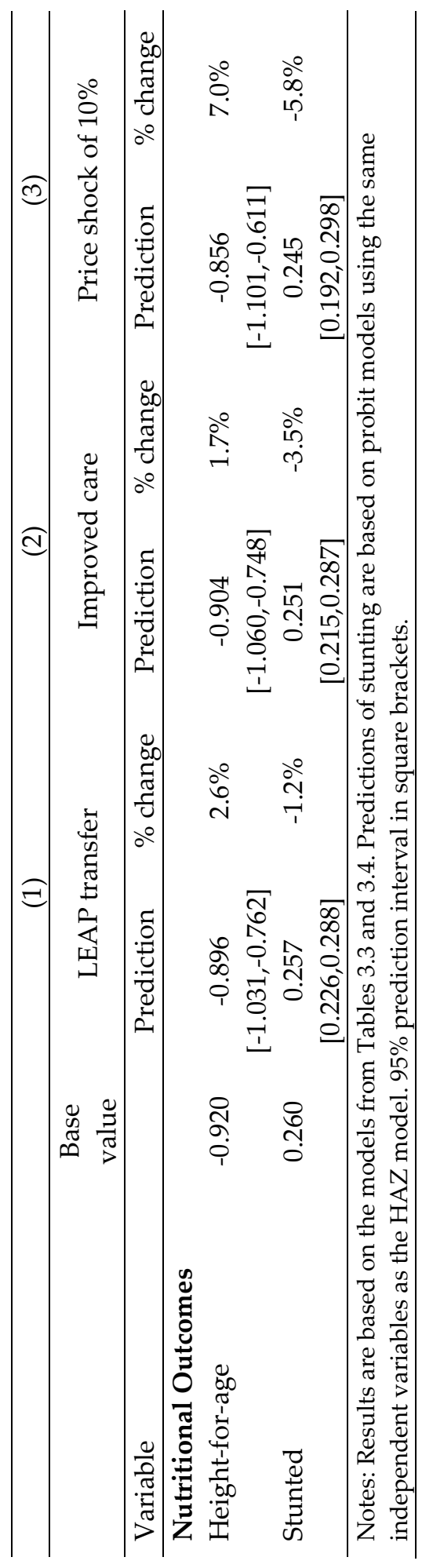




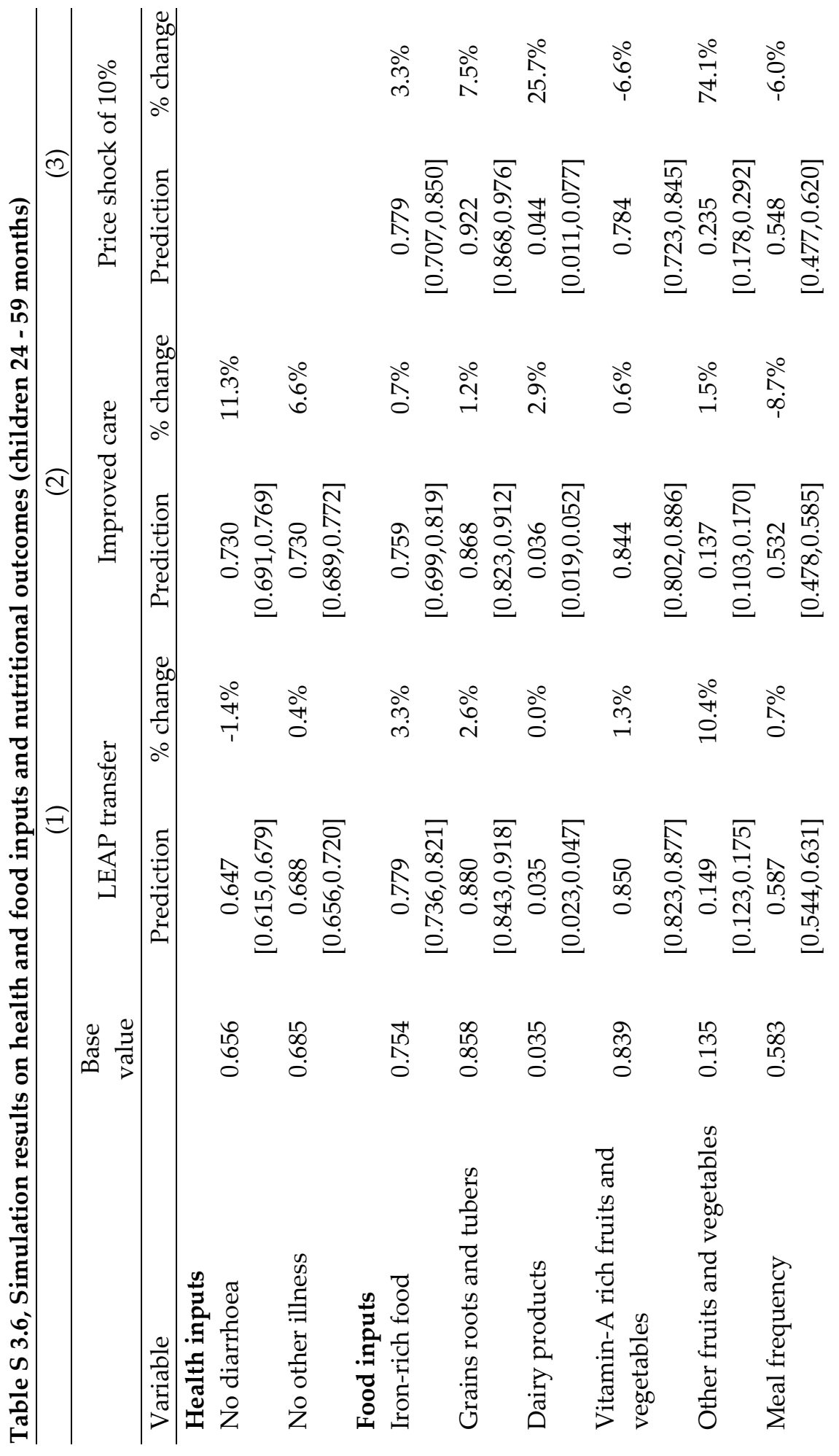




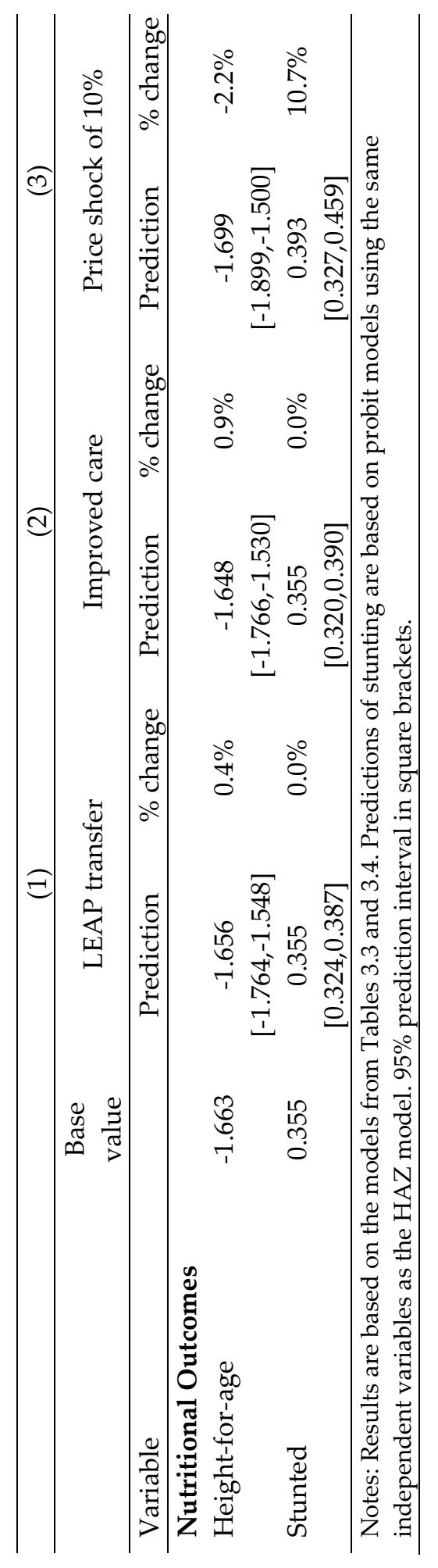


Figure S 3.1, Relation between log of monthly household consumption and illness (children under $5, \mathrm{~N}=9,450$ )

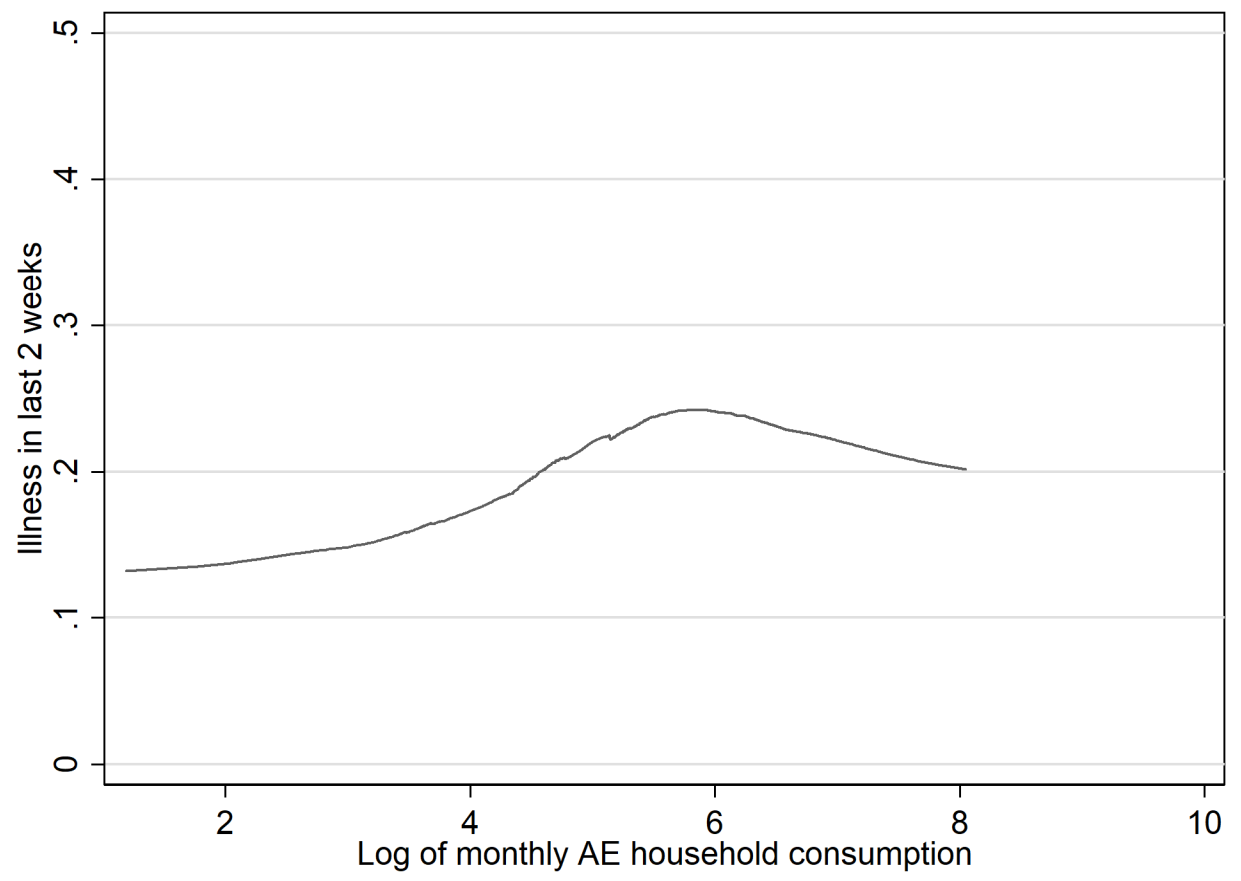

Source: GLSS 2012/2013 
Figure $\mathrm{S} 3.2$, Relation between $\log$ of monthly household consumption and child deaths in the household ( $\mathrm{N}=2,497$ households)

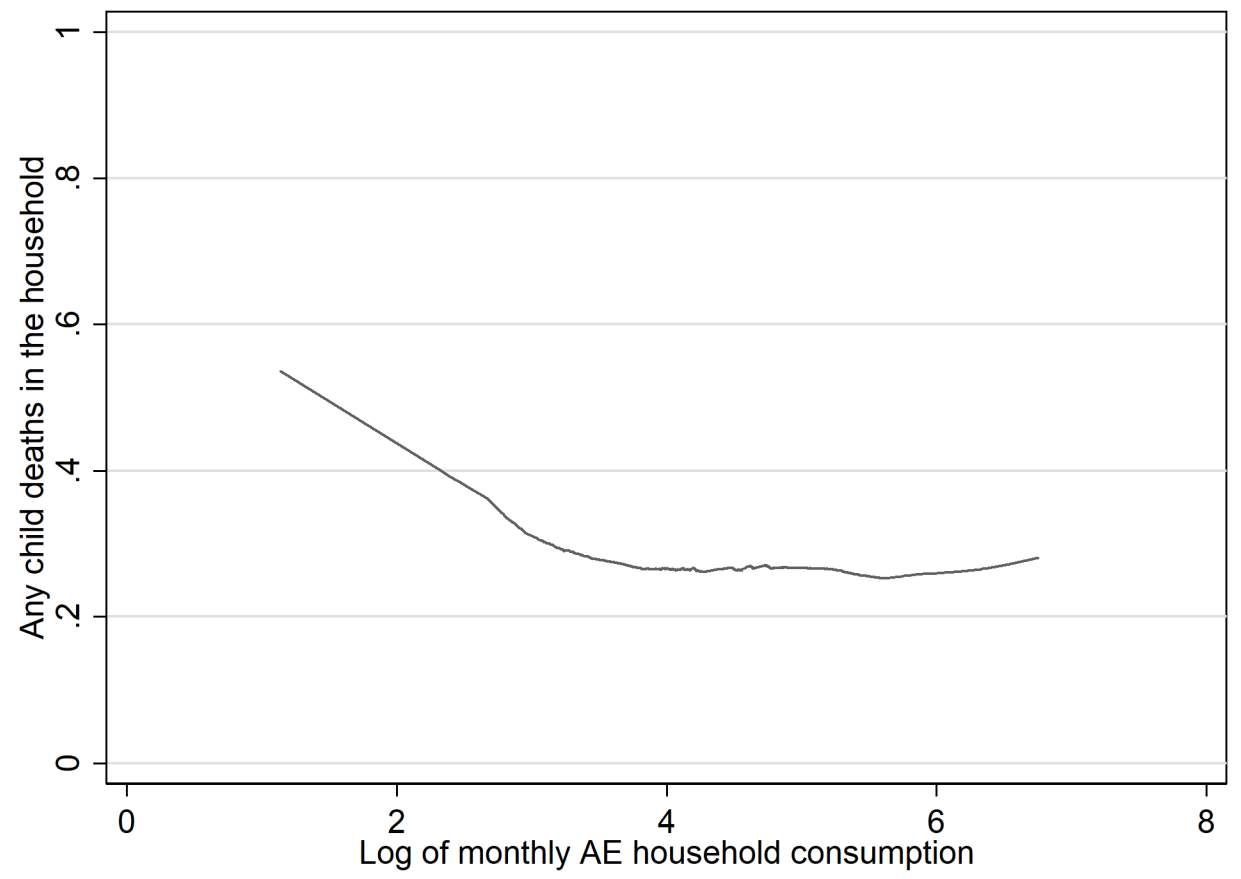

Source: LEAP1000 Baseline data 
4. Intra-household dynamics in Northern Ghana: is there a gender bias in the allocation of household resources? 


\subsection{Introduction}

The intra-household dynamics in resource allocation and decision-making can be important determinants of malnutrition as depicted in Figure 1.2. After all, young children are at the mercy of their caregivers when it comes to feeding and care. It is generally the adults in the household that decide how resources are allocated to each member and children have relatively little voice in this matter. In addition, poor households have limited resources at their disposal and therefore must make important decisions on how to spend their limited budget. There has been considerable attention in recent years on the intra-household allocation of resources among poor households (Doss, 2013, Haddad et al., 1997, Strauss et al., 2000). That is, how income gets distributed among members of the household.

In general, there are two main models of household behaviour in the literature: unitary household models and collective household models. Unitary household models are rooted in the seminal work of the economics of the household by Becker $(1965,1981)$. The key assumption is that households maximize one single utility function. Note that this assumption does not imply a lack of different preferences among household members or unequal allocation of resources, but rather that the outcome of the intra-household process is a single utility function (Haddad et al., 1997). This outcome can for example be reached if the household members have common preferences, if household members exhibit a high degree of altruism towards each other or if a single person (a benevolent dictator) makes decisions on behalf of all household member. In such models, income of all household members is pooled to maximize the single household utility function.

More recently, the assumptions underlying the unitary model of the household have been called into question and new models have emerged that allow individuality of preferences among household members. These models are broadly called collective models and the main assumption is that households allocate their resources in a Pareto-efficient way (Chiappori, 1992). That is, no member in the household can be made better off without another household member being made worse off. In addition, collective models do not require a unique welfare index to be interpreted as a utility function, and therefore allow the index to be dependent on prices, incomes but also tastes (Quisumbing and Maluccio, 2000). Collective models are further categorized into cooperative models and non-cooperative models. In cooperative models, individuals can choose to either form a household or not. Individuals form a household based on the premise that being in a household generates an economic surplus, which increase utility of all members. The division of these gains depends on the bargaining power of the individual, usually determined by the 'fall-back' or 'treat' point, which is the utility for a member when not in a household. This point is subsequently dependent on so-called extra-environment parameters such as divorce laws and 
customs when marriages are dissolved (Haddad et al., 1997). Non-cooperative models rely on the assumption that an individual's actions are conditional on the actions of others implying that not all non-cooperative approaches are Paretoefficient. Each individual within the household acts alone and one of the attractive features of this model is that income is not pooled, which is consistent with findings from many studies (Haddad et al., 1997).

It is generally assumed that testing whether income is pooled or not can demonstrate the validity of the unitary household model in a given context. For the unitary model to hold, it should not matter who in the household earns the income (or owns the productive assets) or how much each member earns, as all income is pooled to maximize the household's single utility function (Doss, 2013). Hence, if income in the hands of one person (e.g. the spouse) has a different effect on outcomes than income in the hands of another household member (e.g. the husband), the unitary model is rejected. However, it is not always clear in favour of what other model it is rejected and some authors argue that rejecting income pooling is not sufficient to reject the unitary model (Browning et al., 2006).

The prevailing model of intra-household allocation of resources in a given context is of interest to policy makers for a number of reasons, as discussed by Haddad et al. (1997). The most relevant in the context of this chapter is the effect of public transfers on household and individual wellbeing. In the context of this thesis, which deals with the impact of LEAP 1000 on child health outcomes, the prevailing intra-household resource allocation will likely play a significant role in the effectiveness of the programme. If policy makers believe in the unitary model of the household, the effects of this programme should be unaffected by the identity of the beneficiary in the household. But, if the collective model is prevalent in this context, the impact of the programme will differ based on which person in the household receives the transfer.

In addition to the model of the family, it is of interest how resources are shared among household members, in particular to male and female children and whether there is a gender bias in the allocation of resources. Note that this question is fundamentally different from the question on what type of economic model fits best for households in a given context. The way household resources are distributed, can be consistent with all household models discussed above and is not a test of the unitary model versus the collective model. For example, if the husband and wife both have common preferences (or if one of them is the single decision-maker in the household) towards investing more in boys than girls, they may follow the unitary household model, but outcomes for boys and girls in terms of health and education may differ. Alternatively, in a collective household model, both spouses can independently prefer to invest more in children of a particular gender if future prospects for one gender are better or if children of one particular gender (most often boys) can help in productive activities of the household, raising future income for the household. 
The overall aim of this chapter therefore is to examine (before households receive any cash grants), which intra-household dynamics are prevalent. First, it aims to examine how household resources are distributed by investigating to what extent households respond to changes in household composition, especially the addition of a young child, in their household budget, and whether this response is different if the additional child is a boy or a girl. Secondly, the chapter uses the education of parents as a source of bargaining power to assess how bargaining power within the household affects the nutritional status and educational achievement of children and whether there are differences between boys and girls. This is effectively a test of the unitary versus the collective model of the household. The answers to these questions will help to understand what is driving household resource allocation and how these intra-household dynamics may affect the effectiveness of a cash grant to receiving households.

In Ghana, boys tend to remain in the household when they grow up, while girls go to live with their spouses. The economic returns to investments in children's health and education are therefore greater for boys than for girls, since the household is able to reap the benefits of their investments in boys, but not girls (Garg and Morduch, 1998). In addition, most communities in Northern Ghana follow patrilineal descent, giving more importance to sons as they inherit productive assets such as land. On the other hand, dowry received from marrying of daughters has traditionally been a way to accumulate wealth for parents in patrilineal societies (Berry, 1995). Recent figures from Ghana show that gender inequality in outcomes for young children is relatively low. In fact, child mortality among children under five years is slightly higher among boys than girls and boys are also more likely to be stunted than girls (GSS, GHS and ICF International, 2015). In terms of education, gender parity has been achieved at the primary and junior secondary level, but at the senior secondary level the gender parity index is 0.94, indicating that more boys than girls attend school at this level (UNESCO Institute for Statistics, 2014). Gender gaps in education are also higher in Northern Ghana (UNICEF Ghana, 2012). Based on these parameters, it is expected that little bias exists in young child investments, whereas for older (school-going) children, there may be a pro-male bias.

Turning to the unitary household model versus the collective model, previous research has generally rejected the unitary model (Haddad et al., 1997). In Ghana, one study examined the differential effect of mother's education and father's education on their daughters' and sons' height-for-age and found that the effect of maternal education is larger for daughters than for sons and the effect of paternal education is larger for sons than for daughters (Thomas, 1994). This result points towards a collective model of the household, with different preferences between spouses. However, this study was conducted on an urban sample, which is in contrast to the rural, poor population considered in this chapter. The dynamics of rural households may be different, but if anything, it is expected that 
rural households exhibit a similar model of intra-household dynamics as the urban sample in Thomas (1994). This is because also in rural households, fathers may want to invest more in boys as they can assist in the income-generating activities of the households, whereas mother may prefer to invest in girls.

The chapter is organized as follows. The next section discusses the data and methods. Section 4.3 presents the results of the outlay equivalence analysis and the tests for the unitary model of the household. Section 4.4 discusses the implications of the findings and section 4.5 concludes.

\subsection{Data and methods}

Data for this study are derived from the baseline survey of the Livelihood Empowerment Against Poverty (LEAP) 1000 impact evaluation. The LEAP 1000 impact evaluation is a longitudinal, mixed-method study implemented by a consortium of research partners including UNICEF Office of Research - Innocenti, the University of North Carolina at Chapel Hill, the Institute of Statistical, Social and Economic Research at the University of Ghana and the Navrongo Health Research Centre. Quantitative baseline data was collected between July September 2015 from 2,497 households in five districts in the Northern and Upper East Regions.

The baseline survey consists of a rich number of modules, covering many dimensions of household wellbeing. Particularly, it includes a detailed consumption module with more than 120 items, modelled after the consumption module of the Ghana Living Standards Survey (GLSS), which is the basis for welfare analysis in Ghana. ${ }^{26}$ This chapter uses baseline data only, and so none of the eligible households had yet received the transfer. Moreover, a comprehensive analysis of baseline characteristics showed that the treatment and comparison households are highly similar. ${ }^{27}$ Thus, we can use the full sample for this chapter.

Before describing the methods, it is necessary to acknowledge that the data used for this chapter are not ideal for an intra-household analysis, since it was not specifically designed for such purposes. For example, no individual income was collected (e.g. Thomas, 1990) nor ownership of assets assignable to individuals in the household (e.g. Quisumbing and Maluccio, 2003, Doss, 2006). Even though the data are not perfect, there remain two reliable and complementary methods to assess the intra-household resource allocation in the sample, testing whether

\footnotetext{
${ }^{26}$ One difference between the LEAP 1000 baseline survey and the GLSS consumption module is that the LEAP1000 survey was conducted during one single visit to the household, while the GLSS consumption module is based on six weekly visits, at which the frequent expenditures for each week are recorded.

${ }^{27}$ For more details on the study design and baseline analysis, see the baseline report (UNICEF Office of Research - Innocenti et al., 2016).
} 
household exert bias in their behaviour towards boys or girls and whether fathers and mothers have different preferences to invest in their sons or daughters.

\subsubsection{Outlay equivalence analysis}

First, this chapter follows the method developed by Deaton (1989), and widely used (e.g. Deaton et al., 1989, Haddad and Reardon, 1993, Gibson and Rozelle, 2004, Parpiev et al., 2012) to test for boy/girl discrimination in resource allocation in the sample using outlay equivalence ratios. The intuition behind this technique is that the addition of a child in a household, keeping everything else equal, asserts a pure negative income effect on exclusive adult goods in the household budget (Deaton and Muellbauer, 1986). Adult goods are goods that are exclusively consumed by adults, such as alcohol, tobacco and adult clothing. A child will not bring in any income but requires household resources such as food and health care. If the total household budget is fixed, the household thus needs to readjust the household budget, and for example give up spending on adult goods to cover expenditures for children. The change in consumption of adult goods provides an assessment of the preference of parents. If this change is large, parents are more willing to give up spending on exclusive adult goods in favour of their children. Disaggregating by sex, it also allows testing whether the response to a male child is different from the change in response to a female child. The difference in this reaction reveals household preferences regarding the gender of their children.

The approach taken in this chapter (the so-called Rothbarth approach) is different than studies attempting to estimate the collective model of the household, which has gained significant attention in recent years (Browning et al., 2013). The main difference is that the Rothbarth approach only allows the estimation of resource sharing between unitary parents and children, whereas the full collective model can distinguish sharing between women, men and children. However, both methods rely on valid and exclusive adult goods for identification of resource shares within the household. In addition, in a validation exercise both methods perform similarly when compared to observed private consumption in the household (Bargain et al., 2018). Since this chapter is not concerned with sharing between adult men and women, the Rothbarth approach is sufficient to estimate gender bias for children in the household.

To operationalize this technique, we estimate the following parametric Engel curve:

$$
w_{i}=\frac{p_{i} q_{i}}{x}=\alpha_{i}+\beta_{i} \ln \left(\frac{x}{n}\right)+\eta_{i} \ln (n)+\sum_{j=1}^{J-1} \gamma_{i j}\left(\frac{n_{j}}{n}\right)+\delta_{i} \cdot z+u_{i}
$$


This formula relates the share of expenditure on adult good $i,\left(w_{i}=\frac{p_{i} q_{i}}{x}\right)$, to the natural logarithm of total expenditure per capita $\left(\ln \left(\frac{x}{n}\right)\right) \cdot{ }^{28}$ Household composition is modelled through the natural logarithm of household size $(\ln (n))$ and the ratios $\left(n_{j} / n\right)$ of each sex/age group. Following Deaton (1989), there are eight age/sex groups: $0-4$ years, $5-14$ years, $15-55$ years and $55+$ years for both males and females. These age groups are useful because $0-4$ year old children are considered infants, while 5-14 year olds are of school-going age. We exclude one group (females 55+) to avoid perfect multicollinearity among the age/sex groups. Vector $z$ includes additional control variables, in this case district dummies. In line with the survey set-up, standard errors of the Engel curve estimation are clustered at the community level. Given equation 4.1, the outlay equivalence ratio $\pi_{i r}$ for good $i$ and sex/age group $r$ can be computed as follows (Deaton, 1989):

$$
\pi_{i r}=\frac{\left(\eta_{i}-\beta_{i}\right)+\gamma_{i r}-\sum_{j=1}^{J} \gamma_{i j}\left(n_{j} / n\right)}{\beta_{i}+w_{i}}
$$

All parameters in this equation are described above. Equation 4.2 uses the point estimates $\eta_{i}, \beta_{i}$, and $\gamma_{i r}$ from the Engel curve estimation, and replacing $w_{i}$ and the $n_{j} / n$ ratios by their values at the sample mean. Formulas for calculating standard errors for the ratios are provided in Deaton (1989) and by Deaton et al. (1989) and are estimated with the delta-method utilizing Stata's nlcom command.

In short, $\pi_{i r}$ measures the effect of an additional person of type $r$ on demand for good $i$, expressed as the \% change in expenditure per person that would have been necessary to produce the same effect on demand. For example, if $r$ is the number of boys $0-4$ years old, and good $i$ is adult clothing, a $\pi_{i r}$ of -0.2 means that the addition of a young boy to the household exerts a similar effect on the demand for adult clothing as a 20 percent reduction in per capita household expenditures.

Deaton's outlay equivalence method is criticized by some because in certain cases where pro-male bias is expected, the method fails to reveal any significant bias towards boys (Gibson and Rozelle, 2004, Kingdon, 2005). Examples include Bangladesh (Ahmad and Morduch, 1993), India (Case and Deaton, 2003, Fuwa et al., 2006, Subramanian and Deaton, 1991), Pakistan and Taiwan (Deaton, 1997). Reasons proposed for the failure of the method include the relatively low share of valid adult goods in households budgets and the fact that some adult

\footnotetext{
${ }^{28}$ The lumpiness of expenditures for certain goods and/or measurement error in the consumption of a good are potential issues with this estimation technique. Instrumental variables such as income or local wages are potential solutions, but such measurements were not collected for this survey.
} 
goods, such as tobacco and alcohol, are addictive and might therefore not respond well to an addition of children in the household (Strauss et al., 2000). In addition, while Deaton's method is useful to examine household responses to additional children by gender, it is unable to uncover if there are different preferences between father and mother to make investments in their sons or daughters. Therefore, this chapter also employs an alternative test to examine intra-household preferences, as a complement to Deaton's outlay equivalence analysis. The specifics of this test are discussed next.

\subsubsection{Testing for common preferences}

The second technique uses education of the mother and father as a source of bargaining power in the household, to test whether educational and nutritional outcomes of girls are different from boys (Thomas, 1994, Quisumbing and Maluccio, 2000). Individuals with more human capital as a result of more schooling are more likely to own a larger share of the household resources and therefore household decisions are more likely to reflect their preferences (Malapit et al., 2019). Hence, if the effect of father's or mother's education is different for their sons than daughters, then this provides evidence of different preferences between husbands and wives pointing to non-unitary household models.

This technique is operationalized by estimating the following regression (Quisumbing and Maluccio, 2000):

$$
E_{i j}=\beta_{0}+\beta_{1} X_{c i j}+\beta_{2} X_{f j}+\beta_{3} X_{m j}+\beta_{4} G_{i j} \cdot X_{f j}+\beta_{5} G_{i j} \cdot X_{m j}+e_{i j}
$$

With $E_{i j}$ the educational outcome of child $i$ in household $j, X_{c i j}$ representing child characteristics (age, age squared and sex); $X_{f j}$ and $X_{m j}$ are father's and mother's educational achievement (in years of completed education) and are considered exogenous; ${ }^{29} G_{i j}$ is a dummy indicator for female child and $e_{i j}$ is the error term. We use the deviation from the cohort mean as educational outcome, i.e. $E_{i j c}=S_{i j c}-\overline{E_{c}}$, with $S_{i j c}$ schooling in years for child $i$ aged $c$ years old, and $\overline{E_{c}}$ is the mean years of schooling for children aged $c$ years. The advantage of this deviation is that it is not censored at zero, and better resembles a normal distribution which works better with an OLS regression. Thus, equation 4.3 can be estimated using OLS on the entire sample of children of school-going age (6 - 17 years), and on the subsample of children in households with two or more children, using family fixed effects (FE) to control for family unobservables. However, if outcomes are affected by individual heterogeneity, a random effects (RE) model is more appropriate. We

\footnotetext{
${ }^{29}$ Parental education is assumed to be completed before marriage and childbearing so there is no contemporaneous relation between this measure and the error term in the equation.
} 
test for OLS versus RE by using a Lagrange Multiplier (LM) test, and FE versus RE using a Hausman test.

Secondly, we use individual educational expenditure as educational input. This measure seeks to quantify the current investments parents make in the education of their children. Since this indicator is heavily skewed with a few large outliers, we transform this variable using the inverse hyperbolic sine: $\log \left(y_{i}+\right.$ $\left.\left(y_{i}{ }^{2}+1\right)^{1 / 2}\right)$. The benefit of this transformation is that its interpretation is similar as a normal $\log$ transformation, but values equal to zero in the source variable $\left(y_{i}\right)$ are also defined and not dropped in the analysis (Burbidge et al., 1988). Standard errors in all the above analysis are again clustered at the community level.

Next, we use the same technique to test for different preferences using nutritional status among children under five:

$$
N_{i j}=\beta_{0}+\beta_{1} X_{c i j}+\beta_{2} X_{f j}+\beta_{3} X_{m j}+\beta_{4} G_{i j} \cdot X_{f j}+\beta_{5} G_{i j} \cdot X_{m j}+e_{i j}
$$

With $N_{i j}$ being nutritional status, measured by height-for-age z-score (HAZ) and all other parameters as described above. Since z-scores are standardized, they resemble a standard normal distribution and equation 4.4 can be simply estimated with OLS. We also disaggregate this analysis by age group (< 23 months and $\geq 24$ months).

Finally, we use equation 4.4 to examine a measure for nutritional inputs as a more current indicator for investments in the nutrition of children. More specifically, we use an index composed of indicators for breastfeeding, dietary diversity and meal frequency with a score ranging from zero to six, with higher scores indicator better practices (Ruel and Menon, 2002). ${ }^{30}$ This indicator is then standardized against the sample mean.

\subsection{Results}

\subsubsection{Outlay equivalence ratios}

The first task in the outlay equivalence analysis is to establish a reliable set of adult goods. Theoretically, there are several potential candidates. Most commonly used in the literature are alcohol and tobacco, adult clothing and footwear, recreation, meals outside the home (e.g. Deaton, 1989), but also personal care, transport and health (Deaton et al., 1989, Parpiev et al., 2012) or gambling (Gibson and Rozelle, 2004). In the LEAP 1000 baseline data, there are seven potential candidates: tobacco \& alcohol, adult clothing \& footwear, recreation, adult health expenditures, adult education expenditures, transportation \& communication, and meals outside the home. Health and education expenditures are collected at the individual level and

\footnotetext{
${ }^{30} \mathrm{~A}$ full description of the construction of this indicator is given in Appendix B of Chapter 5.
} 
can thus be easily assigned to adults or children. The mean budget shares for each of these categories and the total share of all candidate adult goods are presented in Table 4.1. Health expenditures constitute the largest share of the adult goods in the household budget at 5.4 percent, followed by transportation and communication expenses (1.6 percent). Clothing and recreation both represent a share of 1.1 percent in the household budget and the remaining categories are all less than 1 percent. ${ }^{31}$ In total, these seven candidate adult goods are more than 10 percent of the total household expenditures.

The demographic composition of the households in the sample reflects the targeting criteria for the LEAP 1000 cash transfer programme. Households are relatively large with more than six members on average and a large share of young children (13.4 percent for boys $0-4$ years and 13.5 percent for girls $0-4$ years). There are also few elders in the households and many members of reproductive age. In addition, the total per capita expenditure of the households in the sample points to significant poverty, with an average per capita expenditure of just under 78 cedi per month, which translates to roughly US\$ 0.63 per capita per day. ${ }^{32}$

The results of the outlay equivalence analysis are presented in Table 4.2. In theory, the outlay equivalence ratios for children should be negative, as the addition of a child to the household is hypothesized to have a pure negative income effect on valid adult goods. Indeed, the ratios are negative for all adult goods for children $0-4$ years old. For older children $5-15$ years old, the ratios are negative for 11 of 16 cases. For tobacco and alcohol, education expenditures and meals outside the home (girls only), the ratios are positive, though not significantly different from zero. For education and meals outside the home, it is plausible that children in this age range can benefit as well from expenditures on these items.

For girls $0-4$ years old, the outlay equivalence ratio for all adult goods is 0.52 , which is significantly different from zero. This ratio implies that the addition of a young girl to the household exerts a similar effect on the demand for adult goods as a 52 percent decrease in total per capita household expenditures. The ratio for girls in this age range is also larger (more negative) than the ratio for boys. The outlay equivalence ratios for older children are of similar magnitude for both sexes, and both are not significantly different from zero.

\footnotetext{
31 There are many instances where the household reported zero expenditure on various adult goods, which may affect the estimation. However, only 11 percent of households reported zero spending on all adult goods combined.

32 The exchange rate during data collection (September 2015) was: GHC $1=$ US\$ 0.2448.
} 
Table 4.1, Descriptive statistics (means and standard deviations) of variables used in the outlay equivalence analysis (Ghana LEAP 1000)

\begin{tabular}{lcc}
\hline & Mean & SD \\
\hline Budget share tobacco and alcohol & 0.002 & 0.015 \\
Budget share adult clothing & 0.011 & 0.017 \\
Budget share recreation & 0.011 & 0.033 \\
Budget share adult health expenditures & 0.054 & 0.111 \\
Budget share adult educational expenditures & 0.007 & 0.030 \\
Budget share transportation and communication & 0.016 & 0.042 \\
Budget share meals outside the home & 0.001 & 0.008 \\
Budget share all candidate adult goods & 0.103 & 0.128 \\
Household size & 6.605 & 2.603 \\
Log of household size & 1.818 & 0.374 \\
Per capita household expenditures & 77.925 & 55.859 \\
Log of per capita household expenditures & 4.151 & 0.639 \\
Share of male children 0-4 years & 0.134 & 0.128 \\
Share of female children 0-4 years & 0.135 & 0.126 \\
Share of male children 5-14 years & 0.129 & 0.134 \\
Share of female children 5-14 years & 0.121 & 0.126 \\
Share of male adults 15-55 years & 0.185 & 0.105 \\
Share of female adults 15-55 years & 0.236 & 0.096 \\
Share of male adults 55+ years & 0.026 & 0.061 \\
Share of female adults 55+ years & 0.034 & 0.070 \\
Number of male children 0-4 years & 0.833 & 0.774 \\
Number of female children 0-4 years & 0.845 & 0.770 \\
Number of male children 5-14 years & 0.967 & 1.093 \\
Number of female children 5-14 years & 0.898 & 1.020 \\
Number of male adults 15-55 years & 1.175 & 0.762 \\
Number of female adults 15-55 years & 1.491 & 0.773 \\
Number of male adults 55+ years & 0.176 & 0.386 \\
Number of female adults 55+ years & 0.220 & 0.434 \\
\hline Observations & 2,497 & \\
\hline
\end{tabular}

For adults, the equivalence ratios could go either way. For adults aged $15-$ 55 years, 12 of the ratios are positive while four are negative. The largest ratio is for education expenditures, which makes sense as the younger part of this age group may still be in school. They would also be more likely to be in secondary or tertiary education, which carries higher costs than primary school. The outlay equivalence ratios for total adult goods for both males and females are positive and significant, and very similar at 0.57 for males and 0.58 for female. There is a higher number of negative ratios for older adults, 10 out of 16 . For elderly females, the ratio for all 
adult goods is positive and significantly different from zero, but about half the size of the ratio for prime-aged adults. This is particularly driven by a positive ratio on educational expenditures for adults, which may seem strange. A potential explanation could be that older females are more supportive of the secondary education of older children in the household.

The next step is to test for the equality of $\pi$-ratios between males and females. A simple F-test of the equality of the coefficient in the Engel curve estimation, is sufficient to test for any discrimination between boys and girls in the household (Deaton, 1989). The results of this exercise are presented in Table 4.3. Equality of the $\pi$-ratios is accepted in all but one case: the ratios of adult education expenditures when all four groups of children are considered. All in all, there is very little evidence that any boy-girl discrimination exists among households in the LEAP 1000 sample.

The final step in this analysis is to test whether the adult goods in the analysis are valid or exclusive adult goods. Deaton (1989) proposes a test of separability with the basic idea that the number of children will affect the total expenditure on adult goods, but not the allocation within adult goods, given expenditure on adult goods. This can be tested by regressing the expenditure on each adult good on total expenditure on adult goods and the number of household members in the various age and sex groups. If these goods are truly adult goods, the age and gender of the children should have no effect in this regression, i.e. the combined effect of their coefficients is zero, which can be tested by an F-test after the regression. As Deaton (1989) discusses, there could be a problem with regressing the expenditure of one adult good on total expenditure on adult goods due to simultaneity bias, in a context where adult goods only constitute a minor share of total expenditures, as is the case here. The solution is to estimate a twostaged model, using total household expenditure as an instrument for total expenditure on adult goods in the first stage.

The F-tests are expected to be insignificant (accepting the hypothesis that their combined effect is not different from zero) for children, but not necessarily for adults. As depicted in Table 4.4, this hypothesis is accepted for six out of seven goods for children $0-4$ years and six out of seven goods for children $5-14$ years. When combining the two age groups, there are three rejections (at the 10 percent level). This is partly due to the difference in $\pi$-ratios for adult education and health expenditures which, as argued above, may benefit older children but not younger children. All in all, there is no overwhelming evidence that the choice of adult goods is incorrect.

As a robustness check, the analysis is also conducted for small and large households separately, using the median household size of six members as a cutoff. Especially in larger households with more children, parents may need to make stronger trade-offs and gender bias could be more easily detectable. Results (not shown) are not substantially different from the results presented here. 
In sum, the outlay equivalence analysis shows that as expected, most of the ratios for children are negative, but very few are significantly different from zero. One notable exception is the outlay equivalence ratio for all adult goods for girls 0 -4 years old. This ratio implies that an additional female child $0-4$ years old in the household is like a reduction in the demand for adult goods equivalent to a 52 percent decrease in per capita expenditures. This effect is within a range of effects found in the literature, for example -22 percent for girls $0-4$ years old in Ivory Coast, -63 percent and -23 percent for girls aged $0-2$ and $3-4$ years old respectively in Thailand (Deaton, 1989) and -34 percent for girls $0-6$ years old in Papua New Guinea (Gibson and Rozelle, 2004). None of the ratios is significantly different between male and female children, suggesting that there exists no systematic bias towards either sex in the LEAP 1000 sample. Outlay equivalence ratios for prime-age adults are predominantly positive, and significant in the case of education and all adult goods. For older males, none of the ratios are significantly different from zero, but the addition of an older female in the household, results in increased expenditures on health, education and meals outside the home, and a reduction in expenditures on alcohol and tobacco, recreation and transportation and communication. Also, in the case of adults, none of the ratios differs significantly by gender. 


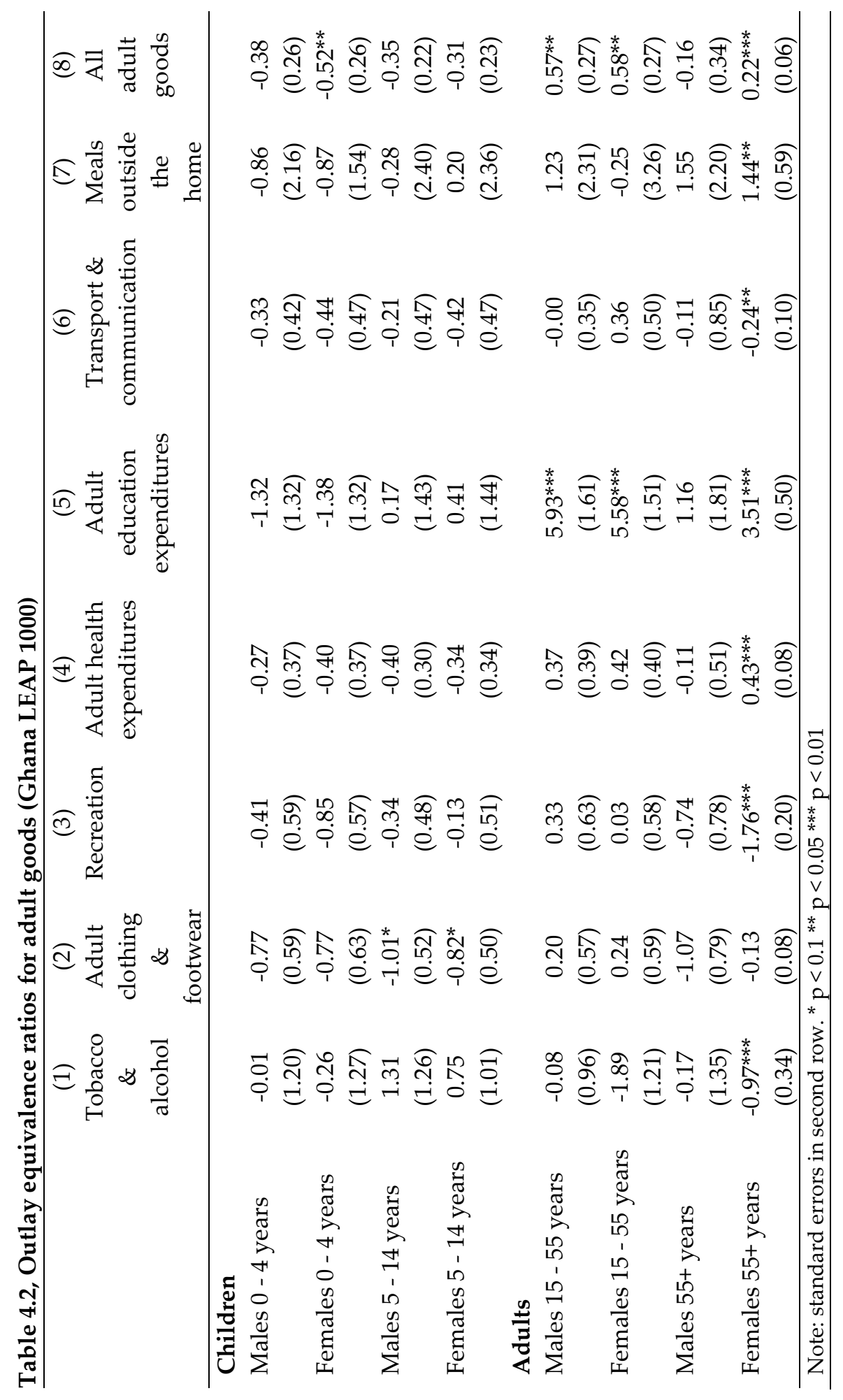




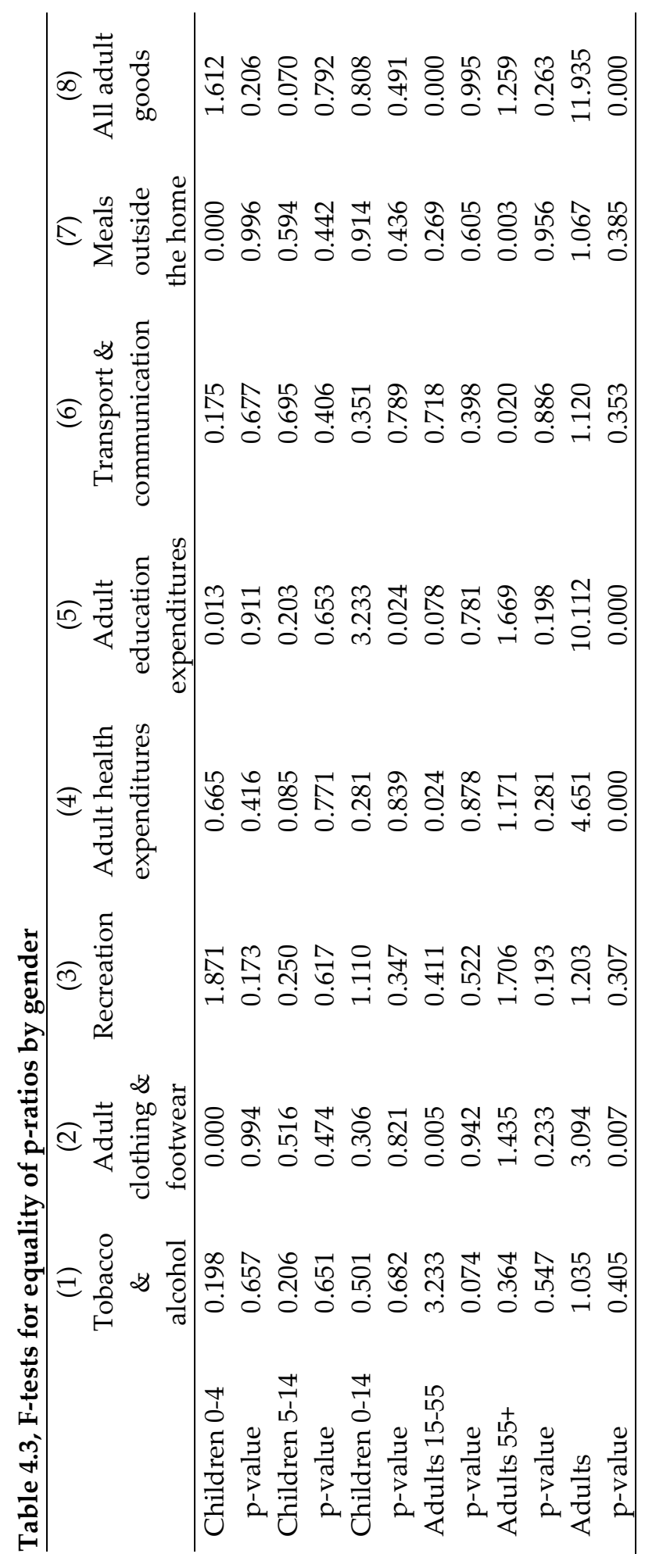




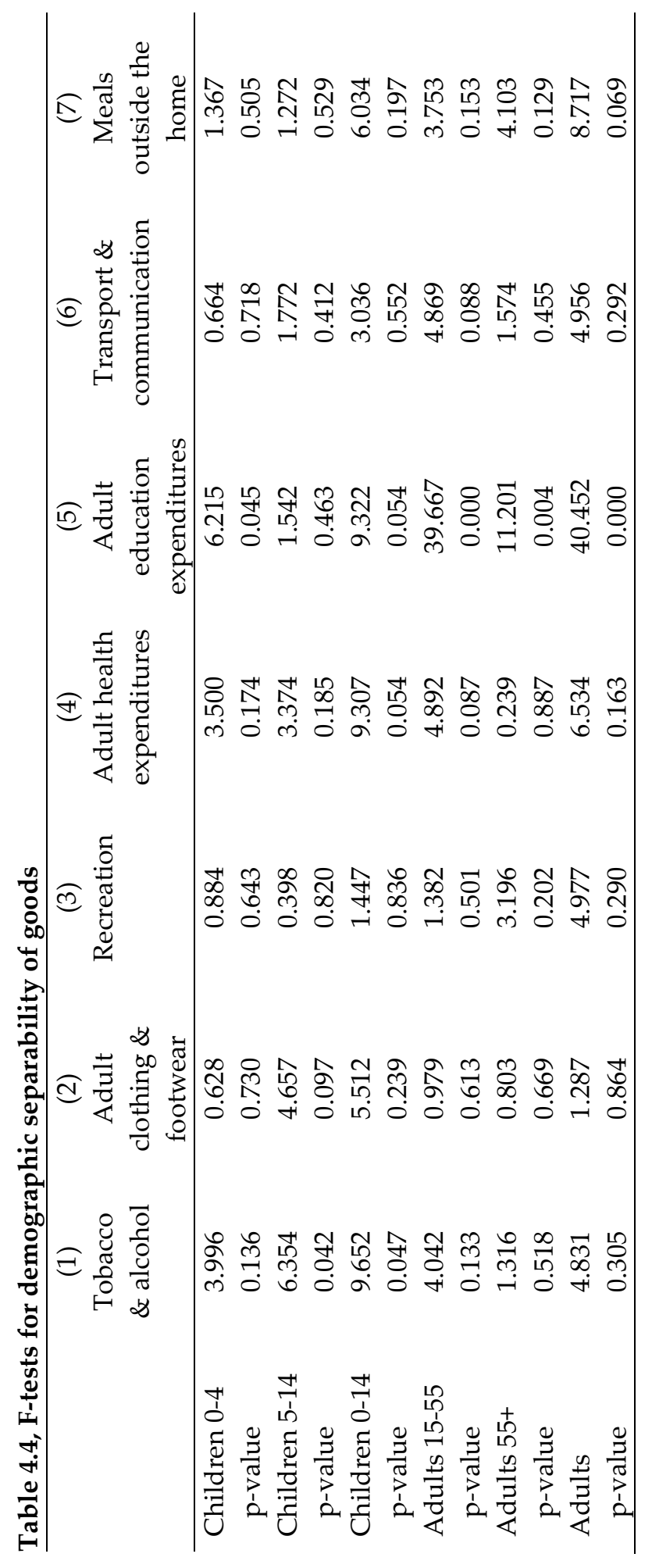




\subsubsection{The effect of parental education on educational achievement and nutritional status of sons and daughters}

This section presents the results from the analysis using parental education as a proxy for bargaining power in the household. If educational achievement of the father (mother) has a larger effect on the education and/or nutrition of their sons (daughters), this would be suggestive of non-common preferences within the household. Table 4.5 lists the variables used in the analysis on educational achievement of children. Only children of normal school age are used in the analysis, and to test whether there are any different results by primary and secondary education, the sample is also split into primary school aged children (611 years) and secondary school aged children ( $12-17$ years). Only households that have two or more children in the relevant age range are included to allow the estimation of a household fixed effects model comparing children within the same household. Recall that the analysis uses two educational indicators. First, the deviation from the cohort mean, which is a measure of how well a child is doing compared to peers of his or her age. The mean of this variable is, as it should be, zero. The second indicator is an input indicator, educational expenditure. This measure attempts to identify the actual inputs parents invest in their children. Parents spend on average $60 \mathrm{GH} \not$ on educational costs during a school year, and secondary education carries more costs than primary education. The educational attainment of parents is poor, with mothers having completed on average 0.34 years of schooling. The number is more than double for fathers, but still on average less than one year of schooling. In only 5 percent of the cases, the mother has achieved a higher level of education than the father.

Tables 4.6 (deviation from cohort means) and 4.7 (expenditures) present the results with respect to individual educational outcomes and inputs. Educational achievement as measured by deviation of the cohort mean seems to increase with higher levels of paternal education, and this effect is particularly strong among older children (12 - 17 years). This main effect is significantly different between fathers and mothers in the total sample of children (at the 10 percent level), but not in any of the subgroups. The interaction effect between mother's education and the daughter dummy is positive and significant in the younger cohort, suggesting that girls with better educated mothers do better relative to children of the same age. However, when accounting for the total effects of parental education, the effect of father's education is not significantly different from the effect of mother's education. 
Table 4.5, Variables used in the analysis on educational outcomes

\begin{tabular}{|c|c|c|c|c|c|c|}
\hline \multirow[t]{2}{*}{ Variable } & \multicolumn{2}{|c|}{$\begin{array}{c}\text { All children } 6 \text { - } \\
17 \text { years }\end{array}$} & \multicolumn{2}{|c|}{$\begin{array}{l}\text { Children } 6 \text { - } \\
11 \text { years }\end{array}$} & \multicolumn{2}{|c|}{$\begin{array}{l}\text { Children } 12 \text { - } \\
17 \text { years }\end{array}$} \\
\hline & Mean & SD & Mean & SD & Mean & SD \\
\hline $\begin{array}{l}\text { Education (deviation from } \\
\text { cohort mean) }\end{array}$ & 0.00 & 1.58 & 0.00 & 0.95 & -0.07 & 2.52 \\
\hline $\begin{array}{l}\text { Educational expenditures } \\
(\mathrm{GH} \varnothing)\end{array}$ & 60.04 & 98.28 & 50.33 & 72.60 & 76.74 & 136.77 \\
\hline $\begin{array}{l}\text { Educational expenditures } \\
\text { (transformed) }\end{array}$ & 3.25 & 2.29 & 3.11 & 2.25 & 3.30 & 2.46 \\
\hline Sex $=$ Female & 0.47 & 0.50 & 0.46 & 0.50 & 0.46 & 0.50 \\
\hline Age in years & 10.17 & 3.13 & 8.28 & 1.72 & 14.10 & 1.72 \\
\hline Age in years squared & 113.18 & 68.49 & 71.59 & 29.04 & 201.91 & 49.30 \\
\hline $\begin{array}{l}\text { Education of mother in } \\
\text { years }\end{array}$ & 0.34 & 1.53 & 0.37 & 1.63 & 0.23 & 1.25 \\
\hline $\begin{array}{l}\text { Education of father in } \\
\text { years }\end{array}$ & 0.92 & 2.79 & 0.91 & 2.74 & 0.87 & 2.88 \\
\hline $\begin{array}{l}\text { Mother has higher } \\
\text { education than father }\end{array}$ & 0.05 & 0.21 & 0.05 & 0.21 & 0.03 & 0.18 \\
\hline Observations & \multicolumn{2}{|c|}{3,298} & \multicolumn{2}{|c|}{1,941} & \multicolumn{2}{|c|}{677} \\
\hline
\end{tabular}

Also, in the fixed effects regressions, there does not seem to be any indication of preferences towards boys or girls. None of the coefficients of the interaction terms between the female dummy and parental education is statistically significant. In addition, the difference between the effect of mother's education and father's education is not significant. The Hausman test rejects the random effects model in favour of the fixed effects model in all cases.

Table 4.7 reports results on educational expenditures. As expected, older children require more educational expenditures, consistent with the idea that schooling becomes more expensive in higher grades. Both maternal and paternal schooling is associated with higher expenditures on children, suggesting that better educated parents spend more on the education of their children. The interaction effects are mostly insignificant, except in two cases of the FE models. For secondary school aged children, there is a negative interaction effect of mother's education with the female dummy, suggesting that more educated mothers spend less on their older daughters. The total effect of mother's education is not significantly different from the effect of father's education though. For younger children, more educated fathers tend to spend more on daughters of primary school age, and this effect is significantly different from the effect of mother's education. 
As a sensitivity check, a dummy is included in the regression indicated whether the mother has achieved a higher level of education than the father. In addition, an interaction between this dummy and the daughter dummy is included. If education is a good proxy for bargaining power in the household, a mother with higher education than her spouse should be able to better exert her preferences and allocate resources accordingly (Thomas, 1994). This dummy is not significant in all models (Tables S4.1 and S4.2 in the Appendix to this chapter). In the fixed effects regressions, however, the interaction between the daughter dummy and whether the mother has higher education than the father, is negative and significant. This suggests that mothers prefer to invest less in their daughters if they have higher education than their spouses. In the disaggregated age groups, the effect is still negative but not significant. In addition, the total effect of mother's education versus father's education is not significantly different in any of the models. For educational expenditures, the same applies. The dummy and the interaction term are not significant in any of the models. In addition, the significant difference between the effect of father's and mother's education for the younger age group disappears.

Finally, the analysis is conducted using dummy indicators for parental indicators rather than years of education to account for the potential non-linear relation of parental education with educational achievement of children. Due to the low levels of parental education, a dummy is created equal to one if the parent had any schooling, and equal to zero if the parent never went to school. Results are presented in Appendix Tables S4.3 and S4.4 and some interesting patterns emerge from this analysis. First, it is confirmed that children of better educated fathers perform better in school because the dummy indicator for fathers having attended school is positive and significant in the full age group and the older cohort. In the older age group, the interaction between the daughter dummy and mother's education is negative and significant, while it is positive and significant for father's education. This suggests that daughters of better educated mothers are worse off compared to children of their age, while daughters of better educated fathers are better off. The effect of parental education is significantly different between fathers and mothers in the older age group. Note that in this analysis, the random effects model is preferred over the fixed effects model and OLS, but the results are quite consistent across the different specifications. ${ }^{33}$

In terms of educational expenditures, similar findings emerge as well. Parents who attained at least some schooling tend to spend more on the education of their offspring. Again, the interaction effect of father's education with the female

${ }^{33}$ Including the dummy for mothers who have higher educational achievement than fathers, does not change these results substantially (results not shown but available upon request). 
dummy is positive and significant for the younger age group, however, this effect is not significantly different from the effect of mother's education in this analysis.

This effect on educational achievement for the older cohort of children is perhaps better illustrated in Figure 4.1, which plots the predictions of schooling (measured as deviation from the cohort mean) with their estimated confidence intervals under four scenarios, disaggregated by sex of the child. In households where both parents have achieved some schooling (first row of the graph) the predicted effect for boys is significantly positive, while that for girls is insignificant. The second row shows that in households where the mother has gained some education, but the father hasn't, the predicted effects on girls are negative, while the effect for boys in such households are close to zero. In contrast, girls who have a father with some schooling and a mother with no schooling, are predicted to have completed more years of schooling compared to their peers of the same age. For boys in such households this effect is not different from zero. The analysis in Table S4.3 shows that these effects of parental education on boys are significantly different from the effect on girls. However, the analysis in Table S4.4 revealed that differences in inputs (expenditures) cannot explain these differences, and therefore other mechanisms are probably at stake here.

\section{Figure 4.1, Prediction of schooling by maternal and paternal schooling, disaggregated by sex (with $95 \% \mathrm{CI}$ )}

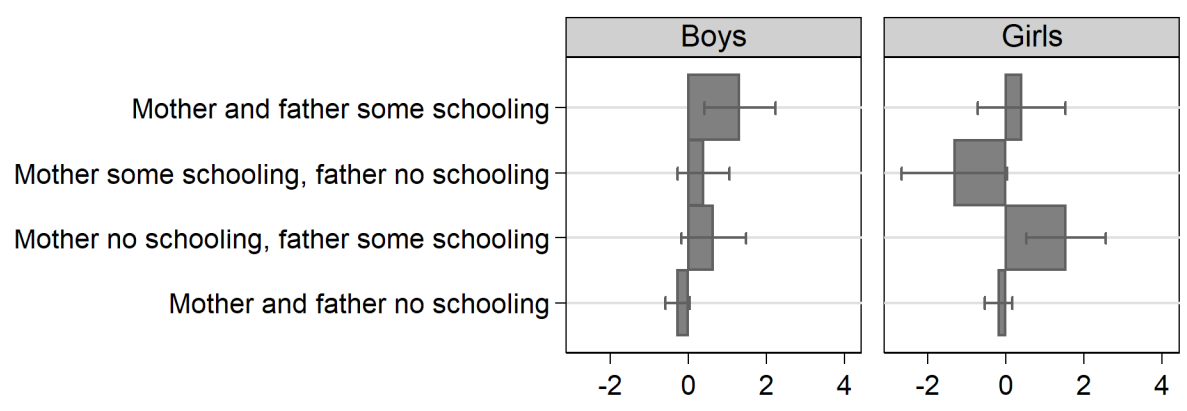

Education: deviation from cohort mean

Note: only children aged $12-17$ years old are included in the graph 
Table 4.6, Effects of husband's and wife's human capital on children's education, deviation from cohort means

\begin{tabular}{|c|c|c|c|c|c|c|}
\hline & $(1)$ & $(2)$ & (3) & $(4)$ & $(5)$ & (6) \\
\hline & \multicolumn{2}{|c|}{$\begin{array}{c}\text { Children } 6 \text { - } 17 \\
\text { years }\end{array}$} & \multicolumn{2}{|c|}{$\begin{array}{l}\text { Children } 6 \text { - } 11 \\
\text { years }\end{array}$} & \multicolumn{2}{|c|}{$\begin{array}{c}\text { Children } 12 \text { - } 17 \\
\text { years }\end{array}$} \\
\hline & OLS & $\begin{array}{l}\text { Fixed } \\
\text { effects }\end{array}$ & OLS & $\begin{array}{l}\text { Fixed } \\
\text { effects }\end{array}$ & OLS & $\begin{array}{l}\text { Fixed } \\
\text { effects }\end{array}$ \\
\hline \multicolumn{7}{|l|}{ Child characteristics } \\
\hline Sex $=$ female & $\begin{array}{c}0.050 \\
(0.061)\end{array}$ & $\begin{array}{c}0.017 \\
(0.070)\end{array}$ & $\begin{array}{c}0.011 \\
(0.054)\end{array}$ & $\begin{array}{c}0.030 \\
(0.063)\end{array}$ & $\begin{array}{c}0.111 \\
(0.215)\end{array}$ & $\begin{array}{c}0.066 \\
(0.209)\end{array}$ \\
\hline Age in years & $\begin{array}{l}-0.023 \\
(0.077)\end{array}$ & $\begin{array}{l}-0.002 \\
(0.072)\end{array}$ & $\begin{array}{l}-0.030 \\
(0.111)\end{array}$ & $\begin{array}{c}0.104 \\
(0.112)\end{array}$ & $\begin{array}{l}-0.221 \\
(1.153)\end{array}$ & $\begin{array}{c}0.598 \\
(1.064)\end{array}$ \\
\hline $\begin{array}{l}\text { Age in years } \\
\text { squared }\end{array}$ & $\begin{array}{c}0.001 \\
(0.004)\end{array}$ & $\begin{array}{c}0.001 \\
(0.004)\end{array}$ & $\begin{array}{c}0.002 \\
(0.007)\end{array}$ & $\begin{array}{l}-0.005 \\
(0.007)\end{array}$ & $\begin{array}{c}0.008 \\
(0.041)\end{array}$ & $\begin{array}{l}-0.021 \\
(0.038)\end{array}$ \\
\hline \multicolumn{7}{|l|}{ Parental education } \\
\hline $\begin{array}{l}\text { Maternal schooling } \\
\text { in years }\end{array}$ & $\begin{array}{l}-0.007 \\
(0.016)\end{array}$ & & $\begin{array}{l}-0.014 \\
(0.011)\end{array}$ & & $\begin{array}{c}0.041 \\
(0.099)\end{array}$ & \\
\hline $\begin{array}{l}\text { Paternal schooling } \\
\text { in years }\end{array}$ & $\begin{array}{l}0.036^{* *} \\
(0.015)\end{array}$ & & $\begin{array}{c}0.013 \\
(0.012)\end{array}$ & & $\begin{array}{l}0.135^{* * *} \\
(0.041)\end{array}$ & \\
\hline \multicolumn{7}{|l|}{ Interaction term } \\
\hline $\begin{array}{l}\text { Female } x \text { mother's } \\
\text { education }\end{array}$ & $\begin{array}{c}0.022 \\
(0.026)\end{array}$ & $\begin{array}{l}-0.004 \\
(0.026)\end{array}$ & $\begin{array}{l}0.051^{* *} \\
(0.021)\end{array}$ & $\begin{array}{c}0.028 \\
(0.024)\end{array}$ & $\begin{array}{l}-0.090 \\
(0.122)\end{array}$ & $\begin{array}{l}-0.161 \\
(0.124)\end{array}$ \\
\hline $\begin{array}{l}\text { Female } x \text { father's } \\
\text { education }\end{array}$ & $\begin{array}{l}-0.005 \\
(0.017)\end{array}$ & $\begin{array}{c}0.004 \\
(0.021) \\
\end{array}$ & $\begin{array}{c}0.004 \\
(0.017) \\
\end{array}$ & $\begin{array}{c}0.022 \\
(0.020) \\
\end{array}$ & $\begin{array}{l}-0.021 \\
(0.051) \\
\end{array}$ & $\begin{array}{c}0.061 \\
(0.047) \\
\end{array}$ \\
\hline
\end{tabular}

F-test on main effects (p-value)

Father's schooling $=$

Mother's schooling

0.082

0.173

0.406

F-test on total effect (p-value)

Father's schooling $=$

Mother's schooling

0.534

0.381

0.179

F-test on interaction effect (p-value)

Father's schooling =

Mother's schooling

0.811

0.833

0.114

FE vs. RE (p-value)

0.006

0.019

0.075

RE vs. OLS (p-value)

0.000

0.000

0.000

R-squared

0.022

0.023

0.045

Observations

3,298

3,298

1,941

1,941

677

677

Notes: Cluster-robust standard errors reported in brackets. ${ }^{*} \mathrm{p}<0.1^{* *} \mathrm{p}<0.05^{* * *} \mathrm{p}<0.01$ 
Table 4.7, Effects of husband's and wife's human capital on children's educational expenditures (inverse hyperbolic sine transformed)

\begin{tabular}{|c|c|c|c|c|c|c|}
\hline & $(1)$ & $(2)$ & (3) & $(4)$ & (5) & (6) \\
\hline & \multicolumn{2}{|c|}{$\begin{array}{c}\text { Children } 6 \text { - } 17 \\
\text { years }\end{array}$} & \multicolumn{2}{|c|}{$\begin{array}{c}\text { Children } 6-11 \\
\text { years }\end{array}$} & \multicolumn{2}{|c|}{$\begin{array}{c}\text { Children } 12-17 \\
\text { years }\end{array}$} \\
\hline & OLS & $\begin{array}{l}\text { Fixed } \\
\text { effects }\end{array}$ & OLS & $\begin{array}{c}\text { Fixed } \\
\text { effects }\end{array}$ & OLS & $\begin{array}{c}\text { Fixed } \\
\text { effects }\end{array}$ \\
\hline \multicolumn{7}{|l|}{ Child characteristics } \\
\hline Female & $\begin{array}{c}0.052 \\
(0.084)\end{array}$ & $\begin{array}{l}-0.031 \\
(0.096)\end{array}$ & $\begin{array}{l}-0.037 \\
(0.111)\end{array}$ & $\begin{array}{l}-0.050 \\
(0.116)\end{array}$ & $\begin{array}{c}0.050 \\
(0.221)\end{array}$ & $\begin{array}{c}0.123 \\
(0.266)\end{array}$ \\
\hline Age in years & $\begin{array}{l}0.719^{* * *} \\
(0.094)\end{array}$ & $\begin{array}{l}0.776^{* * *} \\
(0.086)\end{array}$ & $\begin{array}{l}0.570^{*} \\
(0.298)\end{array}$ & $\begin{array}{l}0.846^{* * *} \\
(0.228)\end{array}$ & $\begin{array}{c}0.956 \\
(1.168)\end{array}$ & $\begin{array}{c}1.832 \\
(1.225)\end{array}$ \\
\hline $\begin{array}{l}\text { Age in years } \\
\text { (squared) }\end{array}$ & $\begin{array}{c}-0.030^{* * * *} \\
(0.004)\end{array}$ & $\begin{array}{l}-0.033^{* * * *} \\
(0.004)\end{array}$ & $\begin{array}{l}-0.020 \\
(0.018)\end{array}$ & $\begin{array}{l}-0.037^{* * * *} \\
(0.014)\end{array}$ & $\begin{array}{l}-0.039 \\
(0.041)\end{array}$ & $\begin{array}{l}-0.070 \\
(0.043)\end{array}$ \\
\hline \multicolumn{7}{|l|}{ Parent's education } \\
\hline $\begin{array}{l}\text { Mother's education } \\
\text { in years }\end{array}$ & $\begin{array}{c}0.115^{* * *} \\
(0.025)\end{array}$ & & $\begin{array}{l}0.115^{* * *} \\
(0.029)\end{array}$ & & $\begin{array}{l}0.104^{*} \\
(0.060)\end{array}$ & \\
\hline $\begin{array}{l}\text { Father's education } \\
\text { in years }\end{array}$ & $\begin{array}{c}0.081^{* * *} \\
(0.027)\end{array}$ & & $\begin{array}{l}0.065^{* *} \\
(0.029)\end{array}$ & & $\begin{array}{l}0.151^{* * *} \\
(0.038)\end{array}$ & \\
\hline \multicolumn{7}{|l|}{ Interaction term } \\
\hline $\begin{array}{l}\text { Female } x \text { mother's } \\
\text { education }\end{array}$ & $\begin{array}{l}-0.018 \\
(0.041)\end{array}$ & $\begin{array}{l}-0.055 \\
(0.035)\end{array}$ & $\begin{array}{l}-0.020 \\
(0.044)\end{array}$ & $\begin{array}{l}-0.037 \\
(0.028)\end{array}$ & $\begin{array}{l}-0.106 \\
(0.135)\end{array}$ & $\begin{array}{l}-0.194^{* *} \\
(0.088)\end{array}$ \\
\hline $\begin{array}{l}\text { Female } x \text { father's } \\
\text { education }\end{array}$ & $\begin{array}{c}0.000 \\
(0.026)\end{array}$ & $\begin{array}{c}0.010 \\
(0.024) \\
\end{array}$ & $\begin{array}{c}0.036 \\
(0.038) \\
\end{array}$ & $\begin{array}{l}0.061^{* *} \\
(0.028) \\
\end{array}$ & $\begin{array}{l}-0.066 \\
(0.057) \\
\end{array}$ & $\begin{array}{l}-0.068 \\
(0.048) \\
\end{array}$ \\
\hline
\end{tabular}

F-tests on "main effects" (p-value)

Father's schooling =

Mother's schooling

0.425

0.309

0.496

F-test on equality of total effects (p-value)

Father's schooling $=$

Mother's schooling

0.781

0.936

0.613

F-test on interaction terms with daughter dummy (p-value)

Father's schooling =

Mother's schooling

0.148

0.034

0.224

FE vs. RE (p-value)

0.001

0.005

0.279

RE vs. OLS (p-value)

0.000

0.000

0.000

Observations $3,298 \quad 3,298$ 1,941 1,94 677 677

Notes: Cluster-robust standard errors reported in brackets. ${ }^{*} p<0.1{ }^{* *} p<0.05^{* * *} p<0.01$ 
The final analysis in this chapter to examine intra-household dynamics uses nutritional status of young children as an outcome. The key indicator for longterm nutritional status is height-for-age (HAZ), which reflects cumulative growth. It is widely recognised that children all over the world have the same growth potential in early childhood, given the right conditions, such as adequate feeding and low exposure to infectious diseases (WHO and Onis, 2006). Since this chapter is interested in differences in intra-household preferences, deviations from normal growth best reflect such preferences because such deviations represent former investment decisions in children. Table 4.8 presents the key variables used in this analysis. Children's raw heights are converted to z-scores using the WHO growth reference tables (WHO Multicentre Growth Reference Study Group and Onis, 2006). The mean z-score for all children in the sample is -1.25 indicating that the average child in the sample has a growth deficit of 1.25 standard deviations compared to the median of a healthy reference population from the WHO standards. The infant and young child feeding (IYCF) index also underscores the poor feeding practices in our sample, with an average score of 3.23 out of the maximum of six points. Education of the parents is again low, with mothers having completed on average less than one year of schooling, and fathers nearly 1.5 years. The analysis includes only children living in households where at least two children in the age group are present. A similar statistical procedure is conducted as with the educational analysis above: OLS with robust standard errors, and subsequently a fixed effects and random effects model. The analysis is disaggregated by age group, with the cut-off at 24 months. Note however, that the number of observations drops drastically when disaggregating by subgroup, as the analysis requires two children of the same age group in the household for the FE models.

The results of the analysis on HAZ are presented in Table 4.9. The main effect of father's education on HAZ is positive, and statistically significant in two of the three OLS models. For example, an additional year of paternal education is associated with an increase of nearly 0.1 SD in HAZ for the older age group. The difference in the main effect of paternal and maternal education is significant in both subsamples disaggregated by age. The total effect of paternal education is also significant different in all groups. The Hausman tests indicate that with respect to $\mathrm{HAZ}$, a random effects approach is preferred over a fixed effects model. This is an indication that individual heterogeneity plays a bigger role in the determination of height-for-age. In the RE models, the total effect of paternal education is consistently larger and statistically significantly different from maternal education. This suggests that daughters from higher educated fathers are better-off compared to sons. The different effect of maternal versus paternal schooling is perhaps again better illustrated in a graph. Figure 4.2 plots the linear prediction of HAZ (using the estimates from the preferred RE model) for all values of paternal and maternal schooling, disaggregated by sex. The left graph shows that HAZ of girls is 
predicted to decrease when maternal schooling increases, while the line of boys is flat. For paternal schooling (right graph), the predicted value of HAZ increases for girls with higher levels of paternal schooling. The results in Table 4.9 show that this effect on girls is significantly different between fathers and mothers.

Table 4.8, Variables used in the analysis on nutritional outcomes

\begin{tabular}{|c|c|c|c|c|c|c|}
\hline \multirow[t]{2}{*}{ Variable } & \multicolumn{2}{|c|}{$\begin{array}{l}\text { All children } 4 \text { - } \\
59 \text { months }\end{array}$} & \multicolumn{2}{|c|}{$\begin{array}{c}\text { Children } 4-23 \\
\text { months }\end{array}$} & \multicolumn{2}{|c|}{$\begin{array}{c}\text { Children } 24 \text { - } 59 \\
\text { months }\end{array}$} \\
\hline & Mean & SD & Mean & SD & Mean & SD \\
\hline Height-for-age z-score & -1.25 & 1.70 & -1.18 & 1.90 & -1.68 & 1.40 \\
\hline IYCF index & 3.23 & 1.36 & 3.83 & 1.52 & 2.84 & 1.20 \\
\hline $\begin{array}{l}\text { IYCF index } \\
\text { (standardized) }\end{array}$ & -0.04 & 0.98 & 0.39 & 1.10 & -0.32 & 0.87 \\
\hline Female & 0.50 & 0.50 & 0.51 & 0.50 & 0.48 & 0.50 \\
\hline Age in months & 28.47 & 17.85 & 12.20 & 5.17 & 41.85 & 10.24 \\
\hline Age in months squared & 1128.97 & 1065.73 & 175.37 & 132.50 & 1855.88 & 841.03 \\
\hline $\begin{array}{l}\text { Education of mother in } \\
\text { years }\end{array}$ & 0.78 & 2.21 & 0.96 & 2.72 & 0.42 & 1.60 \\
\hline $\begin{array}{l}\text { Education of father in } \\
\text { years }\end{array}$ & 1.35 & 3.15 & 1.56 & 3.59 & 0.56 & 1.97 \\
\hline $\begin{array}{l}\text { Mother higher } \\
\text { education than father }\end{array}$ & 0.10 & 0.30 & 0.07 & 0.26 & 0.07 & 0.26 \\
\hline Observations & \multicolumn{2}{|c|}{1,638} & \multicolumn{2}{|c|}{134} & \multicolumn{2}{|c|}{326} \\
\hline
\end{tabular}

Again, several sensitivity checks are performed. Including the dummy identifying mothers with higher education than fathers does not change the results substantially (Table S4.5 in the Appendix). However, using dummies for parental education instead of years of education, results in the loss of significance of the effect of father's education on HAZ. This could be because the effect of paternal education only kicks in after several years of education (i.e. the intensive margin), rather than at the extensive margin of whether the father ever went to school or not.

When we look at inputs (infant and young child feeding), we find no differential effects of father's education and mother's education in the full sample (Table 4.10). In the younger subsample however, we find a negative main effect of mother's education $(-0.12 \mathrm{SD})$ and a positive main effect of father's education (0.09 $\mathrm{SD}$ ) on IYCF and this difference is significant at the 5 percent level. The interaction terms are both insignificant, but the total effect difference between father's and mother's education is still significantly different. This again suggests that daughters of better educated fathers are better off, especially when they are very young. For the older subsample, the interaction effect for mother's education is 
negative and significant (-0.09 SD in the RE model), but the overall effect is not different between mother's and father's education. For the younger subsample, including the dummy for mothers with higher education than their spouses removes the significant difference for the total effect, but the difference in the main effect remains significantly different (Table S4.7, columns 4-6). The difference in the younger age group also remains significant when we use dummies for parental education rather than years (Table S4.8, columns 4-6). For the older age group, the main effect of mother's education (any schooling) is positive and significant, and significantly different from the effect of paternal education in this specification (Table S4.8, columns 7-9). However, there is no significant difference in the total effect.

We plot the predictions from this last model again to illustrate this effect (Figure 4.3). For young girls (right panel), their score on the IYCF index is large and positive when their father has some schooling and their mother none (second bar from below). But the prediction on the IYCF index is significantly lower and negative in case their mother has attained some schooling, while the father has none (third bar from below). This corroborates the findings on HAZ from above and shows that particularly in the first years of life, fathers, rather than mothers, might show a stronger preference to invest in the nutrition of their daughters. 


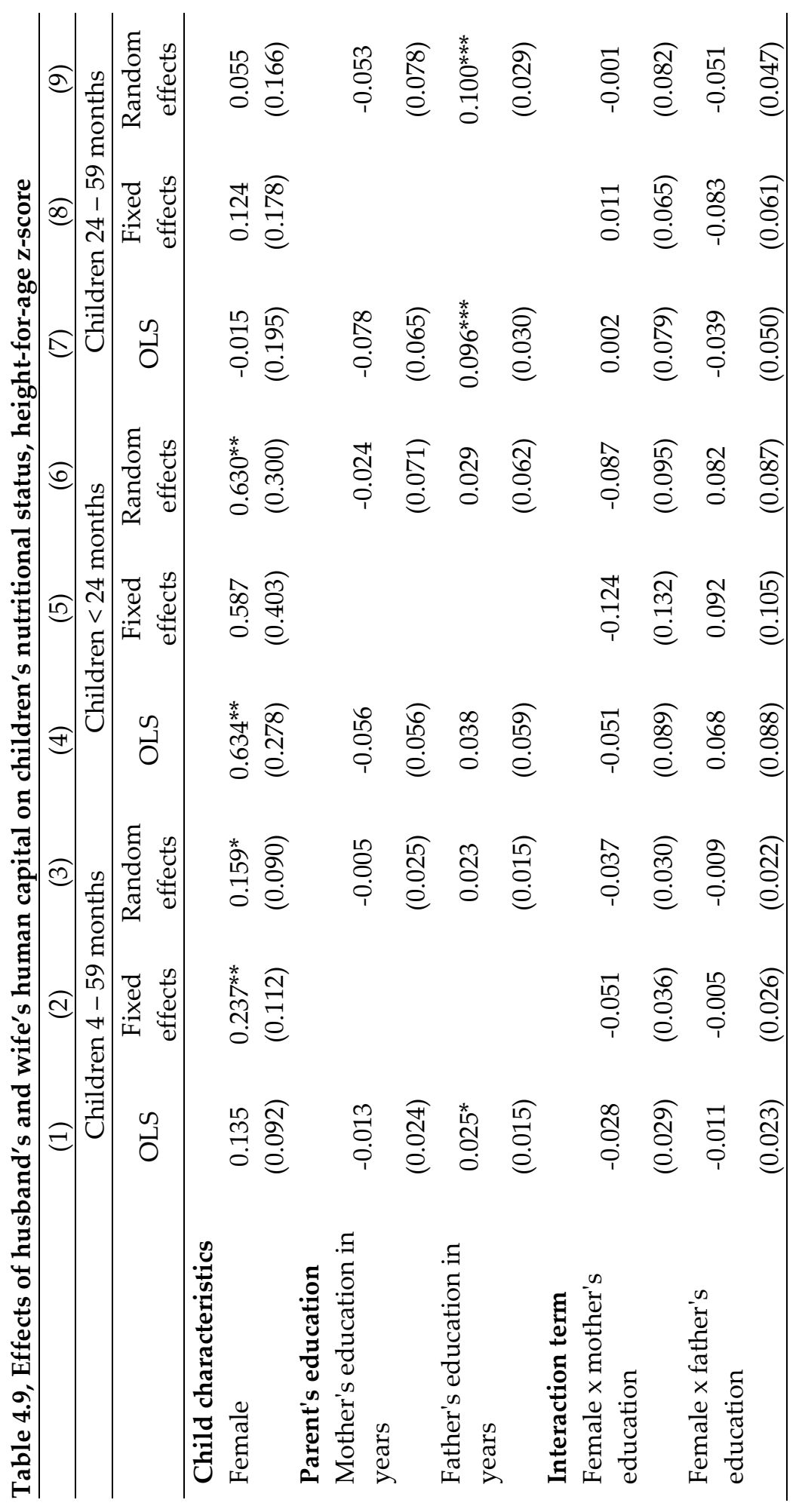




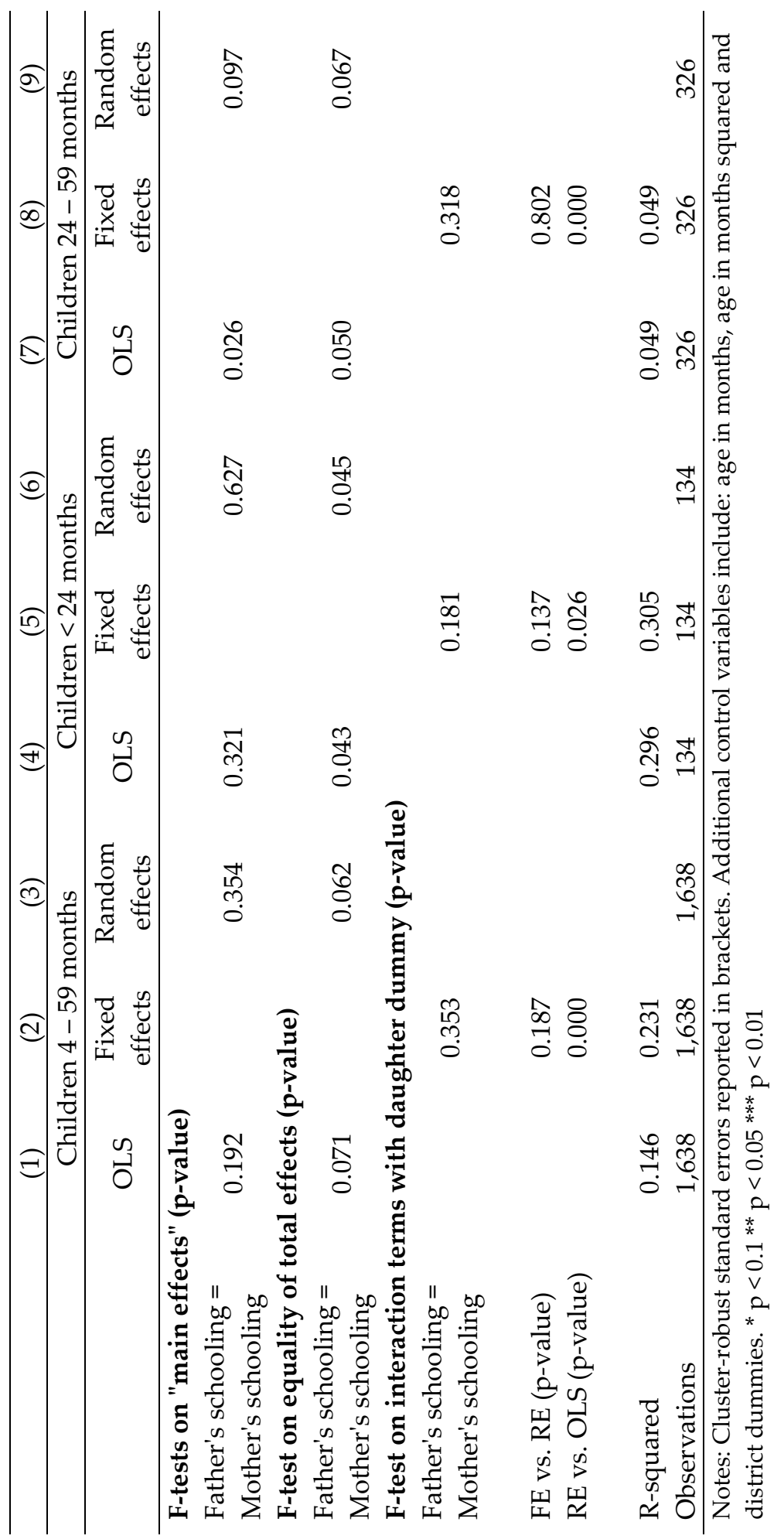



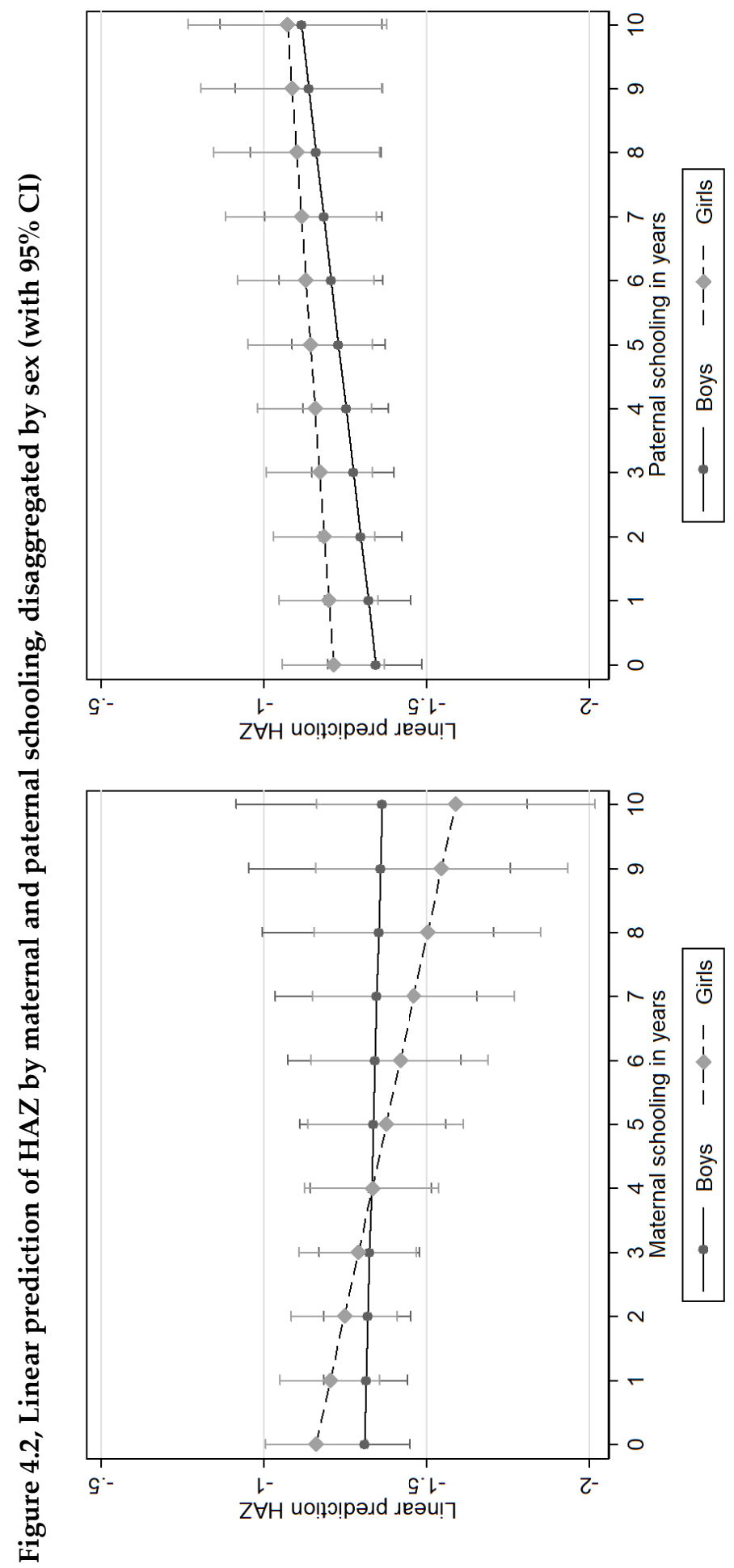


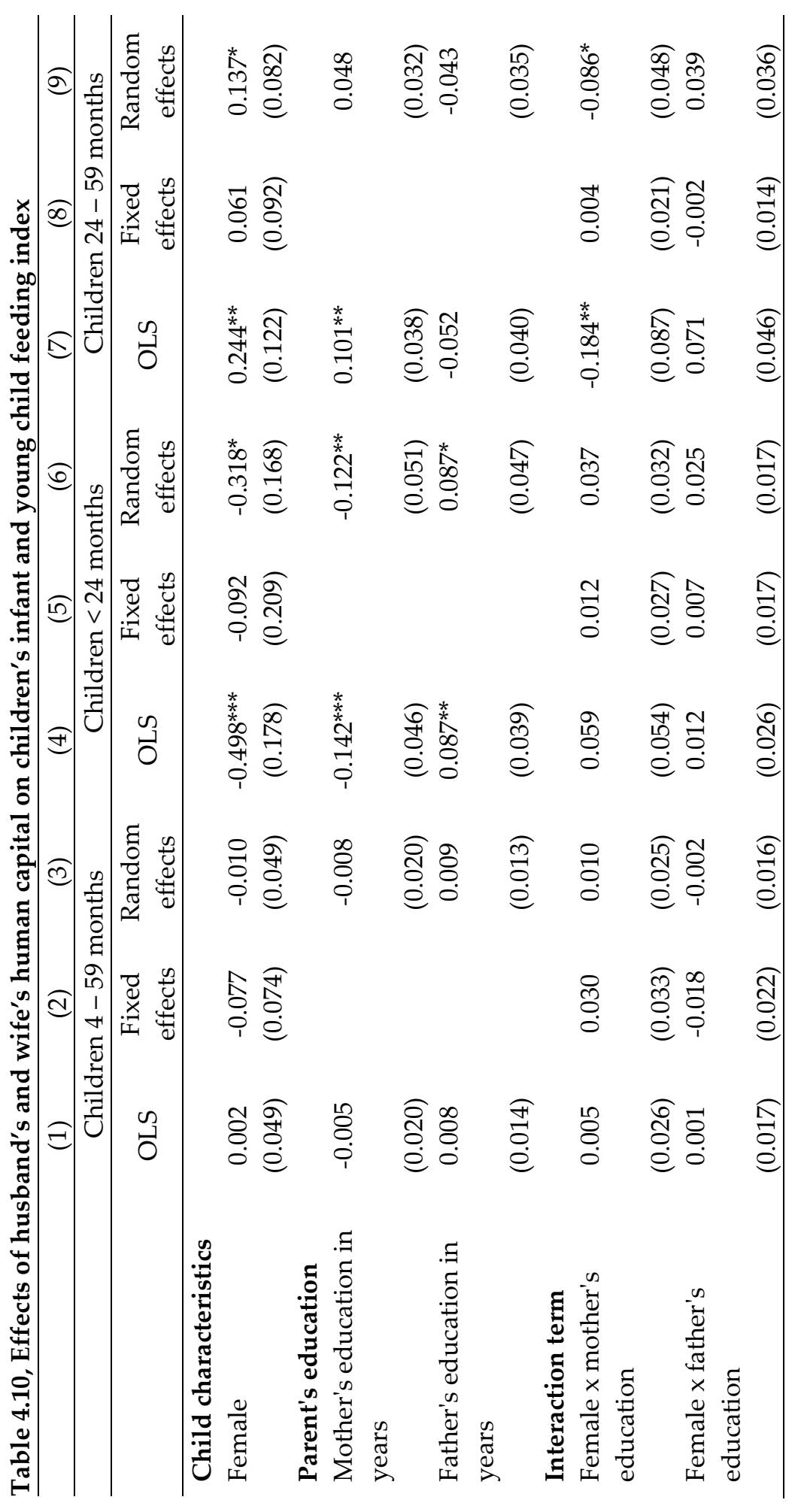




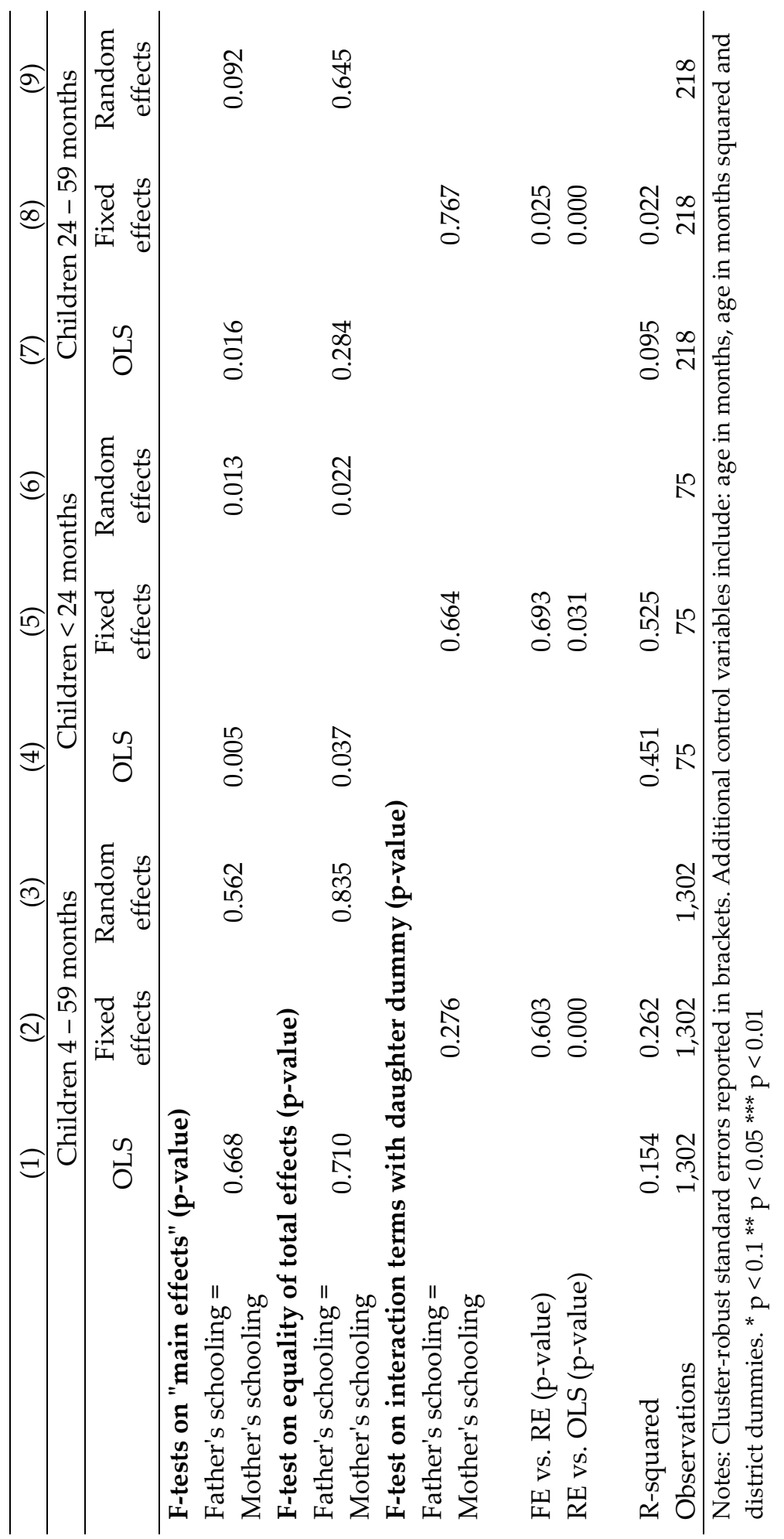




\section{Figure 4.3, Predictions of IYCF index by maternal and paternal schooling, disaggregated by sex (with $95 \% \mathrm{CI}$ )}

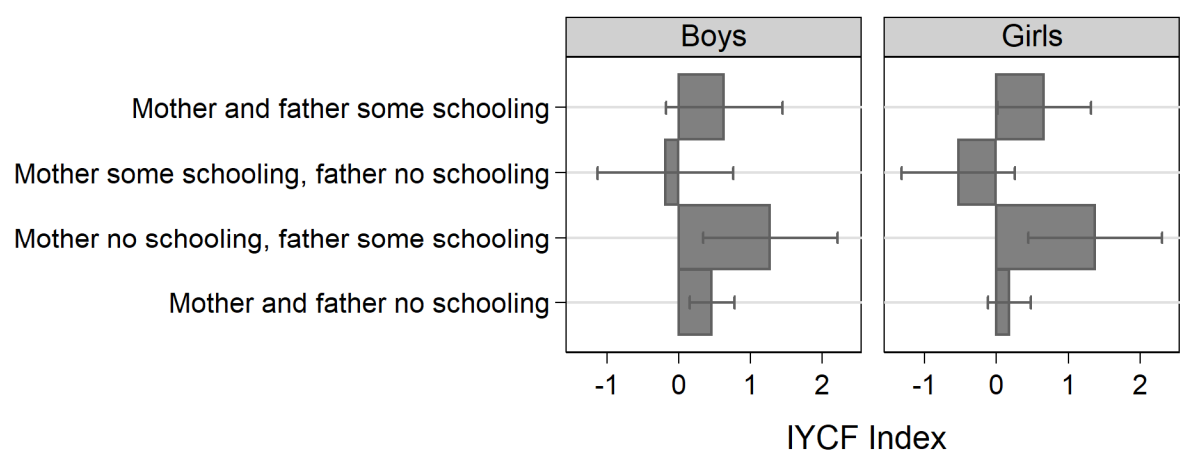

Note: this graph includes the younger children (4-23 months) only

\subsection{Discussion}

The aim of this chapter was to identify the prevailing intra-household dynamics in the sample of LEAP 1000 households before receiving any cash grants. Intrahousehold dynamics likely play a role in the effectiveness of the cash transfer and how it may impact child and household wellbeing. For example, cash in the hands of women is often thought to be invested in children whereas cash in the hands of men is not. This is the reason why many cash transfer programmes around the globe are targeted to women (Kabeer, 1999). This chapter assessed the intrahousehold dynamics using two complementary methods: outlay equivalence analysis and a test for common preferences between husband and wife. The reasoning behind the outlay equivalence analysis is that the addition of a child to a household exerts a pure negative income effect on a set of valid adult goods. If the response of the household in terms of reduced expenditure on adult goods differs between male and female children, then this can be interpreted as bias towards one of the sexes. The analysis in this chapter shows, however, that there is little evidence of systematic bias towards boys or girls as indicated by the insignificant difference between the $\pi$-ratios of boys and girls. This is not entirely surprising as in other countries in sub-Saharan Africa, no gender bias was found in Côte d'Ivoire (Deaton, 1989) and Burkina Faso (Haddad and Reardon, 1993) using similar methods.

However, Deaton's outlay equivalence method is criticized by some because in certain cases where pro-male bias is expected, the method fails to reveal any significant bias towards boys (Gibson and Rozelle, 2004). Reasons proposed for the failure of the method include the relatively low share of valid adult goods 
in households budgets and the fact that some adult goods, such as tobacco and alcohol, are addictive and might therefore not respond well to an addition of children in the household (Strauss et al., 2000). ${ }^{34}$ The total share of adult goods in the current analysis (10.3 percent), however, is quite large in comparison to other studies and nearly as large as in the study of Gibson and Rozelle (2004) at 12.3 percent, who find significant pro-male bias in Papua New Guinea and larger than in the study by Fuwa (2014) at 7 percent, who finds significant bias towards older girls (5 - 15 years) in the rural Philippines. Thus, the low share of adult goods in the total household budget does not seem to be a restricting factor for finding insignificant effects in this analysis.

To further test the dynamics of intra-household allocation, this chapter employed a complementary test of the unitary versus collective model by using parental education as a source of bargaining power in the household. This approach tests whether the effect of mother's education on daughter's educational attainment and nutritional status is different from the effect of father's education on daughters, and similarly for sons. The results of this analysis show that there is some evidence that fathers have a stronger preference to invest in daughters than mothers. More specifically, girls of secondary school age (12 - 17 years) seem to benefit from living in a household where the father has received some form of formal education compared to boys. In contrast, similar girls in household where only the mother completed some formal schooling, are worse off compared to boys. This preference is not explained, however, by the amount of educational expenditure invested in their children.

Similar findings emerged from the analysis using nutritional status as outcome. More years of maternal schooling is associated with lower HAZ for girls, while higher paternal schooling is positively related to HAZ for girls. The effects of father's education on HAZ are further corroborated by similar findings on nutritional inputs (infant and young child feeding practices), especially when girls are still young. It is interesting to note that these effects appear to be driven by the construction of the schooling indicators for parents. While the analysis on educational outcomes finds primarily significant effects when the educational attainment of parents is coded as a dummy variable, indicating none versus some schooling, the effects on nutritional status (HAZ) only appear when schooling is measured in years. This could be an indication that effects on education are driven by the extensive margin of schooling (any schooling), while the effects on nutrition are driven by the intensive margin (number of years) of schooling. This is relevant for policy because it helps to understand what works better in terms of educational policy: getting more people into school or making sure that those in school stay in

\footnotetext{
${ }^{34}$ Note that this could also be the reason why the $\pi$-ratios for older children in Table 4.2 using tobacco and alcohol were positive as opposed to the expected negative.
} 
school for a longer period. The findings above suggest that both policies have different effects on the next generation.

The suggestive result that fathers, as opposed to mothers, seem to be more inclined to invest in daughters is somewhat surprising. Previous research in urban Ghana found the opposite: fathers are more interested to invest in their sons, while mothers have a preference to invest in their daughters (Thomas, 1994). The findings are also in contrast with results that show that higher women's status is generally associated with improved nutritional status of children (Maffioli et al., 2009, Smith et al., 2003). However, these studies have not focused on the difference of the effect of female autonomy on boys versus girls but rather on children in general. Overall in sub-Saharan Africa, there is little indication of a strong preference towards sons or daughters, in contrast with South Asia where a strong son bias exists. The magnitude of preferences is higher among more educated women, though (Rossi and Rouanet, 2015). In their four country study, Quisumbing and Maluccio (2000) find mixed results across countries. In Bangladesh, daughters of higher educated fathers completed fewer years of schooling compared to their brothers, and better-educated mothers seem to favour investing in the human capital of their daughters. Similarly, girls with bettereducated fathers and mothers who bring in fewer assets at marriage are also at a disadvantage in Ethiopia. There is little evidence in Indonesia on gender preferences but findings from South Africa resemble this chapter's findings in Ghana: father's education has a positive effect on their daughter's educational attainment, while mother's education has a negative effect. Quisumbing and Maluccio (2000) hypothesize that this effect is due to women relying on their sons to look after them in old-age and hence investing in boys is a long-term investment strategy. Such findings have also emerged from Senegal, where women rely on their sons in case of widowhood (Lambert and Rossi, 2016). This is especially the case for women with rivals in a polygamous marriage, as the only way for them to have access to their husband's inheritance in a patrilineal society, is by having a son. Further analysis of the data indeed shows that there is some suggestive evidence that this is also the case in Ghana. The difference between the effect of mother's and father's education on older girls is stronger in polygamous households (Table S4.9 in the Appendix to this chapter). However, this is not the case for nutritional status (results not shown), suggesting that the influence of the form of marriage is more important for older children than for younger children.

Why would fathers invest more in their daughters compared to their sons in Northern Ghana? As discussed in the introduction, this area in Ghana follows a patrilineal inheritance system such that boys inherit productive assets in the households, while girls are married off and move to live in another household. In addition, the social norm in most parts of West-Africa reflect that fathers are mainly responsible for providing food for the family (Akresh et al., 2016, Kazianga and Wahhaj, 2013). From a pure investment point of view, daughters can provide 
benefits to fathers by (i) being economically active while living in the household, and (ii) raising the value of the bride-price. Being economically active is often in conflict with being in school for older girls, while the findings in this chapter point to larger effects of father's education on girls' schooling in the older age group. Alternatively, the bride-price in sub-Saharan countries can be substantial (AbdulKorah, 2011, Anderson, 2007), and other studies have found that improved access to education has increased female education in Indonesia and Zambia, but only among ethnic groups that practice bride-price payments (Ashraf et al., 2016). Although specific information on bride-price practices are unknown in the area under study in this chapter, it can be assumed that higher educated females yield higher payments, providing an economic incentive for fathers to invest in their daughters.

Taken together, the findings in this chapter provide only limited support to the rejection of the unitary household model. The first test, using Deaton's outlay equivalence method, yielded no detectable gender bias in household expenditures. The second test, using parental education as a source of bargaining power, found some suggestive evidence that fathers tend to invest more in their daughters in terms of education and nutrition. This effect appears to be driven by years of education with the nutritional outcomes, and whether parents had any schooling in the context of educational attainment of their children. Already more than 20 years ago, Alderman et al. (1995) argued that most of the evidence pointed to non-unitary household models as the prevailing model. In the context of the LEAP 1000 cash transfer programme, a unitary household model makes it easier for policy makers, as the outcomes of the programme will not be affected by which member of the household receives the transfer. A recent review suggests that targeting transfers to women can lead to improvements in health and education for children, particularly if the transfers are conditional (Yoong et al., 2012). However, another review (having included different studies than the Yoong et al. (2012) review) concluded that the sex of the transfer recipient did not determine the impact of the transfer programmes studied (Bastagli et al., 2016). A study in Lesotho found that the impact of a cash grant led to different educational outcomes for boys and girls, favouring secondary school-aged girls, but not in households that were headed by a female (Sebastian et al., 2016). Female heads also seemed to prefer to invest in their sons in this case.

As with any study, the analysis in this chapter is limited in several ways. The data employed are not necessarily ideal to study intra-household dynamics, with the lack of individual incomes and assets. However, the chapter provides an example that even under circumstances where this is not the primary objective of the data collection efforts, some techniques are available to test hypotheses about intra-household dynamics. Furthermore, the analysis on nutritional analysis is limited by the low number of observations in the disaggregated analysis, due to 
the restriction that there need to be at least two children within the age group in the household to be included in the analysis.

\subsection{Conclusion}

This chapter sought to explore the dynamics of intra-household allocations in a sample of poor, rural households in Northern Ghana. Data are derived from the baseline data of an ongoing longitudinal impact evaluation of a cash transfer programme targeted to pregnant women and women with young infants. The chapter first sets out to test whether there exists any gender bias in the household expenditure data, using an outlay equivalence analysis, pioneered by Deaton (1989). This analysis is unable to uncover significant gender bias in the expenditure data, although it does find that parents give up a significant share of spending on adult goods when an additional girl aged $0-4$ years old is added to the household. The chapter then moves on to a simple test of the unitary household model. It takes parental education as a source of bargaining power and tests whether father's and mother's education have different effects on daughters and sons in terms of their educational attainment and nutritional status. The findings reveal some suggestive evidence that fathers are more interested to invest in their daughters. In a context where the culture of bride-price is widely practiced, it is possible that fathers invest in their daughters to increase the value of the bride-price. However, further research is needed to unpack this relationship in more detail. In the context of the LEAP 1000 cash transfer programme, the findings provide indicative evidence that the unitary household model does not hold. However, this chapter also showed that mothers might favour their sons over their daughters, possibly affecting the impacts of the programme depending on the sex of the child. This prediction will be further tested in the impact analysis of Chapter 5 . 


\title{
4.6 Appendix to Chapter 4
}

Table S 4.1, Effects of husband's and wife's human capital on children's education, deviation from cohort means (including dummy for mother having higher education than father)

\begin{tabular}{|c|c|c|c|c|c|c|}
\hline & $(1)$ & $(2)$ & (3) & $(4)$ & $(5)$ & (6) \\
\hline & \multicolumn{2}{|c|}{$\begin{array}{c}\text { Children } 6 \text { - } 17 \\
\text { years }\end{array}$} & \multicolumn{2}{|c|}{$\begin{array}{c}\text { Children } 6 \text { - } 11 \\
\text { years }\end{array}$} & \multicolumn{2}{|c|}{$\begin{array}{c}\text { Children } 12 \text { - } 17 \\
\text { years }\end{array}$} \\
\hline & OLS & $\begin{array}{l}\text { Fixed } \\
\text { effects }\end{array}$ & OLS & $\begin{array}{l}\text { Fixed } \\
\text { effects }\end{array}$ & OLS & $\begin{array}{l}\text { Fixed } \\
\text { effects }\end{array}$ \\
\hline \multicolumn{7}{|l|}{ Child characteristics } \\
\hline Sex $=$ female & $\begin{array}{c}0.057 \\
(0.061)\end{array}$ & $\begin{array}{c}0.033 \\
(0.070)\end{array}$ & $\begin{array}{c}0.012 \\
(0.053)\end{array}$ & $\begin{array}{c}0.037 \\
(0.062)\end{array}$ & $\begin{array}{c}0.108 \\
(0.214)\end{array}$ & $\begin{array}{c}0.084 \\
(0.210)\end{array}$ \\
\hline Age in years & $\begin{array}{l}-0.021 \\
(0.077)\end{array}$ & $\begin{array}{l}-0.001 \\
(0.072)\end{array}$ & $\begin{array}{l}-0.030 \\
(0.111)\end{array}$ & $\begin{array}{c}0.101 \\
(0.111)\end{array}$ & $\begin{array}{l}-0.211 \\
(1.158)\end{array}$ & $\begin{array}{c}0.509 \\
(1.089)\end{array}$ \\
\hline $\begin{array}{l}\text { Age in years } \\
\text { squared }\end{array}$ & $\begin{array}{c}0.001 \\
(0.004)\end{array}$ & $\begin{array}{c}0.000 \\
(0.004)\end{array}$ & $\begin{array}{c}0.002 \\
(0.007)\end{array}$ & $\begin{array}{l}-0.005 \\
(0.007)\end{array}$ & $\begin{array}{c}0.008 \\
(0.042)\end{array}$ & $\begin{array}{l}-0.018 \\
(0.039)\end{array}$ \\
\hline \multicolumn{7}{|l|}{ Parental education } \\
\hline $\begin{array}{l}\text { Maternal schooling } \\
\text { in years }\end{array}$ & $\begin{array}{l}-0.008 \\
(0.032)\end{array}$ & & $\begin{array}{l}-0.004 \\
(0.020)\end{array}$ & & $\begin{array}{c}0.047 \\
(0.202)\end{array}$ & \\
\hline $\begin{array}{l}\text { Paternal schooling } \\
\text { in years }\end{array}$ & $\begin{array}{l}0.036^{* *} \\
(0.015)\end{array}$ & & $\begin{array}{c}0.011 \\
(0.013)\end{array}$ & & $\begin{array}{c}0.135^{* * *} \\
(0.043)\end{array}$ & \\
\hline $\begin{array}{l}\text { Mother better } \\
\text { educated than } \\
\text { father }\end{array}$ & $\begin{array}{c}0.011 \\
(0.234)\end{array}$ & & $\begin{array}{l}-0.114 \\
(0.212)\end{array}$ & & $\begin{array}{l}-0.040 \\
(0.878)\end{array}$ & \\
\hline \multicolumn{7}{|l|}{ Interaction term } \\
\hline $\begin{array}{l}\text { Female } x \text { mother's } \\
\text { education }\end{array}$ & $\begin{array}{c}0.052 \\
(0.040)\end{array}$ & $\begin{array}{c}0.061 \\
(0.042)\end{array}$ & $\begin{array}{l}0.055^{*} \\
(0.032)\end{array}$ & $\begin{array}{c}0.052 \\
(0.035)\end{array}$ & $\begin{array}{l}-0.125 \\
(0.226)\end{array}$ & $\begin{array}{c}0.021 \\
(0.226)\end{array}$ \\
\hline $\begin{array}{l}\text { Female } x \text { father's } \\
\text { education }\end{array}$ & $\begin{array}{l}-0.009 \\
(0.017)\end{array}$ & $\begin{array}{l}-0.005 \\
(0.021)\end{array}$ & $\begin{array}{c}0.004 \\
(0.016)\end{array}$ & $\begin{array}{c}0.017 \\
(0.019)\end{array}$ & $\begin{array}{l}-0.018 \\
(0.053)\end{array}$ & $\begin{array}{c}0.045 \\
(0.045)\end{array}$ \\
\hline $\begin{array}{l}\text { Female } x \text { mother } \\
\text { better educated } \\
\text { than father }\end{array}$ & $\begin{array}{l}-0.309 \\
(0.289)\end{array}$ & $\begin{array}{l}-0.696^{* *} \\
(0.349)\end{array}$ & $\begin{array}{l}-0.042 \\
(0.246)\end{array}$ & $\begin{array}{l}-0.271 \\
(0.255)\end{array}$ & $\begin{array}{l}0.402 \\
(1.346)\end{array}$ & $\begin{array}{l}-1.994 \\
(1.749)\end{array}$ \\
\hline
\end{tabular}

F-test on main effects (p-value)

Father's schooling =

Mother's schooling $\quad 0.268$

F-test on total effect (p-value)

Father's schooling $=$

Mother's schooling 0.641

F-test on interaction effect (p-value)

Father's schooling =

Mother's schooling

0.616

0.691

)




\begin{tabular}{|c|c|c|c|c|c|c|}
\hline & $(1)$ & $(2)$ & (3) & $(4)$ & $(5)$ & (6) \\
\hline & \multicolumn{2}{|c|}{$\begin{array}{c}\text { Children } 6 \text { - } 17 \\
\text { years }\end{array}$} & \multicolumn{2}{|c|}{$\begin{array}{c}\text { Children } 6 \text { - } 11 \\
\text { years }\end{array}$} & \multicolumn{2}{|c|}{$\begin{array}{c}\text { Children } 12 \text { - } 17 \\
\text { years }\end{array}$} \\
\hline & OLS & $\begin{array}{l}\text { Fixed } \\
\text { effects }\end{array}$ & OLS & $\begin{array}{l}\text { Fixed } \\
\text { effects }\end{array}$ & OLS & $\begin{array}{l}\text { Fixed } \\
\text { effects }\end{array}$ \\
\hline FE vs. RE (p-value) & & 0.004 & & 0.036 & & 0.023 \\
\hline RE vs. OLS (p-value) & & 0.000 & & 0.000 & & 0.000 \\
\hline R-squared & 0.022 & & 0.023 & & 0.045 & \\
\hline Observations & 3,298 & 3,298 & 1,941 & 1,941 & 677 & 677 \\
\hline
\end{tabular}


Table S 4.2, Effects of husband's and wife's human capital on children's educational expenditures (inverse hyperbolic sine transformed) (including dummy for mother having higher education than father)

\begin{tabular}{|c|c|c|c|c|c|c|}
\hline & (1) & (2) & (3) & (4) & (5) & (6) \\
\hline & \multicolumn{2}{|c|}{$\begin{array}{c}\text { Children } 6 \text { - } 17 \\
\text { years }\end{array}$} & \multicolumn{2}{|c|}{$\begin{array}{c}\text { Children } 6 \text { - } 11 \\
\text { years }\end{array}$} & \multicolumn{2}{|c|}{$\begin{array}{c}\text { Children } 12 \text { - } 17 \\
\text { years }\end{array}$} \\
\hline & OLS & $\begin{array}{l}\text { Fixed } \\
\text { effects }\end{array}$ & OLS & $\begin{array}{l}\text { Fixed } \\
\text { effects }\end{array}$ & OLS & $\begin{array}{l}\text { Fixed } \\
\text { effects }\end{array}$ \\
\hline \multicolumn{7}{|l|}{ Child characteristics } \\
\hline Sex $=$ female & $\begin{array}{c}0.046 \\
(0.085)\end{array}$ & $\begin{array}{l}-0.028 \\
(0.098)\end{array}$ & $\begin{array}{l}-0.037 \\
(0.114)\end{array}$ & $\begin{array}{l}-0.047 \\
(0.119)\end{array}$ & $\begin{array}{c}0.042 \\
(0.228)\end{array}$ & $\begin{array}{c}0.124 \\
(0.269)\end{array}$ \\
\hline Age in years & $\begin{array}{l}0.719^{* * *} \\
(0.095)\end{array}$ & $\begin{array}{l}0.776^{* * *} \\
(0.086)\end{array}$ & $\begin{array}{l}0.570^{*} \\
(0.297)\end{array}$ & $\begin{array}{c}0.845^{* * *} \\
(0.227)\end{array}$ & $\begin{array}{c}0.994 \\
(1.172)\end{array}$ & $\begin{array}{l}1.826 \\
(1.242)\end{array}$ \\
\hline $\begin{array}{l}\text { Age in years } \\
\text { squared }\end{array}$ & $\begin{array}{l}-0.030^{* * *} \\
(0.004)\end{array}$ & $\begin{array}{c}-0.033^{* * *} \\
(0.004)\end{array}$ & $\begin{array}{l}-0.020 \\
(0.018)\end{array}$ & $\begin{array}{c}-0.037^{* * *} \\
(0.014)\end{array}$ & $\begin{array}{l}-0.041 \\
(0.041)\end{array}$ & $\begin{array}{l}-0.070 \\
(0.044)\end{array}$ \\
\hline \multicolumn{7}{|l|}{ Parental education } \\
\hline $\begin{array}{l}\text { Maternal schooling } \\
\text { in years }\end{array}$ & $\begin{array}{c}0.136^{* * *} \\
(0.048)\end{array}$ & & $\begin{array}{l}0.111^{* *} \\
(0.054)\end{array}$ & & $\begin{array}{c}0.093 \\
(0.118)\end{array}$ & \\
\hline $\begin{array}{l}\text { Paternal schooling in } \\
\text { years }\end{array}$ & $\begin{array}{c}0.078^{* * *} \\
(0.028)\end{array}$ & & $\begin{array}{l}0.065^{* *} \\
(0.031)\end{array}$ & & $\begin{array}{l}0.152^{* * *} \\
(0.036)\end{array}$ & \\
\hline $\begin{array}{l}\text { Mother better } \\
\text { educated than father }\end{array}$ & $\begin{array}{l}-0.211 \\
(0.442)\end{array}$ & & $\begin{array}{c}0.043 \\
(0.534)\end{array}$ & & $\begin{array}{c}0.090 \\
(0.966)\end{array}$ & \\
\hline Interaction term & & & & & & \\
\hline $\begin{array}{l}\text { Female } x \text { mother's } \\
\text { education }\end{array}$ & $\begin{array}{l}-0.040 \\
(0.058)\end{array}$ & $\begin{array}{l}-0.042 \\
(0.047)\end{array}$ & $\begin{array}{l}-0.021 \\
(0.068)\end{array}$ & $\begin{array}{l}-0.025 \\
(0.046)\end{array}$ & $\begin{array}{l}-0.204 \\
(0.130)\end{array}$ & $\begin{array}{l}-0.182 \\
(0.136)\end{array}$ \\
\hline $\begin{array}{l}\text { Female } x \text { father's } \\
\text { education }\end{array}$ & $\begin{array}{c}0.003 \\
(0.026)\end{array}$ & $\begin{array}{c}0.008 \\
(0.025)\end{array}$ & $\begin{array}{c}0.036 \\
(0.038)\end{array}$ & $\begin{array}{l}0.059 * \\
(0.031)\end{array}$ & $\begin{array}{l}-0.055 \\
(0.063)\end{array}$ & $\begin{array}{l}-0.069 \\
(0.050)\end{array}$ \\
\hline $\begin{array}{l}\text { Female } x \text { mother } \\
\text { better educated than } \\
\text { father }\end{array}$ & $\begin{array}{c}0.222 \\
(0.433)\end{array}$ & $\begin{array}{l}-0.132 \\
(0.364)\end{array}$ & $\begin{array}{c}0.006 \\
(0.516)\end{array}$ & $\begin{array}{l}-0.133 \\
(0.393)\end{array}$ & $\begin{array}{c}1.262 \\
(1.277)\end{array}$ & $\begin{array}{l}-0.135 \\
(0.806)\end{array}$ \\
\hline
\end{tabular}

F-test on main effects (p-value)

$\begin{array}{lll}\text { Father's schooling }= & 0.366 & 0.538\end{array}$

Mother's schooling

F-test on total effect (p-value)

$\begin{array}{lll}\text { Father's schooling }= & 0.853 & 0.914\end{array}$

Mother's schooling

F-test on interaction effect (p-value)

Father's schooling $=\quad 0.400$

0.218

0.479

Mother's schooling 


\begin{tabular}{|c|c|c|c|c|c|c|}
\hline & $(1)$ & $(2)$ & (3) & (4) & (5) & (6) \\
\hline & \multicolumn{2}{|c|}{$\begin{array}{c}\text { Children } 6 \text { - } 17 \\
\text { years }\end{array}$} & \multicolumn{2}{|c|}{$\begin{array}{c}\text { Children } 6 \text { - } 11 \\
\text { years }\end{array}$} & \multicolumn{2}{|c|}{$\begin{array}{c}\text { Children } 12 \text { - } 17 \\
\text { years }\end{array}$} \\
\hline & OLS & $\begin{array}{l}\text { Fixed } \\
\text { effects }\end{array}$ & OLS & $\begin{array}{l}\text { Fixed } \\
\text { effects }\end{array}$ & OLS & $\begin{array}{l}\text { Fixed } \\
\text { effects }\end{array}$ \\
\hline FE vs. RE (p-value) & & 0.000 & & 0.009 & & 0.000 \\
\hline RE vs. OLS (p-value) & & 0.000 & & 0.000 & & 0.000 \\
\hline R-squared & 0.071 & 0.049 & 0.093 & 0.081 & 0.059 & 0.037 \\
\hline Observations & 3,298 & 3,298 & 1,941 & 1,941 & 677 & 677 \\
\hline
\end{tabular}




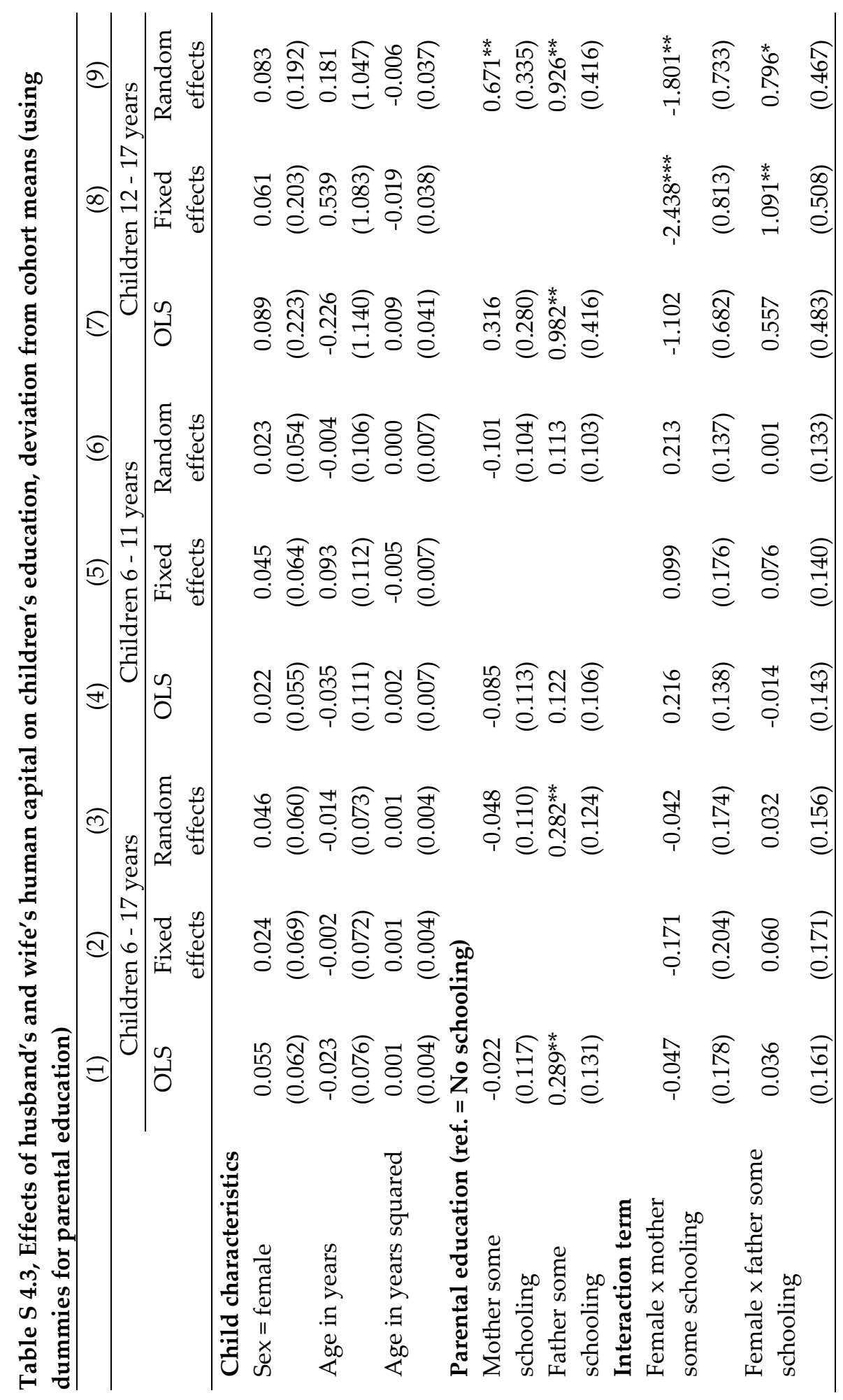




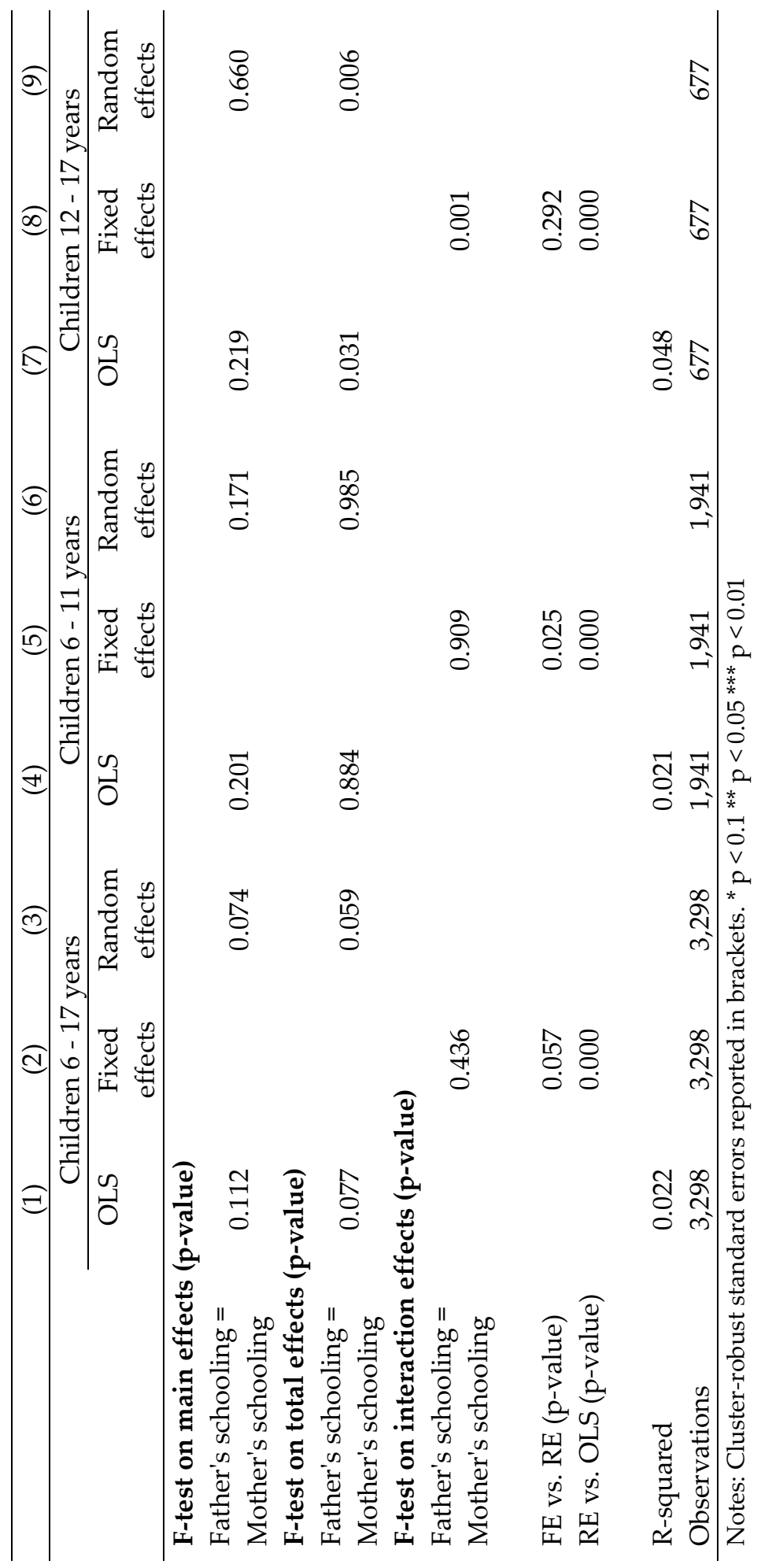




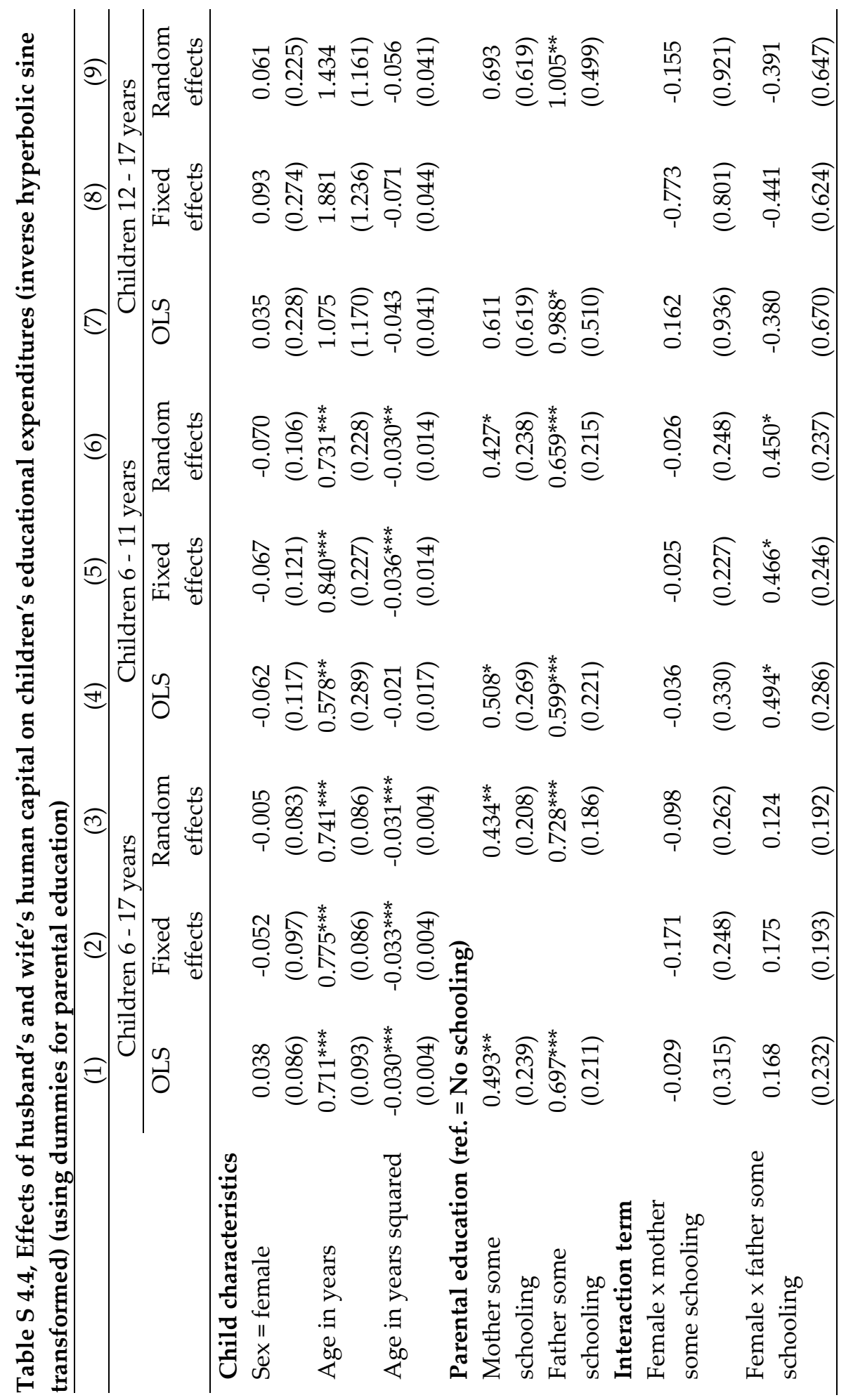




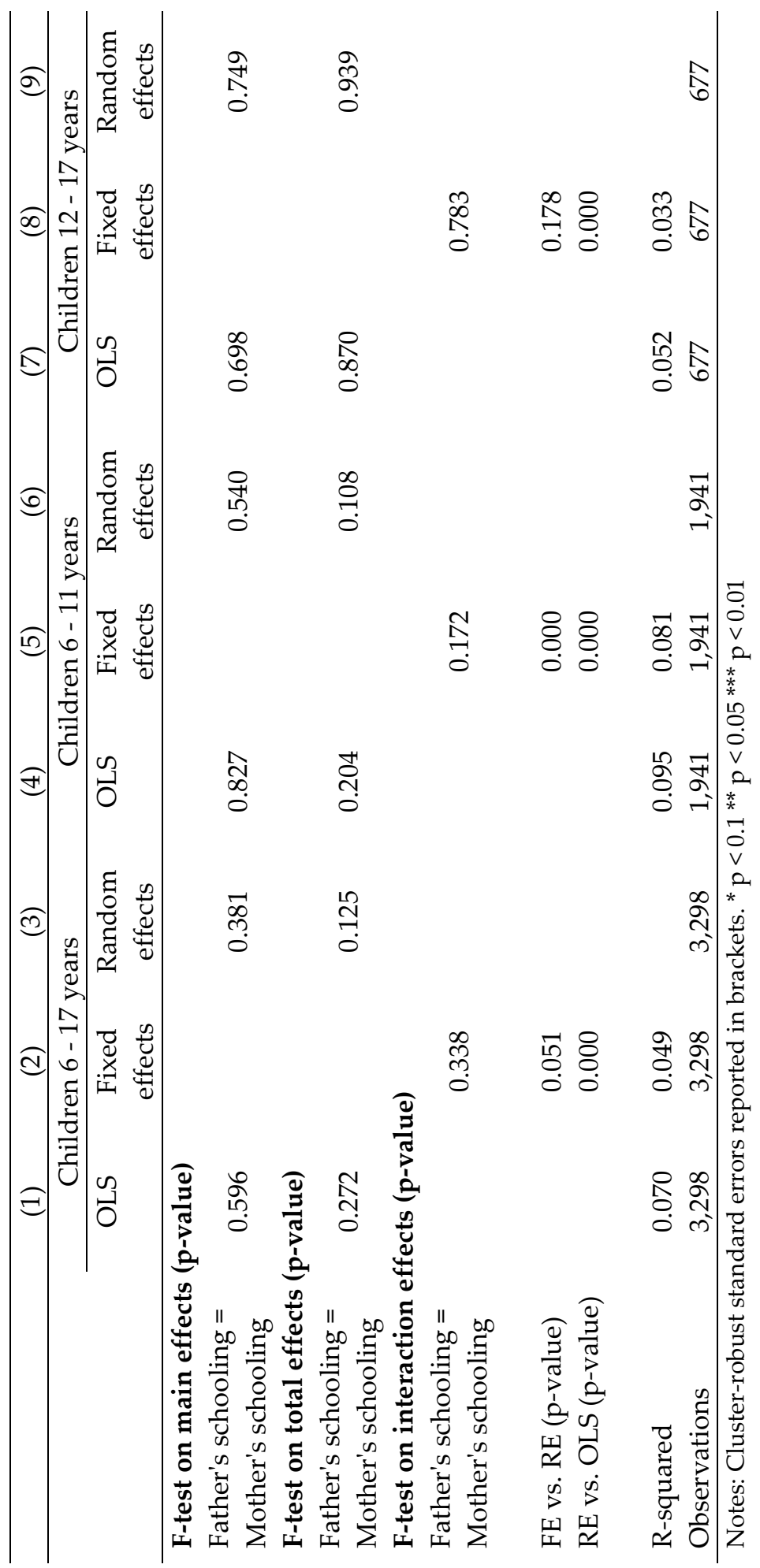




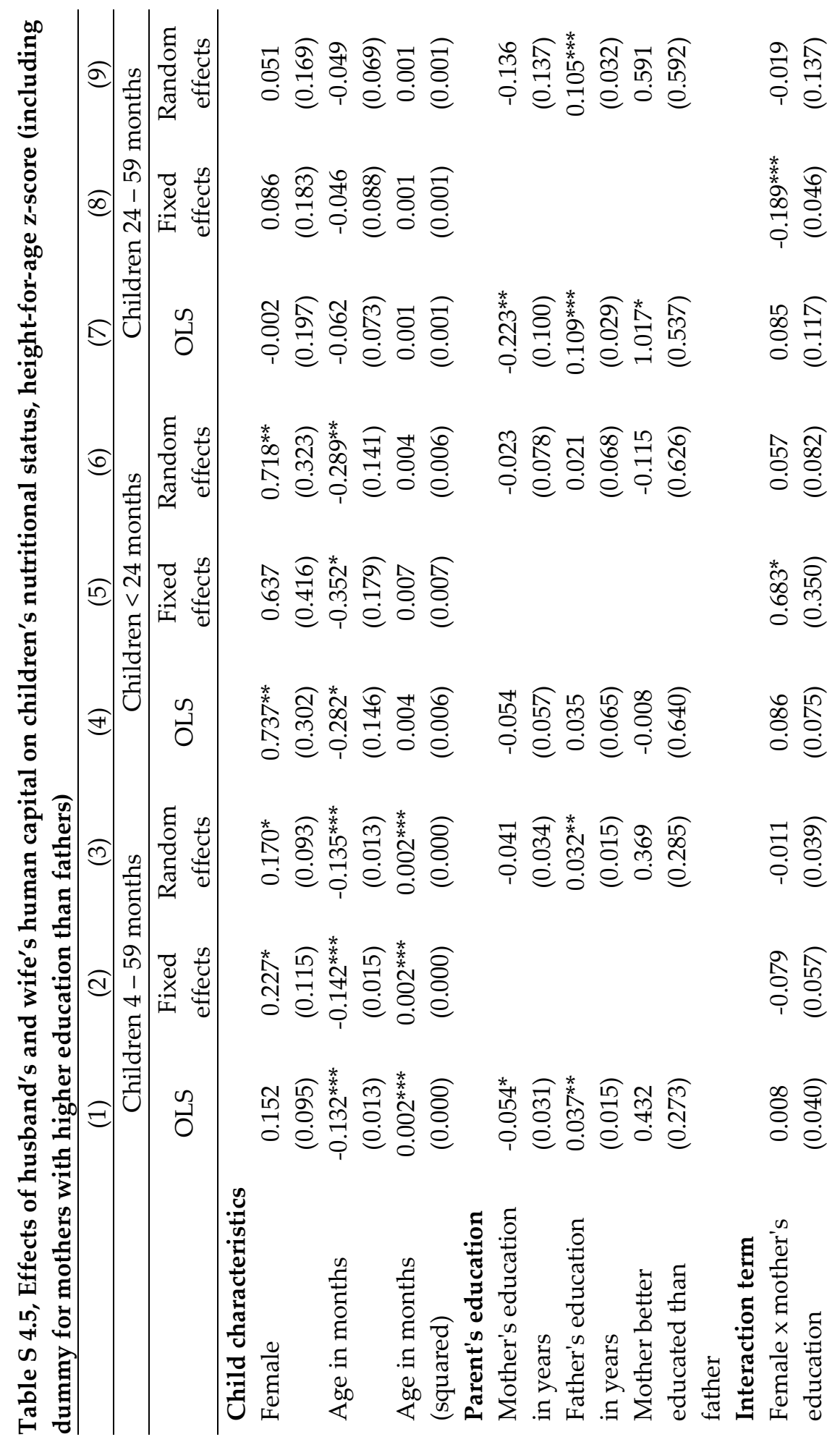




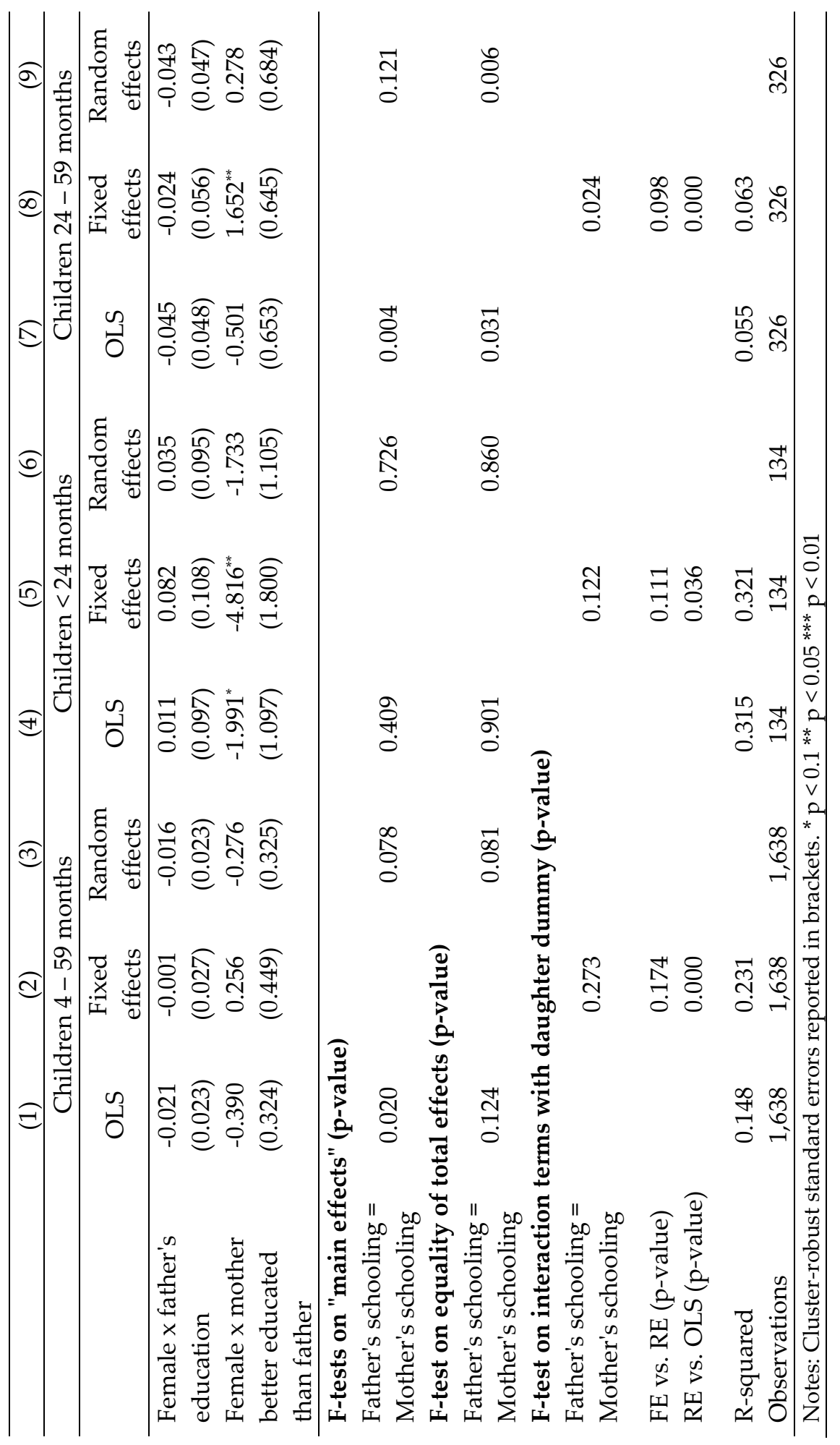




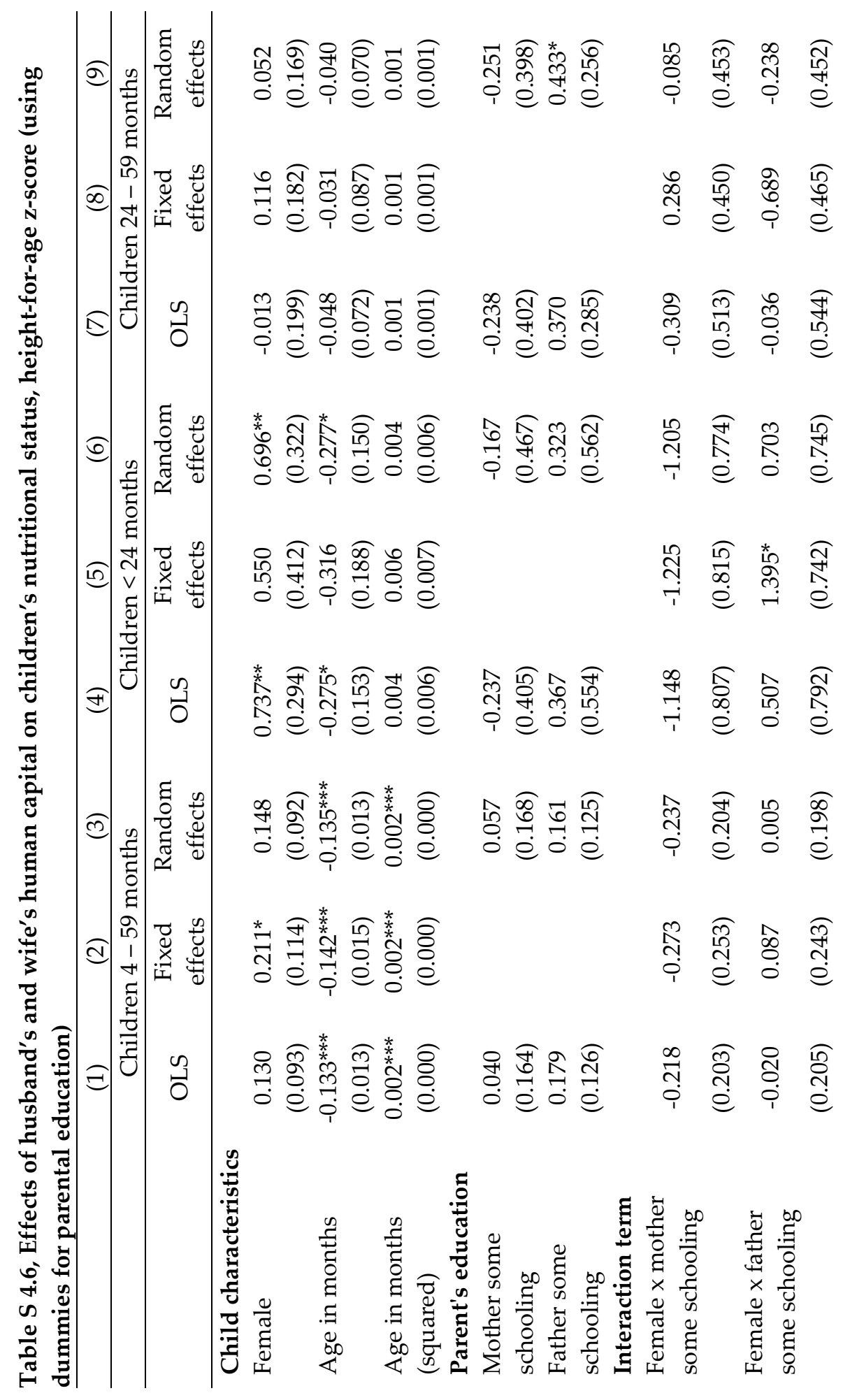




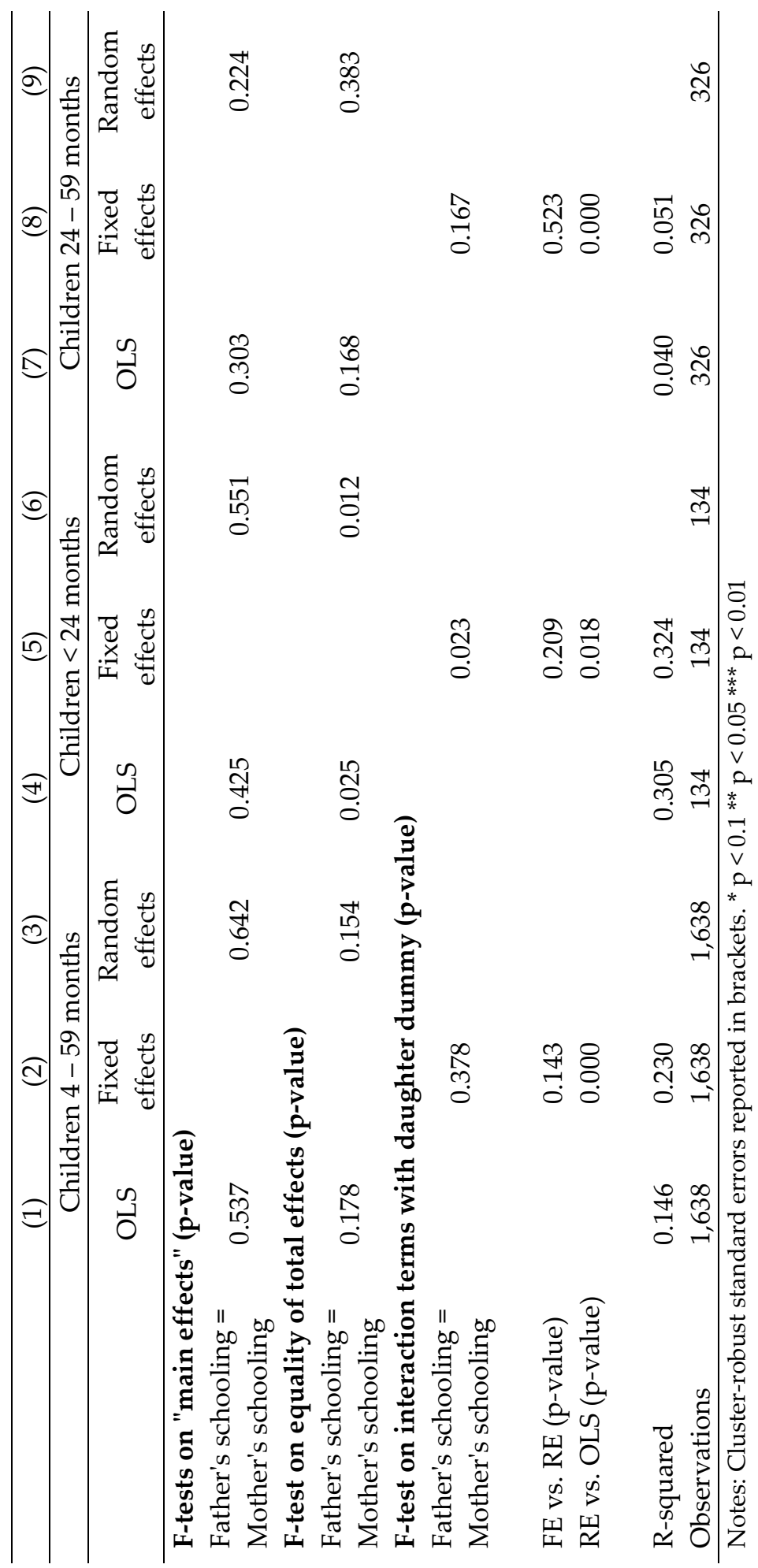




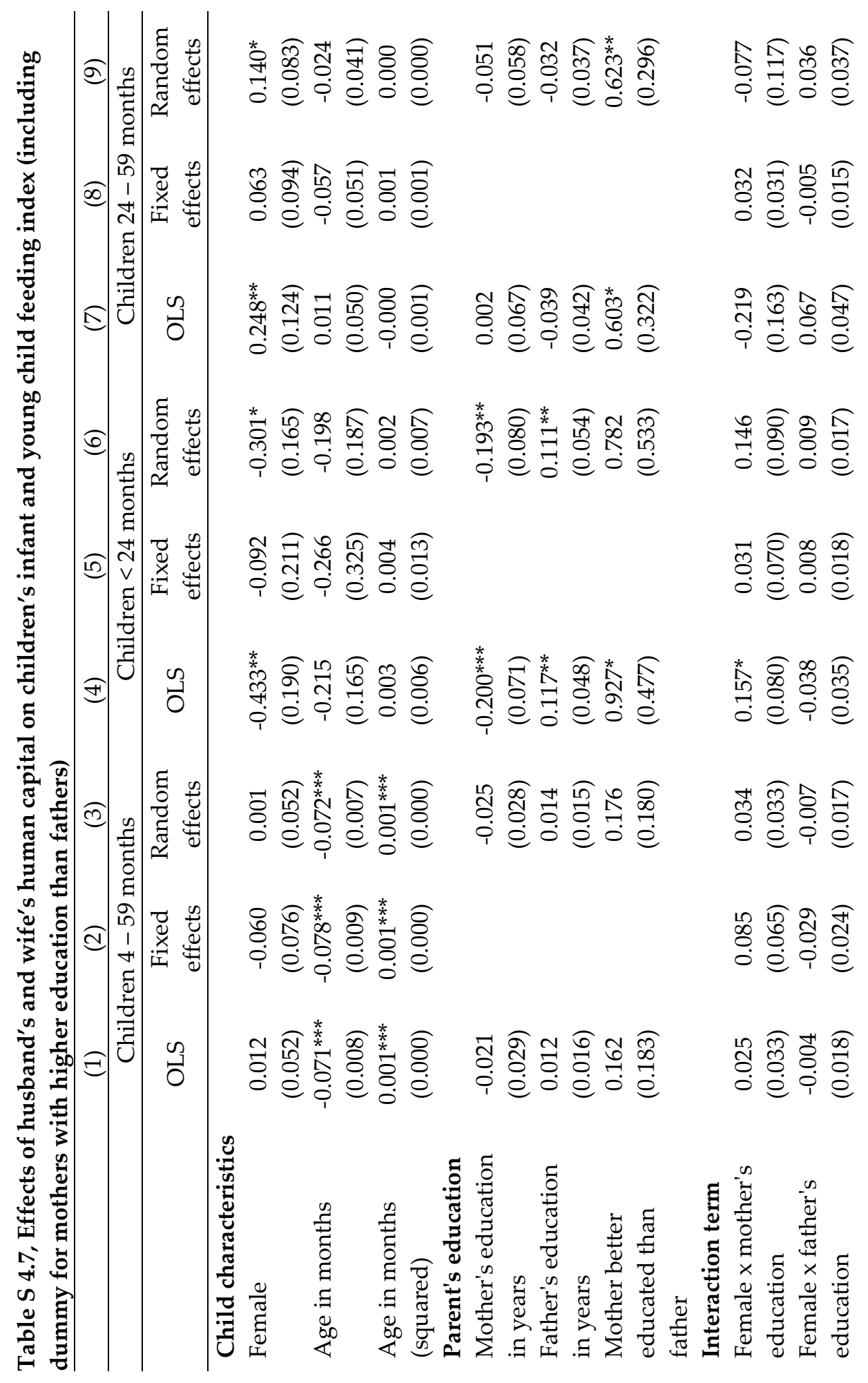




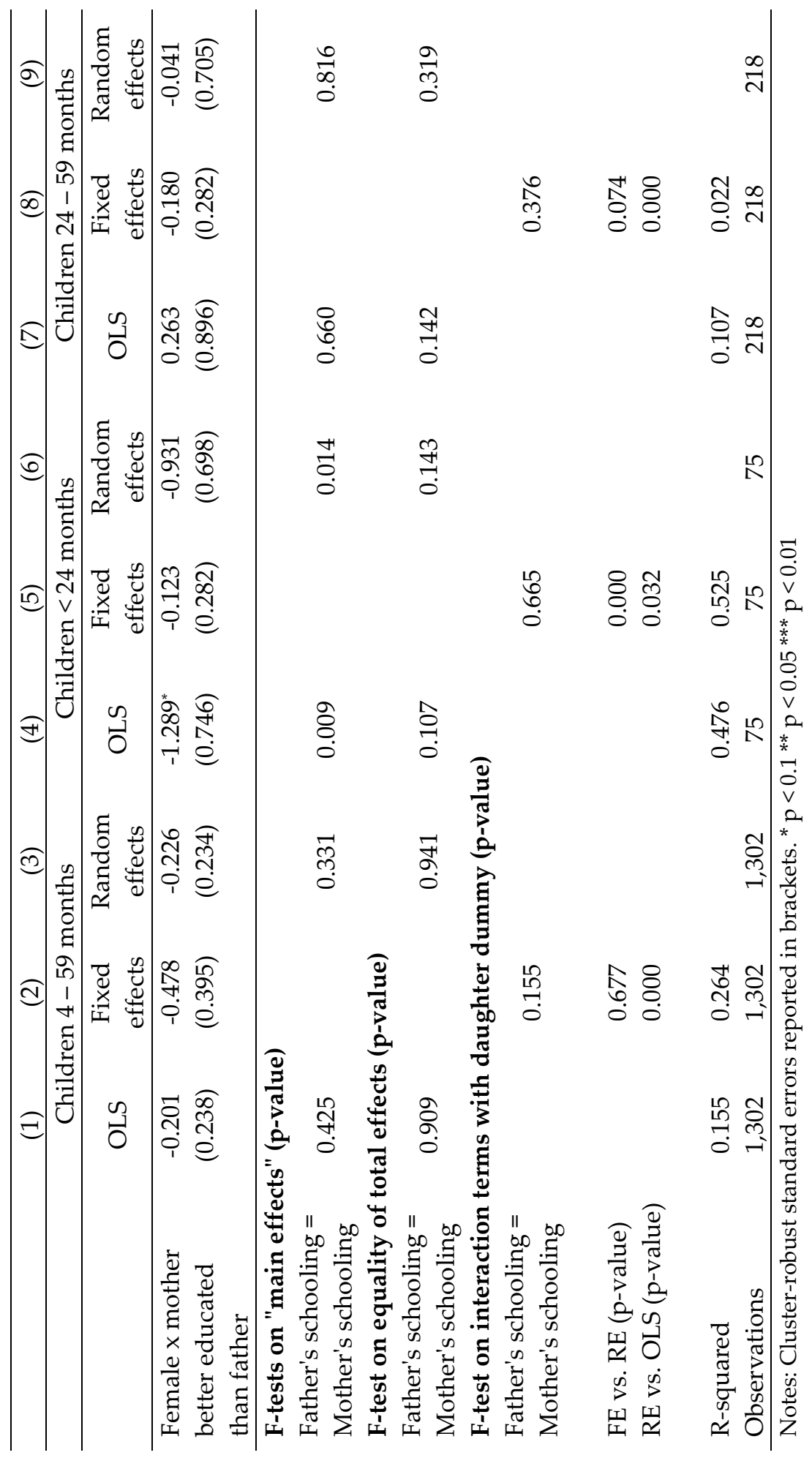




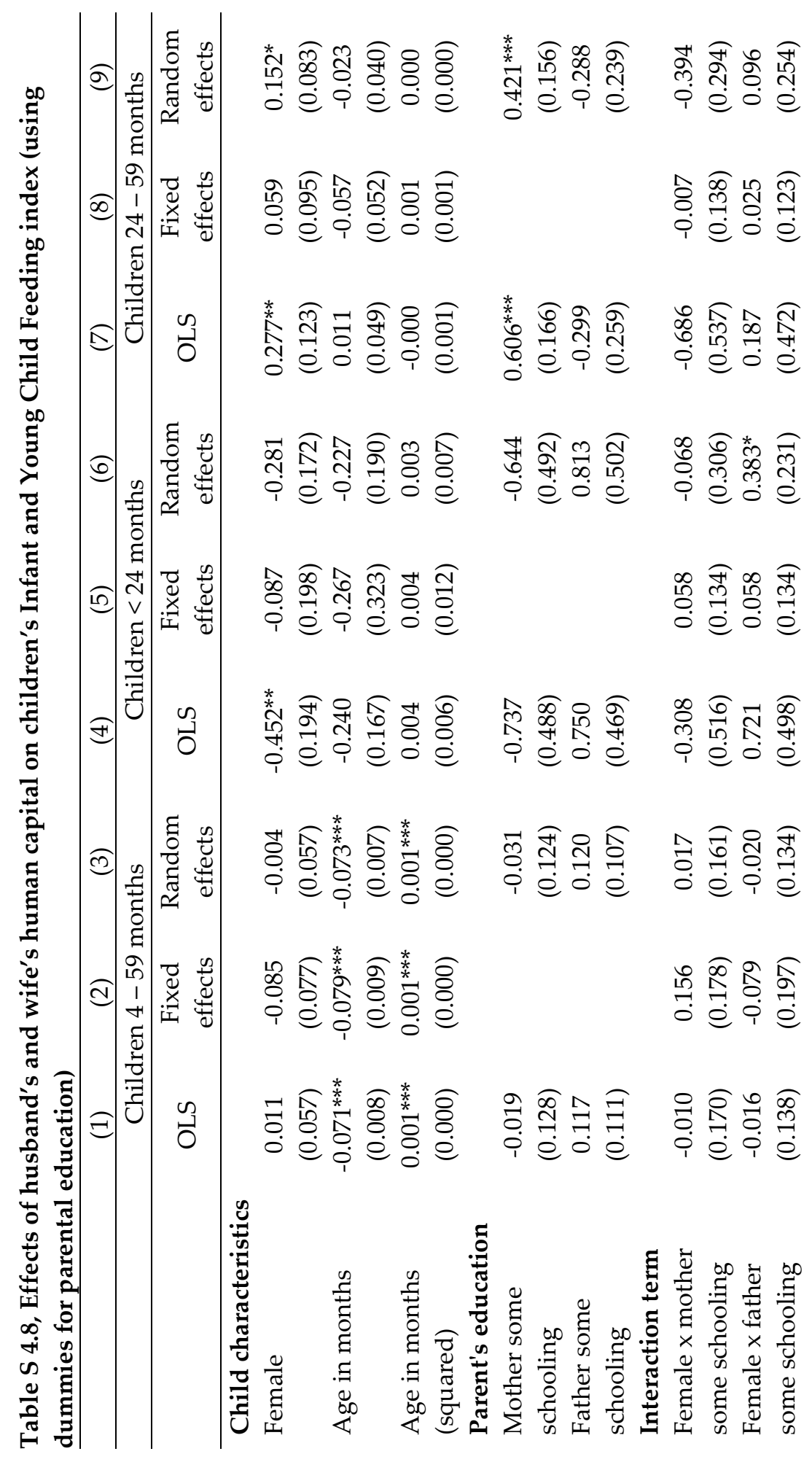




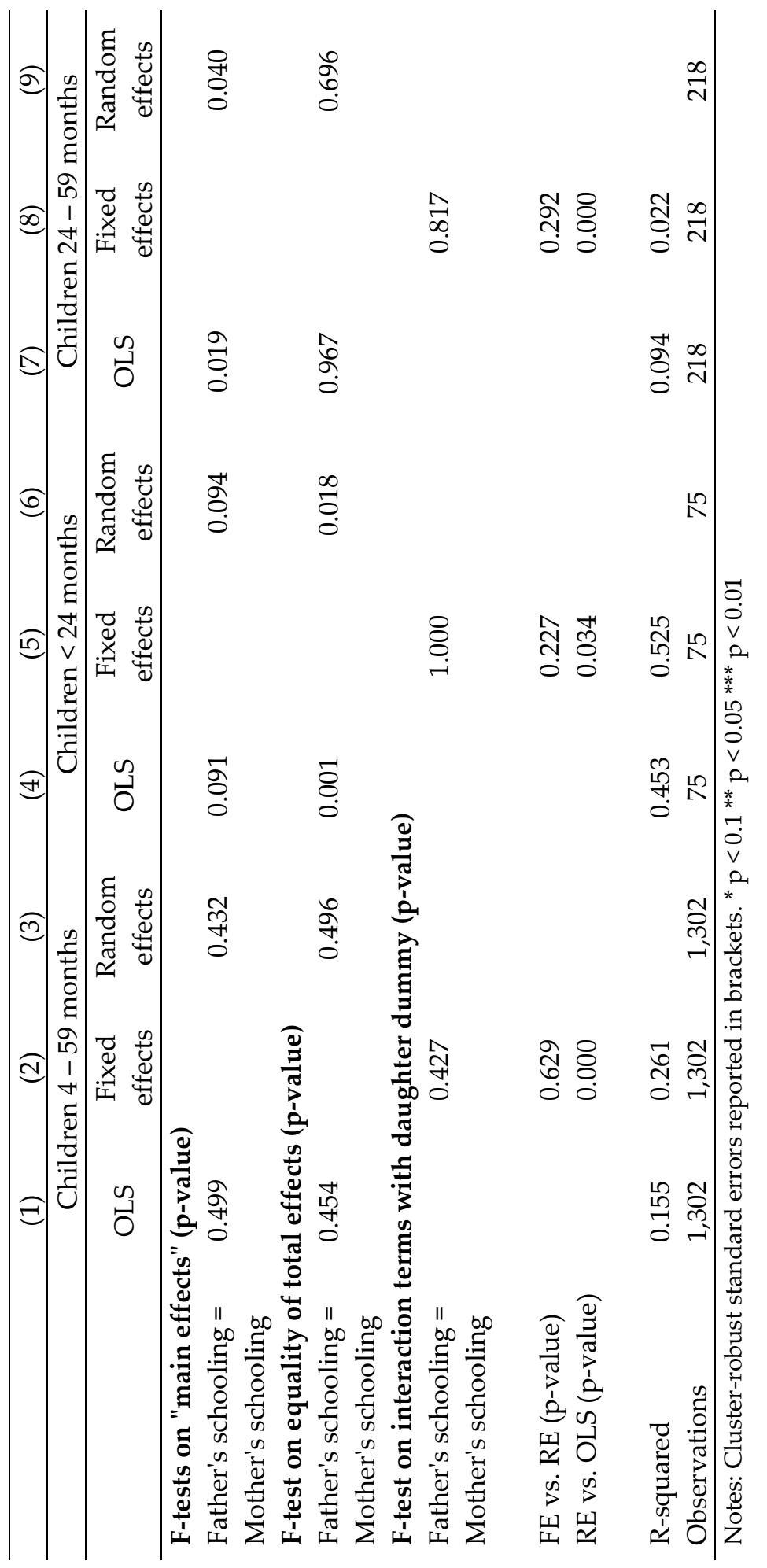




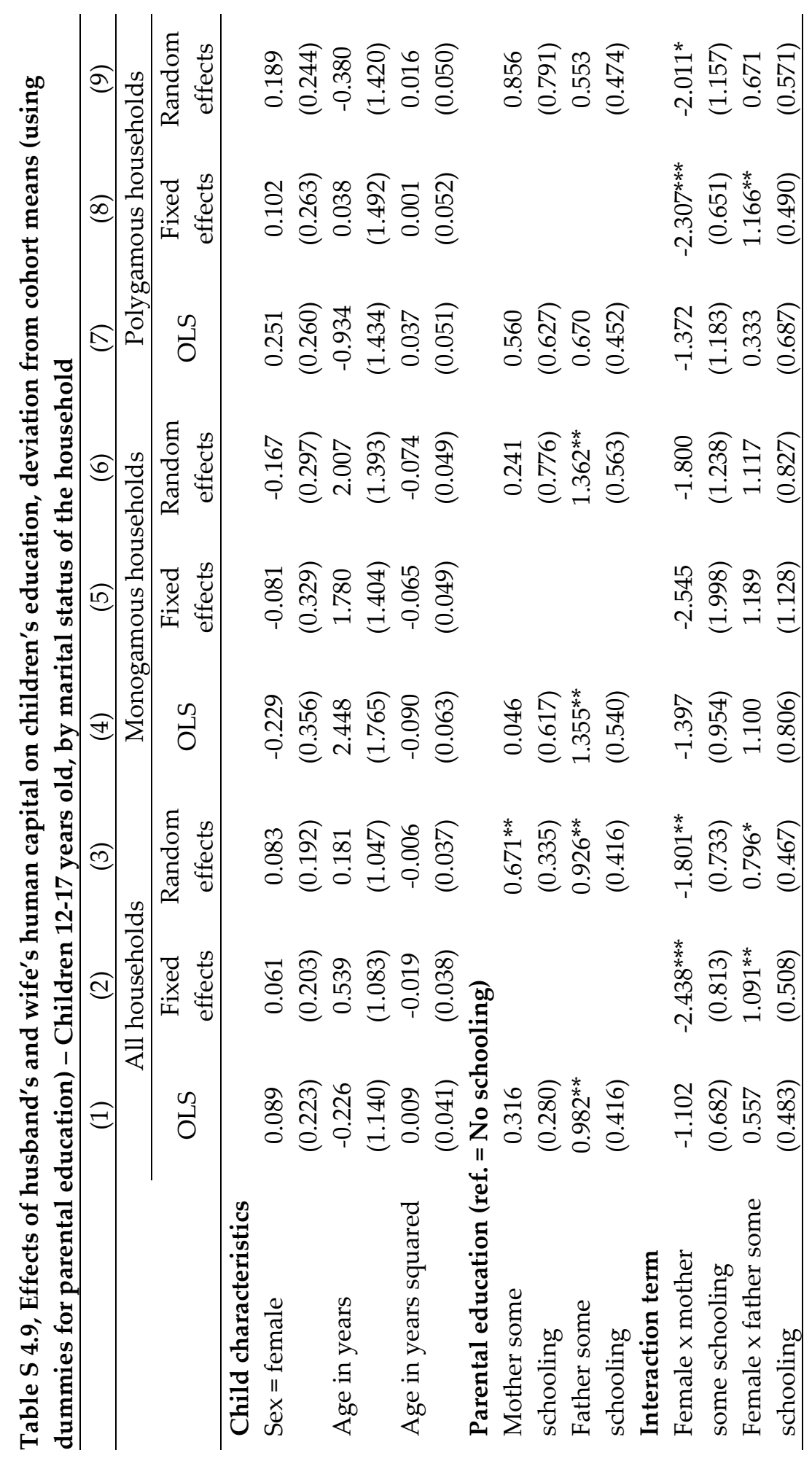




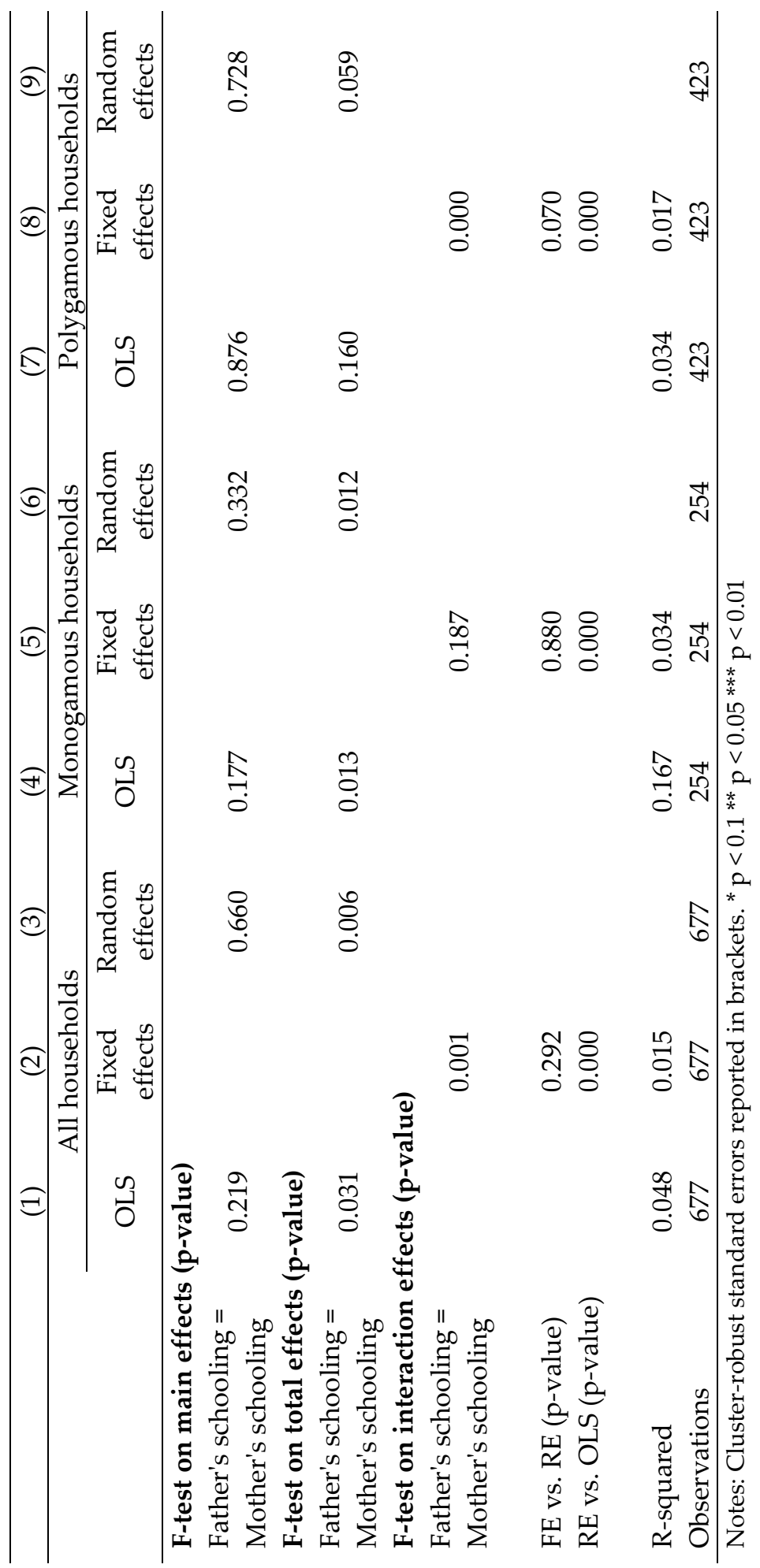




\section{The impact of Ghana LEAP 1000 on young child nutritional status and its determinants}

This chapter is based on:

de Groot, R. and Yablonski, J. (2019). The impact of cash and health insurance on child nutrition during the first 1,000 days: Evidence from Ghana. Unpublished manuscript. 


\subsection{Introduction}

Child malnutrition remains a significant global public health issue, with the latest estimates showing that 155 million children under five are affected by stunting (being too short for age) and 52 million children were wasted (too light for one's height) (UNICEF/WHO/World Bank Group, 2017). It is estimated that malnutrition is the underlying cause of nearly half of child deaths (Black et al., 2008). In Ghana overall, more than one in five children is stunted, and in the area where this study was conducted the percentage is even higher at 33 percent (Ghana Statistical Service (GSS) et al., 2015). Due to its major and long-term consequences for later life outcomes, investments during the first 1,000 days that reduce stunting are estimated to yield large economic returns (Hoddinott et al., 2013).

Child malnutrition is the result of a complex process with a multitude of immediate and underlying determinants, as shown in the conceptual framework of Figure 1.2. Notwithstanding, there has been increasing attention to so-called nutrition-sensitive programming, including for social protection programmes, to help address the burden of malnutrition (Ruel et al., 2013).

Despite the acknowledged potential of social protection, numerous reviews in the last decade indicate limited positive impacts on child nutritional status (for example Fernald et al. (2012), Hoddinott (2010), Lagarde et al. (2009), Leroy et al. (2009), Manley and Slavchevska (2019), Owusu-Addo and Cross (2014), Owusu-Addo et al. (2018), Pega et al. (2017)). Despite diverse methodology and programme design foci, none of these reviews find conclusive evidence of a positive impact of cash transfers on child nutritional status. In addition, a metaanalysis evaluating 15 programmes in 10 countries demonstrated a minor but statistically insignificant impact on child height-for-age (Manley et al., 2013). ${ }^{35}$

While overall evidence points to limited impacts of CTs on child nutritional status, it is difficult to directly attribute lack of impacts to specific programme design factors. For example, Owusu-Addo et al. (2018) hypothesize that the lack of impact may be due to contextual factors, such as access to water and sanitation, the size of the transfer or household size. Other authors point out that the pathways of impact from a CT to child nutrition are not clearly understood (Leroy et al., 2009). It is therefore important to consider the full scope of determinants when analysing the effect of a CT on nutritional outcomes, to better unpack potential pathways and better understand how to design and leverage nutrition-sensitive social protection. In particular, impacts on more immediate determinants of child nutritional status, including children's food intake, and caregiver's behaviours and mental state are understudied (de Groot et al., 2017).

35 See also Chapter 2 of this thesis 
In Ghana, there has been significant interest in integrated programming and social protection specifically to address the complex processes driving high rates of malnutrition. Ghana's flagship CT programme, Livelihood Empowerment Against Poverty (LEAP) is linked with the National Health Insurance Scheme (NHIS), providing beneficiaries with fee waivers for health insurance. This chapter examines the impacts of an extension to the LEAP programme (LEAP 1000) to a new category of beneficiaries, pregnant women and infants under one year. This pilot programme was conducted in 10 districts in Ghana's Northern and Upper East regions. Beneficiaries received between GHC 38 - 53 (approximately USD 9.50 -13.25) per month depending on the number of eligible beneficiaries in the household, corresponding to an increase of about 14 percent of household preprogramme consumption.

This chapter documents the impacts of LEAP 1000 on young child nutrition outcomes, including an analysis of pathways contributing to improved health and nutrition. We use data from a 24-month impact evaluation and combine a regression discontinuity design (RDD) with difference-in-difference (DID) modelling. Consistent with the literature, we find no main impacts of the programme on child nutritional status, but we find significant impacts on household food security, one of the underlying determinants of nutritional status. We proceed by analysing heterogeneous treatment effects to better contextualize the main findings. While previous research has pointed to larger impacts for younger children (Aguero et al., 2007, Leroy et al., 2009), we find no differential impacts by age group. Next, we examine whether the distance and quality of the nearest health facility moderates programme impacts and find that quality of nearby health facilities increases the programme's impact only on food security. We then assess the moderating effects of covariate shocks and find lower programme impacts on weight in case of crop-related shocks. We also find suggestive evidence that complementary programmes have promising potential since there are higher health impacts when communities benefit from additional development programmes. Finally, we examine how intra-household dynamics affect the impact of the transfer, by looking at heterogeneous effects by parent's educational status. We find that girls from mothers with some education have poorer health outcomes as a result of the CT, suggesting that better-educated mothers may not invest the transfer in the health of their daughters.

This chapter contributes to the literature in several ways. First, it evaluates a CT programme that specifically targets children in the critical window of child growth and development of pregnancy through the first year. Some authors argue that CTs may have the best chance of generating an impact in this window (Leroy et al., 2009, Manley and Slavchevska, 2019). Second, this study not only considers the ultimate outcome (malnutrition), but also the various underlying determinants of child malnutrition to contextualize the findings and provide guidance for complementary programming to enhance the effect that CTs can have on child 
nutrition. Finally, this is one of the first studies using a rigorous design that examines a large-scale government-run CT programme in West-Africa on child nutrition and its determinants.

The chapter proceeds as follows. Section 5.2 introduces the Ghana LEAP 1000 programme and the evaluation. Section 5.3 presents the data and baseline descriptive statistics. Section 5.4 discusses the empirical strategy and section 5.5 highlights the results. Section 5.6 discusses the findings and concludes.

\subsection{The Ghana LEAP 1000 programme and evaluation design}

As discussed in the introductory chapter, the Ghana LEAP 1000 programme was launched as a small pilot in two northern regions to include a new category of poor households with pregnant women and infants younger than one year in the existing broader LEAP programme. LEAP 1000 was specifically targeted with the aim of improving young child health and nutritional status during the crucial development window of the first 1,000 days of life, from conception to age two. ${ }^{36}$ This category is now fully integrated in the mainstream LEAP programme, constituting 8 percent of all programme households.

Households that are eligible for LEAP receive between GHC38 - 53 (approximately USD 9.50 - 13.25) per month depending on the number of eligible beneficiaries in the household. The transfer size corresponds to about 14 percent of household pre-programme consumption. Payments are made bi-monthly at designated pay points. In addition, LEAP beneficiaries, including children and dependents under 18 years, are entitled to free health insurance under the National Health Insurance Scheme (NHIS), providing access to out-patient and in-patient services, dental services, and maternal health services via a fee waiver. LEAP succeeded to disburse the grants regularly to beneficiaries with consistent payment intervals and high coverage (UNICEF Office of Research - Innocenti et al., 2018).

UNICEF Office of Research - Innocenti in collaboration with the Institute of Statistical, Social and Economic Research (ISSER) at the University of Ghana, the University of North Carolina at Chapel Hill (USA), and Navrongo Health Research Centre, carried out a mixed-method impact evaluation of the LEAP 1000 roll-out in five of the 10 implementing districts between 2015 and 2017 (Bongo and GaruTempane in Upper East region and Yendi, Karaga and East-Mamprusi in Northern region). Data collection took place using trained female enumerators who were fluent in the various local languages of this area and using tablets for direct data

\footnotetext{
${ }^{36}$ For programmatic reasons only children up to one were enrolled, but with the understanding that children would continue to benefit from the programme through the first 1,000 days given the ongoing nature of the cash transfer programme.
} 
capture. The quantitative evaluation used a regression discontinuity design (RDD) based on the distance to the Proxy Means Test (PMT) eligibility threshold. This evaluation was commissioned by UNICEF Ghana, working closely with LEAP management and the MoGCSP. For more details about the study design see UNICEF Office of Research - Innocenti et al. (2016). The study is registered in the Registry for International Development Impact Evaluations (RIDIE) on 01 July 2015, with number RIDIE-STUDY-ID-55942496d53af.

\subsection{Data, baseline balance and attrition}

\subsubsection{Data and sample}

Data for this study come from the LEAP 1000 longitudinal quantitative impact evaluation. The sample size at baseline was 2,497 households and included 2,875 children under five years old with valid anthropometric measurements. The sample size was powered to detect meaningful impacts for the main programme indicator, stunting. A sample of 2,500 observations would be enough to detect a reduction in stunting of approximately five percentage points, as well as a $0.11 \mathrm{SD}$ increase in the average height-for-age z-score.

We restrict our analysis sample to children between 6 and 59 months old for several reasons. First, it is recommended that children under 6 months are breastfed exclusively; this limits the number of infant and young child feeding (IYCF) variables we can include in our models. Second, measurement error in terms of height are generally more severe for children under 6 months, due to the difficulty of accurately measuring infants. We further restrict our sample to children for whom we have full information on all relevant outcome indicators (nutritional status) and determinants (food intake, health, food security, care and health environment). These restrictions result in a baseline sample of 2,479 children (Table 5.1). At our follow-up, we capture more than 50 percent of these children again, while the remainder of the baseline sample is lost primarily because they age out of the sample. In other words, while they met the age criteria of being between 6 and 59 months at baseline, they were older than 59 months at endline. In turn, another group of children is born or aged into the sample at endline. These children were not yet born or younger than six months during the baseline data collection and were therefore not captured in our baseline sample. Our sample selection strategy results in a total number of child-observations across the two waves of 5,120 (Table 5.1). We also show that there was no selective exit and entry in our sample, as there are no statistical differences in terms of reasons for exiting and entering the sample between our treatment and comparison groups. 
Table 5.1, Analysis sample size, by treatment status, wave and entry/exit characteristics

\begin{tabular}{|c|c|c|c|c|c|c|c|c|}
\hline & & \multicolumn{2}{|c|}{ Treatment } & \multicolumn{2}{|c|}{ Comparison } & \multicolumn{2}{|c|}{ Total } & \multirow{2}{*}{$\begin{array}{c}\mathrm{p}- \\
\text { value }\end{array}$} \\
\hline & & $\mathrm{N}$ & $\%$ & $\mathrm{~N}$ & $\%$ & $\mathrm{~N}$ & $\%$ & \\
\hline 1 & Baseline sample (BL) & 1,297 & & 1,182 & & 2,479 & & \\
\hline 2 & Follow-up (FU) & 664 & 51.2 & 586 & 49.6 & 1,250 & 50.4 & 0.640 \\
\hline \multirow[t]{3}{*}{3} & Lost at FU (1-2) & 633 & 48.8 & 596 & 50.4 & 1,229 & 49.6 & \\
\hline & Reason: & & & & & & & \\
\hline & Household lost at FU & 73 & 11.5 & 72 & 12.1 & 145 & 11.8 & 0.202 \\
\hline & No longer in household & 34 & 5.4 & 40 & 6.7 & 74 & 6.0 & 0.884 \\
\hline & Aged out of sample & 434 & 68.6 & 398 & 66.8 & 832 & 67.7 & 0.920 \\
\hline & Caregiver lost at FU & 36 & 5.7 & 32 & 5.4 & 68 & 5.5 & 0.588 \\
\hline & $\begin{array}{l}\text { No/unreliable } \\
\text { anthropometric } \\
\text { measurement at FU }\end{array}$ & 18 & 2.8 & 23 & 3.9 & 41 & 3.3 & 0.829 \\
\hline & $\begin{array}{l}\text { Other missing } \\
\text { information at } \mathrm{FU}\end{array}$ & 38 & 6.0 & 31 & 5.2 & 69 & 5.6 & 0.087 \\
\hline \multirow[t]{6}{*}{4} & New entrants at FU & 697 & & 694 & & 1,391 & & \\
\hline & Reason: & & & & & & & \\
\hline & Born/aged in the sample & 542 & 77.8 & 532 & 76.7 & 1,074 & 77.2 & 0.657 \\
\hline & $\begin{array}{l}\text { Moved into household } \\
\text { from elsewhere }\end{array}$ & 19 & 2.7 & 11 & 1.6 & 30 & 2.2 & 0.839 \\
\hline & $\begin{array}{l}\text { No/unreliable } \\
\text { anthropometric } \\
\text { measurement at BL }\end{array}$ & 89 & 12.8 & 111 & 16.0 & 200 & 14.4 & 0.625 \\
\hline & $\begin{array}{l}\text { Other missing } \\
\text { information at } \mathrm{BL}\end{array}$ & 47 & 6.7 & 40 & 5.8 & 87 & 6.3 & 0.812 \\
\hline 5 & Endline sample $(2+4)$ & 1,361 & & 1,280 & & 2,641 & & \\
\hline 6 & $\begin{array}{l}\text { Total sample for analysis } \\
(1+5)\end{array}$ & 2,658 & & 2,462 & & 5,120 & & \\
\hline
\end{tabular}

Notes: P-values are reported from Wald tests on the equality of means (ratios) of Treatment and Comparison for each exit or entry reason. Standard errors are clustered at the community level. All tests control for the PMT score.

Our analysis follows the well-known UNICEF conceptual framework of child malnutrition, depicted in Figure 1.2. This framework details the main 
immediate and underlying determinants of child malnutrition and suggests that CTs need to first have an impact on the underlying determinants (or pathways) in order to generate impacts on nutrition outcomes (de Groot et al., 2017). In other words, since CTs have a direct impact on income, we would first expect to see impacts on some of the underlying determinants of child malnutrition. Our analysis therefore takes a broad view and assesses the impacts of LEAP 1000 on nutritional outcomes, the immediate determinants of child malnutrition, and the underlying pathways. The impact evaluation tracked a considerable number of health and nutrition related outcomes, as well as several indicators used to operationalize the underlying determinants of the framework, all according to internationally agreed definitions, and summarized in Table 5.2 (WHO Multicentre Growth Reference Study Group and Onis, 2006, World Health Organization, 2010). Full details of the indicators used in this study, including key references, are provided in Appendix B at the end of this chapter. All indicators are coded in a positive direction, meaning that a higher value indicates an improvement.

Table 5.2, Indicators used in this study

\begin{tabular}{ll}
\hline Outcome/ determinant & Indicators \\
\hline $\begin{array}{l}\text { Outcomes } \\
\text { Immediate determinants } \\
\text { Food intake }\end{array}$ & HAZ, WAZ, WHZ, stunted, wasted, underweight \\
& $\begin{array}{l}\text { Infant and young child feeding (IYCF) index, } \\
\text { breastfeeding, diet diversity and meal frequency }\end{array}$ \\
Health & $\begin{array}{l}\text { Diarrhoea, fever and acute respiratory infections } \\
\text { (ARI) }\end{array}$ \\
$\begin{array}{l}\text { Underlying determinants } \\
\text { Household food security }\end{array}$ & $\begin{array}{l}\text { Household food expenditure, household food } \\
\text { security (HFIAS), household diet diversity } \\
\text { Ware for mothers }\end{array}$ \\
$\begin{array}{l}\text { Women's agency, subjective health, ADL difficulties, } \\
\text { stress, social support, nutritional knowledge } \\
\text { Household health }\end{array}$ & $\begin{array}{l}\text { Source of water, sanitation facility, hand washing } \\
\text { facility, floor material, disposal of child faeces }\end{array}$ \\
\hline
\end{tabular}

Since our indicators consist of different measures with different scales, we also standardize each indicator using the comparison group mean and standard deviation at each wave to be able to compare effect sizes within our own study (Banerjee et al., 2015, Handa et al., 2018b). In addition, we build summary index indicators for each determinant in the framework, by calculating a weighted 
average for each domain following Anderson (2008). ${ }^{37}$ These indices help account for multiple hypothesis testing, as well as provide an overview of overall impacts of LEAP 1000 on the determinants and outcomes of interest.

\subsubsection{Baseline descriptive statistics}

The children in our sample are on average just over two years old and evenly split between boys and girls (Table 5.3). At baseline, 31 percent of the children in our sample were stunted, with an average height-for-age z-score (HAZ) of -1.28. In addition, 15 percent were wasted and approximately 20 percent were underweight. These figures underscore the poor nutritional outcomes for children in our target area, which are the main motivation for the LEAP 1000 programme. In terms of the immediate determinants, the average score on the infant and young child feeding index is 3.3 in the comparison group and 3.4 in the treatment group. Given that the maximum score on this index is 6 , these numbers indicate a considerable gap in dietary practices. The health variables are reverse coded, so that a higher value indicates an improved outcome. Diarrhoea is the most common disease among children in our sample (reported by $41-43$ percent of the sample), followed by fever (reported by 25-29 percent of the sample). Only a small set of children experienced symptoms of acute respiratory infection (reported by 5-6 percent of the sample).

The indicators for the underlying determinants show high food insecurity, accompanied with low levels of household expenditure on food. Using the exchange rate at the time of the baseline survey, these numbers translate to about USD 0.74 and 0.68 per adult equivalent per day for the comparison and treatment group respectively. The indicators for the caregiver show that many caregivers cope with health issues, have relatively little social support and agency, and are exposed to moderate levels of stress. Nutritional knowledge is relatively high, with an average of more than four correct answers out of six questions. The household health environment is poor, with only 10 percent of children having access to an improved source of sanitation, and less than 60 percent access to an improved water source. For only between 21 and 25 percent of children, their faeces are disposed safely.

${ }^{37}$ For the IYCF index, we do not calculate a weighted average but retain the index proposed by Ruel and Menon (2002), converted in standard deviations of the comparison group. 
Table 5.3. Baseline balance test for variables used in analysis

\begin{tabular}{|c|c|c|c|c|}
\hline Variables & $\begin{array}{l}\text { Comparison } \\
\text { group }\end{array}$ & $\begin{array}{l}\text { Treatment } \\
\text { group }\end{array}$ & $\begin{array}{c}\mathrm{p}^{-} \\
\text {value }\end{array}$ & $\begin{array}{l}\text { Normalized } \\
\text { difference }\end{array}$ \\
\hline Age in months & 27.13 & 26.65 & 0.43 & -0.03 \\
\hline Female child & 0.50 & 0.50 & 0.03 & 0.00 \\
\hline \multicolumn{5}{|l|}{ Nutritional status } \\
\hline $\begin{array}{l}\text { Length/height-for-age z- } \\
\text { score }\end{array}$ & -1.27 & -1.29 & 0.77 & -0.02 \\
\hline Stunted (HAZ < -2 SD) & 0.31 & 0.31 & 0.57 & -0.01 \\
\hline \multicolumn{5}{|l|}{ Weight-for-length/height } \\
\hline z-score & -0.49 & -0.51 & 0.77 & -0.01 \\
\hline Wasted (WHZ <-2 SD) & 0.15 & 0.15 & 0.84 & 0.01 \\
\hline Weight-for-age z-score & -1.08 & -1.10 & 1.00 & -0.02 \\
\hline \multicolumn{5}{|l|}{ Underweight (WAZ $<-2$} \\
\hline SD) & 0.19 & 0.20 & 0.42 & 0.02 \\
\hline \multicolumn{5}{|l|}{ Immediate determinants } \\
\hline $\begin{array}{l}\text { Infant and young child } \\
\text { feeding index }\end{array}$ & 3.29 & 3.40 & 0.66 & 0.08 \\
\hline \multicolumn{5}{|l|}{ Breastfeeding score for } \\
\hline IYCF & 0.73 & 0.76 & 0.49 & 0.04 \\
\hline \multicolumn{5}{|l|}{ Diet diversity score for } \\
\hline IYCF & 1.18 & 1.21 & 0.56 & 0.04 \\
\hline $\begin{array}{l}\text { Meal frequency score } \\
\text { for IYCF }\end{array}$ & 1.38 & 1.43 & 0.71 & 0.06 \\
\hline Health index & 0.00 & 0.06 & 0.04 & 0.09 \\
\hline No fever & 0.71 & 0.75 & 0.01 & 0.09 \\
\hline No ARI symptoms & 0.94 & 0.95 & 0.73 & 0.05 \\
\hline No diarrhoea & 0.57 & 0.59 & 0.08 & 0.04 \\
\hline \multicolumn{5}{|l|}{ Underlying determinants } \\
\hline Food security index & -0.01 & -0.06 & 0.71 & -0.07 \\
\hline $\begin{array}{l}\text { Sum of food security } \\
\text { score (5-20) }\end{array}$ & 12.93 & 13.00 & 0.47 & 0.02 \\
\hline $\begin{array}{l}\text { AE food expenditure } \\
\text { per month }(\mathrm{GHC})\end{array}$ & 92.61 & 84.73 & 1.00 & -0.13 \\
\hline $\begin{array}{l}\text { Household diet } \\
\text { diversity score }\end{array}$ & 6.44 & 6.29 & 0.93 & -0.08 \\
\hline Care index & 0.00 & -0.01 & 0.28 & -0.02 \\
\hline $\begin{array}{l}\text { Subjective health ( } 1 \\
\text { very poor - } 5 \text { excellent) } \\
\text { No ADL difficulties }\end{array}$ & $\begin{array}{l}3.20 \\
0.50\end{array}$ & $\begin{array}{l}3.21 \\
0.48\end{array}$ & $\begin{array}{l}0.84 \\
0.70\end{array}$ & $\begin{array}{c}0.01 \\
-0.03\end{array}$ \\
\hline
\end{tabular}




\begin{tabular}{|c|c|c|c|c|}
\hline Variables & $\begin{array}{l}\text { Comparison } \\
\text { group }\end{array}$ & $\begin{array}{l}\text { Treatment } \\
\text { group }\end{array}$ & $\begin{array}{c}\mathrm{p}- \\
\text { value }\end{array}$ & $\begin{array}{c}\text { Normalized } \\
\text { difference }\end{array}$ \\
\hline $\begin{array}{l}\text { MOS-Social Support } \\
\text { score }\end{array}$ & 52.01 & 50.40 & 0.08 & -0.07 \\
\hline Agency score & 2.61 & 2.75 & 0.99 & 0.07 \\
\hline $\begin{array}{l}\text { Cohen perceived stress } \\
\text { scale }\end{array}$ & 28.42 & 28.21 & 0.73 & -0.04 \\
\hline $\begin{array}{l}\text { Nutritional knowledge } \\
\text { score }(0-6)\end{array}$ & 4.33 & 4.34 & 0.25 & 0.00 \\
\hline Health environment index & 0.00 & 0.03 & 0.24 & 0.06 \\
\hline $\begin{array}{l}\text { Improved source of } \\
\text { water }\end{array}$ & 0.58 & 0.60 & 0.91 & 0.04 \\
\hline $\begin{array}{l}\text { Improved source of } \\
\text { sanitation }\end{array}$ & 0.10 & 0.10 & 0.94 & -0.01 \\
\hline $\begin{array}{l}\text { Appropriate hand } \\
\text { washing facilities }\end{array}$ & 0.07 & 0.07 & 0.07 & 0.00 \\
\hline No mud floor & 0.75 & 0.77 & 0.85 & 0.04 \\
\hline $\begin{array}{l}\text { Safe disposal of child } \\
\text { stools } \\
\text { Observations }\end{array}$ & $\begin{array}{c}0.21 \\
1.182\end{array}$ & $\begin{array}{c}0.25 \\
1.297\end{array}$ & 0.29 & 0.11 \\
\hline
\end{tabular}

Notes: P-values are reported from Wald tests on the equality of means of Treatment and Comparison for each variable. A p-value $<0.05$ indicates a significant difference between the treatment and comparison mean. Standard errors are clustered at the community level. All tests control for the PMT score.

\subsubsection{Study design validity checks}

Since the evaluation is quasi-experimental, it is important to conduct a few checks for the validity of our design. There are two main assumptions for the RDD strategy to work. First, eligible households should not be able to manipulate their PMT score to ensure they qualified for the LEAP 1000. The PMT score is based on responses to a short household questionnaire covering household demographics, housing characteristics, agricultural assets and durables ownership. Answers to these questions are entered into a formula to calculate the PMT score. This formula is held by the LEAP Management Unit and is not revealed to the public; therefore, it is unlikely that households would be able to manipulate their eligibility. ${ }^{38}$ More importantly, the PMT score (combined with demographic eligibility according to LEAP categories) is the only factor determining eligibility for receiving LEAP 1000. One way of making sure that potential beneficiaries, survey administrators or

\footnotetext{
${ }^{38}$ In addition, during targeting the answers of a random sample of approximately 50 percent of applying households was validated by physically visiting the dwelling.
} 
programme implementers did not knowingly influence the score is by conducting a manipulation test. The main idea behind such a test is that there should be no discontinuity in the density of the PMT score at the cut-off point (McCrary, 2008). If PMT scores had been manipulated to influence who would become eligible for the programme, we would see an unexpectedly higher number (i.e. density) of candidate households just below the cut-off compared to just above the cut-off. The result of such a manipulation test, following procedures outlined in Cattaneo et al. (2018b) for Ghana LEAP 1000 is plotted in Figure 5.1 using the targeting data of the programme. This graph confirms that there was no manipulation of scores in Ghana LEAP 1000, as the confidence intervals for the lines below and above the cut-off overlap and hence there is no significant difference in the density around the cut-off. In any case, the line is slightly higher on the right side (i.e. the noneligible side) of the threshold, which is further confirmation that scores were not manipulated to make households eligible for the programme.

\section{Figure 5.1, Manipulation test for Ghana LEAP 1000}

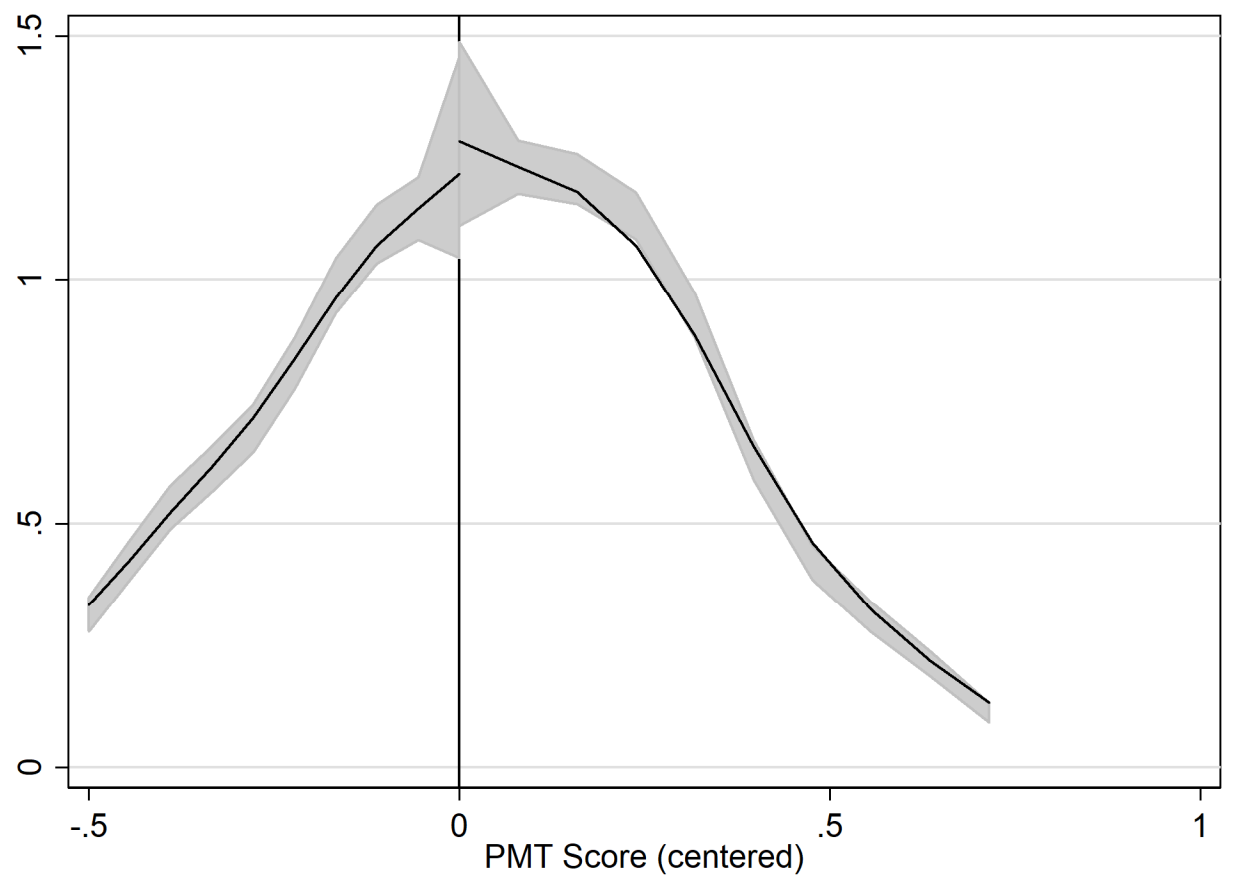

Note: Figure based on Ghana LEAP 1000 targeting data in the five districts of the impact evaluation $(\mathrm{N}=8,058)$. The graph consists of two separate graphs plotted using localpolynomial density estimators on each side of the cut-off, which is why the lines are not connected at the cut-off. 
A second key assumption of the RDD is that there are no discontinuities in outcomes at baseline. To test this, we check baseline balance among the key outcome variables in this study. To test for baseline balance, we perform a Wald test of equality for each indicator separately. As is typical in RD studies, we control for the forcing variable (the PMT score) in this analysis. We also calculate the normalized difference between the treatment group mean and the comparison group mean (Imbens and Rubin, 2015). Fortunately, our design resulted in strong baseline balance among the variables of interest (Table 5.3). There are only two baseline differences that are statistically significant at the 5 percent level, namely whether a child had fever and sex of the child. Because of this first difference, the health score, which is composed of the three indicators for diseases, is also significantly different at baseline. However, the normalized difference for all three imbalanced indicators is low, and much lower than the rule of thumb of 0.25 proposed by Imbens and Rubin (2015).

\subsubsection{Attrition}

In any longitudinal study, attrition may pose threats to the internal and external validity of the results. Since we are dealing with children, we have potential attrition at three levels: household, caregiver and children. In addition, due to our age restrictions, children can age out of the sample after the baseline, but other children can age into the sample at endline. The most important validity check is therefore whether there is any differential entry and exit between the treatment and the comparison group, as this may compromise our quasi-experimental design.

We start by examining the differences between the children who remained in the sample in both waves, and those that left the sample after the baseline (Appendix Table S5.1) and those children that entered the sample at endline (Appendix Table S5.2). In both cases, we find several significant differences between these groups, however, most differences are the result of the difference in age between groups. Those that remained in the sample in both waves are by definition younger than those that are present in the baseline, but not in the endline. For the new entrants at endline, it holds that they are much younger (at baseline) than children who appear in both waves. Since age is a strong determining factor for a range of outcomes, including anthropometrics and illness, it is no surprise that we find that these groups are different in several observable characteristics.

However, the main test of interest here is whether there are any differences between the comparison and treatment group in terms of exit and entry in the sample. We already showed that there are no significant differences in terms of reasons for leaving or entering the sample (Table 5.1). We now continue to test for baseline balance between treatment and comparison children for all indicators among a) the children appearing in both waves (Appendix Table S5.3) b) children 
lost at follow-up (Appendix Table S5.4) and c) children entering the sample at endline (Appendix Table S5.5). Fortunately, this analysis shows that there are no major differences between the treatment and comparison group and hence our study design is not compromised. Given these results, we are also confident that our findings are not driven by survival bias or migration bias.

\subsection{Analytical strategy}

The LEAP 1000 impact evaluation uses a RDD and compares households which are just below a PMT cut-off score (used to determine eligibility for LEAP) to those just above the cut-off score (and thus not eligible for LEAP). Households just above and just below the cut-off are very similar as they have virtually identical PMT scores, and thus the group of households above the cut-off can serve as a valid comparison group for households below the cut-off. Both the treatment and comparison group were interviewed in 2015 and 2017 and the analysis takes advantage of the longitudinal panel structure of the evaluation. More specifically, we use the panel structure of the evaluation data to estimate a difference-indifference (DD) model, comparing the change in the treatment group to the change in the comparison group over time. This methodology nets out changes that may have occurred over time due to other factors (e.g., floods, recession, inflation, rapid economic development) through the change in outcomes in the comparison group.

The validity of the impact estimates obtained by this design depends on 'the parallel trends assumption', which assumes that the change in the comparison group provides a good approximation of the change that would have occurred to children in LEAP 1000 households had they not been part of the programme. The RDD design in combination with the fact that treatment and comparison households are drawn from the same communities increases our confidence in this assumption. However, we also include several individual and household characteristics that are not expected to be influenced by the programme in the impact estimation models to control for potential differences between treatment and the comparison groups and improve the precision of our estimates. These include the age and sex of the child, household PMT score, household size, sex of the household head, age of the household head, and educational level of the household head. All these variables are measured at baseline prior to programme commencement. We also include community fixed effects to control for varying community characteristics.

Formally, we use the following DD model:

$$
Y_{i j t}=\beta_{0}+\beta_{1} P_{i j}+\beta_{2} T_{t}+\beta_{3} P_{i j} \cdot T_{t}+\beta_{4} \boldsymbol{X}_{i j t}+\lambda_{j}+\varepsilon_{i j t}
$$

Where $Y_{i j t}$ is the outcome of interest for child $i$ who lives in community $j$ at time $t . P_{i j}$ is a binary variable set to 1 if the household to which $i$ belongs in community $j$ is in the LEAP 1000 programme, and to 0 if it is not. $T_{t}$ is a dummy 
(binary) variable for time of the observation, set to 1 if the observation is from the endline survey, and to 0 if it is from the baseline. $P_{i j} \cdot T_{t}$ is the interaction term of the programme and the time dummy. $\boldsymbol{X}_{i j t}$ represents a set of observed individual and household characteristics at baseline described above. $\lambda_{j}$ represents a full set of community fixed effects included in the model to control for unobserved characteristics of the communities that do not change in the evaluation interval. Finally, $\varepsilon_{i j t}$ is the usual error term. Equation 5.1 is estimated using ordinary least squares (OLS) regression with standard errors adjusted for clustering at the community level. The coefficient of interest is $\beta_{3}$, which represents the intent-totreat (ITT) effect at of LEAP 1000. Note that due to the study design, we estimate a local average treatment effect (LATE) around the cut-off. It is likely that the impacts of the programme might be different for households further away from the cut-off (i.e. the poorest households) and therefore our estimates should be regarded as a lower bound of the impact of LEAP 1000 (Mehta, 2018).

Since LATE may be sensitive to the choice of neighbourhood around the cut-off (Cattaneo and Vazquez-Bare, 2016), we apply a sensitivity analysis by examining the sample closer to the cut-off. Note that our main sample was already chosen to be as close to the cut-off as possible, by selecting households in a systematic (descending or ascending) way based on their PMT score starting with the household closest to the cut-off on either side. Nevertheless, we employ the methods proposed by Calonico et al. (2017) to select a data-driven bandwidth around the cut-off for our main indicators of interest (nutritional status and the summary indexes of the determinants). Since an optimal bandwidth is calculated for each different indicator, we use both the smallest possible bandwidth and the highest possible bandwidth resulting from these calculations and compare the results to the main analysis for the full sample.

\subsubsection{Heterogeneity analysis}

Besides our main analysis described above, we are interested to examine whether there are any heterogeneous effects of LEAP 1000. Specifically, we are interested whether the programme had a differential effect by age of entry in the programme, moderating effects of nearby health facilities, and moderating effects of positive and negative shocks to the household. We are also interested to examine whether intra-household dynamics play a role in the impact of the programme. We set out to answer the following sub-questions.

Does the impact of LEAP 1000 differ based on the number of months in the programme during the first 1,000 days?

We start our heterogeneity analysis by exploring whether LEAP 1000 had a stronger impact on children who benefitted from the programme for a longer duration. This hypothesis is directly linked to the theory of the first 1,000 days, which states that most of the growth deficit that contributes to stunting occurs 
from conception up to 24 months of age (Victora et al., 2010). In addition, evidence from South Africa suggests that children who were exposed to the Child Support Grant for a longer duration under the age of three, showed significantly higher linear growth compared to children who were only exposed for a minimal time (Aguero et al., 2007). To test this hypothesis in our study setting, we first cut our sample into small age bands of six months and estimate the impact of LEAP 1000 on each of these age groups separately using equation 5.1 on the three nutritional indices and the summary indexes of the immediate and underlying determinants.

Second, we use the full sample at endline and interact the treatment indicator with the number of months a child was exposed during the first 24 months of his or her life. More specifically, we estimate:

$$
Y_{i j}=\beta_{0}+\beta_{1} P_{i j}+\beta_{2} M_{i j}+\beta_{3} P_{i j} \cdot M_{i j}+\beta_{4} \boldsymbol{X}_{i j}+\lambda_{j}+\varepsilon_{i j}
$$

In this equation, $M$ is the number of months exposed to the programme during the first 1,000 days of life and the other parameters are the same as in equation 5.1 above. ${ }^{39}$ The parameter of interest is again $\beta_{3}$ which measures the change in treatment effect based on the number of months exposed the LEAP 1000. A significant interaction effect provides evidence that LEAP 1000 has a differential impact depending on the number of months exposed to the programme.

Does distance to a health facility or quality of the nearest health facility moderate the effect of LEAP 1000 ?

Health facility access and quality may be an important moderator of LEAP 1000 impact. Previous research in Ghana has demonstrated that health facility characteristics are important determinants for child growth and access to health facility is important for weight-for-height (Lavy et al., 1996). Therefore, in this analysis, we will use the data collected from health facilities at baseline to determine if the distance to the health facility and the quality of the health facility moderate the impacts of LEAP 1000 on child health and nutrition. The health facility questionnaire surveyed each primary health facility in the evaluation study area, for a total of 142 facilities. A primary health facility can be a Village Health Post (VHP), a Community-based Health Planning and Services (CHPS) compound or a health centre, with the latter being the most advanced. We construct a measure of distance to the nearest health facility using the GPS coordinates of the households and health facilities collected during the baseline data collection. The average distance to the nearest health facility is about 4.5 kilometres (Table 5.4) and for about two-thirds of our sample, the nearest health facility is within $5 \mathrm{kms}$. To

\footnotetext{
${ }^{39}$ For the comparison group, we calculate the number of potential months of exposure, if they would have been eligible for the programme.
} 
account for the difference in the quality of care between different types of health care facilities, we use two measures of quality. The first is an indicator of whether a doctor is present at the closest health facility. This is supported by the study of Lavy et al. (1996), which found that children are taller in communities with more doctors. For about one-third of our sample, a doctor is present in the nearest health facility. We also construct an indicator using the combination of distance and the presence of a doctor to account for both distance and quality. Finally, we develop a health facility quality index using factor analysis on a wide variety of facility characteristics, including type and number of personnel, facility equipment, services, and drug availability. We then standardize this indicator for easier interpretation. All our quality and distance indicators are well-balanced at baseline (Table 5.4).

Table 5.4. Variables used in the analysis on health facility access and quality

\begin{tabular}{|c|c|c|c|}
\hline Variables & $\begin{array}{l}\text { Comparison } \\
\text { Mean }\end{array}$ & $\begin{array}{l}\text { Treatment } \\
\text { Mean }\end{array}$ & p-value \\
\hline Distance nearest health facility (km) & 4.77 & 4.52 & 0.26 \\
\hline Health facility within 5 kilometres & 0.68 & 0.69 & 0.69 \\
\hline $\begin{array}{l}\text { Doctor present at nearest health } \\
\text { facility }\end{array}$ & 0.31 & 0.31 & 0.56 \\
\hline $\begin{array}{l}\text { Health facility within } 5 \text { kilometres } \\
\text { and doctor present }\end{array}$ & 0.22 & 0.22 & 0.36 \\
\hline Health facility quality index & 0.22 & 0.20 & 0.30 \\
\hline Observations & 1,182 & 1,297 & \\
\hline
\end{tabular}

Notes: P-values are reported from Wald tests on the equality of means of Treatment and Comparison for each variable. A p-value $<0.05$ indicates a significant difference between the treatment and comparison mean. Standard errors are clustered at the community level. All tests control for the PMT score.

We estimate the effect of access and quality of health facility using a triple interaction difference-in-difference model:

$$
\begin{aligned}
Y_{i j t}=\beta_{0}+\beta_{1} P_{i j} & +\beta_{2} T_{t}+\beta_{3} H_{i j}+\beta_{4} P_{i j} \cdot T_{t} \\
& +\beta_{5} P_{i j} \cdot H_{i j}+\beta_{6} T_{t} \cdot H_{i j}+\beta_{7} P_{i j} \cdot T_{t} \cdot H_{i j}+\beta_{8} X_{i j t}+\lambda_{j}+\varepsilon_{i j t}
\end{aligned}
$$

In this model, $H_{i j}$, represents the indicator for distance to health facility or quality of the nearest health facility and the other parameters are specified as above in equation 5.1. The parameter of interest is $\beta$, which measures how the treatment effect varies with respect to $H_{i j}$ (Bedoya et al., 2017). 
Does the experience of community-level shocks or positive events affect the impact of LEAP 1000 ?

In our third heterogeneity analysis, we examine the importance of shocks on the impact of LEAP 1000. It is widely accepted that negative shocks in utero and during early childhood can have lasting consequences throughout life (e.g. Almond and Currie, 2011, Strauss and Thomas, 2008). Hence, it is interesting to assess whether LEAP 1000 was able to mitigate some of the negative consequences due to shocks. Reversely, it may also be that unexpected positive events increase or complement the impact of LEAP 1000. Households in our sample experienced many shocks to their livelihoods, as shown in Table 5.5. These shocks were collected as part of the community survey that accompanied the endline data collection. Respondents to the community survey included a group of key informants of each community, such as assembly members, unit committee members, community chairmen, traditional leaders, opinion leaders, youth and women's groups members or chairs. Supervisors administered the community questionnaire, which elicited information on the provision of basic services, including access to roads, schooling and health facilities; on events that happened in the community since 2015, both negative and positive; and information on other development programmes in the community..$^{40}$ For our analysis, we use both positive and negative events that occurred in the year of the endline survey to test whether the effect of LEAP 1000 varies with respect to the occurrence of such events. The most common shock was crop diseases and pests ( $77-81$ percent of the sample), followed by livestock diseases (72- 75 percent). Extreme weather events, such as droughts and floods, occurred in a minority of the communities in our sample. Other events included in this analysis are sharp increases in prices and interruption of the water supply. For positive events, we consider new roads or transportation networks (12 percent of our sample) and other development programmes operating in the community (910 percent).

\footnotetext{
${ }^{40}$ For reasons of logistics and efficiency, the community questionnaire was only conducted in communities where more than five sampled households resided. Hence, the number of observations is slightly lower for this analysis.
} 
Table 5.5. Experience of shocks

\begin{tabular}{lccc}
\hline Variables & $\begin{array}{c}\text { Comparison } \\
\text { Mean }\end{array}$ & $\begin{array}{c}\text { Treatment } \\
\text { Mean }\end{array}$ & $\begin{array}{c}\mathrm{p}- \\
\text { value }\end{array}$ \\
\hline Negative shock & & & \\
$\quad$ Drought in 2017 & 0.13 & 0.13 & 0.46 \\
$\quad$ Flood in 2017 & 0.17 & 0.16 & 0.04 \\
Crop disease/pest in 2017 & 0.78 & 0.81 & 0.73 \\
$\quad$ Livestock disease in 2017 & 0.75 & 0.73 & 0.19 \\
$\quad$ Interruption water supply in 2017 & 0.30 & 0.30 & 0.54 \\
$\quad$ Sharp change in prices in 2017 & 0.17 & 0.17 & 0.35 \\
Positive shock & & & \\
$\quad$ New road/transportation in 2017 & 0.12 & 0.11 & 0.38 \\
$\quad$ Development programme in 2017 & 0.10 & 0.09 & 0.55 \\
Observations & 1,121 & 1,226 & \\
\hline
\end{tabular}

Notes: P-values are reported from Wald tests on the equality of means of Treatment and Comparison for each variable. A p-value $<0.05$ indicates a significant difference between the treatment and comparison mean. Standard errors are clustered at the community level. All tests control for the PMT score.

Our analysis follows the same method as in our previous sub-section and we estimate the following equation:

$$
\begin{aligned}
Y_{i j t}=\beta_{0}+\beta_{1} P_{i j} & +\beta_{2} T_{t}+\beta_{3} S_{i j}+\beta_{4} P_{i j} \cdot T_{t} \\
& +\beta_{5} P_{i j} \cdot S_{i j}+\beta_{6} T_{t} \cdot S_{i j}+\beta_{7} P_{i j} \cdot T_{t} \cdot S_{i j}+\beta_{8} \boldsymbol{X}_{i j t}+\lambda_{j}+\varepsilon_{i j t}
\end{aligned}
$$

Here, $S_{i j}$, is a binary indicator equal to 1 if the household $j$ to which child $i$ belongs lives in a community that experienced a shock during 2017, and all the other parameters are defined as above. ${ }^{41}$ The parameter of interest is again $\beta$, which measures how the treatment effect varies when a household experienced a shock.

\footnotetext{
${ }^{41}$ We also conduct sensitivity checks by using district fixed effects rather than community fixed effects for this analysis, as the community fixed effects may pick up all the variation in our health facility and community shock indicators. However, results using district fixed effects are highly similar.
} 
To what extent does intra-household resource allocation influence the impact of LEAP $1000 ?$

Our final heterogeneity analysis relates back to the findings of Chapter 4 of this thesis. Chapter 4 provided some suggestive evidence that better-educated fathers, rather than mothers, are more inclined to invest in their daughters. It must be noted, however, that the evaluation design was not specifically set up to test the effect of intra-household dynamics on the programme impacts. For example, the programme did not randomize the recipient of the grant (as for example in Akresh et al. (2016)) and the large majority of recipients were women (UNICEF Office of Research - Innocenti et al., 2018). We therefore apply a similar methodology as in Chapter 4 . We take the education of the parents as a source of exogenous bargaining power and examine whether effects on girls are significantly different from the effect on boys by educational status of the parents. Even though the transfer is received by the women, this approach assumes that bargaining power within the household influences how the money is spent. More specifically, we create subgroups for children whose:

1) Mother has not attained any formal schooling

2) Mother has attained some formal schooling

3) Father has not attained any formal schooling

4) Father has attained some formal schooling

Within these subgroups we estimate:

$$
\begin{aligned}
Y_{i j t}=\beta_{0}+\beta_{1} P_{i j} & +\beta_{2} T_{t}+\beta_{3} S_{i j}+\beta_{4} P_{i j} \cdot T_{t} \\
& +\beta_{5} P_{i j} \cdot G_{i j}+\beta_{6} T_{t} \cdot G_{i j}+\beta_{7} P_{i j} \cdot T_{t} \cdot G_{i j}+\beta_{8} X_{i j t}+\lambda_{j}+\varepsilon_{i j t}
\end{aligned}
$$

In this equation $G_{i j}$ represents the sex of the child and all other parameters are again defined as in the previous equations. The parameter of interest is again $\beta 7$, which measures how the impact of LEAP 1000 varies by the sex of the child, for each of the subgroups defined above. Based on the analysis in Chapter 4, we expect that the differential effect on girls of better-educated fathers is positive, while the effect on girls for better-educated mothers is negative, because of their preference to invest more in their sons. Note that we use the dichotomous indicator for parent's education in this analysis (as defined in the subgroups), to ease interpretation of the impact estimates. Chapter 4 showed that for the nutritional analysis, results were similar with parental education coded as dummies and years of education. We only use individual-level outcomes for this analysis (nutritional outcomes and immediate determinants), since we expect that differential investments in children are only detectable at an individual level. 


\subsubsection{Multiple hypothesis testing}

Since we are interested to document the impact of LEAP 1000 on a wide variety of outcomes and determinants, we are at risk of rejecting a null hypothesis due to the large number of tests conducted. One approach to reduce the number of tests is to build summary indexes of our main domains of interest, as described in section 5.3.1. In addition, we subject the analysis on the nutritional outcomes and summary indexes to an additional strategy to control the familywise error rate (FWER), where we define the family of tests at the outcome or determinant level (i.e. nutritional outcomes, immediate determinants and underlying determinants are each separate families) (Westfall and Young, 1993). When analysing individual outcomes, we control for the false discovery rate (FDR). Controlling for the FDR as opposed to the more stricter FWER increases the power when conducting hypothesis testing on many individual outcomes and when the costs of falsely rejecting a hypothesis is relatively low (Anderson, 2008). We follow the two-stage procedure proposed by Benjamini et al. (2006) and calculate FDR-adjusted q-values based on Anderson (2008). ${ }^{42}$ For our heterogeneity analysis in section 5.5.2, we adopt a more conservative approach and calculate adjusted p-values while allowing for correlation among the outcomes. More specifically, we use the Dubey/Armitage-Parmar approach (Sankoh et al., 1997).

\subsection{Results}

\subsubsection{Main results}

We start by plotting the main results in an overview graph (Figure 5.2). This graph depicts the ITT effect on the main outcome indicators (HAZ, WAZ and WHZ) as well as the composite index indicators of the immediate and underlying determinants. LEAP 1000 had no measurable impact on any of the anthropometric indices, nor on the immediate determinants of health and food intake. There is a significant impact on one underlying determinant, food security, but not on care and the health environment.

\footnotetext{
42 The FDR q-values can be lower than the unadjusted p-values when many hypotheses are rejected. This is because if there are many true rejections, then we can tolerate several false rejections as well. However, this mainly happens for $\mathrm{p}$-values that are so large that the null hypothesis for that specific test will not be rejected regardless.
} 
Figure 5.2. Intent-to-treat effect of LEAP 1000 on nutritional outcomes and determinants

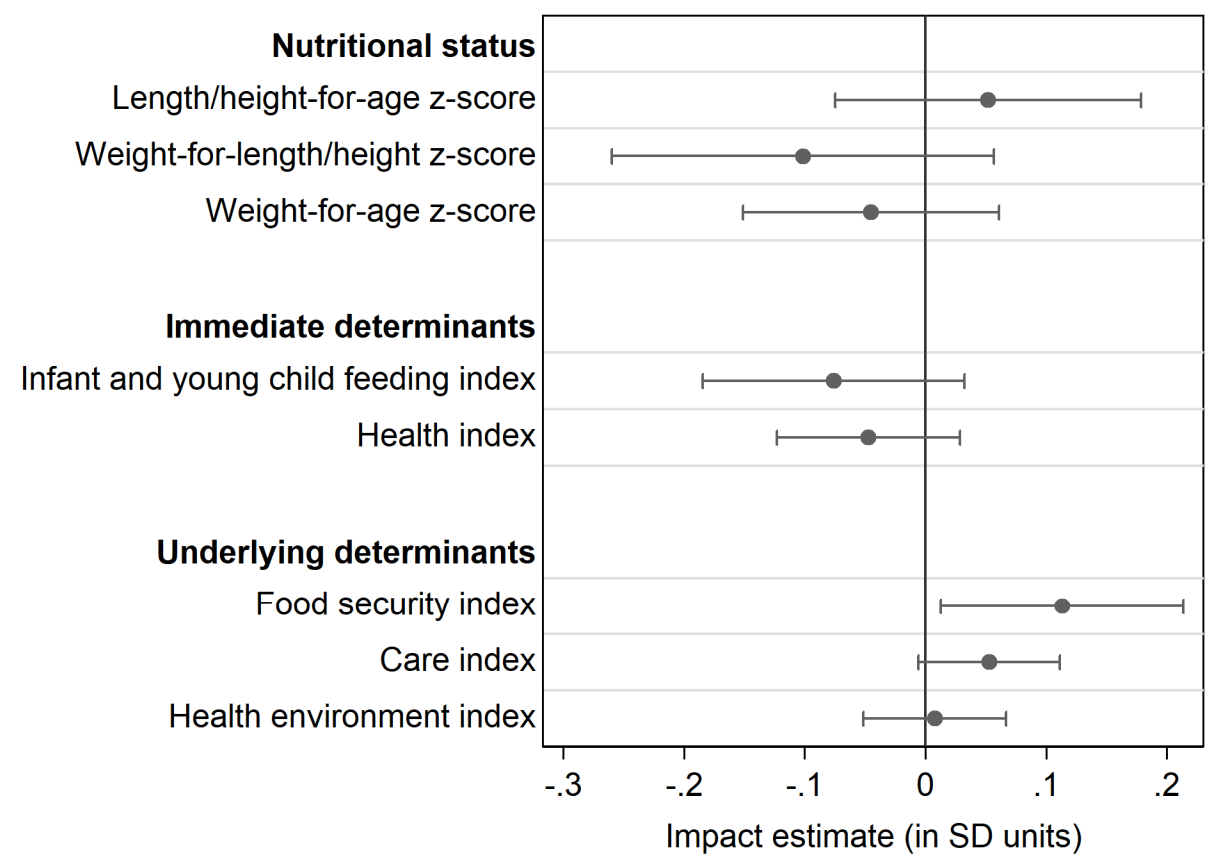

The impacts are presented in more detail in Table $5.6-5.8$ below. In addition to results on HAZ, WAZ and WHZ, we also present the impact estimates for stunting, wasting and underweight in Table 5.6. The estimate for stunting is an insignificant 0.2 percentage point (pp), and the estimate for wasting and underweight is $1.5 \mathrm{pp}$ and $2.6 \mathrm{pp}$ respectively, both not significant. Note that there was an important reduction in the rate of wasting between baseline and endline, from 15 percent to approximately 8 percent, yet this decreased happened for both treatment and comparison groups (Appendix Table S5.6). 
Table 5.6. Impacts on nutritional status (6 - 59 Months)

\begin{tabular}{lccc}
\hline & $\begin{array}{c}\text { Impact } \\
\text { estimate }\end{array}$ & $\begin{array}{c}\text { Unadjusted } \\
\text { p-value }\end{array}$ & $\begin{array}{c}\text { Adjusted p- } \\
\text { value }\end{array}$ \\
\hline Length/height-for-age z-score & 0.052 & 0.428 & 0.646 \\
Stunted (HAZ <-2 SD) & $(0.06)$ & & 0.897 \\
Weight-for-length/height z-score & $\begin{array}{l}0.002 \\
(0.02)\end{array}$ & 0.911 & 0.437 \\
Wasted (WHZ <-2 SD) & $(0.08)$ & 0.215 & 0.697 \\
Weight-for-age z-score & 0.015 & 0.452 & 0.646 \\
Underweight (WAZ <-2 SD) & $(0.02)$ & & 0.378 \\
& -0.045 & 0.411 & \\
\hline$N$ & $(0.05)$ & & \\
\hline
\end{tabular}

Notes: Estimations use difference in difference modelling. Robust standard errors clustered at the community level are in parentheses. Adjusted p-values control for the FWER as described in section 5.4.2. Estimations are adjusted and include child's age, sex, PMT score, household size, sex, age and education of the household head, and community fixed effects. ${ }^{*} p<0.1{ }^{* *} p<0.05 ;{ }^{* * *} p<0.01$.

In Table 5.7, we present the impact estimates for the IYCF index and the health index, as well as the indicators that make up both indexes. We find a significant negative effect on the meal frequency score, suggesting that children in treatment households eat fewer meals than their comparison counterparts. In addition, there is a weakly negative effect for fever, which is significant at the 10 percent level. It indicates that LEAP 1000 children more often experience fever than children in the comparison group. However, note that this result is likely a reflection of the baseline difference on this indicator, since the endline values are quite similar for both groups (71.9 and 72.5 percent for treatment and comparison respectively, Appendix Table S5.6). In addition, the latter effect is not robust to multiple hypothesis testing adjustments.

In terms of the underlying determinants, we find a positive and significant effect of LEAP 1000 on the food security index of 0.11 SD (Table 5.8). This effect is driven by the positive effect on food consumption (0.164 SD) and household diet diversity (0.144 SD). The overall impact on the care index is significant at the 10 percent level but small, with an impact estimate of 0.05 SD. This effect is particularly driven by the significant impact on one of its components, social support, of $0.147 \mathrm{SD}$. However, this second finding is not robust to multiple hypothesis testing. None of the indicators representing the household's health environment show a significant impact. 
Table 5.7. Impacts on food intake and health (6 - 59 Months)

\begin{tabular}{lccc}
\hline & $\begin{array}{c}\text { Impact } \\
\text { estimate }\end{array}$ & $\begin{array}{c}\text { Unadjusted } \\
\text { p-value }\end{array}$ & $\begin{array}{c}\text { Adjusted } \\
\text { p-value }\end{array}$ \\
\hline Infant and young child feeding index & $\begin{array}{c}-0.076 \\
(0.05)\end{array}$ & 0.176 & 0.293 \\
& 0.007 & 0.726 & 0.939 \\
Breastfeeding score & $(0.02)$ & & \\
& 0.031 & 0.612 & 0.939 \\
Diet diversity score & $(0.06)$ & & \\
& $-0.134^{* *}$ & 0.016 & 0.052 \\
Meal frequency score & $(0.06)$ & & \\
& -0.047 & 0.230 & 0.293 \\
Health index & $(0.04)$ & & \\
& $-0.105^{*}$ & 0.076 & 0.298 \\
No fever & $(0.06)$ & & \\
& -0.046 & 0.394 & 0.650 \\
No ARI symptoms & $(0.05)$ & & \\
& 0.005 & 0.934 & 1.000 \\
No diarrhoea & $(0.06)$ & & \\
\hline$N$ & 5,120 & & \\
\hline
\end{tabular}

Notes: Estimations use difference in difference modelling. Impact estimates are mean standardized ITTs; therefore, effect sizes are expressed in SD of the control group. All indicators and indexes are coded such that a higher value represents a better outcome. Robust standard errors clustered at the community level are in parentheses. Adjusted pvalues for the summary indexes control for the FWER and adjusted p-values for the individual outcomes control for the FDR, as described in section 5.4.2. Estimations are adjusted and include child's age, sex, PMT score, household size, sex, age and education of the household head, and community fixed effects. ${ }^{*} p<0.1^{* *} p<0.05 ;{ }^{* *} p<0.01$.

Our sensitivity checks using smaller bandwidths are presented in Appendix Table S5.7. The sensitivity checks largely confirm our main analysis, except that the positive effect on food security disappears when moving closer to the cut-off. This might mean that the effect is more pronounced for households further away from the cut-off, which are by definition slightly poorer than households closer to the cut-off. In addition, note that the sample size decreases drastically when reducing the bandwidth, which can lead to larger standard errors. For instance, the effect size on food security is very similar in column 3 , yet the estimated standard error is nearly twice as large. 
Table 5.8. Impacts on food security, care and health environment (6 - 59 Months)

\begin{tabular}{|c|c|c|c|}
\hline & $\begin{array}{c}\text { Impact } \\
\text { estimate }\end{array}$ & $\begin{array}{c}\text { Unadjusted } \\
\text { p-value }\end{array}$ & $\begin{array}{l}\text { Adjusted } \\
\text { p-value }\end{array}$ \\
\hline Food security index & $\begin{array}{c}0.113^{* *} \\
(0.05)\end{array}$ & 0.030 & 0.088 \\
\hline Food security score & $\begin{array}{l}0.053 \\
(0.06)\end{array}$ & 0.405 & 0.157 \\
\hline Food consumption per AE & $\begin{array}{c}0.164^{* *} \\
(0.07)\end{array}$ & 0.020 & 0.061 \\
\hline Household diet diversity score & $\begin{array}{c}0.144^{* *} \\
(0.07)\end{array}$ & 0.038 & 0.061 \\
\hline Care index & $\begin{array}{l}0.053^{*} \\
(0.03)\end{array}$ & 0.082 & 0.172 \\
\hline Subjective health & $\begin{array}{l}-0.039 \\
(0.06)\end{array}$ & 0.514 & 1.000 \\
\hline No ADL difficulties & $\begin{array}{l}-0.018 \\
(0.06)\end{array}$ & 0.770 & 1.000 \\
\hline Social support scale & $\begin{array}{c}0.147^{* *} \\
(0.07)\end{array}$ & 0.032 & 0.237 \\
\hline Agency score & $\begin{array}{l}0.031 \\
(0.08)\end{array}$ & 0.690 & 1.000 \\
\hline Stress scale & $\begin{array}{l}0.055 \\
(0.06)\end{array}$ & 0.335 & 1.000 \\
\hline Nutritional knowledge & $\begin{array}{l}0.090 \\
(0.07)\end{array}$ & 0.176 & 0.789 \\
\hline Health environment index & $\begin{array}{l}0.008 \\
(0.03)\end{array}$ & 0.800 & 0.795 \\
\hline Improved source of water & $\begin{array}{l}-0.018 \\
(0.05)\end{array}$ & 0.703 & 1.000 \\
\hline Improved sanitation facility & $\begin{array}{l}-0.048 \\
(0.06)\end{array}$ & 0.439 & 1.000 \\
\hline Appropriate handwashing facility & $\begin{array}{l}0.092 \\
(0.07)\end{array}$ & 0.199 & 1.000 \\
\hline
\end{tabular}




\begin{tabular}{lccc}
\hline & $\begin{array}{c}\text { Impact } \\
\text { estimate }\end{array}$ & $\begin{array}{c}\text { Unadjusted } \\
\text { p-value }\end{array}$ & $\begin{array}{c}\text { Adjusted } \\
\text { p-value }\end{array}$ \\
\hline No mud floor & 0.054 & 0.436 & 1.000 \\
& $(0.07)$ & & \\
Safe disposal of child faeces & -0.062 & 0.418 & 1.000 \\
& $(0.08)$ & & \\
\hline$N$ & 5,120 & & \\
\hline
\end{tabular}

Notes: Estimations use difference in difference modelling. Impact estimates are mean standardized ITTs; therefore, effect sizes are expressed in SD of the control group. All indicators and indexes are coded such that a higher value represents a better outcome. Robust standard errors clustered at the community level are in parentheses. Adjusted pvalues for the summary indexes control for the FWER and adjusted p-values for the individual outcomes control for the FDR, as described in section 5.4.2. Estimations are adjusted and include child's age, sex, PMT score, household size, sex, age and education of the household head, and community fixed effects. ${ }^{*} p<0.1^{* *} p<0.05 ;{ }^{* *} p<0.01$.

In sum, the main analysis shows that LEAP 1000 had no measurable impact on any of the three anthropometric indices, nor on the rate of stunting, wasting and underweight. In addition, no positive impact was found on the two underlying determinants of malnutrition, child food intake and health. Among the underlying determinants, food security and care, driven by social support, improved although the latter effect is not robust to multiple hypothesis testing.

The positive results on household food security stand in contrast with the negative impact on child individual meal consumption. We therefore conduct some additional analysis to examine this finding in more detail. For some indicators, we have both a measure at the individual child level as well as on the aggregate household level. In particular, we look into the programme impacts on the number of meals per day consumed by children, versus the number of meals consumed per day as reported by the household. In addition, we examine the consumption of various food groups at the household level and at the child level. The results show that children of LEAP 1000 households experienced a drop in the number of meals they consume per day of 0.12 , while at the household level, the number of meals increased by 0.07 (Table 5.9). The difference between these two effects is significant. In terms of dietary diversity, we observe significant increases in the consumption of cereals, milk products and oil and fats at the household level, but no impacts at the individual child level. There are no differences in effects though between the child and household level, except for the latter category. 
Table 5.9, Impact of LEAP 1000 on number of meals and diet diversity, at child and household level

\begin{tabular}{|c|c|c|c|}
\hline & $\begin{array}{l}\text { Child } \\
\text { level }\end{array}$ & $\begin{array}{c}\text { Household } \\
\text { level }\end{array}$ & $\begin{array}{l}\text { P-value of } \\
\text { difference }\end{array}$ \\
\hline Number of meals per day & $\begin{array}{c}-0.123^{* *} \\
(0.060)\end{array}$ & $\begin{array}{l}0.073^{* *} \\
(0.036)\end{array}$ & 0.004 \\
\hline Cereals & $\begin{array}{l}-0.003 \\
(0.024)\end{array}$ & $\begin{array}{c}0.008^{* * *} \\
(0.003)\end{array}$ & 0.633 \\
\hline White tubers and roots & $\begin{array}{l}-0.001 \\
(0.013)\end{array}$ & $\begin{array}{c}0.009 \\
(0.026)\end{array}$ & 0.708 \\
\hline Vegetables & $\begin{array}{c}0.002 \\
(0.021)\end{array}$ & $\begin{array}{c}0.002 \\
(0.005)\end{array}$ & 0.981 \\
\hline Fruits & $\begin{array}{c}0.002 \\
(0.026)\end{array}$ & $\begin{array}{l}-0.007 \\
(0.024)\end{array}$ & 0.753 \\
\hline Meat & $\begin{array}{c}0.015 \\
(0.014)\end{array}$ & $\begin{array}{c}0.034 \\
(0.024)\end{array}$ & 0.422 \\
\hline Eggs & $\begin{array}{c}0.018 \\
(0.012)\end{array}$ & $\begin{array}{c}0.005 \\
(0.014)\end{array}$ & 0.430 \\
\hline Fish and other seafood & $\begin{array}{c}0.012 \\
(0.027)\end{array}$ & $\begin{array}{c}0.004 \\
(0.017)\end{array}$ & 0.785 \\
\hline Legumes, nuts and seeds & $\begin{array}{c}0.025 \\
(0.024)\end{array}$ & $\begin{array}{c}0.045 \\
(0.032)\end{array}$ & 0.570 \\
\hline Milk and milk products & $\begin{array}{c}0.003 \\
(0.028)\end{array}$ & $\begin{array}{l}0.028^{*} \\
(0.016)\end{array}$ & 0.415 \\
\hline Oils and fats & $\begin{array}{l}-0.001 \\
(0.037)\end{array}$ & $\begin{array}{l}0.074^{* *} \\
(0.036)\end{array}$ & 0.047 \\
\hline Sweets & $\begin{array}{c}0.029 \\
(0.027) \\
\end{array}$ & $\begin{array}{c}0.004 \\
(0.025) \\
\end{array}$ & 0.480 \\
\hline Observations & 5,000 & 3,903 & \\
\hline
\end{tabular}

Note: Estimations use difference-in-difference modelling. Robust standard errors clustered at the community level are in parentheses. Estimations are adjusted and include child's age, sex, PMT score, household size, sex, age and education of the household head, and community fixed effects. ${ }^{*} p<0.1{ }^{* *} p<0.05 ;{ }^{* * *} p<0.01$. P-values of the difference are estimated using seemingly unrelated estimations.

\subsubsection{Heterogeneous effects}

The results of estimating equation 5.1 on the subgroups of six months are shown in Table 5.10. The main age groups of interests are those under two years old, as children in these age groups have had the longest exposure during the first 1,000 days of their life. We find no significant impact of LEAP 1000 on the nutritional status for children under two, except for a positive effect on WHZ of $0.93 \mathrm{SD}$ for children 12-17 months. This positive impact is not accompanied by any impacts on 
the immediate or underlying determinants, however. For the youngest age group, we find a significant positive effect on care, but this impact did not translate into impacts on the immediate determinants. There is a negative impact for WAZ and WHZ for the age groups 24-29 and 30-35 months old, respectively. Since these age groups are not eligible for LEAP 1000, it could be that these children are primarily older siblings in the household and did not benefit as much from the LEAP grant as their younger siblings did.

The results of equation 5.2 for our main outcome variables of HAZ, WAZ and WHZ are plotted in Figure 5.3. The graph shows the linear relationship between months of exposure and the outcome variable for the treatment and comparison group separately. The main interest is whether the slopes of the treatment and comparison group differs. However, all three graphs show that the relationship between months of exposure and nutritional status does not differ between treatment and comparison groups. In other words, the slopes of the lines are quite similar. ${ }^{43}$ We further experiment with breaking down the months of exposure in intervals of four months each, to test whether there may be a nonlinear relation between months of exposure and nutritional status. The results (not shown) indicate that again, there is no difference in treatment effect based on the number of months in LEAP 1000. Overall, the results in this sub-section show that LEAP 1000 did not have a stronger effect on children who were exposed to the programme for a longer duration during their first 1,000 days of life, except for a positive effect on WHZ for children 12-17 months old.

Results from our heterogeneity analysis with respect to health facility access and quality are presented in Table 5.11. Note that only the estimate for the coefficient $\beta$ from equation 5.3 is shown in this table. There are no differential treatment effects for any of our nutritional outcome indicators. In other words, the effect of LEAP 1000 on nutritional outcomes does not vary by any of our measures of distance and quality of the nearest health facility. The same holds for the two immediate determinants of malnutrition, health and food intake. In terms of underlying determinants, we find that the treatment effect on food security is between $0.23-0.27 \mathrm{SD}$ larger for children who live nearest to a health facility with a doctor and in case the health facility with the doctor is within five kilometres. Only in the first case is the effect robust to corrections for multiple inference.

${ }^{43}$ The coefficients of the interaction terms (p-values) are: $-0.002(0.76),-0.004(0.53)$ and -0.003 (0.59) for HAZ, WAZ and WHZ respectively. 


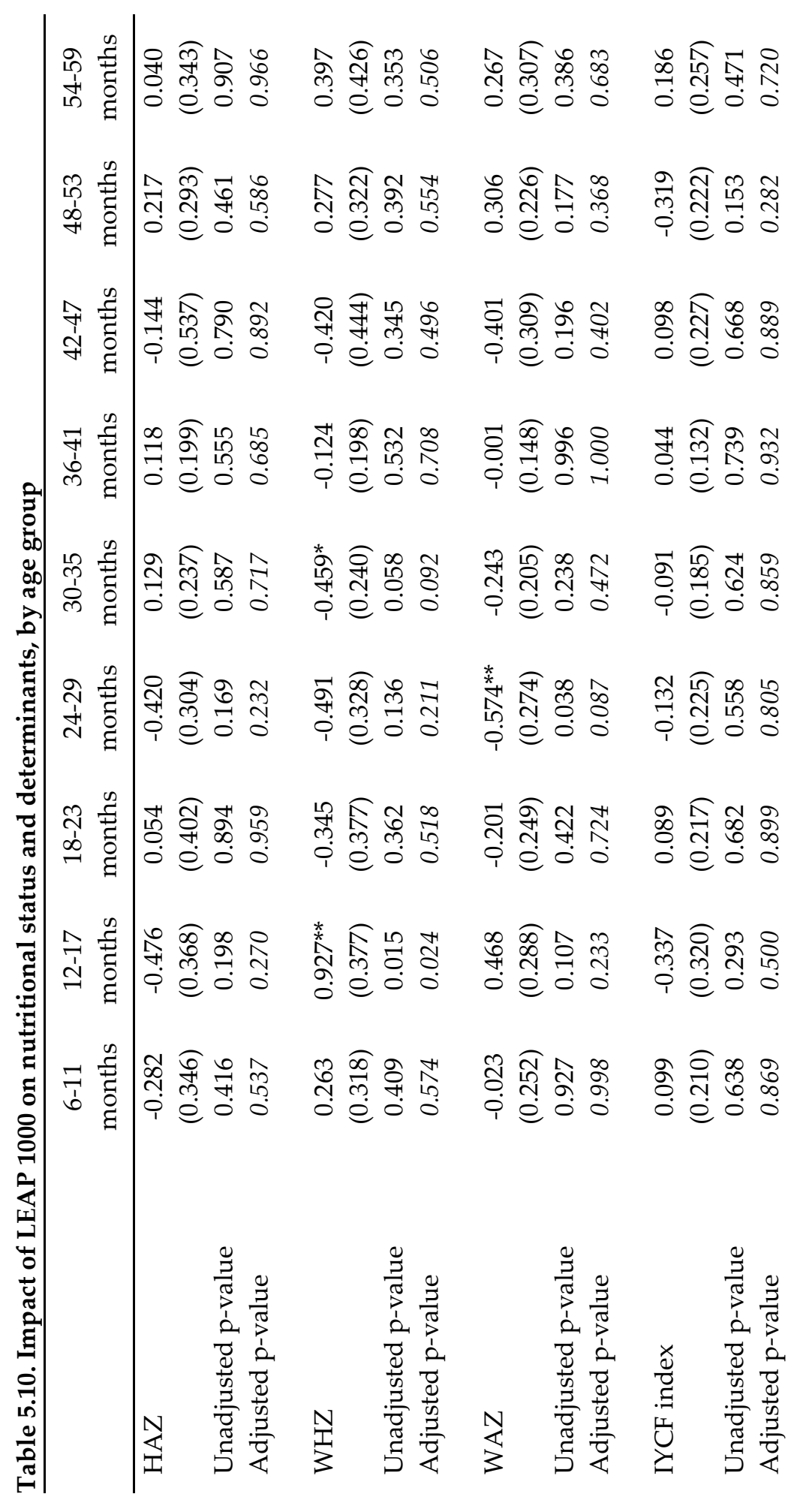




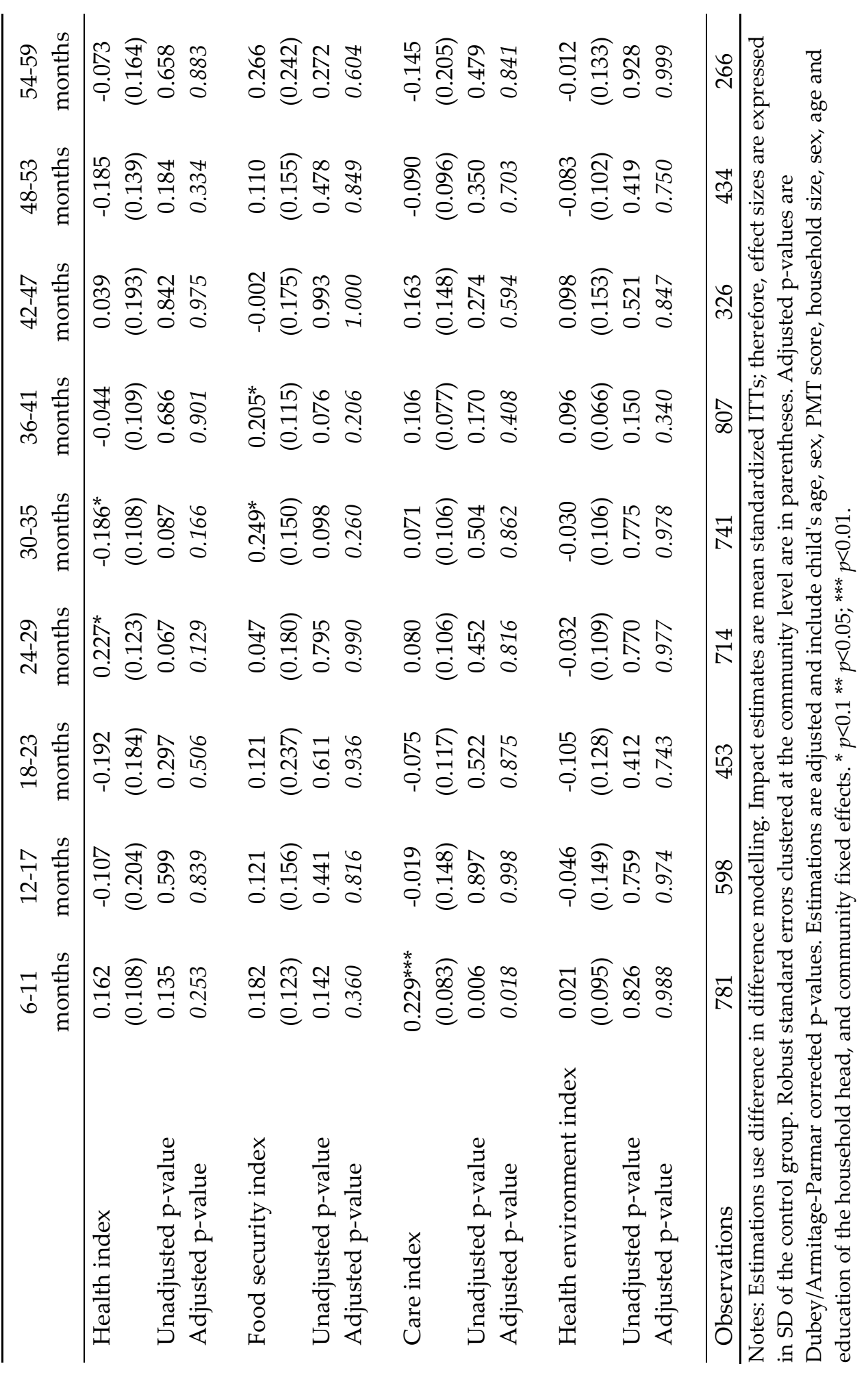



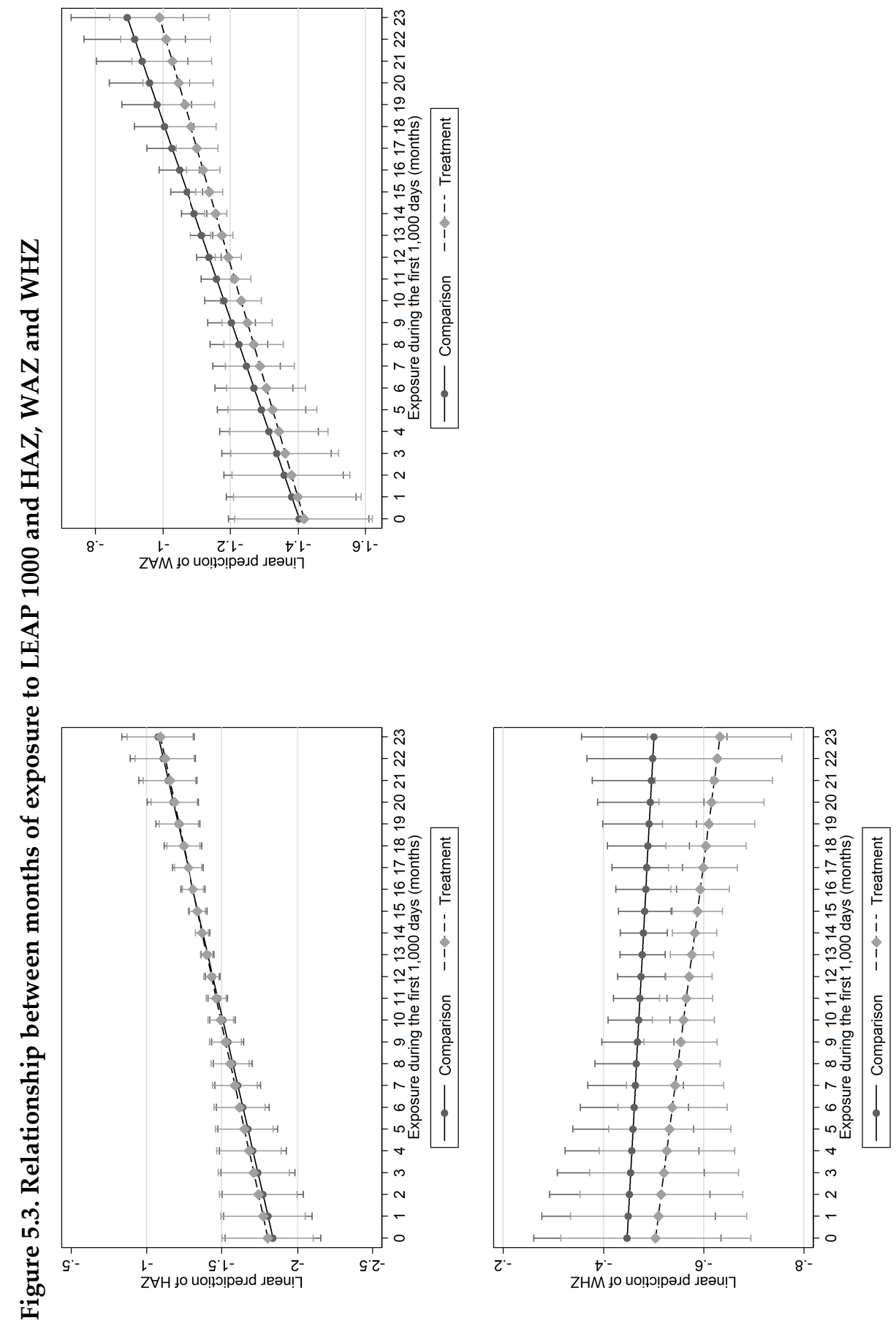


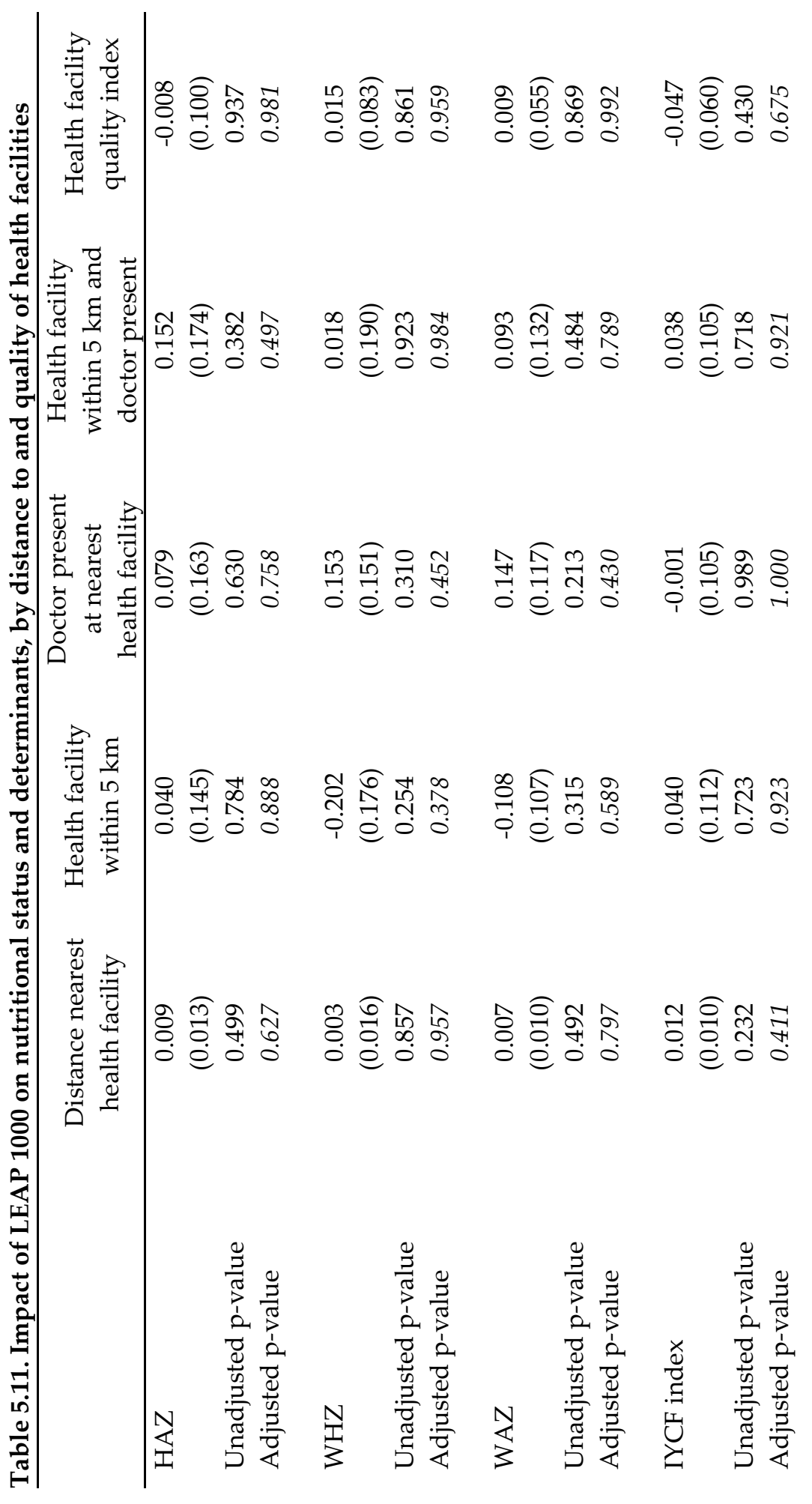




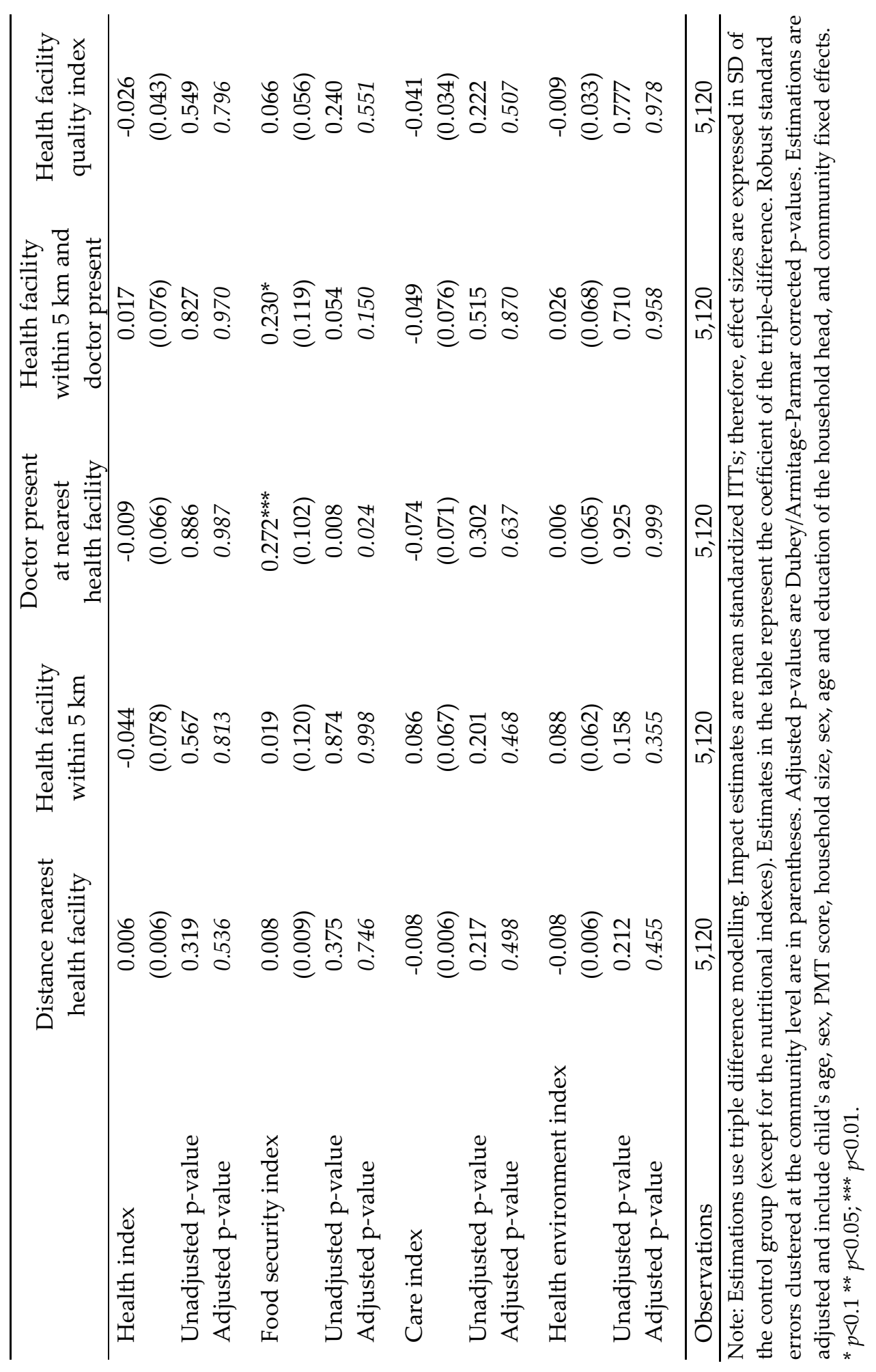




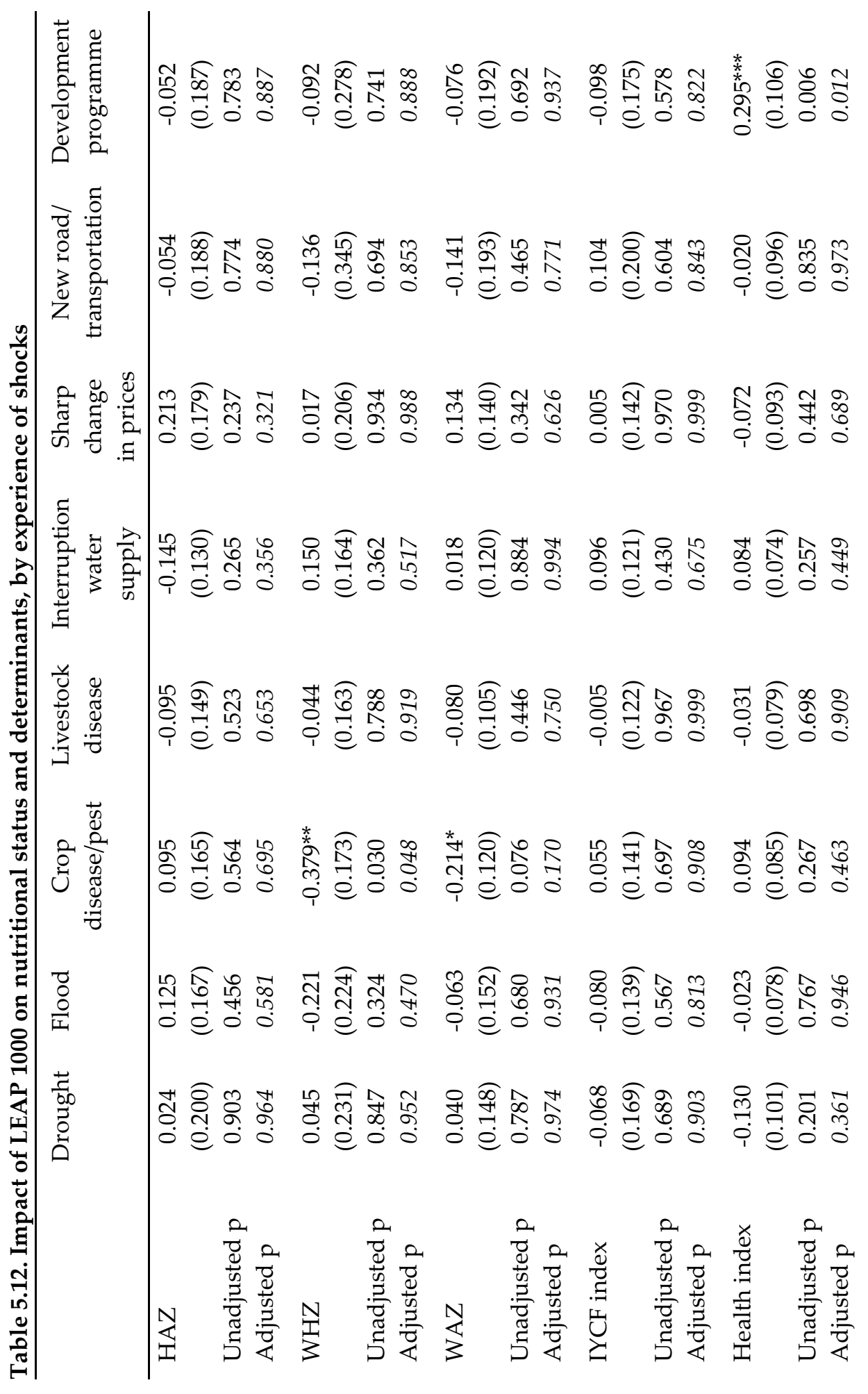




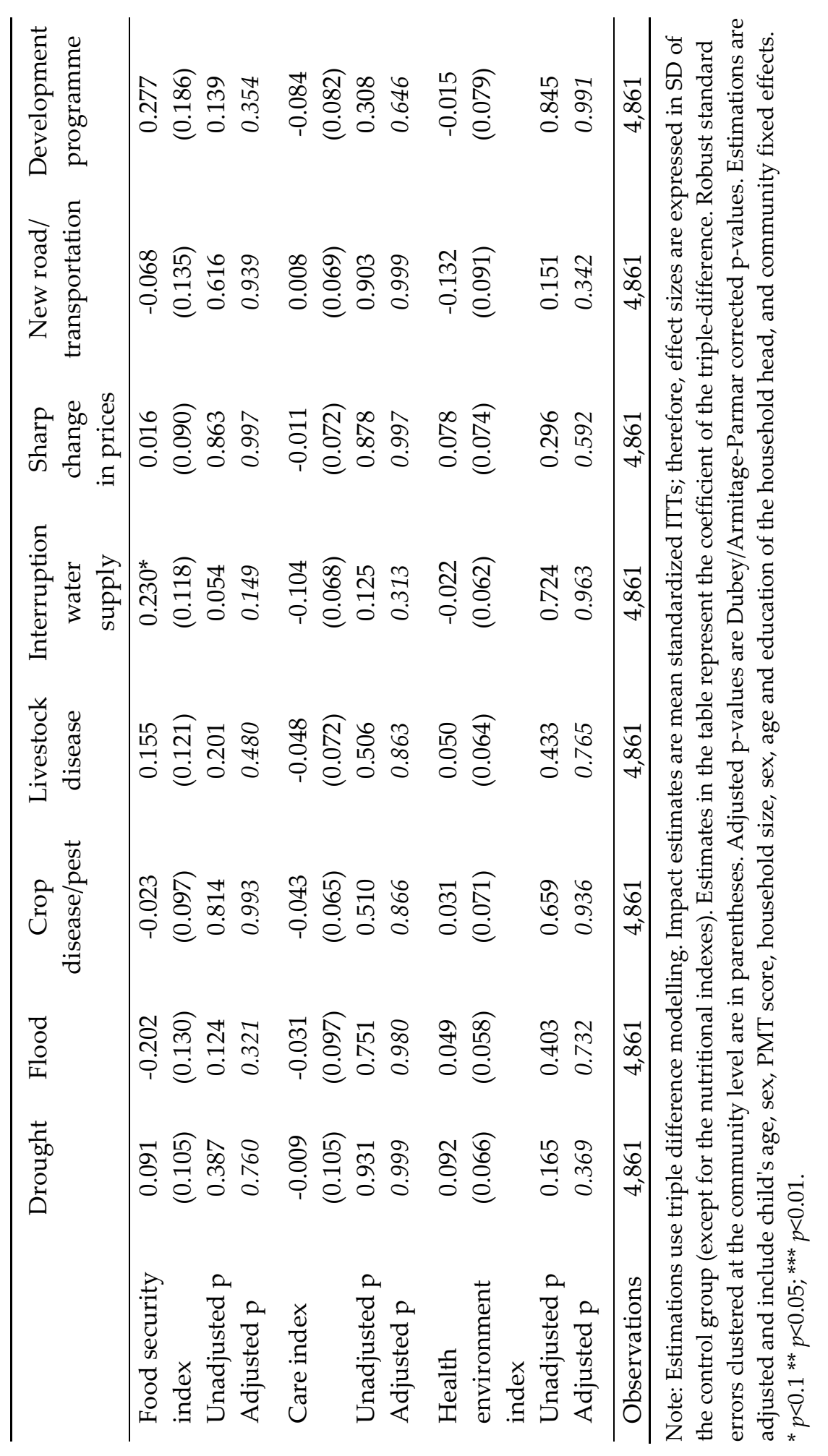


Table 5.13, Impact of LEAP 1000 on nutritional status and immediate determinants of girls, by education of the parents

\begin{tabular}{|c|c|c|c|c|}
\hline & \multicolumn{2}{|c|}{ Mother's schooling } & \multicolumn{2}{|c|}{ Father's schooling } \\
\hline & None & Some & None & Some \\
\hline \multirow[t]{2}{*}{ HAZ } & -0.053 & $0.583^{*}$ & 0.013 & 0.344 \\
\hline & $(0.185)$ & $(0.321)$ & $(0.196)$ & $(0.304)$ \\
\hline Unadjusted p-value & 0.776 & 0.071 & 0.948 & 0.260 \\
\hline Adjusted p-value & 0.882 & 0.100 & 0.985 & 0.349 \\
\hline \multirow{2}{*}{ WHZ } & $0.269^{*}$ & -0.238 & 0.232 & 0.179 \\
\hline & $(0.150)$ & $(0.282)$ & $(0.173)$ & $(0.283)$ \\
\hline Unadjusted p-value & 0.076 & 0.399 & 0.182 & 0.528 \\
\hline Adjusted p-value & 0.121 & 0.562 & 0.278 & 0.704 \\
\hline \multirow[t]{2}{*}{ WAZ } & 0.140 & 0.162 & 0.145 & 0.346 \\
\hline & $(0.116)$ & $(0.226)$ & $(0.128)$ & $(0.226)$ \\
\hline Unadjusted p-value & 0.230 & 0.473 & 0.261 & 0.128 \\
\hline Adjusted p-value & 0.460 & 0.778 & 0.509 & 0.275 \\
\hline \multirow[t]{2}{*}{ IYCF index } & -0.084 & -0.303 & -0.071 & -0.249 \\
\hline & $(0.118)$ & $(0.223)$ & $(0.143)$ & $(0.229)$ \\
\hline Unadjusted p-value & 0.479 & 0.175 & 0.620 & 0.280 \\
\hline Adjusted $p$-value & 0.729 & 0.320 & 0.855 & 0.482 \\
\hline \multirow[t]{2}{*}{ Health index } & -0.058 & $-0.453^{* * *}$ & -0.083 & -0.232 \\
\hline & $(0.084)$ & $(0.132)$ & $(0.089)$ & $(0.143)$ \\
\hline Unadjusted p-value & 0.488 & 0.001 & 0.354 & 0.107 \\
\hline Adjusted p-value & 0.738 & 0.002 & 0.583 & 0.203 \\
\hline Observations & 3,698 & 1,337 & 3,186 & 1,330 \\
\hline
\end{tabular}

Note: Estimations use triple difference modelling. Impact estimates are mean standardized ITTs; therefore, effect sizes are expressed in SD of the control group (except for the nutritional indexes). Estimates in the table represent the coefficient of the triple-difference. Robust standard errors clustered at the community level are in parentheses. Adjusted pvalues are Dubey/Armitage-Parmar corrected p-values. Estimations are adjusted and include child's age, sex, PMT score, household size, sex, age and education of the household head, and community fixed effects. ${ }^{*} p<0.1^{* *} p<0.05 ;{ }^{* * *} p<0.01$.

The results from the heterogeneity analysis on negative and positive shocks are presented in Table 5.12. The most interesting results on nutritional outcomes appear for the crop disease and pest event. The LEAP 1000 treatment effect on WHZ and WAZ is significantly lower for children in households living in communities that experienced this event. The effect on WHZ is robust to 
corrections for multiple hypothesis testing. However, this effect is not accompanied by a negative effect on any of the measured underlying determinants. In terms of positive events, we find that the treatment effect is larger on the health index in communities that have additional development programmes. Unfortunately, the community survey did not specify what types of development programmes were present.

The results for our analysis on the influence of intra-household resource allocation on the programme impacts are presented in Table 5.13. The numbers in the Table again represent the estimate of $\beta$, the differential effect on girls compared to boys for each of the subgroups. One major finding jumps out. For girls whose mother has attained some formal schooling, the impact of LEAP 1000 is 0.45 SD lower on the health index compared to boys. This provides suggestive evidence that better-educated mothers, who are assumed to better exert their preferences, make fewer investments in their daughters compared to their sons, in the presence of an unconditional cash grant. There is also a positive effect on HAZ for this subgroup, but this effect is not robust to multiple hypothesis testing. The effects for fathers are all insignificant, which may be because fathers were not the main recipient of the cash and could therefore not strongly exert their preferences in the spending of the grant.

\subsection{Discussion and conclusion}

This chapter documents the impacts of LEAP 1000 on young child nutrition and its determinants. By reaching children in the critical window of the first 1,000 days of life, LEAP 1000 aims to provide families with the means to improve nutritional status at an early age. To present a complete picture, we follow a well-known conceptual framework of malnutrition to capture not only nutritional outcomes, but also immediate and underlying determinants. Our findings show that after 24 months, LEAP 1000 has not been able to improve nutritional status among beneficiary children. We find a significant main treatment effect on household food security, indicating that the programme was able to positively affect one of the three underlying determinants. Despite the limited effects on child nutrition, the overall impact evaluation found positive impacts on increasing enrolment in the national health insurance programme, and on adult health care utilization (UNICEF Office of Research - Innocenti et al., 2018). However, these effects did not translate into improvements in child health or food intake, the two immediate determinants of malnutrition. We also show that impacts on the number of meals consumed at the household level is positive and statistically different from the negative effect on the number of meals consumed by children in LEAP 1000 households.

Our heterogeneity analysis shows no differential effects for children who were exposed to LEAP 1000 for a longer duration of the 1,000 days window, except 
for a positive effect on WHZ for children 12-17 months old, and a positive effect on care for the youngest age group of 6-11 months. In contrast, a negative effect appears for children 24-35 months old on weight-related nutritional status.

Distance to and quality of a health facility have no additional effect on the impact of LEAP 1000 on nutritional status. However, treatment effects on food security are larger for children living near a health facility with a doctor. Shocks are common occurrences for the households in our sample. The heterogeneity analysis for shocks shows that crop diseases or pests negatively affect the impact of LEAP 1000 on weight-related nutritional outcomes. The introduction of additional development programmes increases the impact of LEAP 1000 on health, showing potential for complementarity between programmes. Finally, we found some suggestive evidence that better-educated mothers invest fewer resources in the health of their daughters compared to their sons.

It is interesting to put our results in context. To do so, we require similar studies that report on nutritional status and the determinants that we examine in this chapter. There is little published academic work that uses a similarly broad perspective as our study, so we rely on a few publicly available evaluation reports. Table 5.14 lists selected characteristics and impacts of five cash transfer programmes in Ethiopia, Kenya, Malawi, Zambia and Zimbabwe. All these programmes are government-run, unconditional cash transfer programmes and reach a significant number of beneficiaries. ${ }^{44}$ Most programmes target labourconstrained and poor households with limited productive capacity. The Zambia Child Grant Programme (CGP) is the only other programme that specifically targets young children. Transfer levels vary substantially with the Zambian programme transferring about 27 percent of baseline consumption, and the Ethiopian programme only 10 percent. Most programmes were accompanied by a $\mathrm{RCT}$, except Ethiopia, which used a quasi-experimental technique to assess impacts.

What is striking from this table, is that none of these programmes had an impact on any of the nutritional status indicators. In the three programmes that collected information on food intake for children, all of them found a significant impact, indicating that one of the immediate determinants of malnutrition was affected. However, none of the programmes had an impact on child health. On the other hand, all programmes had a strong and significant effect on food security, which is further corroborated by other research on this topic (Hidrobo et al., 2018, Tiwari et al., 2016). In two (Zambia, Ethiopia) of the three evaluation that collected some measures of care, no impact was found. Only the Malawi SCTP had a positive impact on caregiver stress. Impacts on the household health environment are generally not collected or reported, but the Zambian evaluation found an

\footnotetext{
${ }^{44}$ Except for the Ethiopia programme, which was a state-level pilot at the time.
} 
impact on ownership of toilets and cement floors, while the Ethiopian study found no improvements in housing quality.

Table 5.14. Programme characteristics and impacts of selected cash transfer programmes in sub-Saharan Africa

$\begin{array}{ccccc}\text { Zambia } & \text { Malawi } & \text { Zimbabwe } & \text { Ethiopia } & \text { Kenya HSNP } \\ \text { CGP } & \text { SCTP } & \text { HSCT } & \text { Tigray } \\ & & & \text { SCTPP }\end{array}$

\begin{tabular}{|c|c|c|c|c|c|}
\hline \multicolumn{6}{|c|}{ Programme characteristics } \\
\hline Targeting & $\begin{array}{l}\text { Household } \\
\text { with a } \\
\text { child } \\
\text { under } 5\end{array}$ & $\begin{array}{l}\text { Ultra-poor } \\
\text { and labour- } \\
\text { constrained }\end{array}$ & $\begin{array}{l}\text { Labour- } \\
\text { constrained } \\
\text { households, } \\
\text { food poor }\end{array}$ & $\begin{array}{c}\text { Extremely } \\
\text { poor, } \\
\text { labour- } \\
\text { constrained }\end{array}$ & $\begin{array}{c}\text { Poor, high } \\
\text { dependency } \\
\text { ratio or } \\
\text { having a } \\
\text { member older } \\
\text { than } 55 \text { years }\end{array}$ \\
\hline $\begin{array}{l}\text { Transfer size } \\
\text { (as \% of } \\
\text { baseline } \\
\text { consumption) }\end{array}$ & $27 \%$ & $18-23 \%$ & $20 \%$ & $10 \%$ & $12 \%$ \\
\hline $\begin{array}{l}\text { Number of } \\
\text { beneficiaries }\end{array}$ & $\begin{array}{c}145,000 \\
\text { (includes } \\
\text { MCT) }\end{array}$ & 163,000 & 55,509 & 3,800 & 60,000 \\
\hline $\begin{array}{l}\text { Evaluation } \\
\text { method }\end{array}$ & $\mathrm{RCT}$ & $\mathrm{RCT}$ & $\mathrm{RCT}$ & IPWRA & $\mathrm{RCT}$ \\
\hline \multicolumn{6}{|l|}{ Impacts } \\
\hline HAZ & No & No & No & No & No (stunting) \\
\hline WHZ & No & No & No & No & No (wasting) \\
\hline WAZ & No & No & No & $\mathrm{n} / \mathrm{a}$ & $\begin{array}{c}\text { No } \\
\text { (underweight) }\end{array}$ \\
\hline IYCF & $\begin{array}{l}\text { Yes (meal } \\
\text { frequency) }\end{array}$ & $\begin{array}{l}\text { Yes (meal } \\
\text { frequency) }\end{array}$ & $\mathrm{n} / \mathrm{a}$ & $\begin{array}{c}\text { Yes } \\
\text { (children < } \\
12)\end{array}$ & $\mathrm{n} / \mathrm{a}$ \\
\hline Health & No & No & $\begin{array}{l}\text { Negative } \\
\text { impact }\end{array}$ & $\mathrm{n} / \mathrm{a}$ & $\begin{array}{c}\text { No (children < } \\
18)\end{array}$ \\
\hline Food security & Yes & Yes & $\begin{array}{l}\text { Yes (diet } \\
\text { diversity) }\end{array}$ & Yes & Yes \\
\hline Care & No & Yes (stress) & $\mathrm{n} / \mathrm{a}$ & $\begin{array}{l}\text { No (health } \\
\text { and stress) }\end{array}$ & $\mathrm{n} / \mathrm{a}$ \\
\hline
\end{tabular}




\begin{tabular}{|c|c|c|c|c|c|}
\hline & $\begin{array}{c}\text { Zambia } \\
\text { CGP }\end{array}$ & $\begin{array}{c}\text { Malawi } \\
\text { SCTP }\end{array}$ & $\begin{array}{c}\text { Zimbabwe } \\
\text { HSCT }\end{array}$ & $\begin{array}{c}\text { Ethiopia } \\
\text { Tigray } \\
\text { SCTPP }\end{array}$ & Kenya HSNP \\
\hline $\begin{array}{l}\text { Health } \\
\text { environment }\end{array}$ & $\begin{array}{c}\text { Yes (toilet } \\
\text { and } \\
\text { cement } \\
\text { floors) }\end{array}$ & $\mathrm{n} / \mathrm{a}$ & $\mathrm{n} / \mathrm{a}$ & $\begin{array}{c}\text { No } \\
\text { (housing } \\
\text { quality) }\end{array}$ & $\mathrm{n} / \mathrm{a}$ \\
\hline
\end{tabular}

Notes: $\mathrm{n} / \mathrm{a}=$ not collected or reported. CGP $=$ Child Grant Programme, SCTP = Social Cash Transfer Programme, HSCT = Harmonized Social Cash Transfer, SCTPP = Social Cash Transfer Pilot Programme, HSNP = Hunger Safety Net Programme, RCT = randomized control trial, IPWRA = inverse probability weighted regression adjustment. Sources: American Institutes for Research (2014), American Institutes for Research (2015), Berhane et al. (2015), Davis et al. (2016), Merttens et al. (2013), University of North Carolina at Chapel Hill et al. (2016).

Another point of interest is the transfer size. The value of the LEAP 1000 transfer constitutes about 14 percent of the baseline consumption of beneficiary households. More importantly, the transfer value lost about 20 percent of its initial value due to persistent inflation in the study area (UNICEF Office of Research Innocenti et al., 2018). Across programmes, a transfer level of approximately 20 percent or more is usually associated with broader impacts across multiple social and productive domains (Davis and Handa, 2015) and the limited scale of impacts we observe in our study could be related to the relatively low transfer size. However, note that the programmes in Zambia, Malawi and Zimbabwe, with transfer sizes of 20 percent or more, also did not have an impact on nutritional outcomes.

Finally, we note the implications of intra-household allocation of resources. The way a CT programme may impact individuals within households is an important question but remains largely a black box (Yoong et al., 2012). Our results showed that while LEAP 1000 was able to impact household level food security, there was a decrease in the meal frequency for children. This inconsistency may be related to a situation in which a poor household needs to allocate sparse resources between members. When faced with an exogenous increase in household disposable income, adult members of the household may be prioritized since they are the ones to generate income for the household. This hypothesis is also consistent with our finding that when faced with a crop-related shock, the impact of LEAP 1000 on WHZ is negative. In this situation, the household may have little of their own produce available and the money from LEAP is used to cater for income-generating adults, thereby worsening the nutritional status of the children in the household. 
In addition, our heterogeneity analysis showed that better-educated mothers may invest fewer resources in the health of their daughters compared to their sons. This finding is compatible with findings from Chapter 4, which showed that daughters of better-educated mothers have poorer educational and nutritional outcomes. This is also consistent with the hypothesis described above, if the mother is the main recipient of the grant and can exert her preferences in the prioritization of the money and sons are in a better position to generate income for the family or act as insurance for old-age or in case of widowhood.

Considering our findings, and given the broader context of findings on the impact of CT programmes on nutrition, what can we say about the potential of CT programmes to address malnutrition? First, it should be noted that CTs have wideranging impacts and are particularly effective to alleviate food insecurity, one of the underlying determinants of malnutrition (e.g. see the review by Bastagli et al. (2016)). This frequently includes significant impacts on improving dietary diversity. However, their current design is not enough to address the complex determination of malnutrition, suggesting a role for additional programming that targets underlying and immediate determinants that are less likely to be impacted via an income or economic pathway. There is increasing interest in linking CT programmes with additional social services as part of strengthening social protection systems overall (Roelen et al., 2017). Since CT programmes often are effective in reaching families living in poverty and/or facing multiple vulnerabilities, linking beneficiaries with other social services is a promising strategy. The LEAP programme already has a linkage approach with the NHIS and is currently looking at ways to strengthen linkages with other services including the Ghana Health Service.

Research unpacking impacts of cash plus programming on child nutrition is limited but promising. For example, recent research in Bangladesh showed that CTs combined with nutrition behaviour change communications (BCC) had a greater impact than CTs alone and led to a decrease in stunting of 7.3 percentage points, combined with an increase in dietary diversity for children (Ahmed et al., 2017). However, the BCC programme was quite intense with weekly sessions and occasional home visits and thus the likelihood that similar impacts would occur in national government-run, at scale programmes is unclear. In addition, the linkages to other services is highly context-specific. For example, Headey et al. (2017) explore what factors are associated with nutritional improvements in six countries and find that asset formation, parental education and access to antenatal care are important drivers, with improvements in sanitation only important for countries in South Asia. In our sample, nutritional knowledge was quite high at baseline, and it seems unlikely that improving knowledge would have been a promising strategy to improve nutritional outcomes.

It might also be that impacts on nutritional outcomes just take longer to appear. Our evaluation only had a 24-month window, and this might be too short 
for families to experience the necessary accumulation of sufficient income security, access to services and subsequent behaviour changes which could lead to improvements in nutritional status. Historical evidence suggests that stunting reduction is a long-term process. For example, it took 40 years for Japan to reduce its stunting prevalence from 50 to 5.7 percent. In contrast to the situation in most developing countries today, this reduction occurred during favourable economic and public health conditions (Schneider, 2018). Recent results from a CCT in Indonesia (Program Keluarga Harapan) showed a reduction in stunting of $9-11$ percentage points after six years of operation (Cahyadi et al., 2018). While there are no strong effects on the underlying determinants of malnutrition, the authors conclude that increased attention to weight and nutrition (particularly protein consumption) during the early years likely contributed to this result. The link between stunting and protein intake, or more generally animal-sourced foods, has been found in other studies as well (Headey et al., 2018).

One important limitation of our study design is that our sample only includes households that are close to either side of the eligibility cut-off. It might be that the poorest households, further away from the programme threshold, benefit more from LEAP 1000. Our results should therefore be considered a lower bound of the average treatment effect (Mehta, 2018). Another limitation is the relatively short time frame of our evaluation, as impacts might take longer to appear.

In conclusion, within the time and analytical frame of our evaluation, we found no impact of Ghana's cash transfer programme LEAP 1000 on nutritional outcomes, despite its explicit objective of decreasing child malnutrition. Our results are in line with findings from other large-scale, government-run cash transfer programmes in sub-Saharan Africa. Future research should focus on effective and context-specific linkages between cash transfer programmes and additional social services, that together are able to improve underlying and immediate determinants of malnutrition. In addition, further research is needed to examine how CTs affect intra-household division of resources and how programmes can be strengthened to benefit the youngest children of the household. 


\subsection{Appendix to Chapter 5}

\subsubsection{Appendix A: Additional tables}

Table S 5.1, Comparison of children in the panel versus children lost at follow-

up

\begin{tabular}{lccc}
\hline Variables & $\begin{array}{c}\text { Lost at } \\
\text { follow-up }\end{array}$ & Panel & p-value \\
\hline
\end{tabular}

\section{Background characteristics}

Age in months

$\begin{array}{ccc}39.623 & 14.345 & 0.000 \\ 0.500 & 0.499 & 0.997 \\ 6.882 & 6.877 & 0.882 \\ 0.585 & 0.516 & 0.001 \\ 0.351 & 0.535 & 0.000 \\ 0.155 & 0.230 & 0.000 \\ 0.544 & 0.266 & 0.000 \\ 0.464 & 0.259 & 0.000 \\ 0.191 & 0.282 & 0.000 \\ 1.446 & 1.450 & 0.997 \\ 0.393 & 0.474 & 0.006 \\ 0.434 & 0.511 & 0.002 \\ 0.983 & 1.001 & 0.499 \\ 0.660 & 0.658 & 0.887 \\ 0.264 & 0.279 & 0.489 \\ 0.168 & 0.174 & 0.693 \\ 0.245 & 0.242 & 0.888 \\ 0.011 & 0.010 & 0.806\end{array}$

Female child

Household size

\# of children aged 0 - 11 months

\# of children aged 12 - 23 months

\# of children aged 24 - 35 months

\# of children aged 36 - 47 months

\# of children aged 48 - 59 months

\# of children aged 60 - 71 months

\# of children 6 - 12

\# of children $13-17$

\# of adults $18-24$

\# of adults $25-34$

\# of adults $35-44$

\# of adults $45-54$

\# of adults $55-64$

\# of adults 65 and more

Single or double orphan

Anthropometric outcomes

Length/height-for-age z-score

$-1.499$

$-1.066$

0.000

Stunted (HAZ <-2 SD)

0.342

0.277

0.004

Weight-for-length/height z-score

$-0.440$

$-0.559$

0.066

Wasted (WHZ <-2 SD)

0.128

0.171

0.003

Weight-for-age z-score

Underweight (WAZ <-2 SD)

$-1.183$

$-0.997$

0.000

0.207

0.182

0.197

Immediate determinants

Breastfeeding score for IYCF

0.232

1.256

0.000

Diet diversity score for IYCF

1.186

1.206

0.449

Meal frequency score for IYCF

1.561

1.249

0.000

Infant and Young Child Feeding Index

2.979

3.711

0.000

(6-59 months)

No fever

0.740

0.715

0.152

No ARI symptoms

0.942

0.944

0.877 


\begin{tabular}{|c|c|c|c|}
\hline Variables & $\begin{array}{l}\text { Lost at } \\
\text { follow-up }\end{array}$ & Panel & p-value \\
\hline No diarrhoea & 0.648 & 0.522 & 0.000 \\
\hline Health index (ICW) & 0.081 & -0.019 & 0.000 \\
\hline \multicolumn{4}{|l|}{ Underlying determinants } \\
\hline Sum of food security score (5-20) & 12.885 & 13.047 & 0.101 \\
\hline $\begin{array}{l}\text { AE food expenditure } p \text { month constant } \\
\text { Greater Accra Aug-17 prices }\end{array}$ & 87.549 & 89.410 & 0.460 \\
\hline Household Diet Diversity Score & 6.311 & 6.410 & 0.217 \\
\hline Food security index (ICW) & -0.059 & -0.014 & 0.129 \\
\hline $\begin{array}{l}\text { Subjective health ( } 1 \text { very poor - } 5 \\
\text { excellent) }\end{array}$ & 3.188 & 3.225 & 0.408 \\
\hline No ADL difficulties & 0.471 & 0.513 & 0.016 \\
\hline MOS-Social Support score(standardized) & 51.015 & 51.318 & 0.702 \\
\hline Agency score & 2.679 & 2.683 & 0.976 \\
\hline $\begin{array}{l}\text { Cohen perceived stress scale (positively } \\
\text { reversed) }\end{array}$ & 28.141 & 28.474 & 0.054 \\
\hline Nutritional knowledge score (0-6) & 4.343 & 4.330 & 0.747 \\
\hline Care index (ICW) & -0.017 & 0.009 & 0.187 \\
\hline Improved source of water & 0.595 & 0.577 & 0.426 \\
\hline Improved source of sanitation & 0.107 & 0.090 & 0.069 \\
\hline Appropriate hand washing facilities & 0.089 & 0.060 & 0.008 \\
\hline No mud floor & 0.753 & 0.767 & 0.372 \\
\hline Safe disposal of child stools & 0.272 & 0.190 & 0.000 \\
\hline Health environment index (ICW) & 0.047 & -0.013 & 0.008 \\
\hline Observations & 1,229 & 1,250 & \\
\hline
\end{tabular}

Notes: P-values are reported from Wald tests on the equality of means (ratios) of Treatment and Comparison for each exit or entry reason. Standard errors are clustered at the community level. All tests control for the PMT score. 
Table S 5.2, Comparison of children in the panel versus new children at follow-

up

\begin{tabular}{lccc}
\hline Variables & $\begin{array}{c}\text { New } \\
\text { Entrants }\end{array}$ & Panel & p-value \\
\hline Age in months & 7.730 & 14.345 & 0.000 \\
Female child & 0.504 & 0.499 & 0.855 \\
Observations & 899 & 1,250 & \\
Household size & 6.906 & 6.877 & 0.614 \\
\# of children aged 0 - 11 months & 0.648 & 0.516 & 0.000 \\
\# of children aged 12 - 23 months & 0.267 & 0.535 & 0.000 \\
\# of children aged 24 - 35 months & 0.284 & 0.230 & 0.004 \\
\# of children aged 36 - 47 months & 0.347 & 0.266 & 0.000 \\
\# of children aged 48 - 59 months & 0.303 & 0.259 & 0.010 \\
\# of children aged 60 - 71 months & 0.309 & 0.282 & 0.111 \\
\# of children 6 - 12 & 1.481 & 1.450 & 0.325 \\
\# of children 13 - 17 & 0.426 & 0.474 & 0.139 \\
\# of adults 18 - 24 & 0.511 & 0.511 & 0.910 \\
\# of adults 25 - 34 & 1.005 & 1.001 & 0.935 \\
\# of adults 35 - 44 & 0.648 & 0.658 & 0.873 \\
\# of adults 45 - 54 & 0.285 & 0.279 & 0.751 \\
\# of adults 55 - 64 & 0.156 & 0.174 & 0.288 \\
\# of adults 65 and more & 0.235 & 0.242 & 0.752 \\
Single or double orphan & 0.053 & 0.010 & 0.001 \\
Observations & 1,391 & 1,250 & \\
\hline
\end{tabular}

Notes: P-values are reported from Wald tests on the equality of means (ratios) of Treatment and Comparison for each exit or entry reason. Standard errors are clustered at the community level. All tests control for the PMT score. 
Table S 5.3, Comparison between comparison and treatment group of children in the panel

\begin{tabular}{|c|c|c|c|}
\hline Variables & Comparison & Treatment & p-value \\
\hline Age in months & 14.573 & 14.143 & 0.110 \\
\hline Female child & 0.502 & 0.497 & 0.183 \\
\hline Household size & 6.415 & 7.285 & 0.136 \\
\hline \# of children aged $0-11$ months & 0.485 & 0.544 & 0.067 \\
\hline \# of children aged $12-23$ months & 0.527 & 0.542 & 0.491 \\
\hline \# of children aged 24 - 35 months & 0.224 & 0.235 & 0.957 \\
\hline \# of children aged 36 - 47 months & 0.276 & 0.256 & 0.007 \\
\hline \# of children aged 48 - 59 months & 0.244 & 0.273 & 0.403 \\
\hline \# of children aged $60-71$ months & 0.249 & 0.310 & 0.451 \\
\hline \# of children $6-12$ & 1.205 & 1.667 & 0.108 \\
\hline \# of children 13 - 17 & 0.413 & 0.527 & 0.408 \\
\hline \# of adults $18-24$ & 0.512 & 0.511 & 0.019 \\
\hline \# of adults $25-34$ & 1.060 & 0.949 & 0.090 \\
\hline \# of adults $35-44$ & 0.584 & 0.723 & 0.505 \\
\hline \# of adults $45-54$ & 0.251 & 0.304 & 0.319 \\
\hline$\#$ of adults $55-64$ & 0.166 & 0.182 & 0.740 \\
\hline \# of adults 65 and more & 0.220 & 0.262 & 0.906 \\
\hline Single or double orphan & 0.014 & 0.006 & 0.407 \\
\hline Length/height-for-age z-score & -1.043 & -1.086 & 0.897 \\
\hline Stunted $(\mathrm{HAZ}<-2 \mathrm{SD})$ & 0.276 & 0.277 & 0.688 \\
\hline Weight-for-length/height z-score & -0.556 & -0.561 & 0.414 \\
\hline Wasted (WHZ <-2 SD) & 0.164 & 0.178 & 0.801 \\
\hline Weight-for-age z-score & -0.988 & -1.005 & 0.382 \\
\hline Underweight (WAZ <-2 SD) & 0.176 & 0.188 & 0.973 \\
\hline Breastfeeding score for IYCF & 1.230 & 1.279 & 0.153 \\
\hline Diet diversity score for IYCF & 1.200 & 1.212 & 0.617 \\
\hline Meal frequency score for IYCF & 1.198 & 1.294 & 0.751 \\
\hline Infant and Young Child Feeding & 3.628 & 3.785 & 0.458 \\
\hline \multicolumn{4}{|l|}{ Index (6-59 months) } \\
\hline No fever & 0.695 & 0.733 & 0.040 \\
\hline No ARI symptoms & 0.925 & 0.961 & 0.236 \\
\hline No diarrhoea & 0.493 & 0.548 & 0.079 \\
\hline Health index (ICW) & -0.081 & 0.036 & 0.009 \\
\hline Sum of food security score (5-20) & 13.085 & 13.014 & 0.245 \\
\hline $\begin{array}{l}\text { AE food expenditure } p \text { month } \\
\text { constant Greater Accra Aug- } 17 \text { prices }\end{array}$ & 94.342 & 85.057 & 0.723 \\
\hline Household Diet Diversity Score & 6.495 & 6.336 & 0.544 \\
\hline Food security index (ICW) & 0.029 & -0.052 & 0.735 \\
\hline
\end{tabular}




\begin{tabular}{lccc}
\hline Variables & Comparison & Treatment & p-value \\
\hline Subjective health (1 very poor - 5 & 3.220 & 3.229 & 0.713 \\
excellent) & & & \\
No ADL difficulties & 0.526 & 0.502 & 0.816 \\
MOS-Social Support & 52.298 & 50.452 & 0.221 \\
score(standardized) & & & \\
Agency score & 2.660 & 2.703 & 0.897 \\
Cohen perceived stress scale & 28.766 & 28.217 & 0.836 \\
(positively reversed) & & & \\
Nutritional knowledge score (0-6) & 4.355 & 4.307 & 0.245 \\
Care index (ICW) & 0.030 & -0.010 & 0.201 \\
Improved source of water & 0.560 & 0.592 & 0.811 \\
Improved source of sanitation & 0.087 & 0.092 & 0.950 \\
Appropriate hand washing facilities & 0.061 & 0.059 & 0.160 \\
No mud floor & 0.763 & 0.771 & 0.385 \\
Safe disposal of child stools & 0.172 & 0.206 & 0.404 \\
Health environment index (ICW) & -0.030 & 0.001 & 0.235 \\
Observations & 586 & 664 & \\
\hline Ner P-vals are repoted from Wald & & & \\
\hline
\end{tabular}

Notes: P-values are reported from Wald tests on the equality of means (ratios) of Treatment and Comparison for each exit or entry reason. Standard errors are clustered at the community level. All tests control for the PMT score. 
Table S 5.4, Comparison between comparison and treatment group of children lost at follow-up

\begin{tabular}{|c|c|c|c|}
\hline Variables & Comparison & Treatment & p-value \\
\hline Age in months & 39.466 & 39.771 & 0.824 \\
\hline Female child & 0.497 & 0.502 & 0.090 \\
\hline Household size & 6.641 & 7.109 & 0.044 \\
\hline \# of children aged $0-11$ months & 0.550 & 0.618 & 0.233 \\
\hline \# of children aged $12-23$ months & 0.351 & 0.351 & 0.189 \\
\hline \# of children aged 24 - 35 months & 0.158 & 0.153 & 0.399 \\
\hline \# of children aged 36 - 47 months & 0.534 & 0.553 & 0.496 \\
\hline \# of children aged 48 - 59 months & 0.448 & 0.479 & 0.603 \\
\hline \# of children aged $60-71$ months & 0.183 & 0.199 & 0.661 \\
\hline \# of children $6-12$ & 1.315 & 1.569 & 0.043 \\
\hline \# of children $13-17$ & 0.371 & 0.414 & 0.809 \\
\hline \# of adults $18-24$ & 0.445 & 0.423 & 0.193 \\
\hline$\#$ of adults $25-34$ & 1.008 & 0.959 & 0.740 \\
\hline \# of adults $35-44$ & 0.626 & 0.692 & 0.781 \\
\hline \# of adults $45-54$ & 0.272 & 0.256 & 0.346 \\
\hline \# of adults $55-64$ & 0.146 & 0.190 & 0.389 \\
\hline \# of adults 65 and more & 0.235 & 0.254 & 0.900 \\
\hline Single or double orphan & 0.008 & 0.013 & 0.882 \\
\hline Length/height-for-age z-score & -1.487 & -1.512 & 0.797 \\
\hline Stunted (HAZ < -2 SD) & 0.344 & 0.340 & 0.675 \\
\hline Weight-for-length/height z-score & -0.424 & -0.455 & 0.199 \\
\hline Wasted (WHZ <-2 SD) & 0.131 & 0.125 & 0.593 \\
\hline Weight-for-age z-score & -1.167 & -1.198 & 0.323 \\
\hline Underweight (WAZ <-2 SD) & 0.203 & 0.210 & 0.323 \\
\hline Breastfeeding score for IYCF & 0.242 & 0.223 & 0.274 \\
\hline Diet diversity score for IYCF & 1.169 & 1.202 & 0.695 \\
\hline Meal frequency score for IYCF & 1.550 & 1.570 & 0.928 \\
\hline Infant and Young Child Feeding & 2.961 & 2.995 & 0.683 \\
\hline \multicolumn{4}{|l|}{ Index (6-59 months) } \\
\hline No fever & 0.718 & 0.760 & 0.100 \\
\hline No ARI symptoms & 0.950 & 0.935 & 0.090 \\
\hline No diarrhoea & 0.654 & 0.641 & 0.393 \\
\hline Health index (ICW) & 0.081 & 0.080 & 0.800 \\
\hline Sum of food security score (5-20) & 12.773 & 12.991 & 0.965 \\
\hline $\begin{array}{l}\text { AE food expenditure } p \text { month } \\
\text { constant Greater Accra Aug-17 prices }\end{array}$ & 90.902 & 84.391 & 0.728 \\
\hline Household Diet Diversity Score & 6.388 & 6.239 & 0.668 \\
\hline Food security index (ICW) & -0.046 & -0.071 & 0.758 \\
\hline
\end{tabular}




\begin{tabular}{lccc}
\hline Variables & Comparison & Treatment & p-value \\
\hline Subjective health (1 very poor - 5 & 3.186 & 3.190 & 0.962 \\
excellent) & & & \\
No ADL difficulties & 0.477 & 0.466 & 0.716 \\
MOS-Social Support & 51.730 & 50.341 & 0.112 \\
score(standardized) & & & \\
Agency score & 2.559 & 2.791 & 0.917 \\
Cohen perceived stress scale & 28.076 & 28.202 & 0.455 \\
(positively reversed) & & & \\
Nutritional knowledge score (0-6) & 4.314 & 4.371 & 0.502 \\
Care index (ICW) & -0.030 & -0.005 & 0.618 \\
Improved source of water & 0.591 & 0.599 & 0.975 \\
Improved source of sanitation & 0.112 & 0.103 & 0.842 \\
Appropriate hand washing facilities & 0.087 & 0.090 & 0.094 \\
No mud floor & 0.738 & 0.766 & 0.691 \\
Safe disposal of child stools & 0.242 & 0.300 & 0.390 \\
Health environment index (ICW) & 0.030 & 0.064 & 0.535 \\
Observations & 596 & 633 & \\
\hline Ner P-valy & & & \\
\hline
\end{tabular}

Notes: P-values are reported from Wald tests on the equality of means (ratios) of Treatment and Comparison for each exit or entry reason. Standard errors are clustered at the community level. All tests control for the PMT score. 
Table S 5.5, Comparison between comparison and treatment group of new children at follow-up

\begin{tabular}{lccc}
\hline Variables & Mean & Mean & p-value \\
\hline Age in months & 8.252 & 7.234 & 0.729 \\
Female child & 0.519 & 0.489 & 0.378 \\
Observations & 437 & 462 & \\
Household size & 6.615 & 7.195 & 0.353 \\
\# of children aged 0 - 11 months & 0.618 & 0.677 & 0.441 \\
\# of children aged 12 - 23 months & 0.272 & 0.263 & 0.375 \\
\# of children aged 24 - 35 months & 0.294 & 0.274 & 0.756 \\
\# of children aged 36 - 47 months & 0.340 & 0.353 & 0.939 \\
\# of children aged 48 - 59 months & 0.295 & 0.311 & 0.162 \\
\# of children aged 60 - 71 months & 0.285 & 0.333 & 0.934 \\
\# of children 6 - 12 & 1.284 & 1.677 & 0.155 \\
\# of children 13 - 17 & 0.369 & 0.484 & 0.462 \\
\# of adults 18 - 24 & 0.571 & 0.452 & 0.471 \\
\# of adults 25 - 34 & 1.016 & 0.994 & 0.990 \\
\# of adults 35 - 44 & 0.612 & 0.683 & 0.947 \\
\# of adults 45 - 54 & 0.288 & 0.283 & 0.949 \\
\# of adults 55 - 64 & 0.140 & 0.172 & 0.602 \\
\# of adults 65 and more & 0.231 & 0.240 & 0.930 \\
Single or double orphan & 0.050 & 0.056 & 0.305 \\
Observations & 694 & 697 & \\
\hline
\end{tabular}

Notes: P-values are reported from Wald tests on the equality of means (ratios) of Treatment and Comparison for each exit or entry reason. Standard errors are clustered at the community level. All tests control for the PMT score. 
Table S 5.6, Variable means by survey round and treatment status

\begin{tabular}{|c|c|c|c|c|}
\hline & $(1)$ & (2) & (3) & $(4)$ \\
\hline & Baseline & Baseline & Endline & Endline \\
\hline & \multicolumn{4}{|c|}{ Comparison Treatment Comparison Treatment } \\
\hline HAZ & -1.262 & -1.288 & -1.397 & -1.393 \\
\hline Stunted (HAZ <-2 SD) & 0.311 & 0.306 & 0.304 & 0.308 \\
\hline WHZ & -0.487 & -0.515 & -0.479 & -0.578 \\
\hline Wasted (WHZ <-2 SD) & 0.147 & 0.152 & 0.074 & 0.086 \\
\hline WAZ & -1.075 & -1.100 & -1.109 & -1.172 \\
\hline Underweight (WAZ <-2 SD) & 0.189 & 0.199 & 0.162 & 0.196 \\
\hline IYCF Index & 3.294 & 3.395 & 3.357 & 3.304 \\
\hline Breastfeeding score for IYCF & 0.736 & 0.766 & 0.249 & 0.219 \\
\hline Diet diversity score for IYCF & 1.185 & 1.207 & 1.275 & 1.315 \\
\hline Meal frequency score for IYCF & 1.372 & 1.422 & 1.833 & 1.770 \\
\hline Health index & 0.003 & 0.055 & 0.001 & 0.018 \\
\hline No fever & 0.709 & 0.746 & 0.725 & 0.719 \\
\hline No ARI symptoms & 0.937 & 0.947 & 0.957 & 0.958 \\
\hline No diarrhoea & 0.576 & 0.594 & 0.653 & 0.683 \\
\hline Food security index & -0.014 & -0.068 & -0.010 & 0.033 \\
\hline Sum of food security score (5-20) & 12.922 & 12.984 & 13.079 & 13.203 \\
\hline $\begin{array}{l}\text { AE food expenditure p month } \\
\text { constant Greater Accra Aug-17 } \\
\text { prices }\end{array}$ & 92.408 & 84.670 & 58.904 & 60.499 \\
\hline Household Diet Diversity Score & 6.418 & 6.259 & 6.723 & 6.805 \\
\hline Care index & -0.003 & -0.014 & 0.001 & 0.035 \\
\hline Subjective health $(1-5)$ & 3.209 & 3.213 & 3.752 & 3.713 \\
\hline No ADL difficulties & 0.501 & 0.485 & 0.623 & 0.594 \\
\hline MOS-Social Support score & 51.731 & 50.000 & 53.118 & 54.138 \\
\hline Agency score & 2.613 & 2.734 & 3.950 & 4.093 \\
\hline Cohen perceived stress scale & 28.376 & 28.147 & 29.138 & 29.109 \\
\hline Nutritional knowledge (0-6) & 4.328 & 4.331 & 4.384 & 4.496 \\
\hline Health environment index & 0.009 & 0.040 & 0.004 & 0.052 \\
\hline Improved source of water & 0.586 & 0.608 & 0.666 & 0.673 \\
\hline Improved source of sanitation & 0.103 & 0.097 & 0.250 & 0.230 \\
\hline $\begin{array}{l}\text { Appropriate hand washing } \\
\text { facilities }\end{array}$ & 0.075 & 0.075 & 0.096 & 0.127 \\
\hline No mud floor & 0.751 & 0.771 & 0.717 & 0.756 \\
\hline Safe disposal of child stools & 0.210 & 0.253 & 0.360 & 0.403 \\
\hline Observations & 1,182 & 1,297 & 1,280 & 1,361 \\
\hline
\end{tabular}




\begin{tabular}{|c|c|c|c|}
\hline & Full sample & $\begin{array}{c}\text { Lowest } \\
\text { bandwidth }\end{array}$ & $\begin{array}{c}\text { Highest } \\
\text { bandwidth }\end{array}$ \\
\hline \multicolumn{4}{|l|}{ Nutritional status } \\
\hline \multirow[t]{2}{*}{ HAZ } & 0.052 & 0.026 & 0.029 \\
\hline & $(0.06)$ & $(0.15)$ & $(0.12)$ \\
\hline Unadjusted p-value & 0.428 & 0.865 & 0.820 \\
\hline Adjusted p-value & 0.646 & 0.924 & 0.831 \\
\hline \multirow[t]{2}{*}{ Stunted (HAZ < -2 SD) } & 0.002 & -0.010 & 0.018 \\
\hline & $(0.02)$ & $(0.04)$ & $(0.03)$ \\
\hline Unadjusted p-value & 0.911 & 0.837 & 0.602 \\
\hline Adjusted p-value & 0.897 & 0.822 & 0.588 \\
\hline \multirow[t]{2}{*}{ WHZ } & -0.102 & -0.076 & -0.184 \\
\hline & $(0.08)$ & $(0.15)$ & $(0.13)$ \\
\hline Unadjusted p-value & 0.215 & 0.641 & 0.180 \\
\hline Adjusted p-value & 0.437 & 0.889 & 0.351 \\
\hline \multirow[t]{2}{*}{ Wasted (WHZ < -2 SD) } & 0.015 & 0.025 & 0.034 \\
\hline & $(0.02)$ & $(0.04)$ & $(0.03)$ \\
\hline Unadjusted p-value & 0.452 & 0.519 & 0.239 \\
\hline Adjusted p-value & 0.697 & 0.768 & 0.416 \\
\hline \multirow[t]{2}{*}{ WAZ } & -0.045 & -0.046 & -0.120 \\
\hline & $(0.05)$ & $(0.13)$ & $(0.10)$ \\
\hline Unadjusted p-value & 0.411 & 0.749 & 0.241 \\
\hline Adjusted p-value & 0.646 & 0.924 & 0.391 \\
\hline \multirow[t]{2}{*}{ Underweight (WAZ <-2 SD) } & 0.026 & 0.049 & $0.067^{*}$ \\
\hline & $(0.02)$ & $(0.04)$ & $(0.03)$ \\
\hline Unadjusted p-value & 0.165 & 0.309 & 0.055 \\
\hline Adjusted p-value & 0.378 & 0.601 & 0.130 \\
\hline \multicolumn{4}{|l|}{ Immediate determinants } \\
\hline \multirow[t]{2}{*}{ IYCF index } & -0.076 & $-0.215^{*}$ & -0.029 \\
\hline & $(0.05)$ & $(0.11)$ & $(0.09)$ \\
\hline Unadjusted $p$-value & 0.176 & 0.064 & 0.755 \\
\hline Adjusted p-value & 0.293 & 0.117 & 0.767 \\
\hline
\end{tabular}




\begin{tabular}{lccc}
\hline & Full sample & $\begin{array}{c}\text { Lowest } \\
\text { bandwidth }\end{array}$ & $\begin{array}{c}\text { Highest } \\
\text { bandwidth }\end{array}$ \\
\hline Health index & -0.047 & 0.001 & -0.077 \\
Unadjusted p-value & $(0.04)$ & $(0.07)$ & $(0.06)$ \\
Adjusted p-value & 0.230 & 0.974 & 0.226 \\
Underlying determinants & 0.293 & 0.981 & 0.398 \\
Food security index & & & \\
& $0.113^{* *}$ & 0.020 & 0.109 \\
Unadjusted p-value & $(0.05)$ & $(0.11)$ & $(0.09)$ \\
Adjusted p-value & 0.030 & 0.863 & 0.248 \\
& 0.088 & 0.852 & 0.317 \\
Care index & & & \\
& $0.053^{*}$ & $0.118^{*}$ & $0.080^{*}$ \\
Unadjusted p-value & $(0.03)$ & $(0.07)$ & $(0.05)$ \\
Adjusted p-value & 0.082 & 0.087 & 0.093 \\
& 0.172 & 0.290 & 0.268 \\
Health environment index & 0.008 & 0.088 & 0.084 \\
Unadjusted p-value & $(0.03)$ & $(0.07)$ & $(0.06)$ \\
Adjusted p-value & 0.800 & 0.275 & 0.186 \\
\hline Observations & 0.795 & 0.477 & 0.317 \\
\hline Nos & 5,120 & 1,205 & 1,914 \\
\hline
\end{tabular}

Notes: Estimations use difference in difference modelling. Robust standard errors clustered at the community level are in parentheses. Adjusted p-values control for the FWER as described in section 5.4.2. Estimations are adjusted and include child's age, sex, PMT score, household size, sex, age and education of the household head, and community fixed effects. ${ }^{*} p<0.1{ }^{* *} p<0.05 ;{ }^{* *} p<0.01$. Optimal bandwidth selection as proposed by Calonico et al. (2017). 


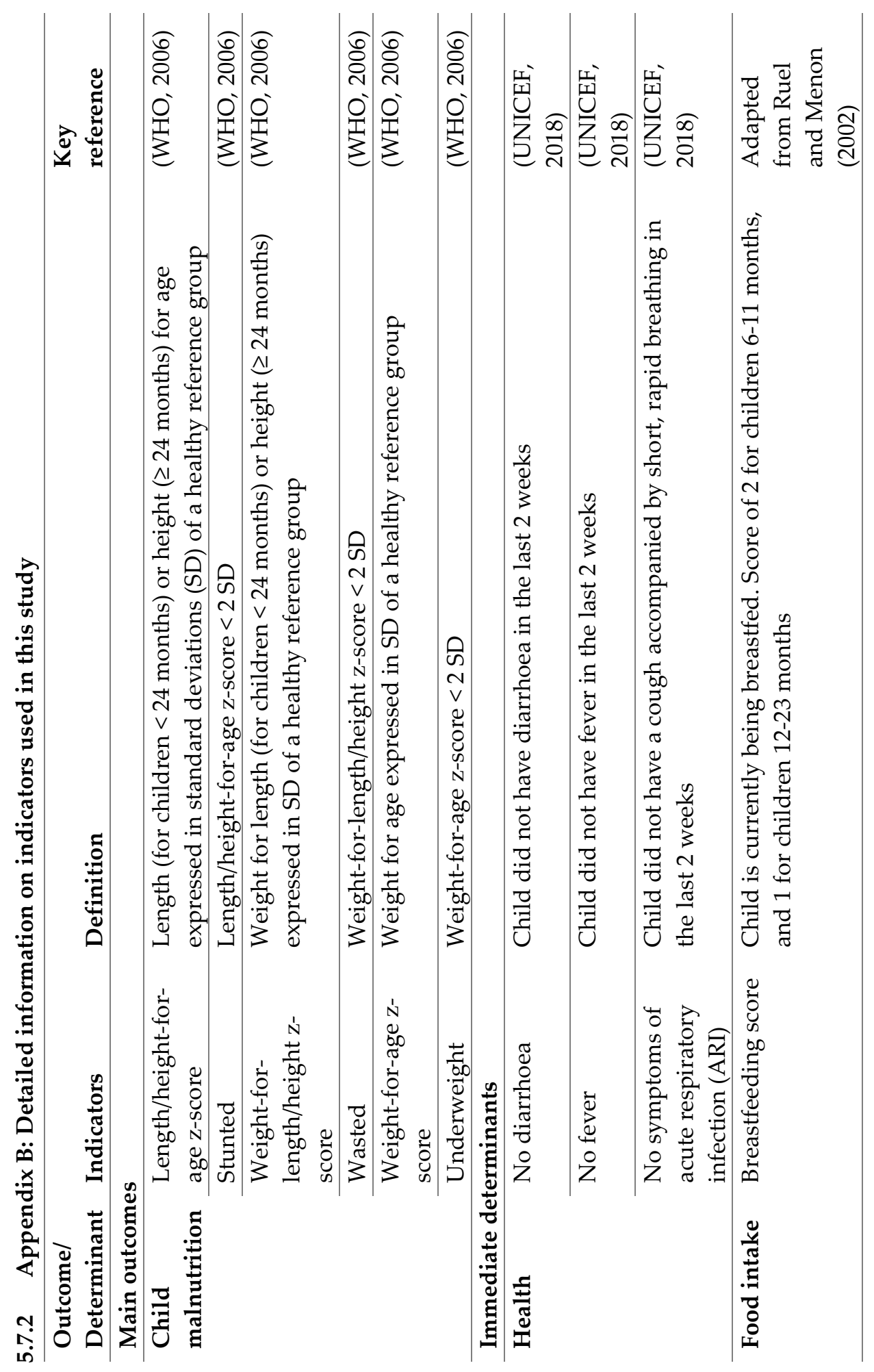




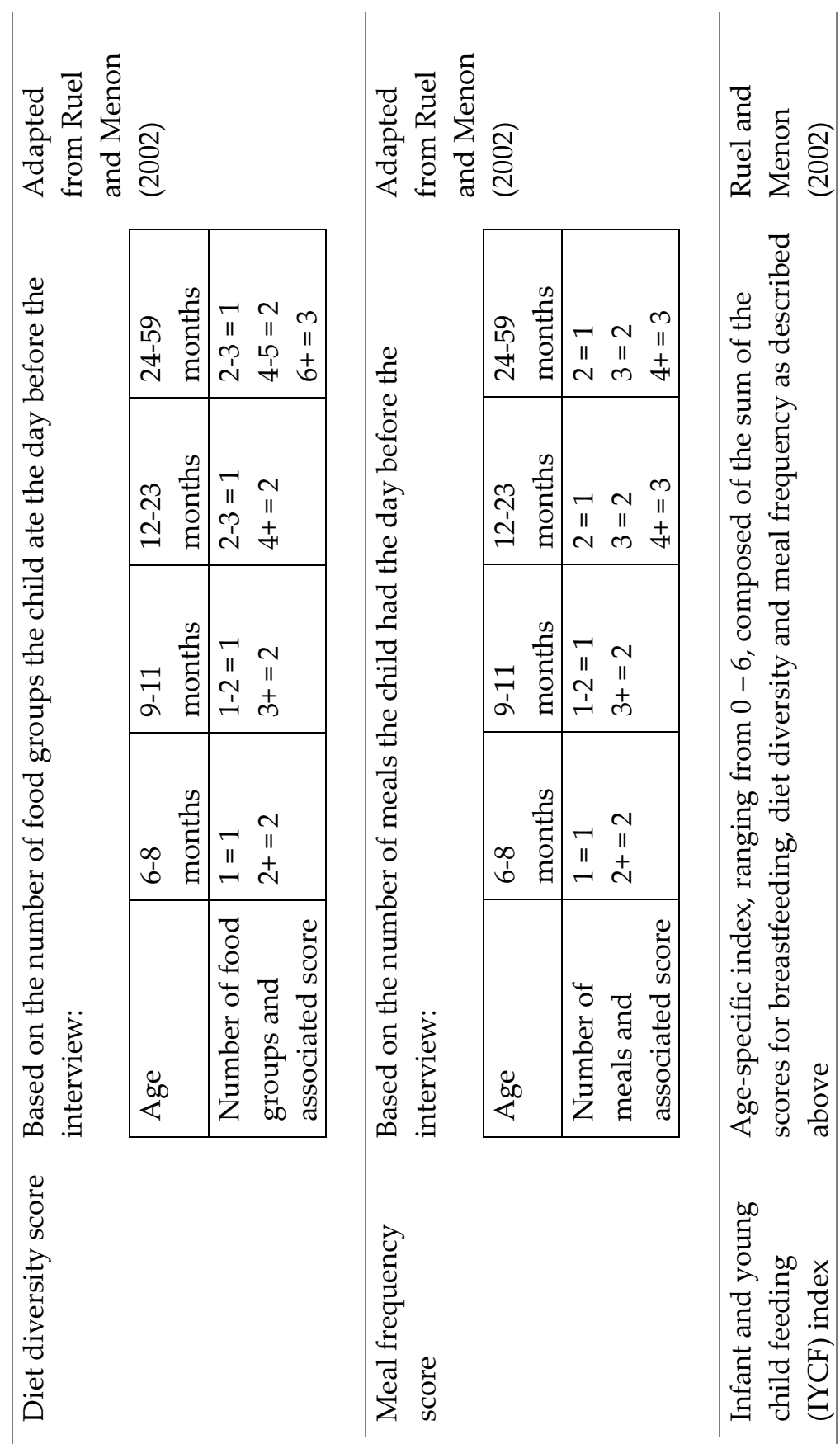




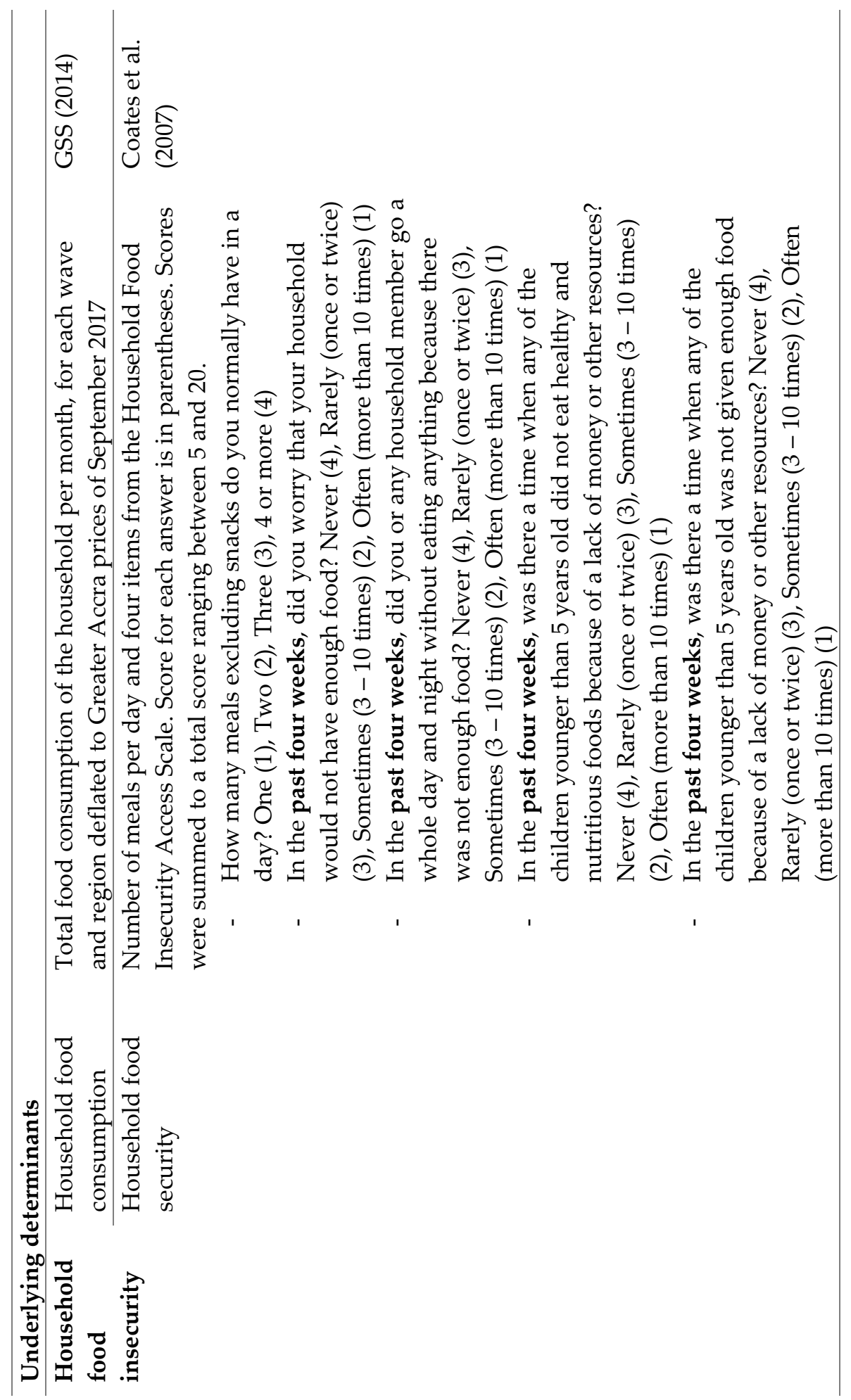




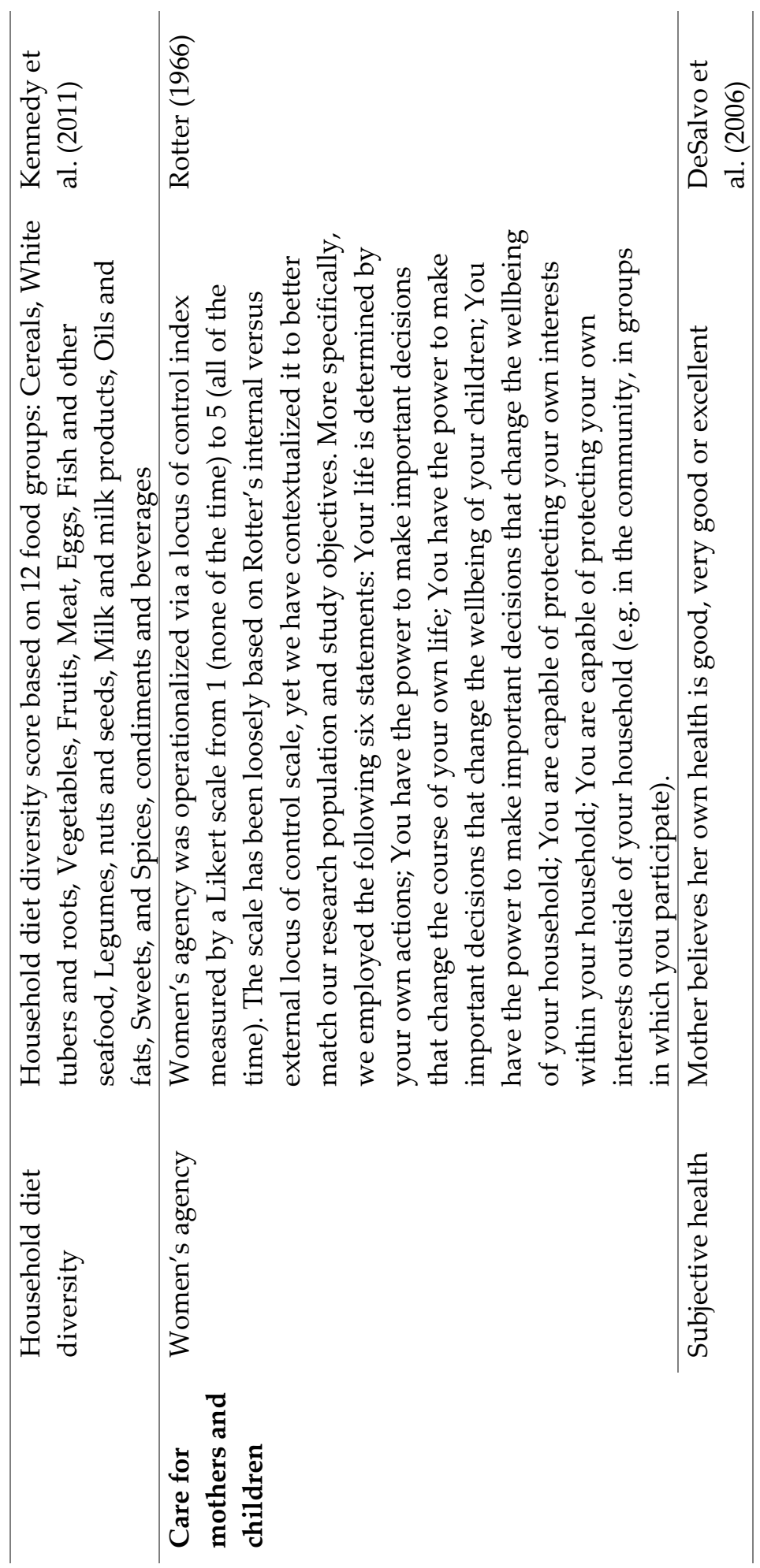




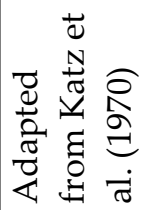

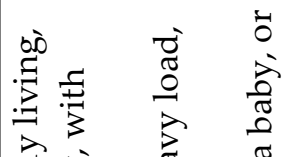

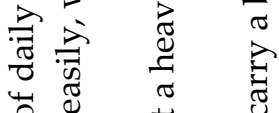

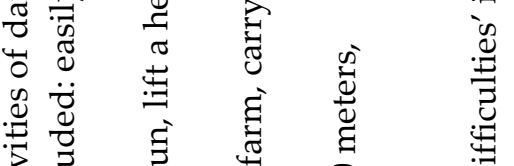

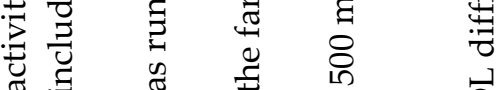

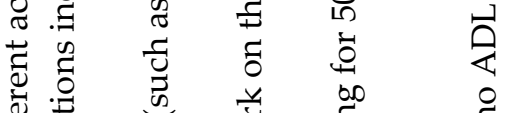

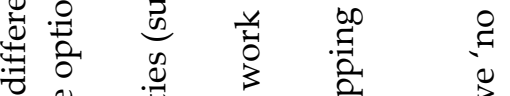

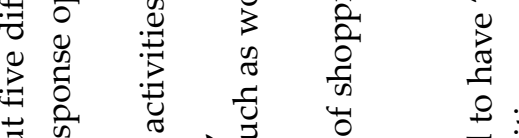

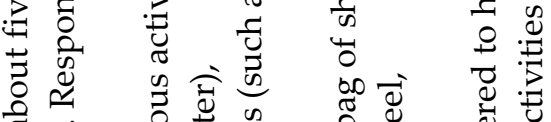

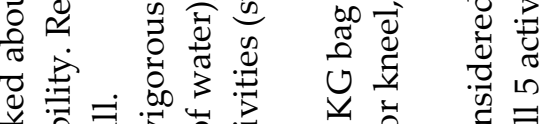

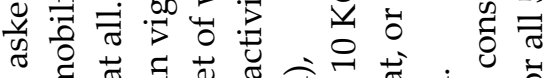

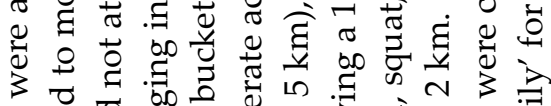

क व

䒕䒕

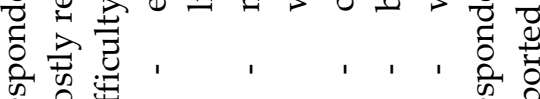

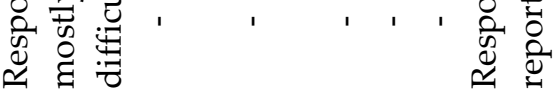

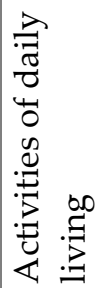




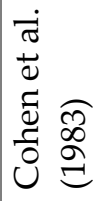

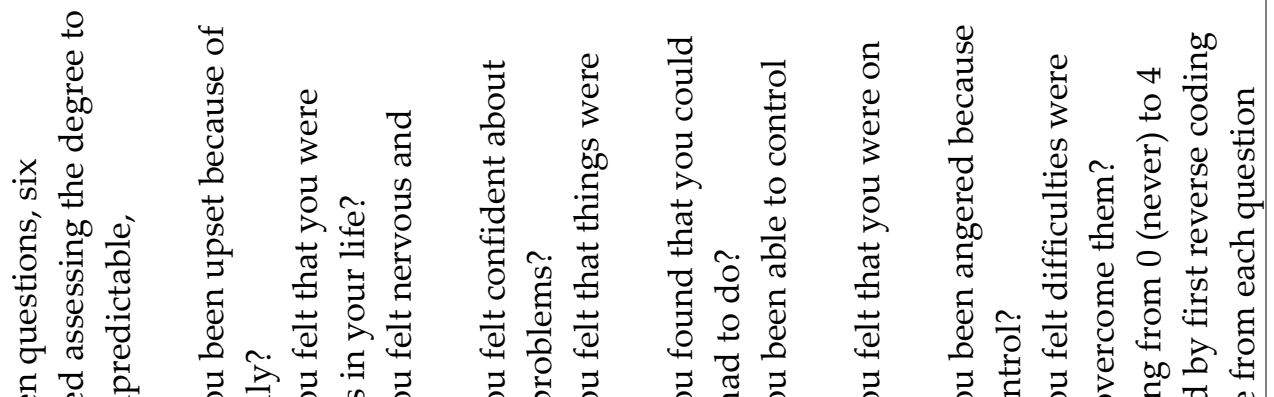

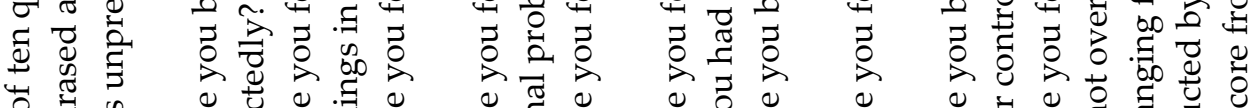

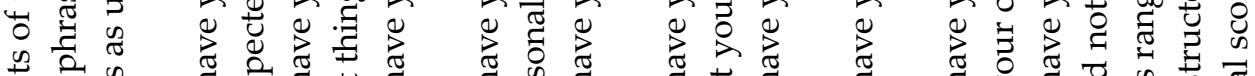

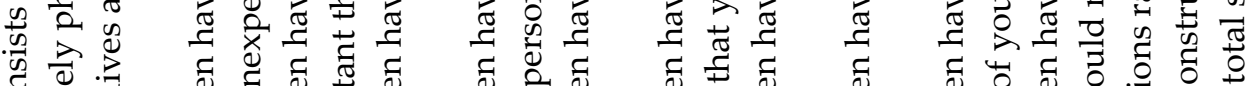

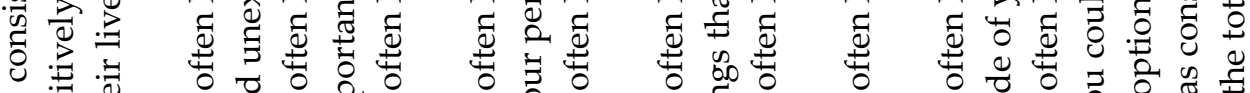

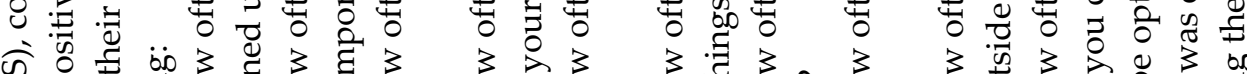

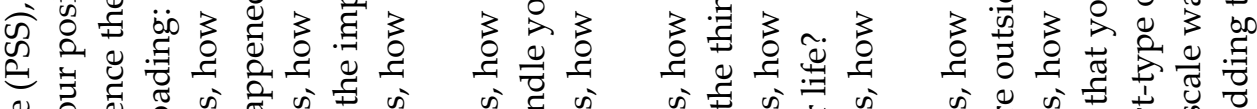

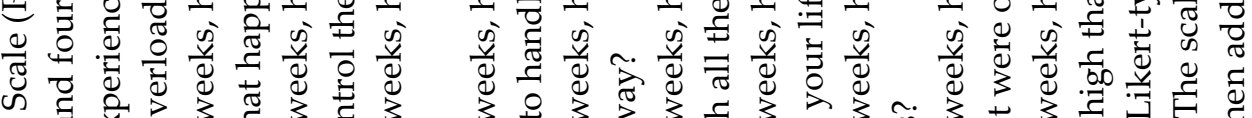

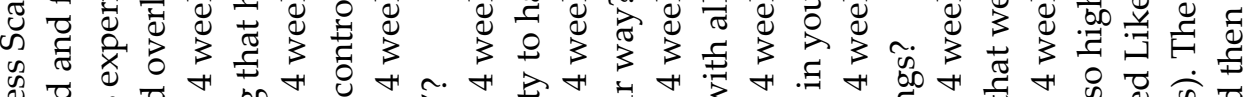

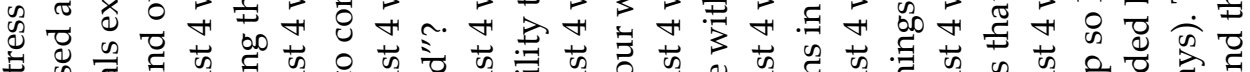

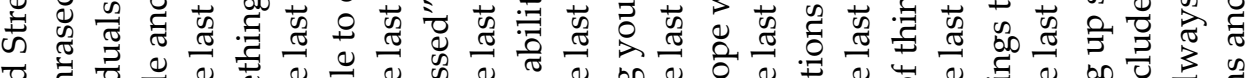

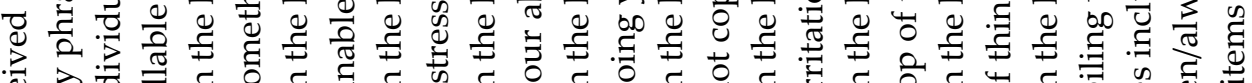

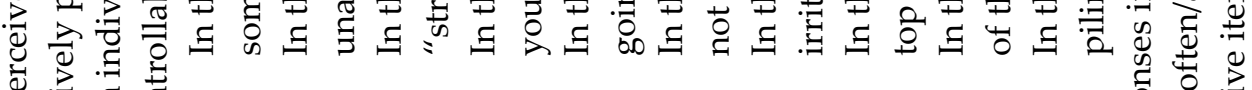

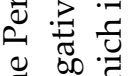

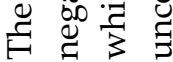




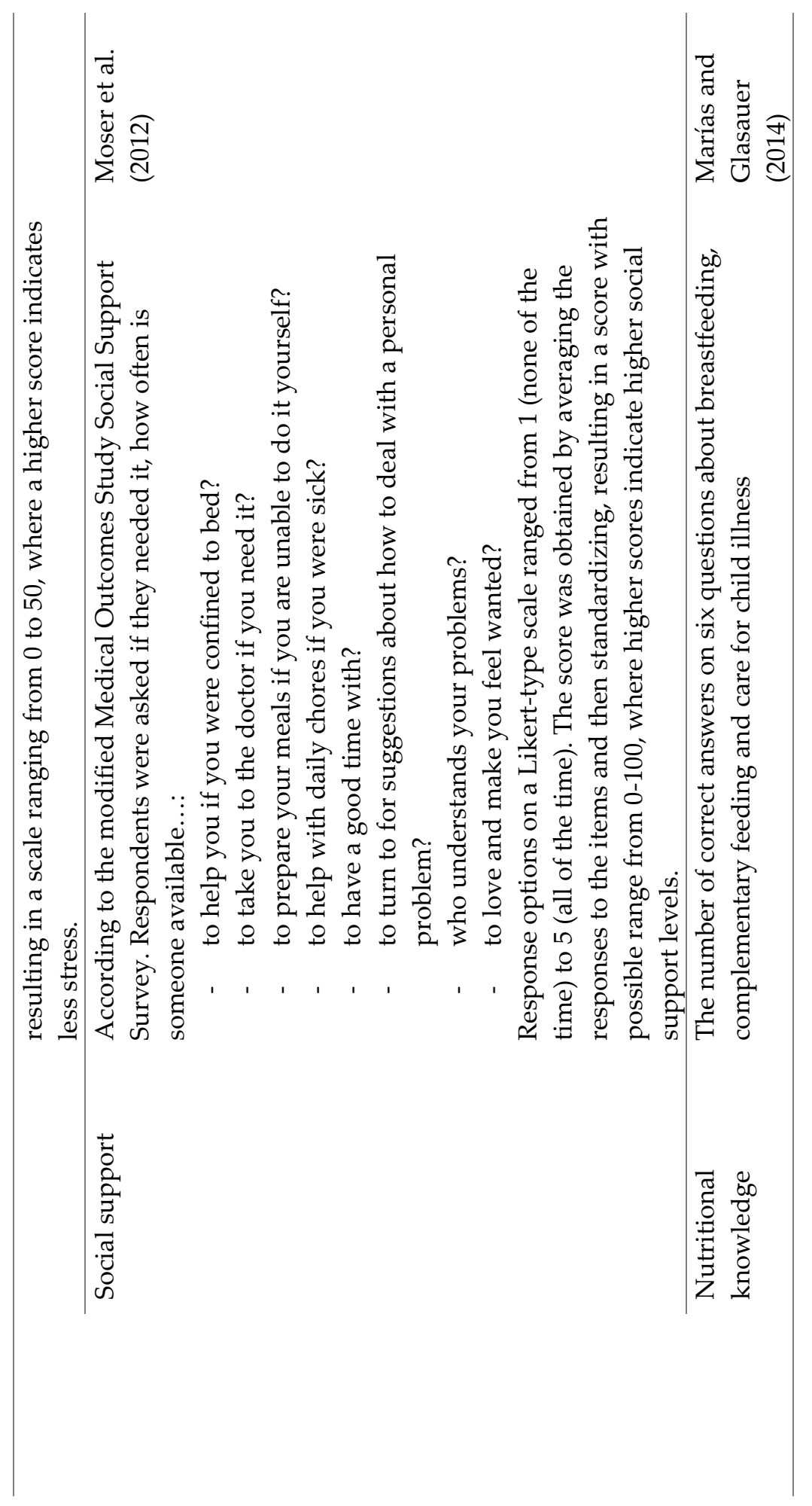




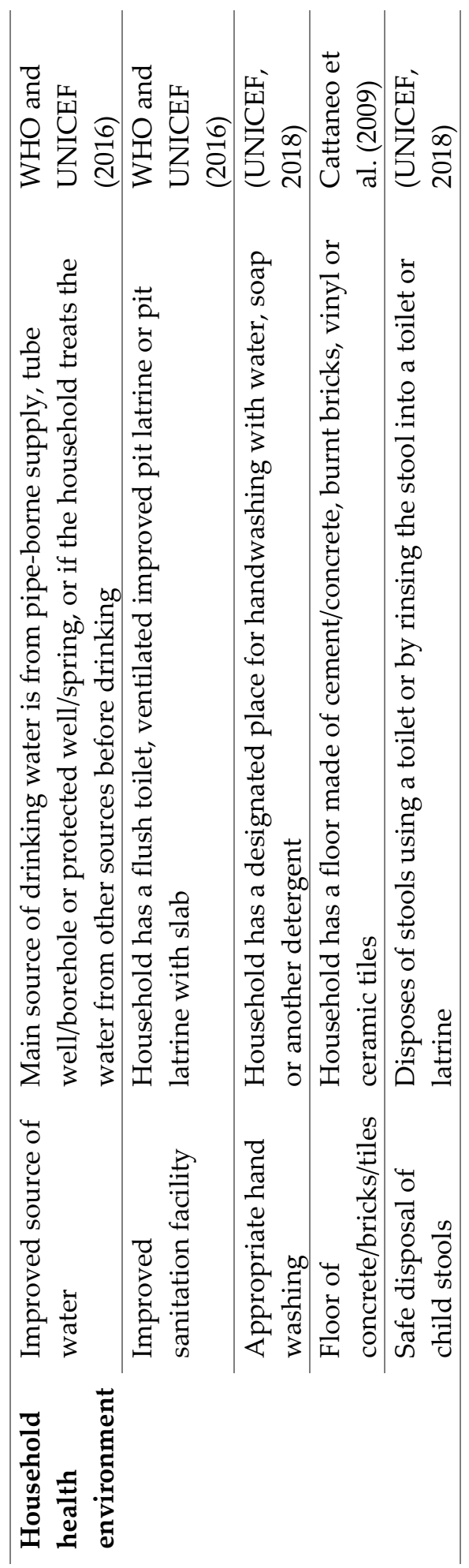


6. Conclusion and policy implications 


\subsection{Introduction}

This final chapter aims to answer the research questions posed in the Introduction by bringing together the findings from the previous chapters. Next, the policy implications for the Ghana LEAP programme as well as for cash transfer programmes in general are discussed. The chapter continues with a discussion of the limitations of this study and proposes areas for further research. The chapter ends with concluding remarks.

\subsection{Main findings and answers to the research questions}

In the introductory chapter of this thesis, the following main research question was posed:

To what extent can an unconditional cash transfer programme improve child nutritional status?

And the following sub-questions were listed:

a. What are the pathways of impact on child nutritional status for a cash transfer programme?

b. What factors mediate or moderate CT programme impacts on child malnutrition?

c. How does intra-household allocation of resources play a role in the determination of children's outcomes?

d. To what extent do intra-household dynamics affect the impact of a cash transfer on nutritional status?

This section will start by discussing findings that answer the sub-questions and then circle back to the overall research question.

1. What are the pathways of impact on child nutritional status for a cash transfer programme?

This thesis has used the conceptual framework of malnutrition (Figure 1.2), first developed by UNICEF in 1990 and still relevant in current research on the determinants of nutritional status (Smith and Haddad, 2015). In its simplest form, this framework identifies health and food intake as the two immediate determinants of malnutrition, and food security, care for mothers and children, and a healthy environment as underlying determinants. A cash transfer is generally received at the household level, and thus investments made with the cash need to work their way through one of these three pathways to generate an impact on nutritional status. Chapter 2 reviewed the evidence on the impact of cash transfer programmes (CTs) on all pathways of this framework. It found that there is a wealth of evidence that CTs have a positive impact on food security at 
the household level, as well as on health care utilization (especially in Latin America and when linked to conditionalities). There is fairly limited evidence, however, on the impact of CTs on water, sanitation and hygiene, despite the relative importance of this pathway for child health (Günther and Fink, 2010) and nutrition (Dangour et al., 2013). The effect of CTs on the immediate determinants of child nutrition is mixed. While many studies examine the effect on household level food security, only a few measure the impact on individual level food intake of the child. Those that do, generally find an increase in high-nutritional-value foods, such as animal-sourced foods. Such foods have been linked to better nutritional status in a variety of settings (Headey et al., 2018) and hence, this is a promising pathway for CTs to improve child nutrition. The impacts of CTs on child health are mixed, with some studies pointing to a positive effect and others to no effects. Supply-side conditions, such as health facility access and health care quality probably play an important role in this regard, as well as health knowledge of the main caregiver of a child (Lagarde et al., 2009). CTs, without additional investments, are therefore unlikely to change these conditions. At the outcome level (nutritional status), the impacts are even more mixed. While some studies find positive effects of CTs on child nutritional status (most notably Mexico and South Africa), most studies find mixed or null effects. When looking through the framework of Figure 1.2, there could be many reasons for CTs not having an impact on child nutrition, and most studies acknowledge that the pathways of impact or non-impact are poorly understood (Leroy et al., 2009).

Chapter 3 proceeds to examine the determinants of malnutrition in an empirical framework, based on the conceptual framework in Figure 1.2. The baseline data of the LEAP 1000 impact evaluation are used for this exercise. The findings suggest that maternal agency and health (components of 'care for mothers and children' in the terminology of Figure 1.2) contribute to improved child health status. Household resources - in the form of consumption - are positively associated with food intake and nutritional outcomes. Chapter 3 then continues to conduct several simulations to examine the potential of various public policies and their potential effect on reducing malnutrition. Results show that consumption growth (through a cash transfer), improving maternal care and avoiding sudden price shocks have a positive - but rather limited effect - on the reduction of malnutrition. For example, the simulated effect of a cash transfer equivalent in size as provided by the LEAP programme is an increase in the average HAZ of $0.02 \mathrm{SD}$ and a reduction in the level of stunting of 0.3 percentage points.

Chapter 5 uses two waves of the impact evaluation to examine the actual impact of the Ghana LEAP 1000 programme on malnutrition and its determinants, again inspired by the framework in Figure 1.2. The impact analysis finds no main treatment effect on nutritional status, nor on the two immediate determinants of food intake and health. However, there is a positive effect on one of the three underlying determinants, household food security. This latter effect corresponds to 
findings from other CTs across the world, as described above. It is interesting to compare the predictions from Chapter 3 to the actual impacts of Chapter 5. For the main outcome, HAZ and stunting, the impact analysis found an insignificant increase in the average HAZ of $0.05 \mathrm{SD}$ and an insignificant impact on stunting of $0.2 \mathrm{pp}$ (Table 5.6). Both estimates are well in line with their predictions of Chapter 3. Although the sign of the impact on stunting is positive, it is still very close to zero, like its prediction in Chapter 3. In terms of food intake, Chapter 3 predicted small but positive changes in the intake of various food groups, which is in line with the small and insignificant impact estimate on the diet diversity score (0.03 SD - Table 5.7). In addition, the negative association between household consumption and child health in Chapter 3 is also supported by the impact estimate on the health index (-0.05 SD - Table 5.7). Like its prediction, the impact estimate on child health is small and insignificant. One difference between the prediction in Chapter 3 and the actual impact of Chapter 5 concerns the meal frequency indicator. Chapter 3 predicted a small but positive change in meal frequency because of increased household consumption, yet Chapter 5 found a significant negative impact of LEAP on the meal frequency score. We turn back to this finding when discussing the role of intra-household dynamics below.

In sum, the findings from this study show that child malnutrition has several determinants, and CTs have most consistent impacts on one of the pathways, food security at the household level, in some cases leading to improvements in children's individual food intake. For these results to translate into improved nutritional status, it is just as important to create a healthy environment around the child to minimize the impact of illnesses on the growth potential. However, there is only limited evidence that CTs, if implemented in isolation, are also able to impact child nutrition through the health pathway.

\section{What factors mediate or moderate CT programme impacts on child malnutrition?}

There may be several context-specific factors that affect the impact of a CT programme on child nutrition. The review from Chapter 2 listed a number of factors that help explain some of the heterogeneous effects observed in the review. The size of the transfer seems to be important, for beneficiaries to adjust their consumption patterns to more and higher quality foods, as well as to make investments into their livelihoods and possibly the health environment around their house. A general rule of thumb is that the transfer should represent an increase of between 15-25 percent of pre-programme consumption (Davis and Handa, 2015, Leroy et al., 2009). The age of children and the targeting of the population are also important components for the success of CTs. Since younger children under two years old are still in their critical window of the first 1,000 days, targeting interventions such as CTs at this age range is potentially very effective. In addition, Manley et al. (2013) argue that targeting CTs to those populations that are most susceptible to nutritional deficiencies (such as household living in poverty, or 
household far away from health services) can yield larger benefits. Another important moderating factor identified by the review in Chapter 2 is supply-side conditions such as markets, prices, health facility access and quality of health services. CTs are primarily a demand-side intervention, putting cash in the hands of households, but if there are no avenues to spend that cash in a sensible way (e.g. on higher quality or more nutritious foods, or proper health care), then the impacts of CTs on the immediate determinants of child nutrition may be negligible. This was also examined in Chapter 3, which showed that a shock that permanently increases prices was predicted to lead to poorer nutritional outcomes. The final moderating factor identified in Chapter 2 is the duration of programme participation. Child nutrition, and especially stunting, is a condition that accumulates over time, and hence interventions to address it also need time to generate effects. In addition, since CTs primarily address the underlying determinants of nutrition (particularly resources for household food security), it is reasonable to expect that it requires enough time for household to adapt their consumption patterns and make the appropriate investments, to generate impacts on nutritional status.

The impact evaluation in Chapter 5 can test a number of these moderating factors in the context of the Ghana LEAP 1000 programme. First, the transfer size was relatively low, at 14 percent of pre-programme consumption. This may be the reason for the limited number of impacts observed in the evaluation, although we cannot be sure since the evaluation did not randomize the amount of the transfer to properly test this hypothesis. Other research has shown however, that transfer size could be important for nutritional outcomes. A study in Pakistan, comparing different cash modalities, found that the probability of being wasted was lower in a treatment arm which provided double the cash amount compared to the standard cash treatment. The size of the grant did not matter for the impact on stunting and HAZ, which was similarly large for both cash treatments (Fenn et al., 2017). An experiment in Rwanda, benchmarking an integrated nutrition programme with an equivalent amount of cash, and a large amount of cash (more than US\$ 500 over the study period of 12 months) found that the large transfer modestly improved HAZ and WAZ by about 0.1 SD (McIntosh and Zeitlin, 2018). However, both studies examine programmes that were not government-run, so it is unlikely if these results also translate to large, national CTs. In particular the transfer size in the latter study may be too high for most SSA governments to transfer to a large segment of the population, notwithstanding political implications of transferring such amounts. For example, US\$500 is more than three times the value of the annual LEAP cash grant.

The heterogeneity analysis in Chapter 5 shows no differential impacts by age group, except for a positive effect on WHZ for children 12-17 months old, and a positive effect on care for the youngest age group of 6-11 months. In contrast, there is a negative effect for children 24-35 months old on weight-related 
nutritional status, possibly suggesting that children in this age range were not prioritized by the household. Hence there is only limited evidence that LEAP 1000 had a larger impact on younger children.

Chapter 5 also examined the moderating effects of access to and the quality of nearby health facilities, which are considered critical supply-side conditions. The findings show that distance to and quality of a health facility have no additional effect on the impact of LEAP 1000 on nutritional status. However, treatment effects on food security are larger for children living near a health facility with a doctor present. It could be that health facilities with doctors are located in better integrated locations, with better access to markets and other services. This would allow households in such areas to have better access to higher quantity and quality of foods as well as better nutrition related services. Overall, though, these supplyside conditions only seem to play a limited role in the effectiveness of LEAP 1000.

Another potential moderating factor on the impact of CTs on nutrition is a shock to the household livelihood. An unexpected shock could suddenly change the living conditions of a household, leading to poorer outcomes. A CT could provide a safety net during such events by providing a reliable source of minimum income to the household in case other income sources are affected by the shock. A positive shock on the other hand could open up new opportunities, supported by a small amount of reliable cash from a CT. Chapter 5 examined both negative and positive shocks. Shocks that impact households' crops have a negative effect on the impact of LEAP 1000 on weight-related nutritional outcomes. This means that children in LEAP 1000 household do worse than children in non-LEAP 1000 households in the face of such an event. Chapter 5 hypothesized that this could be explained by households prioritizing other household members in terms of food allocation during a shock, to invest in those members that are able to generate income as labourers. On the other hand, Chapter 5 found that the introduction of additional development programmes, as an example of a positive event, increases the impact of LEAP 1000 on child health. This complementarity is a promising avenue for future improvements on linkages between programmes.

The final moderating factor in Chapter 2 is duration of the programme. Since this study only had a 24-month window, it could be that there is more time required before impacts on long-term outcomes, such as stunting, appear. Households need time to fully internalize the transfer, adjust their behaviour, potentially make investments in their income-generating activities, and so on to build a stronger foundation for their household livelihood. For example, in Bangladesh, stunting reduced from 55 percent to 43 percent in the decade between 1997 and 2007, which is considered 'rapid' (Headey et al., 2015, Jain, 2018). It is therefore important to follow LEAP 1000 households over a longer period to identify the long-term effects of the programme.

In sum, based on the literature review, Chapter 2 hypothesized several moderating factors for the impact of CTs on child nutrition. However, there is only 
limited evidence for these moderating factors in the context of the Ghana LEAP 1000 programme. Younger children did not necessarily benefit more from the programme, and presence of (quality) health facilities was not related to higher programme impacts. Since these are findings from one particular programme, more research is needed to examine these and other moderating factors.

\section{How does intra-household allocation of resources play a role in the determination of children's outcomes?}

A novel aspect of this study is to introduce the concept of intra-household allocation of resources into the framework of Figure 1.2. The rationale is that CTs are generally targeted at the household level, and adult members pick up the cash. Hence, to impact the children of the households, the cash needs to be allocated in a child-sensitive way. The intra-household dynamics of the household could therefore play an important role in the effectiveness of a CT programme on children's outcomes. The review in Chapter 2 identified several studies that found larger impacts on girls' outcomes when cash was given to the main female caretaker, pointing to some form of heterogeneity in the allocation of additional income. However, there remains only limited evidence available and some studies (e.g. in Burkina Faso) have showed the opposite, i.e. that cash in the hands of fathers is more effective to improve children's wellbeing.

To explore this idea in more detail, Chapter 4 first uses the baseline data of the LEAP 1000 impact evaluation to examine if and how intra-household dynamics play a role in the determination of children's outcomes. It employs two sets of complementary tests. First, outlay equivalence analysis is used to examine any gender bias in the household expenditure data. This analysis looks at the household response when an additional child enters the household. It therefore measures the general preference of the household to invest in their children. The second test investigates whether there are differences between parents in terms of investing in female versus male children. More specifically, parental education is used as a source of bargaining power to investigate its effects on the educational attainment and nutritional status of boys versus girls in the household.

The outlay equivalence analysis shows that parents are willing to give up spending on adult goods in favour of children in the household as most ratios are negative. For example, the addition of a female child $0-4$ years old in the household has a similar effect on expenditures on adult goods as cutting total household expenditures in half (-52 percent). This effect is within a range of effects found in the literature, for example -22 percent for girls $0-4$ years old in Ivory Coast, -63 percent and -23 percent for girls aged $0-2$ and $3-4$ years old respectively in Thailand (Deaton, 1989) and -34 percent for girls $0-6$ years old in Papua New Guinea (Gibson and Rozelle, 2004). However, the effects on girls are not significantly different from the effect on boys, suggesting that the household as a unit has no preference for either sex. 
Chapter 4 proceeds by examining parental education as a source of bargaining power, and how power within the household influences children's educational and nutritional outcomes. This analysis reveals suggestive evidence that fathers are more inclined to invest in their daughters compared to their sons. Girls of secondary school age (12 - 17 years) seem to benefit from living in a household where the father has received some form of formal education compared to boys. In contrast, similar girls in households where only the mother completed some formal schooling, are worse off compared to boys. This difference in preferences is not explained, however, by the amount of educational expenditure invested in their children. When looking at nutritional outcomes (HAZ), there is also suggestive evidence that young girls of better-educated fathers are better off compared to boys. This holds both in terms of inputs (infant and young child feeding practices) as outcomes (HAZ). Chapter 4 concluded that fathers may prefer to invest in their daughters to yield a higher bride price at marriage, though this hypothesis cannot be tested with the data at hand.

In sum, this study found that intra-household dynamics matter for children's outcomes to some extent. In general, households tend to give up spending on adult goods when an additional child joins the household, irrespective of whether the additional child is a boy or a girl. Educational and nutritional outcomes of girls tend to be somewhat better in case the father has attained more education, suggesting that fathers are inclined to invest in their daughters.

\section{To what extent do intra-household dynamics affect the impact of a cash transfer on nutritional status?}

The findings of Chapter 4 could have an important implication for the effect of LEAP 1000 on nutritional outcomes. If not mothers, but fathers are more inclined to invest in their children, particularly girls, then giving the cash out to women may not be the most effective strategy. The impact analysis in Chapter 5 shows that while the number of meals at the household level increased, the number of meals consumed by children decreased. This finding could be explained by a system of resource allocation in the household that doesn't prioritize children, but rather adults. This might be a fully rational choice, if it is considered that working-age adults benefit more from increased food consumption, to generate additional income for the household. In that case, it might take longer to observe positive impacts on child nutritional status, as households are still in the process of adjusting their consumption patterns and income-generating activities. It must be assumed then, that all members, including children, benefit from the additional resources flowing into the household as a result from such a strategy. However, if additional resources are spent in the same way as the LEAP 1000 grant, we have already seen that this does not necessarily benefit children. 
The results from Chapter 4 feed directly into the impact analysis in Chapter 5 by examining whether the effects for boys and girls are different depending on whether their father or mother has achieved any schooling. Results show that there is a negative effect on health of daughters from better-educated mothers, which is in line with the findings of Chapter 4 . This finding can also be explained in the hypothesis posited above, in case mothers divert resources away from their daughters to other income-generating members of the household. Here, we can easily assume that the effect is less pronounced for boys, as boys are more likely to contribute to household economic activities.

In sum, the impact analysis reveals that there are differences in impacts between household members, particularly in the number of meals. There is also suggestive evidence that daughters of better-educated mothers have poorer health status because of LEAP 1000 . However, the analysis is unable to fully understand what intra-household dynamics are driving these findings. In addition, it remains largely unclear if difference in preferences between spouses can also explain some of the null impacts observed in Chapter 5.

All of this brings us back to the main research question: To what extent can an unconditional cash transfer programme improve child nutritional status?

The literature review in Chapter 2 already provided a careful look at the current evidence and concluded that the direct effect of CTs on child nutrition was very mixed, and the pathways of impact were poorly understood and only examined in a limited number of cases. Chapter 3 further examined the drivers of malnutrition in the Ghana LEAP 1000 study population and found that an increase in income alone would yield a positive, yet very limited improvement in nutrition for families living close to the poverty threshold. A novel aspect of this study is to introduce intra-household dynamics into the mix and Chapter 4 showed that there may be differences in preferences between fathers and mothers, with fathers more inclined to invest in their daughters. Chapter 5 was able to utilize two waves of data to study the impacts of the Ghana LEAP 1000 programme on child nutrition and its determinants. The main analysis showed no significant impacts on nutritional status, nor on the two immediate determinants of food intake and health. However, LEAP 1000 had a positive effect on one of the three underlying determinants, household food security. The heterogeneity analysis showed no differential impacts by age group, but quality of nearby health facilities increased the programme's impact on food security. The programme had lower impacts on weight in case of crop-related shocks and higher health impacts when communities benefit from additional development programmes. Another unique element of this study is that it was able to 'predict' certain outcomes using the baseline data in Chapter 3 and 4, which were then tested with the two waves of data in Chapter 5. Notably, the prediction of the marginal impact of the LEAP programme on nutritional outcomes was confirmed in the impact analysis in Chapter 5. In 
addition, the finding from Chapter 4 that better-educated mothers might have a stronger preference to invest in their sons compared to their daughters was to some degree also confirmed in Chapter 5.

Based on the findings in this study, a simple answer to the main research question would be, at least in the context of the Ghana LEAP 1000 programme: 'it can' $t^{\prime}$. However, this would be too simplistic and ignore some of the positive impacts on underlying determinants, as well as the wealth of evidence from other CTs around the world. A better, more nuanced, answer to the main research question is that a CT, when implemented in isolation, is unlikely to yield strong impacts on young child nutrition, but when coupled with complementary programmes aimed at addressing multiple underlying and immediate determinants at the same time, would have the potential to make a difference. In addition, a long-term perspective is needed as evidence shows that increased wealth and improving the education and status of women all have positive effects on child nutritional status (Maffioli et al., 2009, Smith and Haddad, 2015).

\subsection{Policy implications}

The findings of this study have important policy implications, as governments across the world embark on ambitious social protection agendas, many with nutritional goals in mind, as they seek to meet the SDGs. This is particularly related to SDG 2 to end hunger, achieve food security and improved nutrition, for which the first two targets are shown in Table 6.1. It is interesting to note that the targets and indicators do not mention any concrete tool to achieve these targets. At the same time, other targets include tools such as target 1.3 on social protection floors and target 3.8 on universal health coverage (UNDESA, 2018). This begs the question: what can we expect from a CT if the objective is to improve child nutritional status? Giving (unconditional) cash to households will improve their living conditions, but given the complex determinants of child nutrition, is it enough?

The results from this study show that while cash certainly helps, especially for improving the household's food security situation, it is likely not enough. It is therefore important to explore complementarities between programmes across different sectors that can affect the underlying and immediate determinants of nutrition simultaneously (World Bank, 2018a). There is an increasing interest in such an integrated approach with promising findings from early studies (Roelen et al., 2017). At a more general level, studies have shown that integrated programmes are better than the sum of their parts (Sedlmayr et al., 2017). There are also promising findings on CTs and nutrition. For example, in Bangladesh, an integrated programme with cash transfers and behaviour communication change (BCC) led to an increase in children's dietary diversity and a 7 pp reduction in stunting (Ahmed et al., 2017). In Rwanda, however, an integrated programme 
(without a cash transfer) aimed to address malnutrition had no effect on nutritional outcomes after one year, similar as a programme which gave a cost-equivalent amount of cash (McIntosh and Zeitlin, 2018). This indicates that the context matters in which a programme is delivered, and policy makers need to make informed decisions on which programme components to combine. For example, if knowledge and practices related to child nutrition are already at a decent level, then a BCC campaign is unlikely to have a large complementary effect.

Table 6.1, SDG 2: End hunger, achieve food security and improved nutrition and promote sustainable agriculture

\begin{tabular}{|c|c|}
\hline Target & Indicator \\
\hline $\begin{array}{l}2.1 \text { By } 2030 \text {, end hunger and ensure } \\
\text { access by all people, in particular the } \\
\text { poor and people in vulnerable } \\
\text { situations, including infants, to safe, } \\
\text { nutritious and sufficient food all year } \\
\text { round }\end{array}$ & $\begin{array}{l}\text { 2.1.1 Prevalence of undernourishment } \\
\text { 2.1.2 Prevalence of moderate or severe } \\
\text { food insecurity in the population, } \\
\text { based on the Food Insecurity } \\
\text { Experience Scale (FIES) }\end{array}$ \\
\hline $\begin{array}{l}2.2 \text { By } 2030 \text {, end all forms of } \\
\text { malnutrition, including achieving, by } \\
2025, \text { the internationally agreed } \\
\text { targets on stunting and wasting in } \\
\text { children under } 5 \text { years of age, and } \\
\text { address the nutritional needs of } \\
\text { adolescent girls, pregnant and } \\
\text { lactating women and older persons }\end{array}$ & $\begin{array}{l}\text { 2.2.1 Prevalence of stunting (height for } \\
\text { age }<-2 \text { standard deviation from the } \\
\text { median of the World Health } \\
\text { Organization (WHO) Child Growth } \\
\text { Standards) among children under } 5 \\
\text { years of age } \\
\text { 2.2.2 Prevalence of malnutrition } \\
\text { (weight for height }>+2 \text { or }<-2 \text { standard } \\
\text { deviation from the median of the WHO } \\
\text { Child Growth Standards) among } \\
\text { children under } 5 \text { years of age, by type } \\
\text { (wasting and overweight) }\end{array}$ \\
\hline
\end{tabular}

Source: UNDESA (2018)

Another implication from this study relates to the transfer size. The transfer amounts in most government-run schemes in SSA are modest to keep them fiscally sustainable and politically feasible. Higher amounts (between 15-25 percent of pre-programme expenditures) are generally associated with more wideranging impacts and multiplier effects when it allows household to invest in productive economic activities (Handa et al., 2018b). However, a modest amount may turn into a small amount if prices of food are volatile and increase fast due to inflation. This is what happened in Ghana. Over the two years of the evaluation, the nominal value of the transfer remained the same, while households faced an 
inflation rate of 20 percent over the same period. While it is unclear if the size of the transfer is the main reason for some of the null effects observed in the study, it is likely that it contributed to lower effects than if the real value of the transfer had remained constant. It is therefore important to regularly review the transfer amounts and adjust them to keep up with purchasing power.

In addition, it is important to consider intra-household dynamics. Especially when cash is given to one member of the household (a parent), but the intention is to improve outcomes for another member (a child), the rules determining the allocation of resources within a household are important to understand. This study has shown that fathers and mothers may have different preferences when it comes to investing in their children, and hence the recipient of the grant can play an important role. In this case, should policy makers then insist on conditions to make sure that the cash is spent in a nutrition-sensitive way so that it benefits the children? Typically, conditional cash transfers have shown larger impacts on those domains that are conditioned (e.g. preventive health visits, health monitoring check-ups and education) (Attanasio et al., 2015, Baird et al., 2014). Unconditional grants on the other hand, allow households to decide the most useful way to spend and invest their money on their most urgent needs, such as food security. There has been little research on the effectiveness of conditions on nutritional outcomes, as most studies thus far have focused on education. The exception is the study by Akresh et al. (2016), which randomizes an unconditional and conditional cash transfer in rural Burkina Faso. They find that the conditional arm is slightly better in improving health outcomes, especially episodes of illness, possibly linked to the increase in preventive health visits (the condition). In terms of anthropometric outcomes, they find some evidence that the impact on WAZ is higher for CCTs, but only after one year of the programme. There are no effects in either arm after two years. Given the larger administrative burden and higher implementation costs of conditionalities, it might also be feasible to implement a strong messaging component into an unconditional programme. Such a 'labelled' cash transfer programme has been shown to improve educational outcomes in Morocco similarly as a conditional programme (Benhassine et al., 2015), yet it has not been studied with nutritional outcomes.

Relatedly, CTs are primarily an intervention that address the demand-side. It seems equally important for policy makers to make investments in the health infrastructure to improve health services for the population. In the present study, only 31 percent of households had access to a health facility with a doctor, and for only 22 percent of the households, a facility with a doctor was within five kilometres of their residence (Table 5.4). Investments in the health infrastructure will likely improve the health environment of children, one of the underlying determinants of malnutrition. In addition, improved health systems can play a moderating effect for the impact of a CT, as households will have better access to 
proper preventive and curative health services to limit the effect of diseases on child growth.

In sum, the central policy conclusion is that UCTs, in the context of the Ghana LEAP 1000 programme, can improve food security at the household level but have a negligible effect on the nutritional status of infants. As a result, UCTs with the objective to improve child health and nutrition are more like household benefits rather than child benefits. Therefore, additional policy measures working across different sectors, for example by linking social protection programmes to complementary programmes, are needed to ensure that the potential of UCTs are maximized to improve child wellbeing (World Bank, 2018a). Moreover, a longterm perspective is required since evidence shows that increased wealth, higher educational achievement and improved status of women all have positive effects on child nutritional status.

\subsection{Limitations and areas for future research}

The limitations of this research have been discussed in each chapter and are summarized here. This section also proposes areas for future research. The analysis in Chapter 3 was limited by the lack of strong instruments for inputs in the child health production function. When available, it would be possible to analyse the effect of the immediate determinants of nutrition on nutritional outcomes. More research is required to identify and test instruments in this equation, for example with longitudinal data.

One of the novel aspects of this study is to introduce how intrahousehold dynamics determine children's outcomes and how these dynamics affect the impact of a CT. As acknowledged in Chapter 4, the study (being an official evaluation of a government programme) was not designed with this specific objective in mind. Hence, the data were not ideal to examine intra-household resource allocation as there is no individual ownership, consumption or income data. Future studies interested in this question should take care to include proper measures. For example, it would be particularly interesting to collect food intake at an individual level for all household members with more detailed methods such as food diaries (Ferro-Luzzi, 2003). Such methods could identify true intra-household resource allocation of food and the impact of a CT on this allocation can be tracked.

The impact evaluation design of Chapter 5 is a regression discontinuity design, while the golden standard of impact evaluation is a randomized control trial. However, the implementation of the RD was ideal in this study, with a sharp threshold and no manipulation of the score, leading to a very balanced treatment and comparison sample at baseline. When these conditions hold, RD is one of the most credible methods for assessing impact (Cattaneo et al., 2018a). The impact estimate of the RD, however, is an average treatment effect at the threshold and might therefore not be generalizable to subjects further away from the cut-off. 
Usually it is considered a lower bound of the average treatment effect (Mehta, 2018). Nonetheless, there is merit for future research to explore impacts further away from the threshold, as impacts might be larger for those households that are poorer at baseline.

While the programme studied in this thesis was a linked programme (cash transfers linked with free health insurance), it was not possible to disentangle the effect of the cash versus the health insurance. Members in LEAP 1000 household were significantly more likely to be insured than members in comparison households, although universal health insurance coverage in the treatment group was not reached (UNICEF Office of Research - Innocenti et al., 2018). As the findings of this study suggest that integrated programmes may work better to improve child malnutrition than cash alone, more research is required to study which programmes could best complement cash transfers. Benchmarking studies such as the one by McIntosh and Zeitlin (2018) are particularly interesting to undertake, to assess the complementary effects and cost effectiveness of integrated programmes versus cash. Also multiple treatment studies (e.g. Sedlmayr et al., 2017) are needed to explore which complementarities work best for addressing malnutrition

Another limitation of the impact evaluation in Chapter 5 is the relative short timeframe of 24 months. It might be that improvements in nutrition require a longer time to materialize as household need to adjust their spending patterns and make the appropriate investments in the underlying determinants of malnutrition. Future research should focus on following households over a longer period to explore long-term impacts. A couple of recent studies have begun to examine longterm impacts, such as in Indonesia (6 years) (Cahyadi et al., 2018) and Mexico (13 years) (Parker and Vogl, 2018) among other Latin American programmes. Longterm evidence from UCTs, in SSA and on nutritional outcomes is limited however with only the Zambian programme that included a four year follow-up (Handa et al., 2018b). ${ }^{45}$ Since most SSA programmes were only started in the last decade or so (World Bank, 2018b), there are promising opportunities to follow beneficiaries over a longer time period.

At a more general level, this study has primarily examined one programme in one specific area in Ghana, hence the external validity of the results may be low. Nevertheless, most findings are compared to findings from similar programmes across the SSA region and CTs across the region follow a similar design (Davis et al., 2016), making the outcomes from this study relevant for similar programmes. This study therefore contributes to the growing literature on

${ }^{45}$ Households were also followed up after seven years in 2017, but results have yet to be published. 
CTs in SSA and feeds into the evidence base for governments across the continent when they design, implement and scale-up CTs.

Another general limitation is the focus on stunting and height-for-age as a main outcome indicator for child wellbeing. Recent literature has suggested that the cut-off for stunting (-2 SD) is biologically arbitrary and children both below and above the cut-off could similarly be at risk of impaired development (Perumal et al., 2018). Programmes that fail to have an impact on stunting could still have beneficial outcomes on other nutrition-related outcomes, which should not be discounted. In addition, while stunting is associated with various future life outcomes such as cognitive development and chronic diseases, it does not cause these outcomes. Hence, addressing stunting will not automatically lead to improvements in outcomes that are associated with stunting during early childhood (Leroy and Frongillo, 2019). Direct interventions for improving early childhood development and nutrition are equally important.

\subsection{Concluding remarks}

Child malnutrition remains a global public health challenge affecting millions of children worldwide, primarily in lower-income countries. At the same time, social protection programmes, in the form of cash transfers, have been implemented and scaled-up by governments in lower-income countries, aimed at addressing poverty and vulnerability. This thesis examined how CTs can help address the burden of child malnutrition. It builds upon the literature on the effect of CTs on child nutrition, which has showed mixed results and that pathways of impact are unclear (Chapter 2). The thesis adds intra-household dynamics into the mix, an important element which has thus far been ignored.

Using an impact evaluation of a CT in Northern Ghana, the empirical part of this thesis examined the determinants of child nutrition in Chapter 3, how intrahousehold dynamics affected children's outcomes in Chapter 4 and the impact of the CT on child nutrition and its determinants in Chapter 5. The results show that cash alone is unlikely to make a large contribution to reducing child malnutrition. The determinants of child malnutrition are complex and additional income is only one driver, mostly associated with increasing the resources for food at the household level. There needs to be more effort to address the other determinants of nutrition (care for mothers, healthy household environment) through complementary programming as well as proper investments in the local health infrastructure. In addition, more effort is needed to ensure that programmes aimed at the household level translate into improvements for young children, by considering inequalities in the intra-household division of resources.

This study comes at an important time. The SDGs call for the eradication of child malnutrition (SDG target 2.2) as well as the establishment of appropriate social protection systems (SDG target 1.3). How the latter goal can help achieve the 
former is an important question for policy makers who are looking for complementarities in achieving the SDGs. The results of this thesis provide policy makers with relevant evidence as they continue to design, implement and scale-up social protection programmes that address the needs of vulnerable populations. 


\section{Bibliography}

Abdul-Korah, G. B. (2011) 'Now If You Have Only Sons You Are Dead': Migration, Gender, and Family Economy in Twentieth Century Northwestern Ghana', Journal of Asian and African Studies, 46(4): 390-403.

Aboud, F. E. and Akhter, S. (2011) 'A cluster-randomized evaluation of a responsive stimulation and feeding intervention in bangladesh', Pediatrics, 127(5): e1191-7.

Adato, M. and Bassett, L. (2009) 'Social protection to support vulnerable children and families: the potential of cash transfers to protect education, health and nutrition', AIDS Care, 21 Suppl 1: 60-75.

Adato, M., De la Briére, B., Mindek, D. and Quisumbing, A. (2000) 'The impact of PROGRESA on women's status and intrahousehold relations. Final Report'. Washington DC, International Food Policy Research Institute.

Adler, N. E., Boyce, W. T., Chesney, M. A., Folkman, S. and Syme, S. L. (1993) 'Socioeconomic inequalities in health: no easy solution', Jama, 269(24): 31403145.

Aguero, J., Carter, M. and Woolard, I. (2007) 'The impact of unconditional cash transfers on nutrition: The South African Child Support Grant', Working Papers 39. International Policy Centre for Inclusive Growth.

Ahmad, A. and Morduch, J. (1993) 'Identifying sex bias in the allocation of household resources: evidence from linked household surveys from Bangladesh'. Harvard-Institute of Economic Research.

Ahmed, A., Hoddinott, J., Roy, S. and Sraboni, E. (2017) 'Linking Social Protection and Nutrition in Bangladesh. Results from the Transfer Modality Research Initiative (TMRI)', Presentation at Transform Nutrition: Evidence for Action in South Asia. 8 July 2017. Kathmandu, Nepal, International Food Policy Research Institute.

Ahmed, A. U., Quisumbing, A. R., Nasreen, M., Hoddinott, J. F. and Bryan, E. (2009) Comparing food and cash transfers to the ultra poor in Bangladesh: International Food Policy Research Institute Washington, DC.

Aizer, A. (2011) 'Poverty, Violence, and Health The Impact of Domestic Violence During Pregnancy on Newborn Health', Journal of Human Resources, 46(3): 518-538.

Akresh, R., De Walque, D. and Kazianga, H. (2016) 'Evidence from a randomized evaluation of the household welfare impacts of conditional and unconditional cash transfers given to mothers or fathers', Policy Research Working Paper no. 7730. The World Bank.

Alderman, H., Chiappori, P.-A., Haddad, L., Hoddinott, J. and Kanbur, R. (1995) 'Unitary versus collective models of the household: is it time to shift the burden of proof?', The World Bank Research Observer, 10(1): 1-19. 
Alderman, H. and Garcia, M. (1994) 'Food security and health security: Explaining the levels of nutritional status in Pakistan', Economic Development and Cultural Change, 42(3): 485-507.

Almond, D. and Currie, J. (2011) 'Killing me softly: The fetal origins hypothesis', Journal of Economic Perspectives, 25(3): 153-72.

Ambler, K. (2016) 'Bargaining with grandma: The impact of the South African pension on household decision-making', Journal of Human Resources, 51(4): 900-932.

American Institutes for Research (2013) 'Zambia's Child Grant Program: 24-month impact report'. Washington, DC, American Institutes for Research.

American Institutes for Research (2014) '12-Month Impact Report for Zimbabwe's Harmonised Social Cash Transfer Programmes.'. Washington, DC, Author.

American Institutes for Research (2015) 'Zambia's Child Grant Program: 48-month impact report'. Washington, DC, Author.

Amugsi, D. A., Mittelmark, M. B., Lartey, A., Matanda, D. J. and Urke, H. B. (2014) 'Influence of childcare practices on nutritional status of Ghanaian children: a regression analysis of the Ghana Demographic and Health Surveys', BMJ Open, 4(11): e005340.

Anderson, M. L. (2008) 'Multiple inference and gender differences in the effects of early intervention: A reevaluation of the Abecedarian, Perry Preschool, and Early Training Projects', Journal of the American Statistical Association, 103(484): 1481-1495.

Anderson, S. (2007) 'The economics of dowry and brideprice', Journal of Economic Perspectives, 21(4): 151-174.

Angrist, J. D. and Pischke, J.-S. (2009) Mostly harmless econometrics: An empiricist's companion, Princeton: Princeton University Press.

Arimond, M. and Ruel, M. T. (2002) 'Progress in developing an infant and child feeding index: an example using the Ethiopia Demographic and Health Survey 2000', FCND Discussion Paper No. 143. Washington, D.C., International Food Policy Research Institute.

Arimond, M. and Ruel, M. T. (2004) 'Dietary diversity is associated with child nutritional status: evidence from 11 demographic and health surveys', Journal of Nutrition, 134(10): 2579-85.

Ashraf, N., Bau, N., Nunn, N. and Voena, A. (2016) 'Bride price and female education', NBER Working Paper No. 22417. Cambridge, MA, National Bureau of Economic Research.

Aslam, M. and Kingdon, G. G. (2012) 'Parental education and child healthunderstanding the pathways of impact in Pakistan', World Development, 40(10): 2014-2032.

Åsling-Monemi, K., Pena, R., Ellsberg, M. C. and Persson, L. Å. (2003) 'Violence against women increases the risk of infant and child mortality: a case- 
referent study in Nicaragua', Bulletin of the World Health Organization, 81(1): 10-16.

Assis, A., Costa, P., Santana, M., Pitanqueira, J., Fonseca, N., Pinheiro, S. and Santos, S. (2014) 'Effectiveness of the Brazilian Conditional Cash Transfer Program-Bolsa Alimentação-on the variation of linear and ponderal increment in children from northeast of Brazil', Nutrición Hospitalaria, 31(2): 689-697.

Attanasio, O., Battistin, E., Fitzsimons, E. and Vera-Hernandez, M. (2005a) 'How effective are conditional cash transfers? Evidence from Colombia'.

Attanasio, O., Di Maro, V., Lechene, V. and Phillips, D. (2013) 'Welfare consequences of food prices increases: Evidence from rural Mexico', Journal of Development Economics, 104: 136-151.

Attanasio, O., Gomez, L. C., Heredia, P. and Vera-Hernandez, M. (2005b) 'The short-term impact of a conditional cash subsidy on child health and nutrition in Colombia', Report summary: familias, 3.

Attanasio, O. and Lechene, V. (2002) 'Tests of income pooling in household decisions', Review of Economic Dynamics, 5(4): 720-748.

Attanasio, O. P. and Lechene, V. (2014) 'Efficient responses to targeted cash transfers', Journal of Political Economy, 122(1): 178-222.

Attanasio, O. P., Oppedisano, V. and Vera-Hernández, M. (2015) 'Should cash transfers be conditional? Conditionality, preventive care, and health outcomes', American Economic Journal: Applied Economics, 7(2): 35-52.

Bain, R. E., Gundry, S. W., Wright, J. A., Yang, H., Pedley, S. and Bartram, J. K. (2012) 'Accounting for water quality in monitoring access to safe drinkingwater as part of the Millennium Development Goals: lessons from five countries', Bulletin of the World Health Organization, 90(3): 228-235.

Baird, S., Ferreira, F. H., Özler, B. and Woolcock, M. (2014) 'Conditional, unconditional and everything in between: a systematic review of the effects of cash transfer programmes on schooling outcomes', Journal of Development Effectiveness, 6(1): 1-43.

Banerjee, A., Duflo, E., Goldberg, N., Karlan, D., Osei, R., Parienté, W., Shapiro, J., Thuysbaert, B. and Udry, C. (2015) 'A multifaceted program causes lasting progress for the very poor: Evidence from six countries', Science, 348(6236): 1260799.

Banerjee, A. V., Hanna, R., Kreindler, G. E. and Olken, B. A. (2017) 'Debunking the stereotype of the lazy welfare recipient: Evidence from cash transfer programs', The World Bank Research Observer, 32(2): 155-184.

Barber, S. L. and Gertler, P. J. (2008) 'The impact of Mexico's conditional cash transfer programme, Oportunidades, on birthweight', Tropical Medicine $\mathcal{E}$ International Health, 13(11): 1405-1414. 
Barber, S. L. and Gertler, P. J. (2009) 'Empowering women to obtain high quality care: evidence from an evaluation of Mexico's conditional cash transfer programme', Health Policy and Planning, 24(1): 18-25.

Bargain, O., Lacroix, G. and Tiberti, L. (2018) 'Validating the collective model of household consumption using direct evidence on sharing', IZA Discussion Papers, No. 11653. Bonn, Institute of Labor Economics (IZA).

Bassett, L. (2008) 'Can conditional cash transfer programs play a greater role in reducing child undernutrition?', Discussion Paper No. 0835. Washington D.C., The World Bank.

Bastagli, F., Hagen-Zanker, J., Harman, L., Barca, V., Sturge, G. and Schmidt, T. (2018) 'The Impact of Cash Transfers: A Review of the Evidence from Lowand Middle-income Countries', Journal of Social Policy: 1-26.

Bastagli, F., Hagen-Zanker, J., Harman, L., Barca, V., Sturge, G., Schmidt, T. and Pellerano, L. (2016) 'Cash transfers: what does the evidence say? A rigorous review of programme impact and the role of design and implementation features.'. London, Overseas Development Institute.

Baulch, B. (2011) 'The medium-term impact of the primary education stipend in rural Bangladesh', Journal of Development Effectiveness, 3(2): 243-262.

Baum, A., Garofalo, J. and Yali, A. (1999) 'Socioeconomic status and chronic stress: does stress account for SES effects on health?', Annals of the New York Academy of Sciences, 896(1): 131-144.

Becker, G. S. (1965) 'A Theory of the Allocation of Time', The Economic Journal: 493517.

Becker, G. S. (1981) A Treatise on the Family, Cambridge, MA: Harvard University Press.

Bedoya, G., Bittarello, L., Davis, J. and Mittag, N. (2017) 'Distributional impact analysis: toolkit and illustrations of impacts beyond the average treatment effect', Policy Research Working Paper no. 8139. Washington, DC, The World Bank.

Beegle, K., Coudouel, A. and Monsalve, E. (2018) Realizing the full potential of social safety nets in Africa, Washington, DC: The World Bank.

Behrman, J. R. and Deolalikar, A. B. (1988) 'Health and nutrition', in Chenery, H. and Srinivasan, T. N. (eds) Handbook of Development Economics, pp. 631-711.

Behrman, J. R. and Hoddinott, J. (2005) 'Programme evaluation with unobserved heterogeneity and selective implementation: The Mexican PROGRESA impact on child nutrition', Oxford Bulletin of Economics and Statistics, 67(4): 547-569.

Benhassine, N., Devoto, F., Duflo, E., Dupas, P. and Pouliquen, V. (2015) 'Turning a shove into a nudge? A" labeled cash transfer" for education', American Economic Journal: Economic Policy, 7(3): 86-125.

Benjamini, Y., Krieger, A. M. and Yekutieli, D. (2006) 'Adaptive linear step-up procedures that control the false discovery rate', Biometrika, 93(3): 491-507. 
Bentley, M. E., Wasser, H. M. and Creed-Kanashiro, H. M. (2011) 'Responsive feeding and child undernutrition in low- and middle-income countries', Journal of Nutrition, 141(3): 502-7.

Berhane, G., Devereux, S., Hoddinott, J., Hoel, J., Roelen, K., Abay, K., Kimmel, M., Ledlie, N. and Woldu, T. (2015) 'Evaluation of the Social Cash Transfer Pilot Programme, Tigray Region, Ethiopia. Endline Report'. Washington, DC, International Food Policy Research Institute.

Berhane, G., Hoddinott, J. and Kumare, N. (2017) 'The Impact of Ethiopia's Productive Safety Net Programme on the Nutritional Status of Children 2008-2012', IFPRI Discussion Paper 01604. Washington, DC, IFPRI.

Berry, L. V. (1995) Ghana: A country study: Federal Research Division, Library of Congress.

Bhalla, G., Handa, S., Angeles, G. and Seidenfeld, D. (2018) 'The effect of cash transfers and household vulnerability on food security in Zimbabwe', Food Policy, 74: 82-99.

Bhutta, Z. A., Ahmed, T., Black, R. E., Cousens, S., Dewey, K., Giugliani, E., Haider, B. A., Kirkwood, B., Morris, S. S. and Sachdev, H. (2008) 'What works? Interventions for maternal and child undernutrition and survival', The Lancet, 371(9610): 417-440.

Bhutta, Z. A., Das, J. K., Rizvi, A., Gaffey, M. F., Walker, N., Horton, S., Webb, P., Lartey, A., Black, R. E. and The Lancet Nutrition Interventions Review Group (2013) 'Evidence-based interventions for improvement of maternal and child nutrition: what can be done and at what cost?', The Lancet, 382(9890): 452-477.

Black, M. M. and Aboud, F. E. (2011) 'Responsive feeding is embedded in a theoretical framework of responsive parenting', Journal of Nutrition, 141(3): 490-4.

Black, R. E., Allen, L. H., Bhutta, Z. A., Caulfield, L. E., De Onis, M., Ezzati, M., Mathers, C., Rivera, J. and Maternal \& Child Undernutrition Study Group (2008) 'Maternal and child undernutrition: global and regional exposures and health consequences', The Lancet, 371(9608): 243-260.

Bliss, J., Golden, K., Bourahla, L., Stoltzfus, R. and Pelletier, D. (2018) 'An emergency cash transfer program promotes weight gain and reduces acute malnutrition risk among children 6-24 months old during a food crisis in Niger', Journal of Global Health, 8(1).

Bobonis, G. J., Castro, R. and Morales, J. S. (2015) 'Conditional Cash Transfers for Women and Spousal Violence: Evidence of the Long-Term Relationship from the Oportunidades Program in Rural Mexico'.

Bobonis, G. J., González-Brenes, M. and Castro, R. (2013) 'Public transfers and domestic violence: The roles of private information and spousal control', American Economic Journal: Economic Policy, 5(1): 179-205. 
Bolin, K., Jacobson, L. and Lindgren, B. (2001) 'The family as the health producerwhen spouses are Nash-bargainers', Journal of Health Economics, 20(3): 349362.

Braido, L. H., Olinto, P. and Perrone, H. (2012) 'Gender bias in intrahousehold allocation: Evidence from an unintentional experiment', Review of Economics and Statistics, 94(2): 552-565.

Brown, C., Ravallion, M. and van de Walle, D. (2018) 'A poor means test? Econometric targeting in Africa', Journal of Development Economics, 134: 109124.

Browning, M., Chiappori, P.-A. and Lechene, V. (2006) 'Collective and unitary models: A clarification', Review of Economics of the Household, 4(1): 5-14.

Browning, M., Chiappori, P.-A. and Lewbel, A. (2013) 'Estimating consumption economies of scale, adult equivalence scales, and household bargaining power', Review of Economic Studies, 80(4): 1267-1303.

Brugh, K., Angeles, G., Mvula, P., Tsoka, M. and Handa, S. (2018) 'Impacts of the Malawi social cash transfer program on household food and nutrition security', Food Policy, 76: 19-32.

Burbidge, J. B., Magee, L. and Robb, A. L. (1988) 'Alternative transformations to handle extreme values of the dependent variable', Journal of the American Statistical Association, 83(401): 123-127.

Cahyadi, N., Hanna, R., Olken, B. A., Prima, R. A., Satriawan, E. and Syamsulhakim, E. (2018) 'Cumulative Impacts of Conditional Cash Transfer Programs: Experimental Evidence from Indonesia'. National Bureau of Economic Research.

Calonico, S., Cattaneo, M. D., Farrell, M. H. and Titiunik, R. (2017) 'rdrobust: Software for regression discontinuity designs', The Stata Journal, 17(2): 372404.

Carneiro, P., Mason, G., Moore, L. and Rasul, I. (2017) Child Development Grant Programme Evaluation. Quantitative Midline Report Volume I: Midline findings, Oxford, UK: e-Pact.

Case, A. (2004) 'Does money protect health status? Evidence from South African pensions', Perspectives on the Economics of Aging, pp. 287-312. University of Chicago Press.

Case, A. and Deaton, A. (2003) 'Consumption, health, gender, and poverty', Policy Research Working Paper. Washington, DC, World Bank.

Cattaneo, M., Idrobo, N. and Titiunik, R. (2018a) A Practical Introduction to Regression Discontinuity Designs: Part I. , Cambridge Elements: Quantitative and Computational Methods for Social Science, Cambridge: Cambridge University Press, forthcoming.

Cattaneo, M. D., Galiani, S., Gertler, P. J., Martinez, S. and Titiunik, R. (2009) 'Housing, health, and happiness', American Economic Journal: Economic Policy: 75-105. 
Cattaneo, M. D., Jansson, M. and Ma, X. (2018b) 'Manipulation testing based on density discontinuity', The Stata Journal, 18(1): 234-261.

Cattaneo, M. D. and Vazquez-Bare, G. (2016) 'The choice of neighborhood in regression discontinuity designs', Observational Studies, 2(134): A146.

Chaudhury, N., Friedman, J. and Onishi, J. (2013) 'Philippines Conditional Cash Transfer Program Impact Evaluation 2012'. Manila, World Bank.

Checkley, W., Gilman, R. H., Black, R. E., Epstein, L. D., Cabrera, L., Sterling, C. R. and Moulton, L. H. (2004) 'Effect of water and sanitation on childhood health in a poor Peruvian peri-urban community', The Lancet, 363(9403): 112-118.

Chen, Y. and Li, H. (2009) 'Mother's education and child health: Is there a nurturing effect?', Journal of Health Economics, 28(2): 413-426.

Chiappori, P.-A. (1992) 'Collective labor supply and welfare', Journal of Political Economy, 100(3): 437-467.

Christiaensen, L. and Alderman, H. (2004) 'Child Malnutrition in Ethiopia: Can Maternal Knowledge Augment the Role of Income?', Economic Development and Cultural Change, 52(2): 287-312.

Coady, D., Grosh, M. and Hoddinott, J. (2004) 'Targeting outcomes redux', The World Bank Research Observer, 19(1): 61-85.

Coates, J., Swindale, A. and Bilinsky, P. (2007) 'Household Food Insecurity Access Scale (HFIAS) for measurement of food access: indicator guide'. Washington, DC, Food and Nutrition Technical Assistance Project, Academy for Educational Development.

Cohen, S., Kamarck, T. and Mermelstein, R. (1983) 'A global measure of perceived stress', Journal of Health and Social Behavior: 385-396.

Cooke, E., Hague, S. and McKay, A. (2016) The Ghana poverty and inequality report: Using the 6th Ghana living standards survey: University of Sussex.

Cunha, J. M., De Giorgi, G. and Jayachandran, S. (2019) 'The price effects of cash versus in-kind transfers', The Review of Economic Studies, 86(1): 240-281.

d'Agostino, G., Scarlato, M. and Napolitano, S. (2017) 'Do Cash Transfers Promote Food Security? The Case of the South African Child Support Grant', Journal of African Economies, 27(4): 430-456.

Danese, A. and McEwen, B. S. (2012) 'Adverse childhood experiences, allostasis, allostatic load, and age-related disease', Physiology $\mathcal{E}$ Behavior, 106(1): 29-39.

Dangour, A. D., Watson, L., Cumming, O., Boisson, S., Che, Y., Velleman, Y., Cavill, S., Allen, E. and Uauy, R. (2013) 'Interventions to improve water quality and supply, sanitation and hygiene practices, and their effects on the nutritional status of children', Cochrane Database of Systematic Reviews (8).

Das, J., Hammer, J. and Sánchez-Paramo, C. (2012) 'The impact of recall periods on reported morbidity and health seeking behavior', Journal of Development Economics, 98(1): 76-88. 
Davis, B., Gaarder, M., Handa, S. and Yablonski, J. (2012) 'Evaluating the impact of cash transfer programmes in sub-Saharan Africa: an introduction to the special issue', Journal of Development Effectiveness, 4(1): 1-8.

Davis, B. and Handa, S. (2014) 'The broad range of cash transfer impacts in subSaharan Africa: Consumption, Human Capital and Productive Activity', The Transfer Project Research Brief. Chapel Hill, NC, Carolina Population Center, UNC-Chapel Hill.

Davis, B. and Handa, S. (2015) 'How much do programmes pay? Transfer size in selected national cash transfer programmes in Africa', The Transfer Project Research Brief. Chapel Hill, NC, Carolina Population Center, UNC-Chapel Hill.

Davis, B., Handa, S., Hypher, N., Rossi, N. W., Winters, P. and Yablonski, J. (2016) From evidence to action: the story of cash transfers and impact evaluation in sub Saharan Africa: Oxford University Press.

de Brauw, A., Gilligan, D., Hoddinott, J., Moreira, V. and Roy, S. (2012) 'The impact of Bolsa Familia on child, maternal, and household welfare', IFPRI. Washington, DC.

de Brauw, A., Gilligan, D. O., Hoddinott, J. and Roy, S. (2014) 'The Impact of Bolsa Família on Women's Decision-Making Power', World Development, 59: 487504.

De Cao, E. (2011) 'The height production function from birth to early adulthood', Dondena Working Papers No. 43. Milan, Carlo F. Dondena Centre for Research on Social Dynamics.

de Groot, R., Palermo, T., Handa, S., Ragno, L. P. and Peterman, A. (2017) 'Cash transfers and child nutrition: Pathways and impacts', Development Policy Review, 35(5): 621-643.

Deaton, A. (1989) 'Looking for boy-girl discrimination in household expenditure data', The World Bank Economic Review, 3(1): 1-15.

Deaton, A. (1997) The Analysis of Household Surveys: a Microeconometric Approach to Development Policy, Baltimore: The Johns Hopkins University Press.

Deaton, A. S. and Muellbauer, J. (1986) 'On measuring child costs: with applications to poor countries', Journal of Political Economy, 94(4): 720-744.

Deaton, A. S., Ruiz-Castillo, J. and Thomas, D. (1989) 'The influence of household composition on household expenditure patterns: theory and Spanish evidence', Journal of Political Economy: 179-200.

Debela, B. L., Shively, G. and Holden, S. T. (2015) 'Does Ethiopia's Productive Safety Net Program Improve Child Nutrition?', Food Security, 7(6): 12731289.

DeSalvo, K. B., Bloser, N., Reynolds, K., He, J. and Muntner, P. (2006) 'Mortality prediction with a single general self-rated health question', Journal of General Internal Medicine, 21(3): 267-275. 
Devereux, S. and Sabates-Wheeler, R. (2004) 'Transformative social protection', IDS Working Paper 232. Brighton, Institute of Development Studies.

Devries, K., Mak, J. Y., García-Moreno, C., Petzold, M., Child, J., Falder, G., Lim, S., Bacchus, L., Engell, R. and Rosenfeld, L. (2013) 'The global prevalence of intimate partner violence against women', Science, 340(6140): 1527-1528.

Dewey, K. G. and Begum, K. (2011) 'Long-term consequences of stunting in early life', Maternal \& Child Nutrition, 7(s3): 5-18.

Doss, C. (2006) 'The effects of intrahousehold property ownership on expenditure patterns in Ghana', Journal of African Economies, 15(1): 149-180.

Doss, C. (2013) 'Intrahousehold bargaining and resource allocation in developing countries', The World Bank Research Observer, 28(1): 52-78.

Duflo, E. (2003) 'Grandmothers and Granddaughters: Old-Age Pensions and Intrahousehold Allocation in South Africa', The World Bank Economic Review, 17(1): 1-25.

Elo, I. T., Martikainen, P. and Smith, K. P. (2006) 'Socioeconomic differentials in mortality in Finland and the United States: the role of education and income', European Journal of Population/Revue Européenne de Démographie, 22(2): 179-203.

Engle, P. L. (2002) 'Infant feeding styles: barriers and opportunities for good nutrition in India', Nutrition Review, 60(5 Pt 2): S109-14.

Engle, P. L., Lhotska, L. and Armstrong, H. (1997) The care initiative: guidelines for analysis, assessment, and action to improve nutrition, New York: UNICEF.

Evans, D. K., Hausladen, S., Kosec, K. and Reese, N. (2014) 'Community-Based Conditional Cash Transfers in Tanzania: Results from a Randomized Trial', World Bank Study. Washington, D.C., World Bank.

Evans, D. K., Holtemeyer, B. and Kosec, K. (2017) 'Cash Transfers and Health: Evidence from Tanzania', The World Bank Economic Review: 1hx001.

FAO (2008) An Introduction to the Basic Concepts of Food Security., Rome: Food and Agriculture Organization of the United Nations.

Fenn, B., Colbourn, T., Dolan, C., Pietzsch, S., Sangrasi, M. and Shoham, J. (2017) 'Impact evaluation of different cash-based intervention modalities on child and maternal nutritional status in Sindh Province, Pakistan, at 6 mo and at $1 \mathrm{y}$ : A cluster randomised controlled trial', PLoS medicine, 14(5): e1002305.

Fernald, L. C., Gertler, P. and Hidrobo, M. (2012) 'Conditional cash transfer programs: effects on growth, health, and development in young children', The Oxford Handbook of Poverty and Child Development: 569-600.

Fernald, L. C., Gertler, P. J. and Neufeld, L. M. (2008) 'Role of cash in conditional cash transfer programmes for child health, growth, and development: an analysis of Mexico's Oportunidades', The Lancet, 371(9615): 828-837.

Fernald, L. C., Gertler, P. J. and Neufeld, L. M. (2009) '10-year effect of Oportunidades, Mexico's conditional cash transfer programme, on child 
growth, cognition, language, and behaviour: a longitudinal follow-up study', The Lancet, 374(9706): 1997-2005.

Fernald, L. C. and Gunnar, M. R. (2009) 'Poverty-alleviation program participation and salivary cortisol in very low-income children', Social Science $\mathcal{E}$ Medicine, 68(12): 2180-2189.

Ferré, C. and Sharif, I. (2014) 'Can conditional cash transfers improve education and nutrition outcomes for poor children in Bangladesh? Evidence from a pilot project', Policy Research Working Paper no. 7077. Washington, DC, World Bank.

Ferro-Luzzi, A. (2003) 'Keynote Paper: Individual food intake survey methods", paper presented at the International Scientific Symposium on Measurement and Assessment of Food Deprivation and Undernutrition, Rome, 26-28 June 2002.

Filmer, D., Friedman, J., Kandpal, E. and Onishi, J. (2018) 'General equilibrium effects of targeted cash transfers: nutrition impacts on non-beneficiary children', Policy Research Working Paper no. 8377. Washington, DC, World Bank.

Fiszbein, A. and Schady, N. R. (2009) Conditional cash transfers: reducing present and future poverty, Washington, DC: World Bank Publications.

Food and Agricultural Organization of the United Nations (2015) 'The impact of social cash transfer programmes on community dynamics in sub-Saharan Africa', From PROTECTION to PRODUCTION Research Brief. Rome, Food and Agricultural Organization of the United Nations.

Fuwa, N. (2014) 'Pro-girl Bias in Intra-household Allocation in the Rural Philippines: Revisiting the "Adult Goods" Approach', Review of Development Economics, 18(4): 727-740.

Fuwa, N., Ito, S., Kubo, K., Kurosaki, T. and Sawada, Y. (2006) 'Gender Discrimination, Intrahousehold Resource Allocation, and Importance of Spouses' Fathers: Evidence on Household Expenditure from Rural India', The Developing Economies, 44(4): 398-439.

Gaarder, M. M., Glassman, A. and Todd, J. E. (2010) 'Conditional cash transfers and health: unpacking the causal chain', Journal of Development Effectiveness, 2(1): 6-50.

Galasso, E., Wagstaff, A., Naudeau, S. and Shekar, M. (2017) 'The Economic Costs of Stunting and How to Reduce Them', Policy Research Note 17/05. Washington, DC, World Bank.

Garg, A. and Morduch, J. (1998) 'Sibling rivalry and the gender gap: Evidence from child health outcomes in Ghana', Journal of Population Economics, 11(4): 471493.

Gebrehiwot, T. and Castilla, C. (2018) 'Do Safety Net Transfers Improve Diets and Reduce Undernutrition? Evidence from Rural Ethiopia', Journal of Development Studies: 1-20. 
Gertler, P. (2004) 'Do conditional cash transfers improve child health? Evidence from PROGRESA's control randomized experiment', American Economic Review: 336-341.

Ghana Statistical Service (GSS) (2014) 'Ghana Living Standards Survey 6 (GLSS6) Main Report'. Accra, Ghana Statistical Service.

Ghana Statistical Service (GSS) (2016) 'Statistical Bulletin - Consumer Price Index (CPI) October 2016'. Accra, Ghana Statistical Service.

Ghana Statistical Service (GSS), Ghana Health Service (GHS) and ICF International (2015) 'Ghana Demographic and Health Survey 2014'. Rockville, Maryland, USA, GSS, GHS, and ICF International.

Gibson, J. and Rozelle, S. (2004) 'Is it better to be a boy? A disaggregated outlay equivalent analysis of gender bias in Papua New Guinea', Journal of Development Studies, 40(4): 115-136.

Gilligan, D. O. and Roy, S. (2015) 'Resources, stimulation, and cognition: How transfer programs and preschool shape cognitive development in Uganda', Unpublished Manuscript.

Gitter, S. R. and Barham, B. L. (2008) 'Women's power, conditional cash transfers, and schooling in Nicaragua', The World Bank Economic Review, 22(2): 271290.

Gitter, S. R., Manley, J. and Barham, B. L. (2013) 'Early-Childhood Nutrition and Educational Conditional Cash Transfer Programmes', Journal of Development Studies, 49(10): 1397-1411.

Glassman, A., Duran, D., Fleisher, L., Singer, D., Sturke, R., Angeles, G., Charles, J., Emrey, B., Gleason, J. and Mwebsa, W. (2013) 'Impact of conditional cash transfers on maternal and newborn health', Journal of Health, Population and Nutrition, 31(4 Suppl 2): S48.

Glewwe, P. (1999) 'Why does mother's schooling raise child health in developing countries? Evidence from Morocco', Journal of Human Resources: 124-159.

Günther, I. and Fink, G. (2010) 'Water, Sanitation and Children's Health: Evidence from 172 DHS Surveys', Policy Research Working Paper no. 5275. Washington, DC, World Bank.

Hackstein, K., Miller, C. and Mahdi, E. (2013) 'Impact Evaluation of the EU Contribution to the Palestinian Cash Transfer Programme (CTP) in the Framework of the PEGASE Programme of Support to "Vulnerable Palestinian Families" (VPF)'. Brussels, AETS.

Haddad, L., Alderman, H., Appleton, S., Song, L. and Yohannes, Y. (2003)

'Reducing child malnutrition: How far does income growth take us?', The World Bank Economic Review, 17(1): 107-131.

Haddad, L., Hoddinott, J. and Alderman, H. (1997) Intrahousehold resource allocation in developing countries: models, methods, and policy, Baltimore and London: Johns Hopkins University Press. 
Haddad, L. and Reardon, T. (1993) 'Gender bias in the allocation of resources within households in Burkina Faso: a disaggregated outlay equivalent analysis', Journal of Development Studies, 29(2): 260-276.

Handa, S. (1999) 'Maternal education and child height', Economic Development and Cultural Change, 47(2): 421-439.

Handa, S., Daidone, S., Peterman, A., Davis, B., Pereira, A., Palermo, T. and Yablonski, J. (2018a) 'Myth-Busting? Confronting Six Common Perceptions about Unconditional Cash Transfers as a Poverty Reduction Strategy in Africa', The World Bank Research Observer, 33(2): 259-298.

Handa, S., Natali, L., Seidenfeld, D., Tembo, G., Davis, B. and Zambia Cash Transfer Evaluation Study Team (2018b) 'Can unconditional cash transfers raise long-term living standards? Evidence from Zambia', Journal of Development Economics, 133: 42-65.

Handa, S., Palermo, T. M., Prencipe, L., Peterman, A. and Zambia CGP Evaluation Team (2015a) 'Unconditional Government Social Cash Transfer in Africa Does not Increase Fertility', Innocenti Working Papers 2015-09. Florence, UNICEF Office of Research - Innocenti.

Handa, S., Park, M., Darko, R. O., Osei-Akoto, I., Davis, B. and Daidone, S. (2013a) 'Livelihood Empowerment Against Poverty Program Impact Evaluation'. Chapel Hill, University of North Carolina, Carolina Population Center.

Handa, S. and Peterman, A. (2015) 'Is There Catch-Up Growth? Evidence from Three Continents', Oxford Bulletin of Economics and Statistics.

Handa, S., Peterman, A., Davis, B. and Stampini, M. (2009) 'Opening up Pandora's box: the effect of gender targeting and conditionality on household spending behavior in Mexico's Progresa program', World Development, 37(6): 1129-1142.

Handa, S., Peterman, A., Huang, C., Halpern, C., Pettifor, A. and Thirumurthy, H. (2015b) 'Impact of the Kenya Cash Transfer for Orphans and Vulnerable Children on early pregnancy and marriage of adolescent girls', Social Science \& Medicine, 141: 36-45.

Handa, S., Peterman, A., Seidenfeld, D. and Tembo, G. (2015c) 'Income Transfers and Maternal Health: Evidence from a National Randomized Social Cash Transfer Program in Zambia', Health Economics.

Handa, S., Seidenfeld, D., Tembo, G., Prencipe, L. and Peterman, A. (2013b) 'Zambia's Child Grant Program: 24-Month Impact Report'. Washington, DC, American Institutes for Research.

Harris-Fry, H. A., Paudel, P., Harrisson, T., Shrestha, N., Jha, S., Beard, B. J., Copas, A., Shrestha, B. P., Manandhar, D. S. and Costello, A. M. d. L. (2018) 'Participatory women's groups with cash transfers can increase dietary diversity and micronutrient adequacy during pregnancy, whereas women's groups with food transfers can increase equity in intrahousehold energy allocation', Journal of Nutrition, 148(9): 1472-1483. 
Haushofer, J. and Fehr, E. (2014) 'On the psychology of poverty', Science, 344(6186): 862-867.

Haushofer, J. and Shapiro, J. (2016) 'The short-term impact of unconditional cash transfers to the poor: experimental evidence from Kenya', The Quarterly Journal of Economics, 131(4): 1973-2042.

Haushofer, J. and Shapiro, J. (2018) 'The long-term impact of unconditional cash transfers: Experimental evidence from Kenya', Busara Center for Behavioral Economics, Nairobi, Kenya. Nairobi, Kenya.

Headey, D., Hirvonen, K. and Hoddinott, J. (2018) 'Animal sourced foods and child stunting', American Journal of Agricultural Economics, 100(5): 1302-1319.

Headey, D., Hoddinott, J., Ali, D., Tesfaye, R. and Dereje, M. (2015) 'The other Asian enigma: explaining the rapid reduction of undernutrition in Bangladesh', World Development, 66: 749-761.

Headey, D., Hoddinott, J. and Park, S. (2017) 'Accounting for nutritional changes in six success stories: A regression-decomposition approach', Global Food Security, in press.

Hidrobo, M. and Fernald, L. C. (2013) 'Cash transfers and domestic violence', Journal of Health Economics, 32(1): 304-319.

Hidrobo, M., Hoddinott, J., Kumar, N. and Olivier, M. (2018) 'Social Protection, Food Security, and Asset Formation', World Development, 101: 88-103.

Hidrobo, M., Hoddinott, J., Margolies, A., Moreira, V. and Peterman, A. (2012) 'Impact Evaluation of Cash, Food Vouchers, and Food Transfers among Colombian Refugees and Poor Ecuadorians in Carchi and Sucumbíos'. Washington, DC, International Food Policy Research Institute.

Hidrobo, M., Peterman, A. and Heise, L. (2016) 'The effect of cash, vouchers and food transfers on intimate partner violence: Evidence from a randomized experiment in Northern Ecuador', American Economic Journal: Applied Economics (in press).

Himaz, R. (2008) 'Welfare Grants and Their Impact on Child Health: The Case of Sri Lanka', World Development, 36(10): 1843-1857.

Hoddinott, J. (2010) 'Nutrition and Conditional Cash Transfer Programs', in Adato, M. and Hoddinott, J. (eds) Conditional Cash Transfers in Latin America: A Magic Bullet to Reduce Poverty? Baltimore, Johns Hopkins University Press.

Hoddinott, J., Alderman, H., Behrman, J. R., Haddad, L. and Horton, S. (2013) 'The economic rationale for investing in stunting reduction', Maternal $\mathcal{E}$ Child Nutrition, 9: 69-82.

Houngbe, F., Tonguet-Papucci, A., Altare, C., Ait-Aissa, M., Huneau, J.-F., Huybregts, L. and Kolsteren, P. (2017) 'Unconditional cash transfers do not prevent children's undernutrition in the Moderate Acute Malnutrition Out (MAM'Out) cluster-randomized controlled trial in rural Burkina Faso', Journal of Nutrition, 147(7): 1410-1417. 
Imbens, G. W. and Rubin, D. B. (2015) Causal inference in statistics, social, and biomedical sciences: Cambridge University Press.

International Food Policy Research Institute (2003) 'Sexto Informe: Proyecto PRAF/BID Fase II: Impacto Intermedio'. Washington, DC, International Food Policy Research Institute.

Jain, M. (2018) 'Large Decrease in Child Stunting despite Limited Improvement in Children's Food Intake: Evidence from Rural Bangladesh', Economic Development and Cultural Change, 66(3): 555-583.

Kabeer, N. (1999) 'Resources, agency, achievements: Reflections on the measurement of women's empowerment', Development and Change, 30(3): 435-464.

Kabubo-Mariara, J., Ndenge, G. K. and Mwabu, D. K. (2009) 'Determinants of children's nutritional status in Kenya: evidence from demographic and health surveys', Journal of African Economies, 18(3): 363-387.

Kandpal, E., Alderman, H., Friedman, J., Filmer, D., Onishi, J. and Avalos, J. (2016) 'A Conditional Cash Transfer Program in the Philippines Reduces Severe Stunting', Journal of Nutrition, 146(9): 1793-1800.

Katz, S., Downs, T. D., Cash, H. R. and Grotz, R. C. (1970) 'Progress in development of the index of ADL', The Gerontologist, 10(1_Part_1): 20-30.

Kazianga, H. and Wahhaj, Z. (2013) 'Gender, social norms, and household production in Burkina Faso', Economic Development and Cultural Change, 61(3): 539-576.

Kennedy, G., Ballard, T. and Dop, M. C. (2011) Guidelines for measuring household and individual dietary diversity: Food and Agriculture Organization of the United Nations.

Kilburn, K., Handa, S., Angeles, G., Tsoka, M. and Mvula, P. (2018) 'Paying for Happiness: Experimental Results from a Large Cash Transfer Program in Malawi', Journal of Policy Analysis and Management, 37(2): 331-356.

Kingdon, G. G. (2005) 'Where has all the bias gone? Detecting gender bias in the intrahousehold allocation of educational expenditure', Economic Development and Cultural Change, 53(2): 409-451.

Kumar, D., Goel, N., Mittal, P. C. and Misra, P. (2006) 'Influence of infant-feeding practices on nutritional status of under-five children', The Indian Journal of Pediatrics, 73(5): 417-421.

Lagarde, M., Haines, A. and Palmer, N. (2009) 'The impact of conditional cash transfers on health outcomes and use of health services in low and middle income countries', Cochrane Database of Systematic Reviews, 4(4).

Lambert, S. and Rossi, P. (2016) 'Sons as widowhood insurance: Evidence from Senegal', Journal of Development Economics, 120: 113-127.

Latapi, A. E. and de la Rocha, M. G. (2004) 'External Evaluation of the Impact of the Human Development Program Oportunidades. Mid-term Qualitative 
Evaluation of the Oportunidades Program in Rural Areas.'. Morelos, Mexico, Instituto Nacional de Salud Publica.

Lavy, V., Strauss, J., Thomas, D. and De Vreyer, P. (1996) 'Quality of health care, survival and health outcomes in Ghana', Journal of Health Economics, 15(3): 333-357.

León, M. and Younger, S. D. (2007) 'Transfer payments, mothers' income and child health in ecuador', Journal of Development Studies, 43(6): 1126-1143.

Leroy, J. L. and Frongillo, E. A. (2019) 'Perspective: What Does Stunting Really Mean? A Critical Review of the Evidence', Advances in Nutrition, 10(2): 196204.

Leroy, J. L., García-Guerra, A., García, R., Dominguez, C., Rivera, J. and Neufeld, L. M. (2008) 'The Oportunidades program increases the linear growth of children enrolled at young ages in urban Mexico', Journal of Nutrition, 138(4): 793-798.

Leroy, J. L., Ruel, M. T., Habicht, J.-P. and Frongillo, E. A. (2014) 'Linear growth deficit continues to accumulate beyond the first 1000 days in low-and middle-income countries: global evidence from 51 national surveys', Journal of Nutrition, 144(9): 1460-1466.

Leroy, J. L., Ruel, M. T. and Verhofstadt, E. (2009) 'The impact of conditional cash transfer programmes on child nutrition: a review of evidence using a programme theory framework', Journal of Development Effectiveness, 1(2): 103-129.

Levy, D. and Ohls, J. (2007) 'Evaluation of Jamaica's PATH program: Final report'. Princeton, New Jersey, Mathematica Policy Research.

Lohia, N. and Udipi, S. A. (2014) 'Infant and child feeding index reflects feeding practices, nutritional status of urban slum children', BMC Pediatrics, 14: 290.

Ma, J.-Q., Zhou, L.-L., Hu, Y.-Q., Liu, J.-R., Liu, S.-S., Zhang, J. and Sheng, X.-Y. (2012) 'A summary index of infant and child feeding practices is associated with child growth in urban Shanghai', BMC Public Health, 12(1): 568.

Macours, K., Schady, N. and Vakis, R. (2012) 'Cash transfers, behavioral changes, and cognitive development in early childhood: Evidence from a randomized experiment', American Economic Journal: Applied Economics, 4(2): 247-273.

Maffioli, D., Sacco, P. and Giuseppe, G. (2009) 'Women position in the family and child nutritional status: Asia-Africa comparisons", paper presented at the XXVI IUSSP International Population Conference, Marrakech.

Malapit, H. J. L., Sraboni, E., Quisumbing, A. R. and Ahmed, A. U. (2019) 'Intrahousehold empowerment gaps in agriculture and children's wellbeing in Bangladesh', Development Policy Review, 37(2): 176-203. 
Maluccio, J. A. (2005) Coping with the" coffee Crisis" in Central America: The Role of the Nicaraguan Red de Protección Social, Washington, DC: International Food Policy Research Institute.

Maluccio, J. A. and Flores, R. (2005) Impact evaluation of a conditional cash transfer program: The Nicaraguan Red de Protección Social, Washington, DC: International Food Policy Research Institute.

Manesh, A. O., Sheldon, T. A., Pickett, K. E. and Carr-Hill, R. (2008) 'Accuracy of child morbidity data in demographic and health surveys', International Journal of Epidemiology, 37(1): 194-200.

Manley, J., Gitter, S. and Slavchevska, V. (2013) 'How effective are cash transfers at improving nutritional status?', World Development, 48: 133-155.

Manley, J. and Slavchevska, V. (2019) 'Are Cash Transfers the answer for child nutrition in Sub-Saharan Africa? A Literature Review', Development Policy Review, 37(2): 204-224.

Marías, Y. and Glasauer, P. (2014) Guidelines for assessing nutrition-related knowledge, attitudes and practices, Rome: Food and Agriculture Organization of the United Nations (FAO).

Mary, S. (2018) 'How Much Does Economic Growth Contribute to Child Stunting Reductions?', Economies, 6(4): 55.

McCrary, J. (2008) 'Manipulation of the running variable in the regression discontinuity design: A density test', Journal of Econometrics, 142(2): 698714.

McIntosh, C. and Zeitlin, A. (2018) 'Benchmarking a Child Nutrition Program against Cash: Experimental Evidence from Rwanda', Working Paper. Innovations for Poverty Action.

Mehta, N. (2018) 'An Economic Approach to Generalizing Findings from Regression-Discontinuity Designs', Journal of Human Resources: 11157497R2.

Merttens, F., Hurrell, A., Marzi, M., Attah, R., Farhat, M., Kardan, A. and MacAuslan, I. (2013) 'Kenya Hunger Safety Net Programme Monitoring and Evaluation Component', Impact Evaluation Final Report Oxford, Oxford Policy Management.

Miller, C. and Tsoka, M. (2008) 'Impact Evaluation Report. External Evaluation of the Mchinji Social Cash Transfer Pilot. Boston', Center for International Health and Development, Boston University School of Public Health.

Molyneux, M. (2006) 'Mothers at the service of the new poverty agenda: progresa/oportunidades, Mexico's conditional transfer programme', Social Policy E Administration, 40(4): 425-449.

Morris, S. S., Flores, R., Olinto, P. and Medina, J. M. (2004a) 'Monetary incentives in primary health care and effects on use and coverage of preventive health care interventions in rural Honduras: cluster randomised trial', The Lancet, 364(9450): 2030-2037. 
Morris, S. S., Olinto, P., Flores, R., Nilson, E. A. and Figueiro, A. C. (2004b)

'Conditional cash transfers are associated with a small reduction in the rate of weight gain of preschool children in northeast Brazil', Journal of Nutrition, 134(9): 2336-2341.

Moser, A., Stuck, A. E., Silliman, R. A., Ganz, P. A. and Clough-Gorr, K. M. (2012)

'The eight-item modified Medical Outcomes Study Social Support Survey: psychometric evaluation showed excellent performance', Journal of Clinical Epidemiology, 65(10): 1107-1116.

Moursi, M. M., Martin-Prével, Y., Eymard-Duvernay, S., Capon, G., Trèche, S., Maire, B. and Delpeuch, F. (2008) 'Assessment of child feeding practices using a summary index: stability over time and association with child growth in urban Madagascar', The American Journal of Clinical Nutrition, 87(5): 1472-1479.

Natali, L., Handa, S., Peterman, A., Seidenfeld, D. and Tembo, G. (2018) 'Does money buy happiness? Evidence from an unconditional cash transfer in Zambia', SSM - Population Health, 4: 225-235.

Ntab, B., Simondon, K. B., Milet, J., Cissé, B., Sokhna, C., Boulanger, D. and Simondon, F. (2005) 'A young child feeding index is not associated with either height-for-age or height velocity in rural Senegalese children', Journal of Nutrition, 135(3): 457-464.

Nti, C. A. and Lartey, A. (2008) 'Influence of care practices on nutritional status of Ghanaian children', Nutrition Research and Practice, 2(2): 93-99.

Olinto, P., Flores, R., Morris, S. S. and Veiga, A. (2003) 'The impact of the Bolsa Alimentação Program on food consumption', Annual meetings of the International Association of Agricultural Economists.

Owusu-Addo, E. and Cross, R. (2014) 'The impact of conditional cash transfers on child health in low- and middle-income countries: a systematic review', International Journal of Public Health, 59(4): 609-18.

Owusu-Addo, E., Renzaho, A. and Smith, B. J. (2018) 'The impact of cash transfers on social determinants of health and health inequalities in sub-Saharan Africa: a systematic review', Health Policy and Planning, 33(5): 675-696.

Oxford Policy Management (2013) 'Kenya Hunger Safety Net Programme Monitoring and Evaluation Component: Impact Evaluation Final Report: 2009 to 2012'. Oxford, United Kingdom, Oxford Policy Management.

Oxford Policy Management (2014) 'Child Grants Programme Impact Evaluation: Follow-up Report'. Oxford, Oxford Policy Management.

Oxford Policy Management (2015) 'Evaluation of the Uganda Social Assistance Grants for Empowerment (SAGE) Programme: Impact after one year of programme operations 2012-2013'. Oxford, Oxford Policy Management and Economic Policy Research Centre, Department of Anthropology and Sociology, University of Makerere. 
Oxford Policy Management (2017) Bihar Child Support Programme. Impact Evaluation Endline Report, Oxford, UK: Oxford Policy Management.

Pace, N., Daidone, S., Davis, B. and Pellerano, L. (2018) 'Shaping Cash Transfer Impacts Through 'Soft-Conditions': Evidence from Lesotho', Journal of African Economies, 28(1): 39-69.

Paes-Sousa, R., Santos, L. M. P. and Miazaki, É. S. (2011) 'Effects of a conditional cash transfer programme on child nutrition in Brazil', Bulletin of the World Health Organization, 89(7): 496-503.

Parker, S. and Skoufias, E. (2008) The impact of PROGRESA on work, leisure, and time allocation. Final Report, Washington, DC: International Food Policy Research Institute.

Parker, S. W. and Vogl, T. (2018) 'Do Conditional Cash Transfers Improve Economic Outcomes in the Next Generation? Evidence from Mexico'. National Bureau of Economic Research.

Parpiev, Z., Yusupov, K. and Yusupov, N. (2012) 'Outlay equivalence analysis of child gender bias in household expenditure data', Economics of Transition, 20(3): 549-567.

Paxson, C. and Schady, N. (2010) 'Does money matter? The effects of cash transfers on child development in rural Ecuador', Economic Development and Cultural Change, 59(1): 187-229.

Pearlin, L. I., Schieman, S., Fazio, E. M. and Meersman, S. C. (2005) 'Stress, health, and the life course: Some conceptual perspectives', Journal of Health and Social Behavior, 46(2): 205-219.

Pega, F., Liu, S. Y., Walter, S., Pabayo, R., Saith, R. and Lhachimi, S. K. (2017) 'Unconditional cash transfers for reducing poverty and vulnerabilities: effect on use of health services and health outcomes in low-and middleincome countries', Cochrane Database of Systematic Reviews, (11).

Pereznieto, P., Jones, N., Hamad, B. A. and Shaheen, M. (2014) 'Effects of the Palestinian National Cash Transfer Programme on children and adolescents: A mixed methods analysis', ODI and UNICEF Report, London and Jerusalem.

Perova, E. (2010) 'Buying out of abuse: how changes in women's income affect domestic violence'.

Perumal, N., Bassani, D. G. and Roth, D. E. (2018) 'Use and misuse of stunting as a measure of child health', Journal of Nutrition, 148(3): 311-315.

Peterman, A., Schwab, B., Roy, S., Hidrobo, M. and Gilligan, D. (2015) 'Measuring women's decisionmaking: Indicator choice and survey design experiments from cash and food transfer evaluations in Ecuador, Uganda, and Yemen'. Washington, D.C., International Food Policy Research Institute (IFPRI).

Porter, C. and Goyal, R. (2016) 'Social protection for all ages? Impacts of Ethiopia's productive safety net program on child nutrition', Social Science $\mathcal{E}$ Medicine, 159: 92-99. 
Puentes, E., Wang, F., Behrman, J. R., Cunha, F., Hoddinott, J., Maluccio, J. A., Adair, L. S., Borja, J. B., Martorell, R. and Stein, A. D. (2016) 'Early Life Height and Weight Production Functions with Endogenous Energy and Protein Inputs', Economics and Human Biology, 22: 65-81.

Quisumbing, A. R. and Maluccio, J. A. (2000) Intrahousehold allocation and gender relations: New empirical evidence from four developing countries, Washington, DC: International Food Policy Research Institute.

Quisumbing, A. R. and Maluccio, J. A. (2003) 'Resources at marriage and intrahousehold allocation: Evidence from Bangladesh, Ethiopia, Indonesia, and South Africa', Oxford Bulletin of Economics and Statistics, 65(3): 283-327.

Ragno, L. P., Hague, S., Handa, S., Ablo, M., Twun-Danso, A., Ofori-Addo, L., Alviar, C., Davis, B., Pozarny, P. and Attah, R. (2016) 'Social Protection and the Livelihood Empowerment Against Poverty (LEAP) Programme in Ghana: Generating Positive Change through the Power of Evidence', in Davis, B., Handa, S., Hypher, N., Winder Rossi, N., Winters, P. and Yablonski, J. (eds) From Evidence to Action: The Story of Cash Transfers and Impact Evaluation in Sub-Saharan Africa. New York, The Food and Agriculture Organization of the United Nations and The United Nations Children's Fund and Oxford University Press.

Richards, E., Theobald, S., George, A., Kim, J. C., Rudert, C., Jehan, K. and Tolhurst, R. (2013) 'Going beyond the surface: gendered intra-household bargaining as a social determinant of child health and nutrition in low and middle income countries', Social Science E Medicine, 95: 24-33.

Rico, E., Fenn, B., Abramsky, T. and Watts, C. (2011) 'Associations between maternal experiences of intimate partner violence and child nutrition and mortality: findings from Demographic and Health Surveys in Egypt, Honduras, Kenya, Malawi and Rwanda', Journal of Epidemiology and Community Health, 65(4): 360-367.

Rivera, J. A., Sotres-Alvarez, D., Habicht, J.-P., Shamah, T. and Villalpando, S. (2004) 'Impact of the Mexican program for education, health, and nutrition (Progresa) on rates of growth and anemia in infants and young children: a randomized effectiveness study', Jama, 291(21): 2563-2570.

Robertson, L., Mushati, P., Eaton, J. W., Dumba, L., Mavise, G., Makoni, J., Schumacher, C., Crea, T., Monasch, R. and Sherr, L. (2013) 'Effects of unconditional and conditional cash transfers on child health and development in Zimbabwe: a cluster-randomised trial', The Lancet, 381(9874): 1283-1292.

Roelen, K., Devereux, S., Abdulai, A.-G., Martorano, B., Palermo, T. and Ragno, L. P. (2017) 'How to Make 'Cash Plus' Work: Linking Cash Transfers to Services and Sectors', Innocenti Working Papers no. 10. Florence, UNICEF Office of Research - Innocenti. 
Rosenberg, M., Pettifor, A., Nguyen, N., Westreich, D., Bor, J., Bärnighausen, T., Mee, P., Twine, R., Tollman, S. and Kahn, K. (2015) 'Relationship between Receipt of a Social Protection Grant for a Child and Second Pregnancy Rates among South African Women: A Cohort Study', PloS one, 10(9): e0137352.

Rossi, P. and Rouanet, L. (2015) 'Gender preferences in Africa: A comparative analysis of fertility choices', World Development, 72: 326-345.

Rotter, J. B. (1966) 'Generalized expectancies for internal versus external control of reinforcement', Psychological Monographs: General and Applied, 80(1): 1.

Rubalcava, L., Teruel, G. and Thomas, D. (2009) 'Investments, time preferences and public transfers paid to women', Economic Development and Cultural Change, 57(3): 507.

Ruel, M. T., Alderman, H. and Maternal Child Nutrition Study Group (2013) 'Nutrition-sensitive interventions and programmes: how can they help to accelerate progress in improving maternal and child nutrition?', The Lancet, 382(9891): 536-551.

Ruel, M. T., Levin, C. E., Armar-Klemesu, M., Maxwell, D. and Morris, S. S. (1999) 'Good care practices can mitigate the negative effects of poverty and low maternal schooling on children's nutritional status: Evidence from Accra', World Development, 27(11): 1993-2009.

Ruel, M. T. and Menon, P. (2002) 'Child feeding practices are associated with child nutritional status in Latin America: innovative uses of the demographic and health surveys', Journal of Nutrition, 132(6): 1180-1187.

Saha, K. K., Frongillo, E. A., Alam, D. S., Arifeen, S. E., Persson, L. Å. and Rasmussen, K. M. (2008) 'Appropriate infant feeding practices result in better growth of infants and young children in rural Bangladesh', The American Journal of Clinical Nutrition, 87(6): 1852-1859.

Salazar, M., Högberg, U., Valladares, E. and Persson, L.-Å. (2012) 'Intimate partner violence and early child growth: a community-based cohort study in Nicaragua', BMC Pediatrics, 12(1): 82.

Sanchez, A., Melendez, G. and Behrman, J. (2018) 'Impact of Juntos Conditional Cash Transfer Program on Nutritional and Cognitive Outcomes in Peru: Comparison Between Younger and Older Initial Exposure', Economic Development and Cultural Change.

Sankoh, A. J., Huque, M. F. and Dubey, S. D. (1997) 'Some comments on frequently used multiple endpoint adjustment methods in clinical trials', Statistics in Medicine, 16(22): 2529-2542.

Sawadogo, P. S., Martin-Prével, Y., Savy, M., Kameli, Y., Traissac, P., Traoré, A. S. and Delpeuch, F. (2006) 'An infant and child feeding index is associated with the nutritional status of 6-to 23-month-old children in rural Burkina Faso', Journal of Nutrition, 136(3): 656-663. 
Schady, N. and Rosero, J. (2008) 'Are cash transfers made to women spent like other sources of income?', Economics Letters, 101(3): 246-248.

Schneider, E. B. (2018) 'Stunting: past, present, future. Conference Report'. London, UK, Department of Economic History, London School of Economics and Political Science.

Schubert, B. and Slater, R. (2006) 'Social Cash Transfers in Low-Income African Countries: Conditional or Unconditional?', Development Policy Review, 24(5): 571-578.

Sebastian, A., Paula de la Campos, A., Daidone, S., Davis, B., Niang, O. and Pellerano, L. (2016) 'Gender differences in child investment behaviour among agricultural households: Evidence from the Lesotho Child Grants Programme', WIDER Working Paper 2016/107. Helsinki, UNU-WIDER.

Sedlmayr, R., Shah, A. and Sulaiman, M. (2017) 'Cash-Plus: Poverty Impacts of Transfer-Based Intervention Alternatives', CSAE Working Paper Series 201715-2. Oxford, UK, Centre for the Study of African Economies, University of Oxford.

Shah, P. S. and Shah, J. (2010) 'Maternal exposure to domestic violence and pregnancy and birth outcomes: a systematic review and meta-analyses', Journal of Women's Health, 19(11): 2017-2031.

Shrimpton, R., Victora, C. G., de Onis, M., Lima, R. C., Blössner, M. and Clugston, G. (2001) 'Worldwide timing of growth faltering: implications for nutritional interventions', Pediatrics, 107(5): e75-e75.

Sinha, N. and Yoong, J. (2009) 'Long-term financial incentives and investment in daughters: evidence from conditional cash transfers in North India', World Bank Policy Research Working Paper.

Sinmegn Mihrete, T., Asres Alemie, G. and Shimeka Teferra, A. (2014)

'Determinants of childhood diarrhea among underfive children in Benishangul Gumuz Regional State, North West Ethiopia', BMC Pediatrics, 14(1): 102.

Slater, R. (2011) 'Cash transfers, social protection and poverty reduction', International Journal of Social Welfare, 20(3): 250-259.

Smith, L. C. and Haddad, L. (2002) 'How Potent Is Economic Growth in Reducing Undernutrition? What Are the Pathways of Impact? New Cross-Country Evidence*', Economic Development and Cultural Change, 51(1): 55-76.

Smith, L. C. and Haddad, L. (2015) 'Reducing child undernutrition: past drivers and priorities for the post-MDG era', World Development, 68: 180-204.

Smith, L. C. and Haddad, L. J. (2000) 'Explaining child malnutrition in developing countries: A cross-country analysis', FCND Discussion Paper No. 60. Wahington, DC, International Food Policy Research Institute.

Smith, L. C., Ramakrishnan, U., Ndiaye, A., Haddad, L. and Martorell, R. (2003) 'The importance of women's status for child nutrition in developing 
countries', Research Report 131. Washington, DC, International Food Policy Research Institute.

Soares, F. V., Ribas, R. P. and Osório, R. G. (2010) 'Evaluating the impact of Brazil's Bolsa Familia: cash transfer programs in comparative perspective', Latin American Research Review, 45(2): 173-190.

Soares, F. V. and Teixeira, C. (2010) 'Impact Evaluation of the Expansion of the Food Subsidy Programme in Mozambique', Research Brief No. 17. Brasilia, The International Policy Centre for Inclusive Growth.

Sobkoviak, R. M., Yount, K. M. and Halim, N. (2012) 'Domestic violence and child nutrition in Liberia', Social Science $\mathcal{E}$ Medicine, 74(2): 103-111.

Stecklov, G. and Winters, P. (2011) 'Do cash transfers impact childbearing and childrearing? Experimental evidence from sub-Saharan Africa', Working Paper.

Stecklov, G., Winters, P., Todd, J. E. and Regalia, F. (2007) 'Unintended effects of poverty programmes on childbearing in less developed countries: experimental evidence from Latin America', Population Studies, 61(2): 125140.

Strauss, J., Mwabu, G. and Beegle, K. (2000) 'Intrahousehold allocations: a review of theories and empirical evidence', Journal of African Economies, 9(Supplement 1): 83-143.

Strauss, J. and Thomas, D. (2008) 'Health over the life course', in Schultz, T. P. and Strauss, J. (eds) Handbook of Development Economics, pp. 3375-3474. Amsterdam, North Holland.

Subramanian, S. and Deaton, A. (1991) 'Gender effects in Indian consumption patterns', Sarvekshana, 14(4): 1-12.

Thomas, D. (1990) 'Intra-household resource allocation: An inferential approach', Journal of Human Resources: 635-664.

Thomas, D. (1994) 'Like father, like son; like mother, like daughter: Parental resources and child height', Journal of Human Resources: 950-988.

Tiwari, S., Daidone, S., Ruvalcaba, M. A., Prifti, E., Handa, S., Davis, B., Niang, O., Pellerano, L., van Ufford, P. Q. and Seidenfeld, D. (2016) 'Impact of cash transfer programs on food security and nutrition in sub-Saharan Africa: A cross-country analysis', Global Food Security, 11: 72-83.

Todd, J. E., Winters, P. and Stecklov, G. (2012) 'Evaluating the impact of conditional cash transfer programs on fertility: the case of the Red de Protección Social in Nicaragua', Journal of Population Economics, 25(1): 267290.

Tonguet-Papucci, A., Houngbe, F., Huybregts, L., Ait-Aissa, M., Altare, C., Kolsteren, P. and Huneau, J.-F. (2017) 'Unconditional Seasonal Cash Transfer Increases Intake of High-Nutritional-Value Foods in Young Burkinabe Children: Results of 24-Hour Dietary Recall Surveys within the 
Moderate Acute Malnutrition Out (MAM'Out) Randomized Controlled Trial', Journal of Nutrition, 147(7): 1418-1425.

UN General Assembly (2015) '70/1. Transforming our world: the 2030 Agenda for Sustainable Development', in United Nations (ed) A/RES/70/1. New York, United Nations.

UNDESA (2018) 'Sustainable development knowledge platform'.

UNESCO Institute for Statistics (2014) 'Education Statistics', in UNESCO (ed). Montreal.

UNICEF-ESARO/Transfer Project (2015) 'Social Cash Transfer and Children's Outcomes: A Review of Evidence from Africa'. Nairobi, UNICEF Eastern and Southern African Regional Office.

UNICEF (2013) 'Improving child nutrition - The achievable imperative for global progress'. New York, United Nations Children's Fund.

UNICEF (2018) 'MICS6 Indicators and Definitions'. New York, UNICEF.

UNICEF Ghana (2012) 'Global Initiative on Out-of-School Children. Ghana Country Study'. Accra, Ghana, UNICEF Ghana.

UNICEF Office of Research - Innocenti, Institute of Statistical Social and Economic Research, University of North Carolina at Chapel Hill and Navrongo Health Research Centre (2016) Ghana LEAP 1000 Programme: Baseline Evaluation Report, Florence: UNICEF Office of Research - Innocenti.

UNICEF Office of Research - Innocenti, Institute of Statistical Social and Economic Research, University of North Carolina at Chapel Hill and Navrongo Health Research Centre (2018) 'Ghana LEAP 1000 Programme: Endline Evaluation Report'. Florence, UNICEF Office of Research - Innocenti.

UNICEF/WHO/World Bank Group (2017) 'Levels and trends in child malnutrition. Key findings of the 2017 edition'. New York, United Nations Children Fund.

United Nations Development Programme and National Development Planning Commission (2015) Ghana Millennium Development Goals 2015 Report, Accra: National Development Planning Commission.

United Nations Economic and Social Council (2015) 'Report of the Inter-Agency and Expert Group on Sustainable Development Goal Indicators', in United Nations (ed) E/CN.3/2016/2. New York, United Nations.

University of North Carolina at Chapel Hill (2015) 'Malawi Social Cash Transfer Program Midline Impact Evaluation Report'. Chapel Hill, NC, University of North Carolina.

University of North Carolina at Chapel Hill, CSR-UNIMA and UNICEF Office of Research - Innocenti (2016) 'Malawi Social Cash Transfer Programme Endline Impact Evaluation Report'. Chapel Hill, NC, University of North Carolina. 
van den Bold, M., Quisumbing, A. R. and Gillespie, S. (2013) 'Women's empowerment and nutrition: an evidence review', IFPRI Discussion Paper 01294. Washington D.C., The International Food Policy Research Institute.

van der Hoek, W., Feenstra, S. G. and Konradsen, F. (2002) 'Availability of irrigation water for domestic use in Pakistan: its impact on prevalence of diarrhoea and nutritional status of children', Journal of Health, Population and Nutrition: 77-84.

Vazir, S., Engle, P., Balakrishna, N., Griffiths, P. L., Johnson, S. L., Creed-Kanashiro, H., Fernandez Rao, S., Shroff, M. R. and Bentley, M. E. (2013) 'Clusterrandomized trial on complementary and responsive feeding education to caregivers found improved dietary intake, growth and development among rural Indian toddlers', Maternal \& Child Nutrition, 9(1): 99-117.

Victora, C. G., Adair, L., Fall, C., Hallal, P. C., Martorell, R., Richter, L., Sachdev, H. S. and Maternal Child Undernutrition Study Group (2008) 'Maternal and child undernutrition: consequences for adult health and human capital', The Lancet, 371(9609): 340-357.

Victora, C. G., de Onis, M., Hallal, P. C., Blössner, M. and Shrimpton, R. (2010) 'Worldwide timing of growth faltering: revisiting implications for interventions', Pediatrics: peds. 2009-1519.

Westfall, P. H. and Young, S. S. (1993) Resampling-Based Multiple Testing: Examples and Methods for p-Value Adjustment, New York: John Wiley \& Sons, Inc.

WHO and UNICEF (2016) 'Improved and unimproved water sources and sanitation facilities'.

WHO Multicentre Growth Reference Study Group and Onis, M. (2006) 'WHO Child Growth Standards based on length/height, weight and age', Acta Paediatrica, 95(S450): 76-85.

Wodon, Q. and Zaman, H. (2010) 'Higher food prices in Sub-Saharan Africa: Poverty impact and policy responses', The World Bank Research Observer, 25(1): 157-176.

Working Group on Infant and Young Child Feeding Indicators (2006) Developing and Validating Simple Indicators of Dietary Quality and Energy Intake of Infants and Young Children in Developing Countries: Summary of findings from analysis of 10 data sets., Washington, DC: Food and Nutrition Technical Assistance Project (FANTA), FHI 360.

World Bank (2018a) All Hands On Deck: Reducing Stunting through Multisectoral Efforts in Sub-Saharan Africa, Washington, DC: World Bank.

World Bank (2018b) The State of Social Safety Nets 2018, Washington, DC: World Bank.

World Bank (2018c) 'World Development Indicators Database'. Washington, DC, World Bank. 
World Health Organization (2004) The importance of caregiver-child interactions for the survival and healthy development of young children: A review, Geneva: World Health Organization.

World Health Organization (2010) Indicators for assessing infant and young child feeding practices: part 2: measurement., Geneva: World Health Organization.

Yanez-Pagans, M. (2008) 'Culture and human capital investments: Evidence of an unconditional cash transfer program in Bolivia', IZA Discussion Papers, No. 3678.

Yoong, J., Rabinovich, L. and Diepeveen, S. (2012) 'The impact of economic resource transfers to women versus men. Technical report'. London, EPPICentre, Social Science Research Unit, Institute of Education, University of London.

Yount, K. M., DiGirolamo, A. M. and Ramakrishnan, U. (2011) 'Impacts of domestic violence on child growth and nutrition: a conceptual review of the pathways of influence', Social Science \& Medicine, 72(9): 1534-54. 


\section{Summary}

This PhD dissertation studies the impact of cash transfers on young child nutritional status, with an additional focus on the role of intra-household dynamics. This study is motivated by the fact that still more than 155 million children under the age of five years suffer from stunting (too short for one's age), a chronic condition resulting primarily from prolonged malnutrition and exposure to infectious diseases during early childhood. The burden of malnutrition is particularly large in sub-Saharan Africa (SSA), where more than 1 in 3 children under five are stunted. Malnutrition has severe consequences for later life outcomes, including reduced school achievement, lower economic productivity in adulthood and poorer reproductive health outcomes for girls. Countries' economies can take a huge hit when their children suffer from malnutrition, in the order of 10 percent of GDP. Therefore, investments during early childhood that can improve nutritional status can yield large economic and social returns.

Malnutrition is a multidimensional issue with several underlying risk factors. This study builds on a widely recognized framework of the determinants of malnutrition, which lists food intake and health as the two immediate determinants of malnutrition. These immediate determinants are in turn caused by three underlying determinants: food security, care for mothers and children, and the household health environment. Social protection is increasingly recognized as an important strategy to accelerate progress in improving maternal and child nutrition because it can address structural factors such as poverty and social vulnerability. In particular cash transfer (CT) programmes, which deliver cash directly to households, have gained popularity with governments and other stakeholders in recent years. As a result, several countries in SSA have designed, piloted and scaled-up CTs in the last decade, with the potential to increase coverage to a large section of the population in the near future.

The intersection between these two developments opens up questions on how they can be linked and how CTs can help to address the burden of malnutrition. This is particularly important within the framework of the Sustainable Development Goals (SDGs) which call for the eradication of hunger, including malnutrition (Goal 2.2) and to implement nationally appropriate social protection systems (Goal 1.3). Previous research has mostly examined the direct link between CTs and child nutritional status. However, the results of these studies are mixed and point to the need to better understand the pathways through which CT programmes might work to improve nutritional status.

This dissertation aims to address this knowledge gap by building on the UNICEF conceptual framework of child nutrition to study the underlying and immediate determinant of malnutrition and the impact that a CT can have on these determinants. One novel aspect of this study is to introduce the concept of intra- 
household dynamics in resource allocation and decision-making as a potential determinant of child nutrition. This concept states that there may be inequalities in the allocation of resources such as food and health care within the household, which could affect the effectiveness of a CT that aims to improve the wellbeing of children. This has thus far been ignored in the literature on CTs and nutrition, despite research showing that intra-household dynamics can be important for the health and development of children.

The main objective of this dissertation is to examine to what extent an unconditional cash transfer programme can improve child nutritional status. The following sub-questions are posed:

a. What are the pathways of impact on child nutritional status for a cash transfer programme?

b. What factors mediate or moderate $\mathrm{CT}$ programme impacts on child malnutrition?

c. How does intra-household allocation of resources play a role in the determination of children's outcomes?

d. To what extent do intra-household dynamics affect the impact of a cash transfer on nutritional status?

This thesis aims to answer the research questions by focusing on one particular CT programme in Ghana, the Livelihood Empowerment Against Poverty (LEAP) programme. This programme was initiated in 2008 as a small pilot and transitioned quickly to a national programme reaching 213,000 households by the end of 2017. LEAP officially targets the 'extreme poor' of Ghana, but also applies a categorical targeting approach and selects households with elders over 65 years old, people with a severe disability unable to work and households caring for orphans and vulnerable children (OVC). In 2015, a new demographic group was introduced through the LEAP 1000 programme, pregnant women and households with children under the age of one year. Households are selected into the programme through a proxy means test (PMT). LEAP beneficiaries, including children and dependents under 18 years, as all other indigents are entitled to free health insurance under the National Health Insurance Scheme, providing access to out-patient and in-patient services, dental services, and maternal health services. Households qualifying for the LEAP programme receive GHC 32, 38, 44 or 53 (approximately USD 8.00 - 13.25) per month for one, two, three or four or more eligible members in the household, respectively. The transfer is not conditional on household behaviours, although households with OVC are expected to keep their children in school, register births, vaccinate their children and ensure that their children are not trafficked and do not engage in child labour. In practice, there is no monitoring system in place that verifies compliance with these 'coresponsibilities'. 
This dissertation exploits data from a rigorous impact evaluation that accompanied the expansion to the new category of pregnant women and infants (LEAP 1000). Approximately 2,500 households with pregnant women or children under one year old were followed over two years, from 2015 to 2017. Half of the sample was eligible for the LEAP 1000 programme and the other half was not. The impact evaluation used the PMT eligibility rule to construct a treatment and comparison group through a regression discontinuity design (RD). The main idea of this approach is that households in the close vicinity of the eligibility threshold are 'as good as randomly' assigned to the treatment and comparison group. A major benefit of this evaluation is that the sample includes many young children, which make it ideal to study the determinants of malnutrition and how a CT can affect malnutrition in this population.

The dissertation is composed of an introductory chapter, four main chapters, and a concluding chapter. The chapters are summarized as follows.

Chapter 1 introduces the study and presents the background of the main issues of interest: malnutrition and CT programmes. The chapter then introduces an expanded version of the UNICEF conceptual framework of malnutrition. This framework identifies household food security, care and a healthy environment as the underlying determinants that influence the immediate determinants of children's nutritional intake and health status. The combination and interaction of these two immediate determinants define the final outcome, a child's nutritional status. This study introduces intra-household decision-making and allocation of resources as an additional determinant. Intra-household decision-making determines what part of the income or resources held by the household are distributed among the three main resource components, as well as which household member gets what share of the total available resources. This determinant is a novel addition to the framework based on emerging evidence that intra-household dynamics play an important role in the determination of child health and nutrition as well as the premise that intra-household dynamics matter for the effectiveness of a transfer to the household. The framework also considers several moderators and mediators of the relationship between CTs and child nutrition. For example, the child's dietary intake is mediated by the caregiver's feeding practices and feeding styles. The health status of a child is mediated by the health-seeking behaviour of the caregiver. Household food security is moderated by the availability and price level of food and by external shocks. Women's empowerment (most commonly operationalized as women's decision-making or control over resources), mediates the relationship between CTs and care for mothers and children. The chapter then proceeds to present the main research questions and introduces Ghana and the LEAP programme as the context for the study. 
Chapter 2 presents a literature review to examine the extent to which CT programmes can improve child nutrition. It uses the conceptual framework which captures and explains the pathways and determinants of child nutrition. The literature review uses several techniques to collect as many studies as possible that examine the impact of CTs on any of the pathways from the conceptual framework. This includes a search of academic databases, snowballing from existing reviews and meta-analyses and contacting experts in the field. To avoid any potential publication bias, grey literature is considered along peer-reviewed journal articles. The results from the selected studies are then summarized by each level according to the conceptual framework (e.g. outcome level, immediate determinants and underlying determinants). The focus is on impact pathways and new and emerging findings from sub-Saharan Africa to identify critical elements that determine child nutrition outcomes as well as knowledge gaps requiring further research. Findings from this review demonstrate that an increasing number of studies have highlighted the positive role of CTs in increasing resources for food, health and care. However, the evidence to date on the immediate determinants of child nutrition is mixed with respect to whether CTs can positively impact growth-related outcomes among children. The evidence also points to a lack of knowledge on the impact pathways.

Chapter 3 uses the baseline data of the LEAP 1000 impact evaluation to explain the underlying causes of childhood malnutrition. Guided by the conceptual framework, the chapter uses a health production function to model the relationship between the immediate determinants of malnutrition (food intake and health) and child, parent, household and community characteristics using regression analysis. It then uses the same health production function to examine the relationship between nutritional status (height-for-age) and child, parent, household and community characteristics. The results from this analysis are associations, rather than causal relationships, but they provide important ex-ante information on what characteristics are associated with improved food intake, health and nutritional status. The chapter then proceeds to simulate several policy interventions, including a cash transfer, improvements in maternal care, and a price shock to examine what changes might be expected as a result of these interventions. The findings suggest that maternal agency and health contribute to improved health status. Household resources - in the form of consumption - are positively associated with food intake and nutritional outcomes. The policy simulations show that income growth, improving maternal care and avoiding sudden price shocks have a positive - but rather limited effect - on the reduction of malnutrition. Effects are greater in children under two. The chapter concludes that policies that address underlying determinants simultaneously, and target the youngest population of children, could have the largest effect on reducing malnutrition in this population. 
Chapter 4 also uses the baseline data from the LEAP 1000 impact evaluation. The objective of chapter 4 is to examine the intra-household dynamics in the baseline sample and whether these dynamics affect the wellbeing of children in the household. First, outlay equivalence analysis is used to assess how households change their consumption pattern when an additional child enters the household. More specifically, this analysis uses regression methods to examine how the consumption of exclusive adult goods (items that are only consumed by adults in the household such as tobacco, alcohol, clothing for adults, etc.) responds to an addition of a child to the household. When the household budget is fixed, adults must give up spending on adult goods to cater for the needs of a child. Then, testing whether this response is different when the additional child is a boy or a girl can reveal general gender preference of the household. Next, the chapter aims to analyse whether fathers and mothers have different preferences with regards to investing in their daughters or sons. This analysis uses the educational achievement of the parents as a source of bargaining power and tests how parental education has an effect on outcomes (education and nutrition) and inputs (educational expenditures and infant and young child feeding practices) for sons versus daughters. This analysis is conducted using OLS, fixed effects and random effects.

The outlay equivalence analysis shows that households are willing to give up spending on adult goods in favour of children. However, there is no difference in gender preferences in the allocation of household resources. In other words, parents are willing to give up an equal amount of spending on adult goods, irrespective of whether the child is a boy or a girl. The second analysis reveals suggestive evidence that fathers are more inclined to invest in their daughters compared to their sons. More specifically, girls of secondary school age (12 - 17 years) seem to benefit from living in a household where the father has received some form of formal education compared to boys. In contrast, similar girls in households where only the mother completed some formal schooling, are worse off compared to boys. Similar findings emerge from the analysis using nutritional status as outcome. More years of maternal schooling is associated with lower HAZ for girls, while higher paternal schooling is positively related to HAZ for girls. The effects of father's education on HAZ are further corroborated by similar findings on nutritional inputs (infant and young child feeding practices), especially when girls are still young. These effects might be driven by an investment motive of fathers to obtain a higher bride price when girls are old enough to marry, but more research is needed to fully understand these findings.

Chapter 5 presents results from the impact evaluation of Ghana LEAP 1000 on child nutrition and its determinants, taking advantage of two waves of data. The evaluation constructs a quasi-experimental treatment and comparison group by using the discontinuity of the PMT threshold as a cut-off for eligibility. The chapter 
first establishes that this quasi-experimental strategy was valid by conducting balance tests on all the main indicators and a manipulation test to verify that the PMT scores were not compromised. The main impact analysis uses a difference-indifference approach and compares the change in the treatment group to the change in the comparison group, while controlling for several individual and household characteristics as well as community fixed effects. The chapter then proceeds to conduct heterogeneity analysis by examining the role of i) duration in the programme, ii) distance to and quality of nearby health centres, iii) negative and positive shocks to households' livelihoods, and (iv) the intra-household dynamics. This heterogeneity analysis is conducted through a triple-difference approach which estimates how the treatment effect varies with respect to these moderators.

The results show no main treatment effect on nutritional status, nor on the two immediate determinants of food intake and health. However, there is a positive effect on one of the three underlying determinants, food security. The heterogeneity analysis shows no differential impacts by age group. Quality of nearby health facilities increases the programme's impact on food security. There are also lower impacts on weight in case of crop-related shocks and higher health impacts when communities benefit from additional development programmes. Finally, there is some suggestive evidence that better-educated mothers invest fewer resources in the health of their daughters compared to their sons. Results from this evaluation are compared to results from other programmes and countries (Zambia, Malawi, Kenya, Zimbabwe and Ethiopia) to put them in perspective. This comparison shows that none of these programmes had an impact on any of the nutritional status indicators. In the three programmes that collected information on food intake for children, all of them found a significant impact, indicating that one of the immediate determinants of malnutrition was affected. However, none of the programmes had an impact on child health. On the other hand, all programmes had a strong and significant effect on food security, similar to the Ghana LEAP 1000 programme. Some reasons for the non-impact in the Ghana LEAP 1000 programme could be the relatively low transfer size and the short time frame of the evaluation. The chapter concludes that cash alone is unlikely to yield impacts on young child nutrition and integrated programmes that aim to address multiple underlying determinants at the same time need to be further examined.

Chapter 6 summarizes the main results by answering the research questions, draws conclusions and discusses the implications and way forward.

\section{What are the pathways of impact on child nutritional status for a cash transfer programme?}

The findings from this study show that child malnutrition has several determinants, and CTs have most consistent impacts on one of the pathways, food security at the household level, in some cases leading to improvements in 
children's individual food intake. For these results to translate into improved nutritional status, it is just as important to create a healthy environment around the child, to minimize the impact of illnesses on the growth potential. However, there is only limited evidence that CTs, if implemented in isolation, are also able to impact child nutrition through the health pathway.

2. What factors mediate or moderate CT programme impacts on child malnutrition? Based on the literature review in this dissertation, there are several moderating factors for the impact of CTs on child nutrition. They include, the amount of the transfer in relation to household consumption; age of children when benefitting from the programme; supply-side conditions such as markets, prices, health facility access and quality of health services; livelihood shocks; and duration of programme participation. However, there is only limited evidence for these moderating factors in the context of the Ghana LEAP 1000 programme. Younger children did not necessarily benefit more from the programme, and presence of (quality) health facilities was not related to higher programme impacts. Since these are findings from one particular programme, more research is needed to examine these and other moderating factors.

\section{How does intra-household allocation of resources play a role in the determination of} children's outcomes?

This study found that intra-household dynamics matter for children's outcomes to some extent. In general, households tend to give up spending on adult goods when an additional child joins the household, irrespective of whether the additional child is a boy or a girl. Educational and nutritional outcomes of girls tend to be somewhat better in case the father has attained more education, suggesting that fathers are inclined to invest in their daughters.

4. To what extent do intra-household dynamics affect the impact of a cash transfer on nutritional status?

The impact analysis reveals that there are differences in impacts between household members, particularly in the number of meals. There is also suggestive evidence that daughters of better-educated mothers have poorer health status because of LEAP 1000. However, the analysis is unable to fully understand what intra-household dynamics are driving these findings and more research is needed to address this gap in knowledge.

The main objective of this dissertation is to examine to what extent an unconditional cash transfer programme can improve child nutritional status. Overall, the findings show that a CT, when implemented in isolation, is unlikely to yield strong impacts on young child nutrition, but when coupled with complementary programmes aimed at addressing multiple underlying and immediate determinants at the same time, could have the potential to make a 
difference. In addition, a long-term perspective is needed as other evidence shows that increased wealth and improving the education and status of women all have positive effects on child nutritional status.

The policy implications derived from this study are summarized as follows.

1. While policies that direct cash to poor households certainly helps, especially for improving the household's food security situation, it is likely not enough to systematically improve children's nutritional status. It is therefore important to explore complementarities between programmes across different sectors that can affect the underlying and immediate determinants of nutrition simultaneously through integrated programming. This is an emerging policy area which has shown some promising results thus far.

2. The transfer amount in relation to household consumption is an important element. If a transfer is too low, it is unlikely to change household consumption and investment patterns. In addition, transfer values need to be linked to inflation to preserve purchasing power of the grant.

3. Intra-household dynamics are important to consider. Cash is usually distributed to an adult member of the household and their preferences and bargaining power within the household will have an effect on the impact of the transfer on children. Measures to increase the effectiveness of a CT to improve child wellbeing need to be considered within the context of the programme.

4. While CTs are primarily a demand-side intervention, policy makers need to equally invest in supply-side conditions such as health facilities and health infrastructure to improve the overall health environment for households and their children.

5. A long-term perspective is required since evidence shows that increased wealth, higher educational achievement and improved status of women all have positive effects on child nutritional status.

To conclude, this dissertation examined the impact of cash transfers on young child nutritional status, with an additional focus on the role of intra-household dynamics. The results show that cash alone is unlikely to make a large contribution to reducing child malnutrition. The determinants of child malnutrition are complex and additional income is only one driver, mostly associated with increasing the resources for food at the household level. There needs to be increased effort to address the other determinants of nutrition through complementary programming and proper investments in the local health infrastructure. In addition, more effort is needed to ensure that CT programmes translate into improvements for young children, by considering inequalities in the intra-household division of resources. The results of this thesis provide policy makers with relevant evidence as they continue to design, implement and scale-up social protection programmes that address the needs of vulnerable populations. 


\section{Valorization addendum}

This addendum describes the relevance of this thesis for policy and practice. This study comes at an important time, given the revolution of social protection programmes in lower income countries over the last two decades. At the same time, policy makers in the developing world are looking for interventions to address the high burden of malnutrition among young children, which has severe impacts on the health, development and economic potential of those affected. The Sustainable Development Goals, adopted in 2015, set out an ambitious agenda for policy makers across the world. Target 1.3 calls for the establishment of appropriate social protection floors and target 2.2 calls for ending all forms of malnutrition. This study is at the crossroads of these two targets and examines if and how cash transfer (CTs) programmes can play a role in addressing malnutrition. CTs are a popular form of social protection and have been implemented and scaled up in dozens of low income countries over the last two decades. Therefore, it is important to examine their potential contribution to reducing malnutrition.

The first contribution of this thesis is to highlight what we know thus far on how CTs can help address malnutrition (chapter 2). The answers provided in this chapter help policy makers and development partners to decide on what works best if one of the objectives of a CTs is to improve malnutrition. By looking at past research, it offers lessons for those in the process of designing and implementing CTs to maximize the benefit for populations at risk of malnutrition. For example, elements like the transfer size and the target age group can have a substantial effect on the success of the programme to address malnutrition. This chapter also showed that malnutrition is a multidimensional problem with various underlying determinants. It is important for policy makers to fully understand how these determinants work together and how policy can address such determinants.

The empirical part of the thesis focuses on the Livelihood Empowerment Against Poverty (LEAP) programme in Ghana. More specifically, it deals with an extension of the LEAP programme to a new group of beneficiaries, pregnant women and young infants, named LEAP 1000. While this focus makes the thesis particularly relevant for policy makers in Ghana, lessons learnt from LEAP 1000 are likely transferrable to countries at a similar level of development and on a similar growth path. More countries in sub-Saharan Africa are piloting and scaling up CTs targeted to young children with the objective to improve child nutritional status, for example in Zambia (Child Grant Programme) and Mozambique (Subsidio para a Crianca). In addition, the target group of this CT makes it uniquely positioned to study the potential and the effect of a CT on young child nutrition. 
Next, this study provides contextualized evidence on the determinants of malnutrition in Northern Ghana (chapter 3). It is important to take account of the complex determinants of malnutrition when a policy is designed to address this issue. The findings from this chapter showed that household income and maternal care have a positive relation with health and nutrition of children. Higher prices are negatively associated with nutritional status. Hence, policies that can increase household income, improve maternal care and reduce volatility of prices can all contribute to improvements in the health and nutritional status of children in Northern Ghana. Simulations are an important part of the policy process as they can estimate the likely effect of a policy. Simulations in this thesis show that income growth, improving maternal care and avoiding sudden price shocks have a positive - but rather limited effect - on the reduction of malnutrition. This is important information for policy makers to identify the most effective policies to address malnutrition.

In addition, this thesis is relevant by including household behaviour as an additional determinant of nutritional status. Since infants are cared for by adults living in households, the dynamics of household behaviour and preferences are important considerations for policy makers. For example, parents may have different preferences in which child they want to invest more resources to get returns in the future. Such preferences may have an effect on the effectiveness of policies seeking to address malnutrition, especially when a policy is as fungible as an unconditional CT, which allows families to spend the money as they see fit. The results from this thesis showed that households in general have no strong preference regarding the gender of their children, but that fathers might be more inclined to invest in their daughters compared to their sons. These are important considerations for actors designing and implementing CTs as the expected outcomes can depend on how the intervention is targeted and communicated to the recipient household.

Besides these ex-ante effects, the impact evaluation presented in this thesis provides important evidence on the extent to which an unconditional CT can affect malnutrition and its determinants (chapter 5). This is one of the first impact evaluations of an at-scale, government-run CT in West-Africa and therefore offers vital knowledge to policy makers and other actors in social protection in the region. The results from this impact evaluation showed no impact on nutritional status, nor on the two immediate determinants of food intake and health. However, there is a positive effect on one of the three underlying determinants, food security, which is in line with findings from other CTs in the region. The main lesson from this study is that that cash alone is unlikely to yield impacts on young child nutrition and integrated programmes that aim to address multiple underlying determinants at the same time need to be further examined and tested.

While governments across the world, in particular in lower-income countries, are starting to recognize the potential of social protection, this thesis 
provides several evidence-based lessons to maximize social protection's potential to help address a significant public health problem such as malnutrition. The findings from this study feed into the policy discourse in Ghana, as well as in subSaharan Africa, and can reach actors who are active in the field of social policy design and implementation, such as international organizations, researchers and government officials. Findings from this study have been presented at several international conferences, as well as to policy makers and development actors in Ghana. It is therefore expected that the lessons from this research will continue to influence policy discussions and implementation in Ghana and beyond. 


\section{Curriculum Vitae}

Richard Anthony Leonard de Groot was born on the 29th of August 1987 in Almere, the Netherlands. He grew up in a small town near Breda, where he attended high school from 1999 - 2005. He then obtained a Bachelor's degree in International Business (2009) and a Master's degree in International Economic Studies (2010) at the School of Business and Economics of Maastricht University, the Netherlands. During his Bachelor's degree, he spent one semester abroad at the University of Florida in Gainesville, USA.

After his Master's degree, Richard moved to Siem Reap, Cambodia to work with a local NGO Anjali House, where he initiated an educational programme for young adults to promote educational attainment, enhance personal development and improve career prospects. In 2011, he moved back to the Netherlands and worked as an economic researcher for the CPB Netherlands Bureau for Economic Policy Analysis and later for the Ministry of Social Affairs and Employment. In 2013, he moved back to Cambodia, to Phnom Penh this time. He started working as an independent consultant and conducted research and evaluation projects for international NGOs and development partners, including the World Bank, UNICEF and Plan International. In 2015, he joined the UNICEF Office of Research - Innocenti in Florence, Italy, where he worked on the impact evaluation of Ghana's LEAP 1000 cash transfer programme and related research on cash transfers and child wellbeing. In 2016, he started his PhD programme in Governance and Policy Analysis at the Maastricht Graduate School of Governance in the Netherlands, combining his work for UNICEF with obtaining a PhD degree.

Richard is currently a consultant at the London School of Hygiene and Tropical Medicine on a research project to examine the effect of cash transfer programmes on the lives of people with a disability. He is married to Naomi and they have one daughter, Nore. 


\section{UNU-MERIT/MGSoG Dissertation Series}

2019

\section{Catie Lott}

Diamonds are a Women's Best Friend

Broadening Measures of Women's

Access to Formal Political Decision-

Making

UNU-MERIT/MGSoG Dissertation

Series № 227

\section{Ana Cristina Calderon Ramirez}

Public Management Reforms

Three stories about public procurement agencification in Latin America

UNU-MERIT/MGSoG Dissertation

Series № 226

\section{Camilo Nicanor Carrillo Purin}

Teachers' in-service training and

student achievement:

The effect of in-service training of

Peruvian teachers on student

achievement

UNU-MERIT/MGSoG Dissertation

Series № 225

\section{Hugo Confraria}

Developing scientific capacity in the

Global South

UNU-MERIT/MGSoG Dissertation

Series № 224
Alison Cathles

Educational Pathways and Skills:

Past, Present, and Future

UNU-MERIT/MGSoG Dissertation

Series № 223

\section{Ibrahima Sory Kaba}

Aggregate Fluctuations and

Development: Essays on

Macroeconomic Volatility and

Economic Growth

UNU-MERIT/MGSoG Dissertation

Series № 222

\section{Charlotte Keijser}

Firm Participation, Learning and Innovation in Heterogenous Value

Chains of IT-enabled Services

UNU-MERIT/MGSoG Dissertation

Series № 221

\section{Salih Çevikarslan}

Innovation Strategies and Their

Implications for Technological Change and Market Outcomes:

An Evolutionary Multi-Agent Based

Modelling Approach

UNU-MERIT/MGSoG Dissertation

Series № 220

Wondimagegn Mesfin Tesfaye

Essays on the Impacts of Climate-

Smart Agricultural Innovations on

Household Welfare

UNU-MERIT/MGSoG Dissertation

Series № 219 


\section{Tatevik Poghosyan}

How Board Networks Affect Firm

Performance and Innovation Incentives

in Transition Economies: The Case of

Armenia

UNU-MERIT/MGSoG Dissertation

Series № 218

\section{Arip Muttaqien}

Essays on Inequality and Polirization:

Empirical Studies in Developing Asia

UNU-MERIT/MGSoG Dissertation

Series№ 217

2018

\section{Katrin Marchand}

Essays on Forced Migration and

Labour Market Participation in

Developing Countries

UNU-MERIT/MGSoG Dissertation

Series № 216

\section{Ortrun Merkle}

The Myth of Gender Neutral Power:

Corruption and Gender Norms

UNU-MERIT/MGSoG Dissertation

Series № 215

\section{Biljana Meshkovska}

Life after Trafficking:

(re)integration processes of women that

have been trafficked for the purpose of

sexual exploitation in Europe

UNU-MERIT/MGSoG Dissertation

Series № 214

\section{Vincenzo Vinci}

The Relevance of Institutions and

People's Preferences for Social

Protection

UNU-MERIT/MGSoG Dissertation

Series № 213

\section{Silke Heuser}

The Effectiveness of Environmental

Policies on Reducing Deforestation in

the Brazilian Amazon

UNU-MERIT/MGSoG Dissertation

Series № 212

\section{Jennifer Waidler}

Social Assistance and Remittances and

Their Role in the Fight Against

Poverty

UNU-MERIT/MGSoG Dissertation

Series № 211

\section{Choolwe Muzyamba}

The role of community mobilization in the promotion of maternal health of women living with HIV in Zambia UNU-MERIT/MGSoG Dissertation Series № 210

\section{Juan Carlos A. Castillo Sánchez}

Assessing the Role of the Export Sector in Mexican Economic

Development,1965-2014

UNU-MERIT/MGSoG Dissertation

Series № 209

\section{Tareq Abuelhaj}

Food Security Policy Impact Analysis:

The Econometrics of Cash and Food Assistance Cost Effectiveness UNU-MERIT/MGSoG Dissertation Series № 208 
Marta Férnandez de Arroyabe Arranz

Essays on MEAS and Innovation

UNU-MERIT/MGSoG Dissertation

Series № 207

\section{Clotilde Mahé}

Essays on Migration and Occupational Choice

UNU-MERIT/MGSoG Dissertation Series № 206

\section{Simone Sasso}

Talent on the move. Essays on Human Capital, Graduate Mobility and

Economic Development

UNU-MERIT/MGSoG Dissertation Series № 205

\section{Khaled Walid Rajab}

Strategic Planning under Fragility

UNU-MERIT/MGSoG Dissertation

Series № 204

\section{Mutinta Hambayi Nseluke}

A Tall Order: Improving Child Linear Growth

UNU-MERIT/MGSoG Dissertation Series № 203

Elvis Korku Avenyo

Innovations and Firm Performance

in sub-Saharan Africa: Empirical

Analyses

UNU-MERIT/MGSoG Dissertation

Series № 202

\section{Ni Zhen}

Employment Dynamics, Firm

Performance and Innovation

Persistence in the Context of

Differentiated Innovation Types:

Evidence from Luxembourg

UNU-MERIT/MGSoG Dissertation

Series № 201

\section{Caroline Wehner}

Too Scared to Achieve: The Relation

Between Neuroticism,

Conscientiousness

and Socioeconomic Outcomes

UNU-MERIT/MGSoG Dissertation

Series № 200

\section{Stefania Innocenti}

On Institutional Persistence

UNU-MERIT/MGSoG Dissertation

Series № 199

\section{Hassen Abda Wako}

Economic Globalization, Institutions and Development: Essays on Aid, Foreign Direct Investment and Trade UNU-MERIT/MGSoG Dissertation Series № 198

\section{7}

\section{Hans-Erik Edsand}

Winds of Change

UNU-MERIT/MGSoG Dissertation Series № 197

\section{Ana Patricia Silva Vara}

Redressing the Gender Gap

UNU-MERIT/MGSoG Dissertation Series № 196 


\section{Andrés Iván Mideros Mora}

Essays on the Economic Effects of Noncontributory Social Protection

UNU-MERIT/MGSoG Dissertation Series № 195

\section{Tobias Broich}

New Actors in the Global Economy UNU-MERIT/MGSoG Dissertation Series № 194

\section{Bernard Nikaj}

From No-government to E-government UNU-MERIT/MGSoG Dissertation Series № 193

\section{Ali Safarnejad}

Prioritizing the HIV Response UNU-MERIT/MGSoG Dissertation Series № 192

\section{Clovis Freire}

Diversification and Structural

Economic Dynamics

UNU-MERIT/MGSoG Dissertation

Series № 191

\section{Michael Verba}

Innovation and Knowledge Dynamics: Essays on the Knowledge Economy UNU-MERIT/MGSoG Dissertation Series № 190

\section{Pui Hang Wong}

The Hearts and Minds in Conflict and Peace: The Economics of Counterinsurgency and the Psychology of Reconstruction UNU-MERIT/MGSoG Dissertation Series № 189

\section{Brenda Yamba}

Schooling Despite All Odds: Evidence from Lesotho on Female Child Carers who Stayed in School

UNU-MERIT/MGSoG Dissertation Series № 188

\section{Sheng Zhong}

Moving towards An Energy Efficient Future: Essays on Energy Efficiency, Technology and Development UNU-MERIT/MGSoG Dissertation Series № 187

\section{Julieta Marotta}

Access to Justice and Legal

Empowerment of Victims of Domestic

Violence through Legal Organizations in the City of Buenos Aires: A

Qualitative Empirical Legal Study

UNU-MERIT/MGSoG Dissertation Series, № 186

\section{Andrea Franco-Correa}

On the Measurement of

Multidimensional Poverty as a Policy Tool: Empirical Applications to Chile, Colombia, Ecuador and Peru

UNU-MERIT/MGSoG Dissertation Series, № 185

\section{6}

\section{Yesuf Awel}

Insurance for Growth: Empirical Essays on Insurance Demand and Impacts in Africa UNU-MERIT Dissertation Series, № 108 
Tigist Mekonnen Melesse

Grow More Food using Fewer

Resources: Agricultural Technology

Adoption and Innovation Practices for

Inclusive and Sustainable

Development

UNU-MERIT Dissertation Series, № 107

\section{Eleni Yitbarek}

Getting Ahead or left Behind? Essays on Poverty Dynamics and Social

Mobility in Africa

UNU-MERIT Dissertation Series, № 106

\section{Thuy Dieu Nguyen}

Firm-Level Theory and Evidence of

Corruption

UNU-MERIT Dissertation Series,

№ 105

\section{Raquel Tsukada Lehman}

Essays on Household Production with

Labor-Saving Technology

UNU-MERIT Dissertation Series,

№ 104

\section{Eva Barteková}

Multi-Problem Challenges for a

Renewable Future: Empirical Studies

on Competitive Disadvantages from

Electricity Price Differentials and

Mineral Supply Risk in an Open

Economy

UNU-MERIT Dissertation Series,

№ 103

\section{Jocelyn Olivari}

Entrepreneurial Traits and Innovation:

Evidence from Chile

UNU-MERIT Dissertation Series,

№ 102

\section{Muhammad Shafique}

Essays on the role of knowledge, RED, and Technology-based Firms in the Evolution of Socio-techno-economic System

UNU-MERIT Dissertation Series, № 101

\section{Serdar Türkeli}

Governance of Innovation Policy:

Empirical Studies on Applied Political

Economy by Multi-Methods Analysis

UNU-MERIT Dissertation Series,

№ 100

\section{Ayokunu Adedokun}

Pathways to Sustainable Peace

building in Divided Societies: Lessons

and Experiences from Mozambique

MGSoG Dissertation Series, № 75

\section{Luiz Rothier Bautzer}

Organizing Concurrent Engineering

through ICT Platforms

Blueprinting Product Lifecycle

Management Platforms across

Disciplinary Agencies

MGSoG Dissertation Series, № 74 


\section{Natalia Popova}

Migration in the Periphery of the

European Union:

Determinants of Successful and

Sustainable Labour Market Integration of Return Migrants in Albania, Egypt, Moldova and Tunisia

MGSoG Dissertations Series, № 73

\section{Richard A. Martina}

Uncertainty and Resource Constraint in the Small Island Developing States: Essays in Entrepreneurial Cognition MGSoG Dissertations Series, № 72

\section{Cécile Cherrier}

The Expansion of Basic Social

Protection in Low-income Countries:

An Analysis of Foreign Aid Actors'

Role in the Emergence of Social

Transfers in Sub-Saharan Africa

MGSoG Dissertations series, № 71

\section{Paul Caldron}

The Tacit Bargain in Short-Term

Medical Missions: Why U.S.

physicians go and what it costs

MGSoG Dissertation Series, № 70

\section{Mahmut Kobal}

Customs \& Excellence: A Comparative Approach on Administrative and Regulatory Compliance Perspectives of the EU-Turkey Customs Union MGSoG Dissertation Series, № 69

\section{Craig Loschmann}

Essays on Conflict-related Migration and Development in the Case of

Afghanistan

MGSoG Dissertations Series, № 68

\section{Andrea Milan}

Rural Livelihoods, Location and

Vulnerable Environments: Approaches to Migration in Mountain areas of Latin America

MGSoG Dissertation Series, № 67

\section{Farida Lada}

On Guarding the Welfare of Clinical Trial Subjects While Promoting Novel

Drug Innovation

A Game Theoretical Approach

MGSoG Dissertation Series, № 66

\section{5}

\section{Hibret Belete Maemir}

Dissecting Aggregate Productivity:

International Integration and Growth with Heterogeneous Firms

UNU-MERIT Dissertation Series, № 96

\section{Giorgio Triulzi}

Looking for the Right Path: Technology Dynamics, Inventive Strategies and Catching-up in the Semiconductor Industry

UNU-MERIT Dissertation Series, № 95
Abdul Baseer Qazi
Knowledge flows and networks in the ICT sector: The case of Pakistan UNU-MERIT Dissertation Series, № 94 


\section{Ajay Thutupalli}

Technology Paradigm Shifts in

Agriculture: Drivers of Sustainability

and Catch up

UNU-MERIT Dissertation Series, № 93

\section{Eduardo Urias}

Improving access to HIVIAIDS

treatment in Brazil: When are

Compulsory Licenses effective in Price

Negotiations?

UNU-MERIT Dissertation Series, № 92

\section{Francesca Guadagno}

Why have so few Countries

Industrialised?

UNU-MERIT Dissertation Series, № 91

\section{Daniel Opolot}

The Evolution of Beliefs and Strategic

Behaviour

UNU-MERIT Dissertation Series, № 90

\section{Alejandro Lavopa}

Structural Transformation and

Economic Development: Can

Development Traps be Avoided

UNU-MERIT Dissertation Series, № 89

\section{Jinjin Zhao}

Urban water management reform: The

Case of China

UNU-MERIT Dissertation Series, № 88

\section{Simona Vezzoli}

Borders, Independence and Post-

colonial Ties: the Role of the State in

Caribbean Migration

MGSoG Dissertation Series, № 65

\section{Silvia Consuelo Gómez Soler}

Civil Conflict and Education: How

Does Exposure to Civil Conflict Affect

Human Capital Accumulation?

Evidence from Standardized Exit

Exams in Colombia

MGSoG Dissertation Series, № 64

\section{Paula Nagler}

Occupational Choice in the Developing

World

MGSoG Dissertation Series, № 63

\section{Jasmin Kientzel}

Determinants of Professional

Commitment to Environmental

Sustainability

MGSoG Dissertation Series, № 62

\section{Mehmet Güney Celbiş}

Regional Policies: Convergence, Trade, and the Allocation of Public Capital MGSoG Dissertation Series, № 61

\section{Florian Henning}

Living Up to Standard:

Interoperability Governance and

Standards Adoption in Government

Information Networks

MGSoG Dissertation Series, № 60 
Niels P. Groen

2014

The Never-Ending Project

Understanding E-Government Project

Escalation

MGSoG Dissertation Series, № 59

\section{Derek Copp}

Teacher-Based Reactivity to Provincial

Large-scale Assessment in Canada

MGSoG Dissertation Series, № 58

\section{Michaella Vanore}

Family-Member Migration and the

Psychosocial Health Outcomes of

Children in Moldova and Georgia

MGSoG Dissertation Series, № 57

\section{Sonja Fransen}

The Economic and Social Effects of

Remittances and Return Migration in

Conflict-Affected Areas: The Case of

Burundi

MGSoG Dissertation Series, № 56

\section{Ibrahim Khalil Conteh}

The Impact of Floods on Primary

School Education in Zambia

MGSoG Dissertation Series, № 55

\section{Richard Bluhm}

Growth Dynamics and Development

Essays in Applied Econometrics and

Political Economy

MGSoG Dissertation Series, № 54

\section{Nevena P. Zhelyazkova}

Work-Family Reconciliation and Use of Parental Leave in Luxembourg:

Empirical Analysis of Administrative Records

MGSoG Dissertation Series, № 53

\section{Dirk Crass}

The Impact of Brands on Innovation and Firm Performance: Empirical Evidence from Germany

UNU-MERIT Dissertation Series, № 87

\section{Samyukta Bhupatiraju}

The Geographic Dimensions of Growth and Development

UNU-MERIT Dissertation Series, № 86

\section{François Lafond}

TheEvolution of Knowledge Systems UNU-MERIT Dissertation Series, № 85

\section{Annalisa Primi}

Promoting Innovation in Latin

America: What Countries Have

Learned (and What They Have Not) in

Designing and Implementing

Innovation and Intellectual Property

Policies

UNU-MERIT Dissertation Series, № 84

\section{Fatoumata Lamarana Diallo}

Evaluation of Meal and Deworming Programs for Primary Schools in Rural Senegal

UNU-MERIT Dissertation Series, № 83 
Sachin Kumar Badkas

Metachoice and Metadata: Innovating with Environmental Policy Analysis in Europe

MGSoG Dissertation Series, № 52

\section{Irina S. Burlacu}

An Evaluation of Tax-Benefit Systems Impact on the Welfare of Frontier

Worker:

The Case of Luxembourg and Belgium MGSoG Dissertation Series, № 51

\section{Özge Bilgili}

Simultaneity in Transnational

Migration Research: Links Between

Migrants' Host and Home Country

Orientation

MGSoG Dissertation Series, № 50

\section{Yulia Privalova Krieger}

Reshaping the Big Agenda:

Transnational Politics and Domestic

ResistanceFinancial crisis and social

protection reform in Bosnia and

Herzegovina

MGSoG Dissertation Series, № 49

\section{Marieke van Houte}

Moving Back or Moving Forward?

Return migration after Conflict

MGSoG Dissertation Series, № 48

\section{Oxana Slobozhan}

Global Governance in the Management of Natural Resources: The Case of the Extractive Industries Transparency Initiative (EITI)

MGSoG Dissertation Series, № 47

\section{Luis Bernardo Mejia Guinand}

The Changing Role of the Central

Planning Offices in Latin America: A

Comparative Historical Analysis

Perspective (1950-2013)

MGSoG Dissertation Series, № 46

\section{Cheng Boon Ong}

Ethnic Segregation in Housing,

Schools and Neighbourhoods in the

Netherlands

MGSoG Dissertation Series, № 45

\section{Luciana V. Cingolani}

Bureaucracies for Development:

Oxymoron or Reality? Studies on State

Capacity in Challenging Governance

Contexts

MGSoG Dissertation Series, № 44

\section{Carlos Cadena Gaitán}

Green Politics in Latin American

Cities - Sustainable Transport Agendas

MGSoG Dissertation Series, № 43

\section{Katie Kuschminder}

Female Return Migration and

Reintegration Strategies in Ethiopia

MGSoG Dissertation Series, № 42

\section{Metka Hercog}

Highly-Skilled Migration and New

Destination Countries

MGSoG Dissertation Series, № 41

\section{Margaret Agaba Rugadya}

Can Remittances Influence the Tenure and Quality of Housing in Uganda? MGSoG Dissertation Series, № 40 


\section{Ilire Agimi}

New Governance Under Limited

Statehood: The Case of Local

Government Reform in Kosovo

MGSoG Dissertation Series, № 39

\section{3}

Anant Kamath

Information Sharing through Informal Interaction in Low-Tech Clusters

UNU-MERIT Dissertation Series, № 82

\section{Flavia Pereira de Carvalho}

What we talk about when we talk about Brazilian Multinationals: An Investigation on Brazilian FDI, Economic Structure, Innovation and the Relationship between them UNU-MERIT Dissertation Series, № 81

\section{Jun Hou}

Complementarity in Innovation and Development: A Cross-country

Comparison

UNU-MERIT Dissertation Series, № 80

\section{Rufin Baghana}

Impacts of Government Incentives to RED, Innovation and Productivity: A Microeconometric Analysis of the Québec Case

UNU-MERIT Dissertation Series, № 79

\section{Lilia I. Stubrin}

High-Tech Activities in Emerging Countries: A Network perspective on the Argentinean Biotech Activity UNU-MERIT/MGSoG Dissertation Series, № 78

\section{Kristine Farla}

Empirical Studies on Institutions, Policies and Economic Development MGSoG Dissertation Series, № 38

\section{Marina Petrovic}

Social Assistance and Activation in the Pursuit of Happiness: Shedding New Light on Old Policy Solutions to Social Exclusion

MGSoG Dissertation Series, № 37

\section{Laura Torvinen}

Assessing Governance Assessments: The Case of Mozambique: Governance Assessments in the Context of Aid Effectiveness Discourse MGSoG Dissertation Series, № 36

\section{Biniam Egu Bedasso}

Institutional Change in the Long Shadow of Elite: Essays on Institutions, Human Capital and Ethnicity in Developing Countries MGSoG Dissertation Series, № 35

\section{Sepideh Yousefzadeh Faal}

\section{Deghati}

Childhoods Embargoed: Constructing and Reconstructing Multidimensional Child Poverty in Iran 1984-2009 MGSoG Dissertation Series, № 34 


\section{Robert Bauchmüller}

Investing in Early Childhood Care and

Education: The Impact of Quality on

Inequality

MGSoG Dissertation Series, № 33

\section{Martin Rehm}

Unified Yet Separated: Empirical

Study on the Impact of Hierarchical

Positions within Communities of

Learning

MGSoG Dissertation Series, № 32

2012

\author{
Abdul Waheed \\ Innovation Determinants and \\ Innovation as a Determinant: Evidence \\ from Developing Countries \\ UNU-MERIT Dissertation Series, \\ № 77
}

\section{Bilal Mirza}

Energy Poverty and Rural Energy

Markets in Pakistan

UNU-MERIT Dissertation Series, № 76

\section{Benjamin Engelstätter}

Enterprise Software and Video Games:

An Empirical Analysis

UNU-MERIT Dissertation Series, № 75

\section{Fulvia Farinelli}

Natural Resources, Innovation and

Export Growth: The Wine Industry in

Chili and Argentina

UNU-MERIT Dissertation Series

\section{Rodolfo Lauterbach}

Innovation in Manufacturing: From

Product Variety and Labor

Productivity Growth to Economic

Development in Chile

UNU-MERIT Dissertation Series

\section{Kirsten Wiebe}

Quantitative Assessment of

Sustainable Development and Growth in Sub-Saharan Africa

UNU-MERIT Dissertation Series, № 74

\section{Julio Miguel Rosa}

Organizational Strategies, Firms'

Performance and Spatial Spillovers:

The Canadian Case in Research and

Development.

UNU-MERIT Dissertation Series, № 73

Johannes Wilhelmus Marie Boels Joseph Schumpeter, Honderd Jaar Economische Ontwikkeling: Een Historisch-theoretische Beschouwing. UNU-MERIT Dissertation Series

\section{Dorcas Mbuvi}

Utility Reforms and Performance of the Urban Water Sector in Africa MGSoG Dissertation Series, № 31

\section{Lina Salanauskaite}

Distributional Impacts of Public

Policies: Essays in Ex-Ante and Ex-

Post Evaluation

MGSoG Dissertation Series, № 30 


\section{Esther Schüring}

To Condition or not - is that the

Question?

An Analysis of the Effectiveness of ExAnte and Ex-Post Conditionality in

Social Cash Transfer Programs

MGSoG Dissertation Series, № 29

\section{Joe Abah}

Strong Organisations in Weak States:

Atypical Public Sector Performance in

Dysfunctional Environments

MGSoG Dissertation Series, № 28

\section{Zina Samih Nimeh}

Social Citizenship Rights: Inequality and Exclusion

MGSoG Dissertation Series, № 27

2011

\section{Daniel Vertesy}

Interrupted Innovation: Emerging

Economies in the Structure of the

Global Aerospace Industry

UNU-MERIT Dissertation Series, № 72

\section{Tina Saebi}

Successfully Managing Alliance

Portfolios: AnAlliance Capability View

UNU-MERIT Dissertation Series, № 71

\section{Nora Engel}

Tuberculosis in India: A Case of

Innovation and Control

UNU-MERIT/MGSoG Dissertation

Series, № 70

\section{Evans Mupela}

Connectivity and growth in Sub-

Saharan Africa: The Role of

Communication Satellites

UNU-MERIT Dissertation Series, № 69

\section{Nantawan Kwanjai}

Cross Cultural Intelligence amid

Intricate Cultural Webs: A Tale of the

UnDutchables in the Land of 1002

Smiles

UNU-MERIT Dissertation Series, № 68

\section{Lina Sonne}

Innovation in Finance to Finance

Innovation: Supporting Pro-poor

Entrepreneur-based Innovation

UNU-MERIT Dissertation Series, № 67

\section{Lenka Eisenhamerová}

Legitimacy of 'Humanitarian Military Intervention'

MGSoG Dissertation Series, № 26

\section{Sonila Tomini}

Informal Payments for Health Care

Services in Albania

MGSoG Dissertation Series, № 25

\section{Jinjing Li}

Dynamic Microsimulation in Public

Policy Evaluation

MGSoG Dissertation Series, № 24 


\section{Aziz Atamanov}

Rural Nonfarm Employment and International Migration as

Alternatives to Agricultural

Employment: The Case of Kyrgyzstan

MGSoG Dissertation Series, № 23

\section{Frieda Vandeninden}

Poverty Alleviation: Aid and Social

Pensions

MGSoG Dissertation Series, № 22

\section{Juliana Nyasha Tirivayi}

The Welfare Effects of Integrating

AIDS Treatment with Food Transfers:

Evidence from Zambia

MGSoG Dissertation Series, № 21

\section{Agnieska Ewa Sowa}

Who's Left Behind? Social Dimensions of Health Transition and Utilization of Medical Care in Poland

MGSoG Dissertation Series, № 20

\section{Emmanaouil Sfakianakis}

The Role of Private Actors in the

Provision of Public Goods with

Applications to Infrastructure and

Financial Stability

MGSoG Dissertation Series, № 19

\section{Siu Hing Lo}

White Collars Green Sleeves: An Interorganizational Comparison of Determinants of Energy-Related Behaviors among Office Workers MGSoG Dissertation Series, № 18

\section{Treena $\mathbf{W u}$}

Constraints to Human Capital

Investment in Developing Countries:

Using the Asian Financial Crisis in

Indonesia as a Natural Experiment

MGSoG Dissertation Series, № 17

\section{Henry Espinoza Peña}

Impact Evaluation of a Job-Training

Programme for Disadvantaged Youths:

The Case of Projoven

MGSoG Dissertation Series, № 16

2010

Fernando Santiago

Human Resources Management

Practices and Learning for Innovation in Developing Countries:

Pharmaceutical Firms in Mexico

UNU-MERIT Dissertation Series,

№ 66

\section{Zakaria Babutsidze}

Essays on Economies with

Heterogeneous Interacting Consumers

UNU-MERIT Dissertation Series,

№ 65

\section{Bertha Vallejo}

Learning and Innovation Under Changing Market Conditions: The Auto Parts Industry in Mexico UNU-MERIT Dissertation Series, № 64 


\section{Donatus Ayitey}

Technical Change, Competitiveness and Poverty Reduction: A Study of the Ghanaian Apparel Industry

UNU-MERIT Dissertation Series, № 63

\section{Sergey Filippov}

Multinational Subsidiary Evolution:

Corporate Change in New EU Member States

UNU-MERIT Dissertation Series, № 62

\section{Asel Doranova}

Technology Transfer and Learning under the Kyoto Regime: Exploring the Technological Impact of CDM Projects in Developing Countries

UNU-MERIT Dissertation Series, № 61

\section{Florian Tomini}

Between Family and Friend:

Understanding the Interdependency of Private Transfers

MGSoG Dissertation Series, № 15

\section{Michał Polalowski}

The Institutional Transformation of Social Policy in East Central Europe: Poland and Hungary in Comparative and Historical Perspective MGSoG Dissertation Series, № 14

\section{Maha Ahmed}

Defining, Measuring and Addressing Vulnerability: The Case of Post

Conflict Environments MGSoG Dissertation Series, № 13

\section{Pascal Beckers}

Local Space and Economic Success: The Role of Spatial Segregation of Migrants in the Netherlands

MGSoG Dissertation Series, № 12

\section{Victor Cebotari}

Conflicting Demands in Ethnically

Diverse Societies: Ethno political

Contention and Identity Values in

Europe

MGSoG Dissertation Series, № 11

\section{Dennis Gyllensporre}

Competing and Complementary Perspectives on the EU as a Crisis Management Actor:

An Examination of the Common Security and Defence Policy through the Lenses of Idealism and Realism MGSoG Dissertation Series, № 10

\section{Judit Vall Castello}

Business Cycle and Policy Effects on Labour Market Transitions of Older and Disabled Workers in Spain MGSoG Dissertation Series, № 9

\section{Keetie Roelen}

False Positives or Hidden Dimensions:

The Definition and Measurement of

Child Poverty

MGSoG Dissertation Series, № 8

\section{Denisa Maria Sologon}

Earning Dynamics in Europe

MGSoG Dissertation Series, № 7 


\section{Melissa Siegel}

Money and Mobility: Migration and

Remittances

MGSoG Dissertation Series, № 6

\section{Jessica S. Hagen-Zanker}

Modest Expectations: Causes and

Effects of Migration on Migrant

Households inSource Countries

MGSoG Dissertation Series, № 5

2009

\section{Alexis Habiyaremye}

From Primary Commodity Dependence to Diversification and Growth:

Absorptive Capacity and Technological Catch Up in Botswana and Mauritius. UNU-MERIT Dissertation Series, № 60

\section{Yoseph Getachew}

The Role of Public Capital in Economic Development

UNU-MERIT Dissertation Series, № 59

\section{Sandra Leitner}

Embodied Technological Change and

Patterns of Investment in Austrian

Manufacturing

UNU-MERIT Dissertation Series, № 58

\section{Semih Akçomak}

The Impact of Social Capital on Economic and Social Outcomes UNU-MERIT Dissertation Series, № 57
Abraham Garcia
The Role of Demand in Technical
Change
UNU-MERIT Dissertation Series, № 56

\section{Saurabh Arora}

Coherence in Socio-technical Systems:

A Network Perspective on the

Innovation Process

UNU-MERIT Dissertation Series, № 55

\section{Mirtha R. Muniz Castillo}

Human Development and Autonomy in Project Aid: Experiences from four bilateral projects in Nicaragua and $E l$ Salvador

MGSoG Dissertation Series, № 4

\section{Christiane Arndt}

Governance Indicators

MGSoG Dissertation Series, № 3

\section{Britta Augsburg}

Microfinance: Greater Good or Lesser Evil?

MGSoG Dissertation Series, № 2

\section{8}

\section{Rutger Daems}

Medicines for the Developing World UNU-MERIT Dissertation Series, № 54 


\section{Johannes Hanel}

Assessing Induced Technology:

Sombart's Understanding of Technical

Change in the History of Economics

UNU-MERIT Dissertation Series,

№ 53

\section{Rifka Weehuizen}

Mental Capital: the Economic

Significance of Mental Health

UNU-MERIT Dissertation Series, № 52

\section{Danielle Cloodt}

The Relationship between RED

Partnership Formation, Social

Embeddedness and Innovative

Performance

UNU-MERIT Dissertation Series, № 51

\section{Sabine Fuss}

Sustainable Energy Development

under Uncertainty

UNU-MERIT Dissertation Series, № 50

\section{Geranda Notten}

Measuring and Managing Poverty

Risks

MGSoG Dissertation Series, № 1

2007

\section{Tobias Kronenberg}

Reconciling Environmental

Conservation with Economic

Prosperity: The Feasibility of Double

Dividends in the Short and Long Run

UNU-MERIT Dissertation Series, № 49

\section{Viktoria Kravtsova}

Assessing the Impact of Foreign Direct Investment in Transition Economies UNU-MERIT Dissertation Series, № 48

\section{Suhail Sultan}

The Competitive Advantage of Small and Medium Sized Enterprises: The Case of Jordan's Natural Stone Industry

UNU-MERIT Dissertation Series, № 47

2006

\section{Bulat Sanditov}

Essays on Social Learning and Imitation

UNU-MERIT Dissertation Series, № 46

\section{Mamata Parhi}

Dynamics of New Technology

Diffusion: A Study of the Indian

Automotive Industry

UNU-MERIT Dissertation Series, № 45

\section{Andreas Reinstaller}

Social Structures and the Innovation Process: Their Role in the Demand of Firms and Consumers

UNU-MERIT Dissertation Series, № 44 


\section{Rose Kiggundu}

Innovation systems and Development:

The Journey of a Beleaguered Nile

Perch Fishery in Uganda

UNU-MERIT Dissertation Series,

№ 43

\section{Thomas Pogue}

The Evolution of Research

Collaboration in South African Gold

Mining: 1886-1933

UNU-MERIT Dissertation Series,

№ 42

\section{Geoffrey Gachino}

Foreign Direct Investment, Spillovers and Innovation: The Case of Kenyan

Manufacturing Industry

UNU-MERIT Dissertation Series, № 41

\section{Önder Nomaler}

Technological Change, International

Trade and Growth: An Evolutionary,

Multi-Agents-Based Modeling

Approach

UNU-MERIT Dissertation Series, № 40

\section{5}

\section{Samia Satti Osman Mohamed-}

Nour

Change and Skill Development in the Arab Gulf Countries

UNU-MERIT Dissertation Series, № 39

\section{Elad Harison}

Intellectual Property Rights:

Economics and Policy Analysis

UNU-MERIT Dissertation Series, № 38

\section{Daniel Dalohoun}

Learning to innovate: agricultural innovation and entrepreneurship: the case of Songhai farmers in Benin UNU-MERIT Dissertation Series, № 37

\section{Müge Ozman}

Networks, Organizations and

Knowledge

UNU-MERIT Dissertation Series, № 36

\section{Bas Straathof}

Product Variety and Economic

Growth: The Counteracting Effects of Scale and Idiosyncrasy

UNU-MERIT Dissertation Series, № 35

\section{Wilfred Schoenmakers}

Knowledge Flows between

Multinational Companies: A Patent

Data Analysis

UNU-MERIT Dissertation Series, № 34

\section{Myriam Cloodt}

Mergers and Acquisitions ( $M$ and As) in High-Tech Industries: Measuring the Post-M and A Innovative Performance of Companies UNU-MERIT Dissertation Series, № 33 
2004

\section{Paola Criscuolo}

$R \mathcal{E D}$ Internationalisation and

Knowledge Transfer: Impact on MNEs and their Home Countries

UNU-MERIT Dissertation Series, № 32

\section{Maarten Verkerk}

Trust and Power on the Shop Floor UNU-MERIT Dissertation Series, № 31

\section{Gottfried Leibbrandt}

Adoption, Harmonization and Succession of Network Technologies across Countries

UNU-MERIT Dissertation Series, № 30

\section{Mark Sanders}

Skill Biased Technical change: Its Origins, the Interaction with the Labour Market and Policy Implications UNU-MERIT Dissertation Series, № 29

2003

\section{Nadine Roijakkers}

Inter-firm Cooperation in High-tech Industries: a Study of RED

Partnerships in Pharmaceutical

Biotechnology

UNU-MERIT Dissertation Series, № 28
Viki Sonntag

Speed, Scale and Sustainability

UNU-MERIT Dissertation Series, № 27

\section{Masaru Yarime}

From End-of-Pipe Technology to Clean Technology

UNU-MERIT Dissertation Series, № 26

\section{Stéphane Malo}

The Combinatorial Chemistry

Revolution: Sustaining a Superior

Performance Position through

Technological Learning

UNU-MERIT Dissertation Series, № 25

2002

\section{Annelies Hogenbirk}

Determinants of Inward Foreign Direct Investment: the Case of the Netherlands

UNU-MERIT Dissertation Series, № 24

\section{Bastiaan Johan terWeel}

The Computerization of the Labour Market

UNU-MERIT Dissertation Series 


\section{Marjolein Caniëls}

\section{John Adeoti}

Technology Investment in Pollution Control in Sub-Saharan Africa: The Case of the Nigerian Manufacturing Industry

UNU-MERIT Dissertation Series, № 23

\section{Edward Huizenga}

Innovation Management: How

Frontrunners Stay Ahead: An

Empirical Study on Key Success

Factors in the ICT sector

UNU-MERIT Dissertation Series, № 22

2000

\section{Machiel van Dijk}

Technological Change and the

Dynamics of Industries: Theoretical Issues and Empirical evidence from

Dutch Manufacturing

UNU-MERIT Dissertation Series, № 21

1999

\section{Jan Cobbenhagen}

Managing Innovation at the Company Level: A Study on Non-Sector-Specific Success Factors UNU-MERIT Dissertation Series, № 20
Regional Growth Differentials: The Impact of Locally Bounded Knowledge Spillovers

UNU-MERIT Dissertation Series, № 19

\section{8}

\author{
Aldo Geuna \\ Resource Allocation and Knowledge \\ production: Studies in the Economics \\ of University Research \\ UNU-MERIT Dissertation Series, \\ № 18 \\ 1996

\section{Reinoud Joosten} \\ Dynamics, Equilibria, and Values \\ UNU-MERIT Dissertation Series, \\ № 17
}

\section{Hugo Kruiniger}

Investment, $R \mathcal{E} D$, and the Financing Decisions of the Firm

UNU-MERIT Dissertation Series, № 16

\section{5}

\section{Hans van Meij1}

Endogenous Technological Change: The Case of Information Technology, Theoretical Considerations and Empirical Results UNU-MERIT Dissertation Series, № 15 


\section{René Kemp}

Environmental Policy and Technical

Change: A Comparison of the

Technological Impact of Policy

Instruments

UNU-MERIT Dissertation Series, № 14

\section{Rohini Acharya}

The Impact of New Technologies on

Economic Growth and Trade: A Case

Study of Biotechnology

UNU-MERIT Dissertation Series, № 13

\section{Geert Duysters}

The Evolution of Complex Industrial Systems: The Dynamics of Major IT Sectors

UNU-MERIT Dissertation Series, № 12

\section{Marjan Groen}

Technology, Work and Organisation: A Study of the Nursing Process in Intensive Care Units

UNU-MERIT Dissertation Series, № 11

1994

\section{Huub Meijers}

On the Diffusion of Technologies in a Vintage Framework: Theoretical Considerations and Empirical Results UNU-MERIT Dissertation Series, № 10

\section{Theon van Dijk}

The Limits of Patent Protection: Essays on the Economics of Intellectual

Property Rights

UNU-MERIT Dissertation Series, № 9

\section{Hans Voordijk}

Naar Integrale Logistiek in

Bedrijfsketens: Ontwikkelingen in de Bouw

UNU-MERIT Dissertation Series, № 8

\section{3}

\section{Paul Diederen}

Technological Progress in Enterprises and Diffusion of Innovation:

Theoretical Reflections and Empirical Evidence

UNU-MERIT Dissertation Series, № 7

\section{Ben Dankbaar}

Economic Crisis and Institutional Change: The Crisis of Fordism from the Perspective of the Automobile Industry UNU-MERIT Dissertation Series, № 6

\section{Hanno Roberts}

Accountability and Responsibility: The Influence of Organisation Design on Management Accounting UNU-MERIT Dissertation Series, № 5 


\section{Bart Verspagen}

Uneven Growth between

Interdependent Economies: An

Evolutionary View on Technology

Gaps, Trade and Growth

UNU-MERIT Dissertation Series,

№ 4

\section{Sjoerd Romme}

A Self-organization Perspective on

Strategy Formation

UNU-MERIT Dissertation Series,

№ 3

1989

\section{John Spangenberg}

Economies of Scale, and Atmosphere in

Research Organisations

UNU-MERIT Dissertation Series,

№ 2

1988

\section{John Hagedoorn}

Evolutionary and Heterodox

Innovation Analysis: A Study of

Industrial and Technological

Development in Process Control and

Information Technology

UNU-MERIT Dissertation Series, № 1 